$\lim _{0}$

Past, Current and Future Water Footprints, Water Scarcity and Virtual Water Flows in China

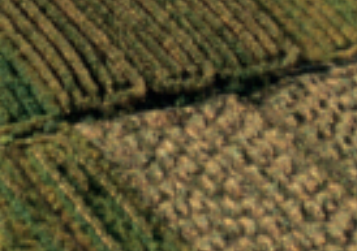

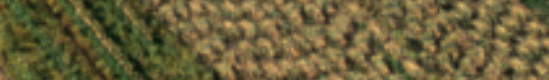

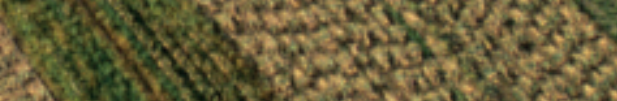

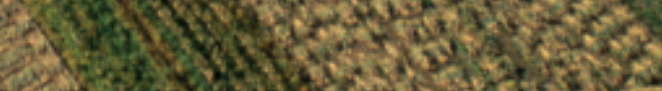

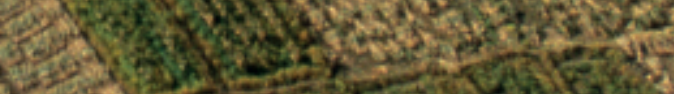

Q

gits

6. 4. 3 .

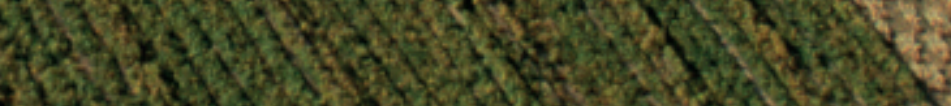

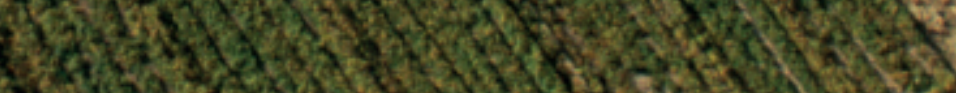

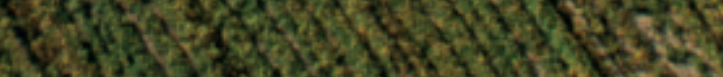


PAST, CURRENT AND FUTURE WATER FOOTPRINTS, WATER SCARCITY AND VIRTUAL WATER FLOWS IN CHINA 
Members of the Awarding Committee:

Prof. dr. G. P. M. R. Dewulf University ot Twente, chairman/secretary

Prof. dr. ir. A. Y. Hoekstra University ot Twente, promoter

Dr. M. M. Mekonnen

University ot Twente, co-promoter

Prof. dr. P. D’Odorico

University of Virginia

Prof. dr. Pute Wu

Northwest A\&F University

Prof. dr. Jiming Jin

Northwest A\&F University/ Utah State University

Prof. dr. W. G. M. Bastiaanssen

Prof. dr. Z. (Bob) Su

Delft University of Technology/ UNESCO-IHE

Prof. dr. J. C. J. Kwadijk

University of Twente

University of Twente

Cover image: Bean fields next to the Yellow River $\odot$ George Steinmetz /National Geographic Creative

Copyrights $\odot$ by La Zhuo, University of Twente, the Netherlands

Printed by IPSKAMP Printing, Enschede, the Netherlands

ISBN: 978-90-365-4064-3

DOI: $10.3990 / 1.9789036540643$

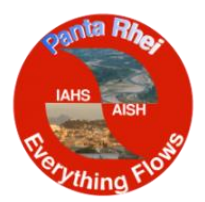





\title{
PAST, CURRENT AND FUTURE WATER FOOTPRINTS, WATER SCARCITY AND VIRTUAL WATER FLOWS IN CHINA
}

\section{DISSERTATION}

\author{
To obtain \\ the degree of doctor at the University of Twente, \\ on the authority of the rector magnificus \\ Prof.dr. H. Brinksma \\ on account of the decision of the graduation committee, \\ To be publicly defended \\ on Thursday 21 April 2016 at 12:45
}

by

La Zhuo

born on 9 March 1988

at Hohhot, China 
This dissertation has been approved by:

Prof. dr. ir. A. Y. Hoekstra

promoter

Dr. M. M. Mekonnen

co-promoter 


\section{Contents}

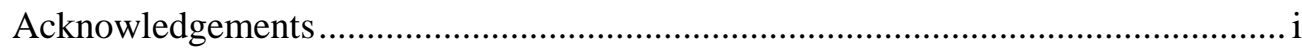

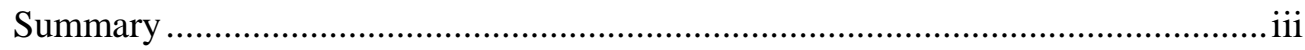

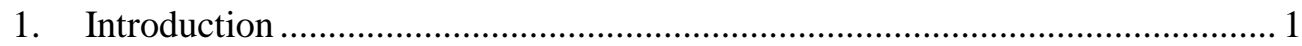

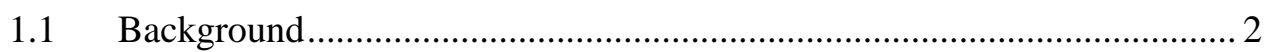

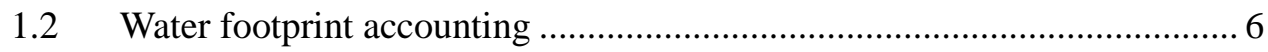

1.3 Research objective and thesis outline ............................................... 8

2. Sensitivity and Uncertainty in Crop Water Footprint Accounting: a Case Study for the Yellow River Basin............................................................................... 11

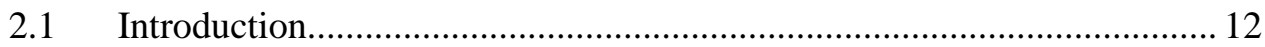

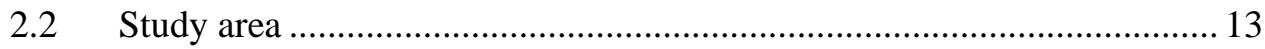

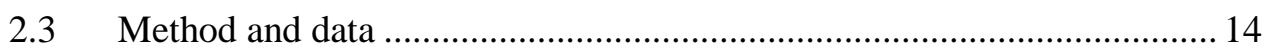

2.3.1 Crop water footprint accounting ................................................. 14

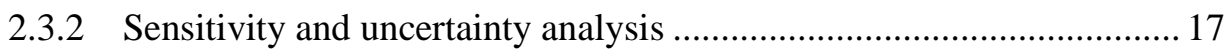

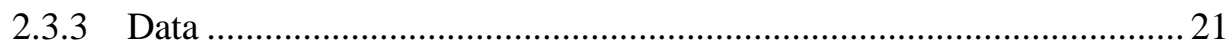

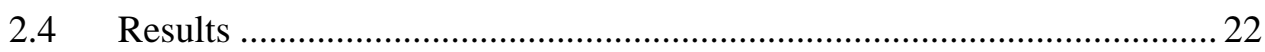

2.4.1 Sensitivity of CWU, Y, and WF to variability of input variables ........ 22

2.4.2 Annual variation of sensitivities in crop water footprints .................... 30

2.4.3 Uncertainties in WF per tonne of crop due to input uncertainties ........ 32

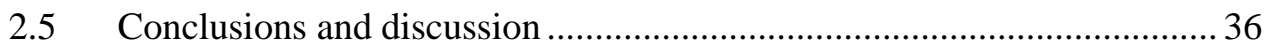

3. Inter- and Intra-annual Variation of Water Footprint of Crops and Blue Water Scarcity in the Yellow River Basin (1961-2009) .................................................... 38

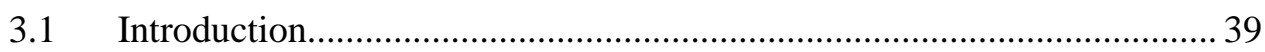

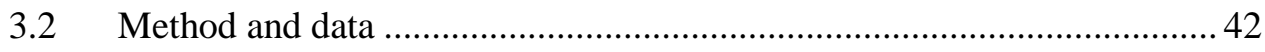

3.2.1 Estimating green and blue water footprints in crop production ........... 42

3.2.2 Estimating grey water footprints in crop production ....................... 45

3.2.3 Blue water footprints related to industry and municipal sectors ....... 46

3.2.4 Blue water scarcity assessment ................................................ 47

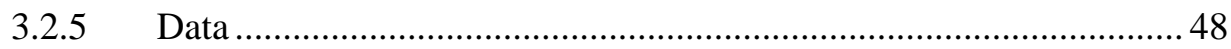

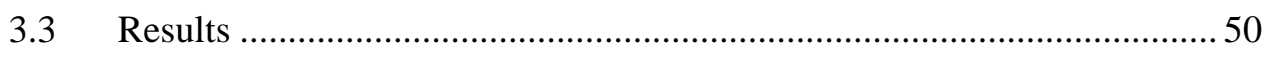

3.3.1 The water footprint of crop production .......................................... 50

3.3.2 The water footprint per tonne of crop .............................................56

3.3.3 Blue water scarcity within the Yellow River Basin ............................ 58

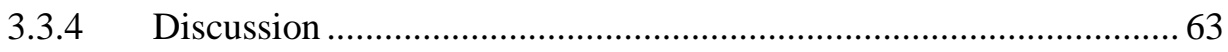


3.4 Conclusions. 66

4. The Effect of Inter-annual Variability of Consumption, Production, Trade and Climate on Crop-related Green and Blue Water Footprints and Inter-regional Virtual

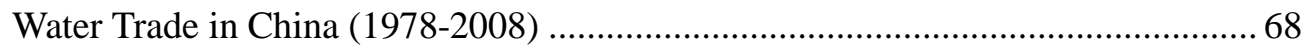

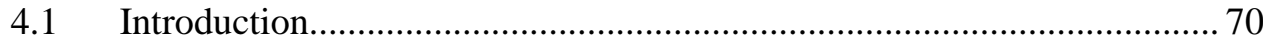

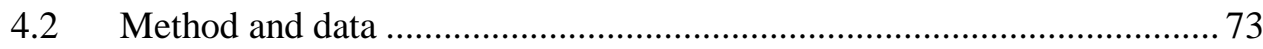

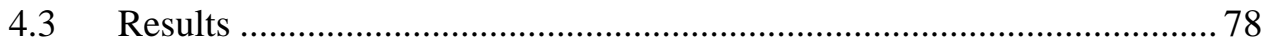

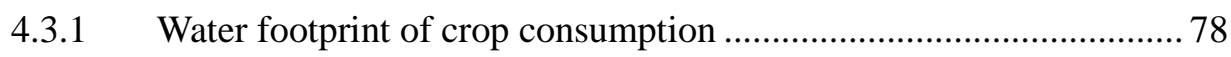

4.3.2 Water footprint of crop production............................................... 81

4.3.3 Crop-related inter-regional VW flows in China ............................. 84

4.3.4 National water saving related to international and inter-regional crop trade 91

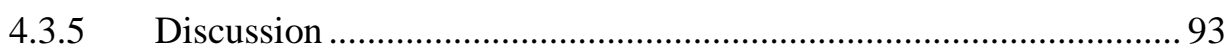

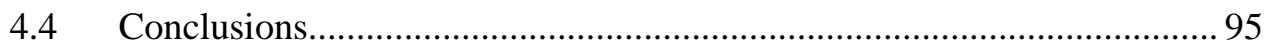

Appendix 4A . An example of assessing the water footprint related to crop consumption in China: wheat in the year 2006............................................. 97

5. Consumptive Water Footprint and Virtual Water Trade Scenarios for China with a Focus on Crop Production, Consumption and Trade .................................. 98

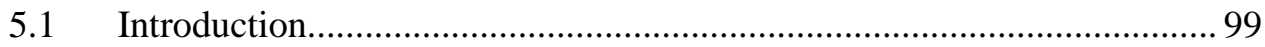

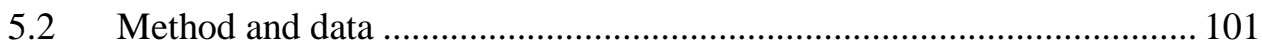

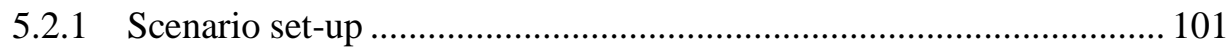

5.2.2 Estimating water footprints and virtual water trade ..................... 107

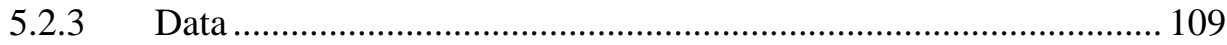

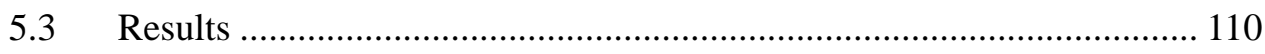

5.3.1 Water footprint of crop production............................................ 110

5.3.2 Water footprint of food consumption ........................................ 114

5.3.3 National virtual water trade related to crop products ..................... 116

5.3.4 Discussion ......................................................................... 118

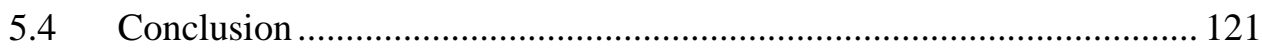

Appendix 5A. Relative changes in annual precipitation in China from 2005 to 2050 across GCMs for RCP2.6 (left) and RCP8.5 (right). ............................ 123

Appendix 5B. Relative changes in annual reference evapotranspiration in China from 2005 to 2050 across GCMs for RCP2.6 (left) and RCP8.5 (right)........... 125 Appendix 5C. Relative changes in the green, blue and total consumptive water footprint $\left(\mathrm{m}^{3} \mathrm{t}^{-1}\right)$ of the 22 considered crops in China across scenarios, compared to the baseline year 2005 .

6. Benchmark Levels for the Consumptive Water Footprint of Crop Production for Different Environmental Conditions: a Case Study for Winter Wheat in China 129

6.1 Introduction. 131 


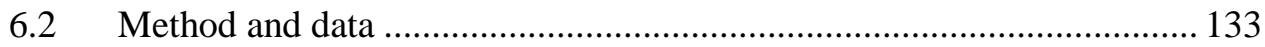

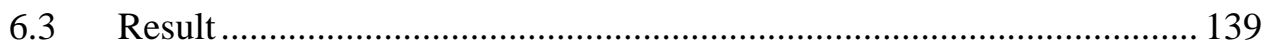

6.3.1 Benchmark levels for the consumptive WF as determined for different years and for rain-fed and irrigated croplands separately..... 139

6.3.2 Benchmark levels for the consumptive WF for dry versus wet years 140

6.3.3 Benchmark levels for the consumptive WF for warm versus cold years

6.3.4 Benchmark levels for the consumptive WF for different soil classes 142

6.3.5 Benchmark levels for the consumptive WF for different climate zones

6.3.6 Water saving potential by reducing WFs to selected benchmark levels

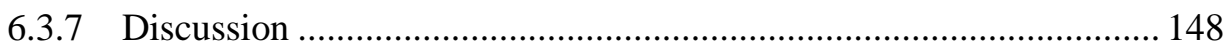

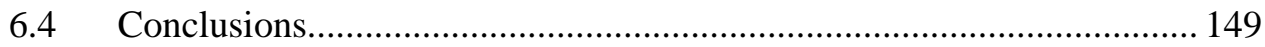

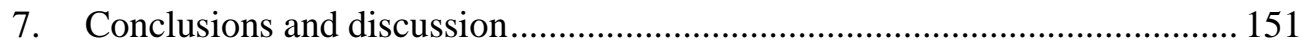

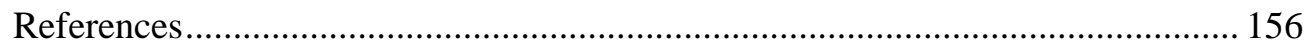

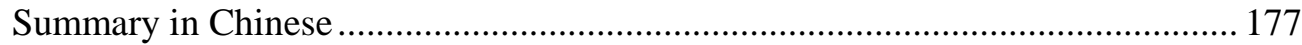

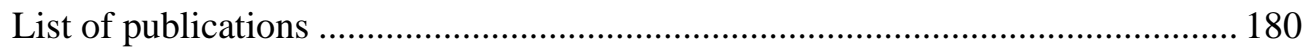






\section{Acknowledgements}

Doing a doctorate study is a challengeable, rumbly while exciting and happy journey for me. Though this thesis is authored by my name, it is not possible to be completed without all who supported and contributed directly and indirectly over the past four years.

First of all, I would like to express my deepest gratitude to my promoter, Prof. dr. ir. Arjen Y. Hoekstra, for offering me the opportunity to be one of his students, his invaluable guidance and support with his wide knowledge, innovative insights, continuous patience and trust throughout the years. Arjen taught me how to be creative, critical and logic when doing research. I am very grateful for his every detailed comment and discussion on my work and his encouragements every time I came across difficulties. I feel very honoured.

I feel very lucky to have my daily supervisor Dr. Mesfin M. Mekonnen, and even luckier to be the first PhD student he ever supervised. Mesfin has helped me solve every tiny issue in my research, improve or correct whichever in my written English words and sentences, as well as figure out solutions with his own valuable experiences and all-time understanding when I was stressed. I sincerely respect and really learned a lot from his depth of knowledge and calmness when facing challenges.

I am also indebted to Prof. Pute Wu from Northwest A\&F University, who has been my supervisor since my BSc. thesis and MSc. study. I thank Prof. Wu very much for introducing me the concept of water footprint, sending me to Beijing for the water footprint training where I got to know Arjen, giving me the opportunity to keep study abroad, and continuous ultimate supports.

I am grateful to Dr. Yoshihide Wada from Utrecht University for his contribution to the Chapter 3 study and his kind helps and the sushi dinner with UU colleagues he 
organized in San Francisco during the AGU FALL Meeting 2013.

My working place for this thesis is warm and pleasant with all the nice colleagues I met at the WEM department over the years. Special thanks to Abebe, Ashok, Denie, Donghai, Ertug, Guoping, Joep, Leonardo, Maarten, Markus, Martijn, Mehmet, Nicolas, Rene, Rick, Ruth, Wenlong, Winnie and Ying for sharing their knowledge and experiences whenever I ask for assistances. I thank very much all-time kind helps from Joke and Anke whenever I visit them, most to Joke, with questions. I enjoyed most of the working time with my former officemates Basma, Caroline, Jane, Jebbe, Lianne and Lisette as well as current roommates Anouk, Hero and Pepijn. Many thanks go to Alexandra, Andry, Anne, Brigitte, Daniel, Filipe, Geert, Hatem, Isaac, Joep, Johan, John, Juan Pablo, Kathelijna, Michiel, Monique, Mireia, Pieter, Suzanne, and many others for nice time and nice talks in our corridor, lunches, cake parties, daghaps, wem uitje or Christmas lunch.

My life in the Netherlands, far away from home, cannot be such colourful and happy without Chinese friends I met here: Lei, Hainan, Lulu, Meiru, Xiaojing, Hairong, Ying Du, Honglin, Binbin, Wenqi, Xiaolong, Xiaolin, Jingwei, Leilei, Rong, Xiaohua, Liang Du, Xingwu, Zhonghua, Fangyuan, Binbin, Xuelong, Yijian, Yong, Lantian, Binlong, Junwen, Liang Ye, and many others. I wish to thank my old best friends Yibo Li, Rimao Qiao, Yan Bai, Zhiyan Li and Fangying Chen who always strengthen me through far away callings, cute postcards or even gathered with me and travelling within Europe during holidays.

Last, but not the least, my profound gratitude from my deep heart goes to my beloved families, especially to my great parents, for their understanding, never ended and strongest backup and uncountable talks making me stronger and more optimistic. Thank you Grandpa, I keep my promises to you and I wish you could have seen this and been happy for me.

La Zhuo

Enschede, 5 March 2016 


\section{Summary}

The increasing water consumption as a result of population growth and economic development, especially in fast growing developing countries, puts an increasing strain on the sustainable use of the globe's finite freshwater resources and poses a key challenge for the future. The objective of the thesis is to evaluate past, current and future water footprints (WFs), water scarcity and virtual water (VW) flows at both river basin and national level in China, focusing on the agricultural sector, high spatial resolution modelling, uncertainties, inter- and intra-annual variation and benchmarks. The parts of the research that are carried out on river basin level focus on the Yellow River Basin (YRB). The main research goal has been translated into five subsequent studies:

Sensitivity and uncertainty in WF accounting in crop production, in a case study for the Yellow River Basin: The study aims to investigate the sensitivity of the WF of a crop to changes in input variables and parameters and to quantify the uncertainties in green, blue, and total consumptive (green plus blue) WFs of crops due to uncertainties in input variables at the scale of a river basin. The 'one-at-a-time' method was applied to analyse the sensitivity of the crop WF to fractional changes of different individual input variables and parameters, and Monte Carlo simulations were used to assess the uncertainties in estimated WFs resulting from uncertainties in a few key input variables. The consumptive WFs of crops were found to be most sensitive to changes in $\mathrm{ET}_{0}$ and $\mathrm{K}_{\mathrm{c}}$. Blue WFs were more sensitive to input variations than green WFs. Uncertainties in key input variables together generate an uncertainty of $\pm 30 \%$ (at 95\% confidence interval) in the estimated WFs of crops.

Inter- and intra- annual variation of WF of crops and blue water scarcity in the Yellow River Basin: The study estimates inter-annual variability of green, blue and grey WFs of crop production over the period 1961-2009 as well as the monthly variation of blue water scarcity over 1978-2009 in the YRB. The average annual 
overall green and blue WFs of crops in the period 2001-2009 were 14\% and 37\% larger, respectively, than in the period 1961-1970. The annual nitrogen- and phosphorus-related grey WFs of crop production grew over the study period by factors of 24 and 36, respectively. The green-blue WF per tonne of crop reduced significantly due to improved crop yields, while the grey WF increased because of the growing application of fertilizers. On average, the YRB faced moderate to severe blue water scarcity during seven months (January-July) per year. Even in the wettest month in a wet year, half of the basin still suffered severe blue water scarcity.

The effect of inter-annual variability of consumption, production, trade and climate on crop-related green and blue WFs and inter-regional VW trade in China: The study quantifies the effect of inter-annual variability of consumption, production, trade and climate on consumptive WFs and VW trade in China for the period of 1978-2008. It is shown that the historical increase in crop yields has helped to reduce the consumptive WF per tonne of crops. As a result, the increases in consumptive WFs of crop production (by 7\%) and crop consumption (by 6\%) were much smaller then the increases in produced and consumed crop quantities over the study period. Historically, the net VW flow within China was from the water-rich South to the water-scarce North, but intensifying North-to-South crop trade reversed the net VW flow since 2000. During the whole study period, China's inter-regional VW flows went dominantly from areas with a relatively large blue WF per unit of crop to areas with a relatively small blue WF per unit of crop, which in 2008 resulted in a trade-related blue water loss of $7 \%$ of the national total blue WF of crop production.

Consumptive WF and VW trade scenarios for China with a focus on crop production, consumption and trade: The study assesses green and blue WFs and VW trade in China under alternative scenarios for 2030 and 2050 focusing on the agricultural sector. Changes in five driving factors were considered: climate, harvested crop area, technology, diet, and population. Four scenarios (S1-S4) were constructed by making use of three of IPCC's shared socio-economic pathways (SSP1-SSP3) and two of IPCC's representative concentration pathways (RCP2.6 
and RCP8.5). The results show that, across the four scenarios and for most crops, the green and blue WF per tonne of crop will decrease, as well as the WF per capita related to food consumption. Changing to a less-meat diet can generate a reduction in the WF of food consumption of $44 \%$ by 2050 as compared to 2005 . In all scenarios, as a result of the projected increase in crop yields and thus overall growth in crop production, China will reverse its role from net VW importer to net VW exporter and attain food self-sufficiency. All scenarios show that China could meet a high degree of food self-sufficiency while simultaneously reducing water consumption in agriculture.

\section{Benchmark levels for the consumptive WF of crop production for different} environmental conditions, with a case study for winter wheat in China: The study explores which environmental factors should be distinguished when determining benchmark levels for the consumptive WF of crops. Benchmark levels for the consumptive WF of winter wheat production in China were determined for all separate years in the period 1961-2008 for China as a whole, for rain-fed versus irrigated croplands, for wet versus dry years, for warm versus cold years, for four different soil classes and for two different climate zones. We simulate consumptive WFs of winter wheat production with the crop water productivity model AquaCrop at a 5 by 5 arc min resolution, accounting for water stress only. It is found that, when determining benchmark levels for the consumptive WF of a crop, it is most useful to distinguish between different climate zones. WF benchmarks for the humid zone are 26-31\% smaller than for the arid zone. If actual consumptive WFs of winter wheat throughout China were reduced to the benchmark levels set by the best $25 \%$ of total national production, distinguishing between benchmark levels for the arid areas and the humid areas, the water saving in an average year would be $53 \%$ of the current water consumption at winter wheat fields in China. The majority of the yield increase and associated improvement in water productivity can be achieved in southern China.

Conclusion: The current work contributes to the advance of the field of water footprint assessment in different ways. First, FAO's crop water productivity model 
AquaCrop has been implemented in large scale WF simulations for the first time in the thesis. Second, it offers the first comprehensive study of sensitivities and uncertainties in WF accounting. Third, it adds to the few studies carried out thus far on the inter- and intra- annual variation of WF of crops, blue water scarcity and VW trade, through one case study for the YRB, and another study for China as a whole. Fourth, it is the first study showing WF and VW trade scenarios for China accounting for both climate change and various socio-economic drivers. Finally, the work contributes to the development of knowledge on how to determine benchmarks as reference levels for consumptive WFs in crop production, by exploring the relevance of different environmental factors when developing WF benchmarks. 
1. Introduction 


\subsection{Background}

Freshwater is a basic source of life and key resource in achieving food security and supporting sustainable economic development (Vörösmarty et al., 2000; Falkenmark and Rockström, 2004; Vörösmarty et al., 2010; Liu et al., 2015). In the period 1961-2013, the global population increased by a factor 2.3, global irrigated area doubled (FAO, 2014b) and global fertilizer consumption (total of nitrogen, phosphorus and potassium) increased by a factor 5.7 (IFA, 2013). Currently, agriculture accounts for $70 \%$ of the global withdrawal of blue water (surface and ground water resources) (FAO, 2014a), mostly for irrigation, and 92\% of the global blue water consumption (Hoekstra and Mekonnen, 2012). Nutrient leaching and runoff from intensively fertilized croplands has caused substantial degradation of water quality and eutrophication of major freshwater bodies and coastal and marine ecosystems (Vitousek et al., 2009). According to Mekonnen and Hoekstra (2015), 48\% of the global population is living in river basins in which the waste assimilation capacity is insufficient to take up the actual nitrogen water pollution. The excessive water consumption and pollution by the agricultural sector are constraining water availability for industry and households and worsening the quality of water for drinking. The total volume of accessible blue water for humans is limited due to the high spatial and temporal variability of water resources (Oki and Kanae, 2006). The increasing pressure by humans on the globe's finite fresh water resources is the biggest threat to ecosystem health. Meanwhile, green water (rainwater stored in the soil) plays an important role in food production as well (Savenije, 2000; Falkenmark and Rockstrom, 2006), accounting for $87 \%$ of consumptive water use for global crop production (1996-2005) (Mekonnen and Hoekstra, 2011). By focusing on blue water, most studies and current water managers overlook the benefits derived from green water as well as the increasing competition over this resource. In order to better understand water scarcity, it is necessary to quantitatively estimate the full consumptive water use in the agriculture sector, including both green and blue water (Shiklomanov, 2000; Falkenmark and Rockström, 2004; Hoekstra et al., 2012).

Globalization of supply chains has led to increasing trade of commodities across economic and hydrological system boundaries and significantly increased consumption of imported water-intensive commodities that are produced elsewhere. In most cases, consumers are 
unaware of how their consumption decision can affect freshwater resources in the locations where the commodities are produced (Hoekstra and Chapagain, 2008; Hoff, 2009; Yang et al., 2013; Vörösmarty et al., 2015). The introduction of the idea of virtual water (VW) trade by Allan (1998) led to the recognition of the fact that water scarce regions can profit from import of water-intensive commodities, thus saving local water resources. In addition, VW trade can generate global water savings if water-intensive products are traded from areas with relatively high water productivity to areas with relatively low water productivity (Chapagain et al., 2006; Konar et al., 2011). Hoekstra (2003) introduced the water footprint (WF) concept, measuring multi-dimensionally (in volume, location and time) both direct and indirect freshwater appropriation of an activity, product, producer or consumer. Unlike the traditional production-based and blue-water-focused water use indicators, the three components of the WF - green WF (rainwater consumption), blue WF (surface or ground water consumption) and grey WF (water required to assimilate aquatic pollution) - provide a comprehensive measure of water use to inform water resources management (Herva et al., 2011; Hoekstra et al., 2011). The WF can be evaluated for different entities, including a process step, a product, a consumer, a geographically delineated area, a business or humanity as a whole (Hoekstra et al., 2011). The WF of consumers within a certain geographic area can be divided into an internal WF (water consumed within the area itself to produce goods that are consumed locally) and an external WF (water consumed in other areas to produce commodities imported by and consumed in the considered area) (Hoekstra et al., 2011).

During the last two decades, a number of water scarcity indicators have been developed and used to measure and map the level of human water use in comparison to water resources availability (Savenije, 2000; Brown and Matlock, 2011; Mekonnen, 2011; Hoekstra et al., 2012; Wada, 2013). The most widely used water scarcity indicators have been the annual runoff-to-population ratio (Falkenmark, 1989) and the annual withdrawal-to-runoff ratio, also called the withdrawal-to-availability ratio (Raskin et al., 1997; Vörösmarty et al., 2000; Alcamo et al., 2003; Oki and Kanae, 2006). Given the importance of sustaining crucial ecological functions, environmental flow requirements were incorporated into scarcity metrics, by subtracting environmental flow requirements from the available water resources 
(Smakhtin et al., 2004b). However, the above water scarcity indicators have measured water scarcity at annual basis, which under-values the importance of the temporal mismatch between water demand and water availability within the year (Savenije, 2000). The shortcoming regarding the variation of water consumption and availability within the year has been addressed by Wada et al. (2011). Another weakness of above water scarcity indicators is that water use is measured in terms of water withdrawal, while only the consumed proportion of the total withdrawal contributes to water scarcity, since return flows can be reused (Perry, 2007). Therefore, a more reliable indicator of blue water scarcity is the ratio of the blue WF in a catchment area to the maximum sustainable blue WF, whereby the latter is taken as the natural runoff in the catchment minus environmental flow requirements, measured on a monthly basis (Hoekstra et al., 2012).

As the world's most populous country, China has been facing increasingly severe water scarcity, caused by a large and growing population, rapid socio-economic development, poor water resources management and the fact that water resources are very unevenly distributed within the country (Jiang, 2009). Due to the spatial distribution of precipitation (Figure 1.1), China's water resources are unevenly distributed between the North and the South. The drier North has $19 \%$ of the national blue water resources, while $45 \%$ of the total population and $65 \%$ of the total arable land is located in the North (Jiang, 2015). Over the period 1978-2008, China's irrigated area has increased by $31 \%$, of which $77 \%$ happened in the water-scarce North, which has worsened the water shortage problems in large river basins in the North (Jiang, 2015). For instance, the Yellow River Basin (YRB) accounts for only $2 \%$ of national blue water resources, while inhabiting $12 \%$ of the national population, accounting for $13 \%$ of the total national grain production and generating $14 \%$ of the country's GDP (YRCC, 2013). Driven by increasing competition over water resources among different sectors, the total blue water withdrawal in the YRB has reached $86 \%$ of the basin's total blue water resources in 2009, of which 59\% was for irrigation (Ringler et al., 2010; YRCC, 2011). China's current water management is unsustainable, focusing on supply augmentation by engineering projects and ignoring the challenge to resolve the imbalance between supply- and demand-management (Jiang, 2015; Zhao et al., 2015). The on-going South-North Water Transfer Project might help alleviate the pressure on physical 
water availability in the North, but the long-term efficiency of the project is being challenged by several problems, such as the pollution of transferred water, limitation of water availability in the South and large environmental and ecological impacts in the water source areas (Yang, 2014; Barnett et al., 2015). Besides, the North annually exports a huge amount of VW ( $\sim 52$ billion $\mathrm{m}^{3} \mathrm{y}^{-1}$ in 1999) through food transfer to the South, which raises the question why real water should be transferred to the North in order to return it in virtual form (Ma et al., 2006).

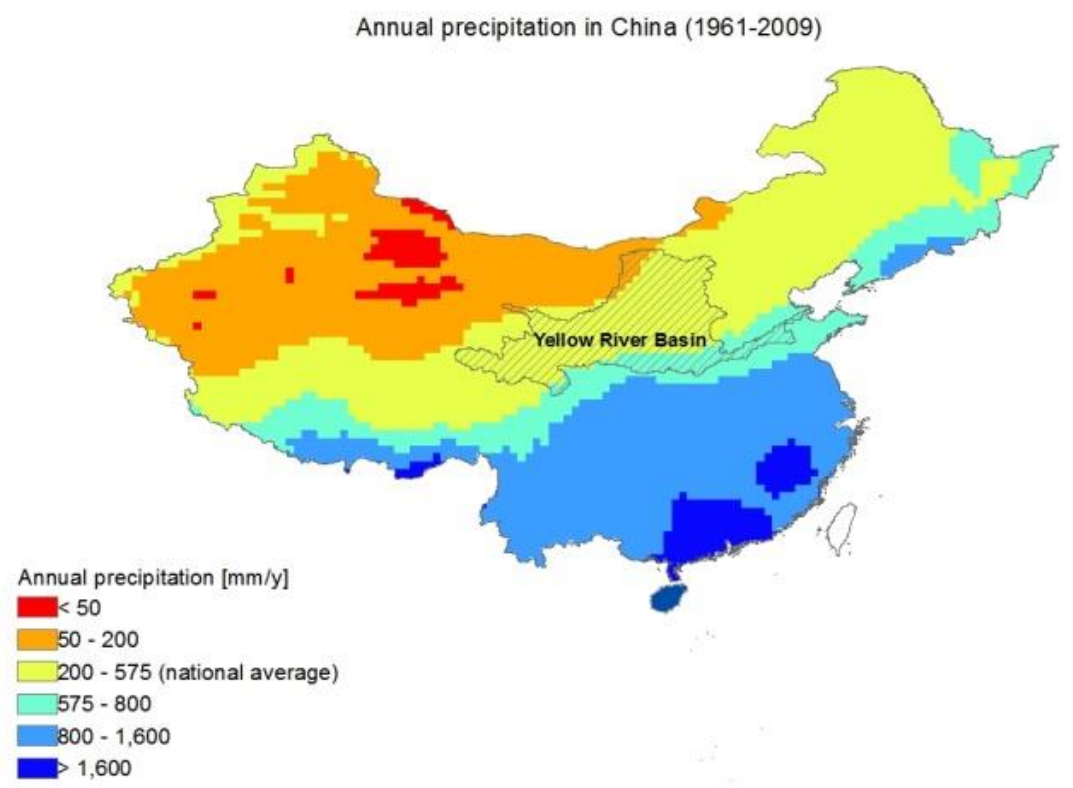

Figure 1.1 Average annual precipitation $\left(m m y^{-1}\right)$ in China for 1961-2009. Data source: Harris et al. (2014).

Water issues in China could be thornier with the expected socio-economic development, the growing population and potential future climate change (Liu and Savenije, 2008; Piao et al., 2010; Dalin et al., 2015; Jiang, 2015). The shift of the Chinese diet towards more water-intensive food items (e.g. meat products, oil crops and sugar crops) could lead to increasing water consumption in food production, thus putting an additional pressure on the already scarce water resources (Liu and Savenije, 2008). The pressure can further be exacerbated given China's governmental plan to pursue self-sufficiency in major grain products (NDRC, 2008; SCPRC, 2014b). At the same time, the projected warming of the 
climate in the coming decades could influence water availability (Piao et al., 2010; Jiang, 2015). The gap between water scarcity in the North and relative water abundance in the South can further widen given predicted decreases in water resources in the North for 2021-2050 as compared to 1961-1990 in the latest representative concentration pathways RCP 2.6 (by 1.3\%) and RCP 8.5 (by 2.3\%) (Wang and Zhang, 2015). Current governmental monitoring programs focus on measuring water withdrawals and irrigation efficiency, but lack integrated monitoring of the drivers of changes in water quantity and quality, so that proactive adaptive management is difficult (Liu and Yang, 2012). Thus, a systematic and comprehensive assessment that describes China's past, current and future water consumption and water scarcity as affected by human activities and climate change is necessary and urgent.

\subsection{Water footprint accounting}

Estimating the water footprints of agricultural products requires spatially and temporally explicit data on land use, soil types, climate, crop parameters, irrigation, and fertilizer application. Given the recent advances in geographic information systems (GIS) and availability of open global GIS datasets with regard to the input data required for calculating WFs of agricultural production, WF accounting at a high spatial resolution taking into account the heterogeneity in climate and other input parameters can now be realized (Mekonnen, 2011). Global green and blue WFs of crop production have been mapped at a spatial resolution of 30 by 30 arc minute (Rost et al., 2008; Liu et al., 2009; Fader et al., 2010; Hanasaki et al., 2010; Liu and Yang, 2010) and even at 5 by 5 arc minute (Mekonnen and Hoekstra, 2010; Siebert and Doll, 2010; Mekonnen and Hoekstra, 2011; Tuninetti et al., 2015). The global grey WF related to anthropogenic nitrogen (N) loads from croplands to groundwater and surface water has been mapped at 5 by 5 arc min level by Mekonnen and Hoekstra (2011), assuming simple leaching-runoff ratios, and the additional grey WF related to $\mathrm{N}$ loads from the domestic and industrial sectors has been estimated by Hoekstra and Mekonnen (2012). Mekonnen and Hoekstra (2015) have improved the global grey WF map related to anthropogenic $\mathrm{N}$ loads by implementing a more advanced soil balance approach for estimating $\mathrm{N}$ loads from croplands (Bouwman et al., 2013). 
Water footprint calculations at a high spatial resolution are based on a large set of assumptions with respect to modelling structure, parameter values, datasets for input variables and period considered that could cause a divergence in outcomes (Mekonnen and Hoekstra, 2010; Hoekstra et al., 2011). However, there are only a few studies on the sensitivities in WF accounting. Examples include the assessment of the sensitivity of the WF of maize to climate variables in the Po Vally in Northern Italy by Bocchiola et al. (2013), the assessment of the sensitivity of the WF of fresh algae cultivation to changes in evaporation estimation method by Guieysse et al. (2013), and the global sensitivity analysis to explore the sensitivity of the WF of crops to input parameter variability by Tuninetti et al. (2015).

Assessment of the variability of WFs and VW flows across different years and analysis of long-term trends is also still in it infancy. Most studies on WF accounting and VW trade analysis refer to a certain year or to the average of a certain period, like a five- or ten-year period. For the case of China, where changes over the past few decades have been very quick, only a few studies are available on long-term variability and trends in WFs, mostly for a small part of the country such as the capital city Beijing (Zhang et al., 2012; Sun et al., 2013a) or an irrigation district (Sun et al., 2012a). One study focuses on analysing the driving factors of the increasing blue WF of food consumption in China as a whole (Zhao and Chen, 2014).

Scenario analysis is a popular tool to explore how alternative futures might unfold from current conditions under alternative human choices (Polasky et al., 2011; Ercin and Hoekstra, 2014). The first scenario analyses related to WF and VW trade have become available only recently, with Fader et al. (2010) and Liu et al. (2013) assessing the global green and blue WF of crop production under climate change scenarios by the late $21 \mathrm{st}$ century. Zhao et al. (2014) did a similar study for China. Global scenarios for WFs and VW trade under alternative socio-economic developments have been developed by Ercin and Hoekstra (2014). Dalin et al. (2015) considered future changes in VW trade related to food products under different socio-economic scenarios in China. Though Konar et al. (2013) have shown the responses in the WFs of major crops and associated global VW trade 
network under scenarios that consider both climate change and socio-economic developments, they have not assessed responses in the WF of total crop production and consumption.

The WF of growing a crop depends on environmental conditions (e.g. climate, soil) and management conditions (e.g. irrigation technology, mulching practice) (Zwart et al., 2010; Mekonnen and Hoekstra, 2011; Tuninetti et al., 2015). WF benchmarks can serve as reference and reduction target for producers who have WFs above the benchmark (Hoekstra, 2013; 2014). WF benchmarks of a crop (in $\mathrm{m}^{3} \mathrm{t}^{-1}$ ) can be set, for example, as the WF that is not exceeded by the best $20-25 \%$ of the total production in a geographic area with similar environmental conditions. A global WF benchmark for one crop type is also meaningful, to show a reasonable WF target achievable in practice everywhere worldwide. A WF benchmark for a specific crop can also be defined based on the best-available technology (e.g. irrigation technology) (Hoekstra, 2014). Mekonnen and Hoekstra (2014) have established global consumptive (green plus blue) and degradative (grey) WF benchmark values, separately, for a large number of crops based on gridded actual WF values for 1996-2005 at a spatial resolution of 5 by 5 arc min. Chukalla et al. (2015) explored reduction potentials for consumptive WFs of crops by applying different types of irrigation technologies, strategies and mulching practices. The variation of consumptive WFs of a crop is closely linked to different types of soils (Tolk and Howell, 2012), variability of climatic variables like precipitation and reference evapotranspiration (Zwart et al., 2010) and whether crops are irrigated or rain-fed (Mekonnen and Hoekstra, 2010; 2011). It is still not clear, however, which of these factors should be considered as most important when developing benchmark levels for the consumptive WF of crops.

\subsection{Research objective and thesis outline}

The overall objective of the thesis is to systematically evaluate past, current and future WFs, water scarcity and VW flows at both river basin and national level in China, focusing on the agricultural sector, high spatial resolution modelling, uncertainties, inter- and intra- annual variation and benchmarks. The thesis has been designed into five sub-research subjects, which will be reported in Chapters 2-6: 
- Sensitivity and uncertainty in crop WF accounting, in a case study for the Yellow River Basin (Chapter 2);

- Inter- and intra-annual variation of WF of crops and blue water scarcity in the Yellow River Basin (Chapter 3);

- The effect of inter-annual variability of consumption, production, trade and climate on crop-related green and blue WFs and inter-regional VW trade in China (Chapter 4);

- Consumptive WF and VW trade scenarios for China with a focus on crop production, consumption and trade (Chapter 5);

- Benchmark levels for the consumptive WF of crop production for different environmental conditions: a case study for winter wheat in China (Chapter 6).

Chapter 2 analyses the sensitivity of and uncertainties in accounting green and blue WFs of crop production at a high spatial resolution, related to variability and uncertainties in important input variables at the scale of a river basin, considering maize, soybean, rice and wheat in the YRB over 1996-2005. The sensitivity of the WF per tonne of crop to seven different input variables and parameters are presented, as well as the uncertainty ranges in the estimated WFs from uncertainties in four key input variables.

Chapter 3 estimates the WFs of crop production in the YRB over the period of 1961-2009 and assesses the monthly blue water scarcity for 1978-2009, by comparing the total blue WF of agriculture, industry and households in the basin to the maximum sustainable blue WF. The inter-annual variation of green, blue and grey WFs of seventeen crops, and the monthly blue water scarcity in the YRB are shown at a high spatial resolution level so that the spatial distribution is also observed.

Chapter 4 investigates the inter-annual developments of green and blue WFs of both production and consumption for twenty-two crops and associated inter-regional VW trade within China from 1978, the start of the economic reform in the country, to 2008. The study shows how the pressure on water resources in the North increased by intensive agricultural production and how the inter-regional VW network within China changed over time.

Chapter 5 is a scenario study for China for 2030 and 2050, developing four scenarios with 
regard to the green and blue WFs of crop production and consumption, and national VW trade. Five driving factors were considered in developing the scenarios: climate change, changes in harvested crop area, technology development, shifts in diet and population growth.

Chapter 6 explores which environmental factors need to be distinguished when setting benchmarks for the consumptive (green-blue) WF of crop production. The study takes winter wheat production in China over 1961-2008 as study case and analyses differences in benchmarks for the consumptive WF of the crop when distinguishing between rain-fed and irrigated crops, between wet and dry years, between cold and warm years, between different soil classes and between different climate zones.

Finally, Chapter 7 concludes the thesis by putting the main findings in the previous chapters into perspective. 


\title{
2. Sensitivity and Uncertainty in Crop Water Footprint Accounting: a Case Study for the Yellow River Basin ${ }^{1}$
}

\begin{abstract}
Water Footprint (WF) Assessment is a fast growing field of research, but as yet little attention has been paid to the uncertainties involved. This study investigates the sensitivity of and uncertainty in crop WF (in $\mathrm{m}^{3} \mathrm{t}^{-1}$ ) estimates related to uncertainties in important input variables. The study focuses on the green (from rainfall) and blue (from irrigation) WF of producing maize, soybean, rice, and wheat at the scale of the Yellow River Basin in the period 1996-2005. A grid-based daily water balance model at a 5 by 5 arc min resolution was applied to compute green and blue WF of the four crops in the Yellow River Basin in the period considered. The one-at-a-time method was carried out to analyse the sensitivity of the crop WF to fractional changes of seven individual input variables and parameters: precipitation $(\mathrm{PR})$, reference evapotranspiration $\left(\mathrm{ET}_{0}\right)$, crop coefficient $\left(\mathrm{K}_{\mathrm{c}}\right)$, crop calendar (planting date with constant growing degree days), soil water content at field capacity $\left(\mathrm{S}_{\max }\right)$, parameters yield response factor $\left(\mathrm{K}_{\mathrm{y}}\right)$ and maximum yield $\left(\mathrm{Y}_{\mathrm{m}}\right)$. Uncertainties in crop WF estimates related to uncertainties in four key input variables: $\mathrm{PR}, \mathrm{ET}_{0}, \mathrm{~K}_{\mathrm{c}}$, and crop calendar were quantified through Monte Carlo simulations.
\end{abstract}

The results show that the sensitivities and uncertainties differ across crop types. In general, the WF of crops is most sensitive to $\mathrm{ET}_{0}$ and $\mathrm{K}_{\mathrm{c}}$, followed by the crop calendar. Blue WFs were more sensitive to input variability than green WFs. The smaller the annual blue WF is, the higher its sensitivity to changes in PR, $\mathrm{ET}_{0}$, and $\mathrm{K}_{\mathrm{c}}$. The uncertainties in the total WF of a crop due to combined uncertainties in climatic inputs (PR and $\mathrm{ET}_{0}$ ) were about $\pm 20 \%$ (at 95\% confidence interval). The effect of uncertainties in $\mathrm{ET}_{0}$ was dominant compared to that of PR. The uncertainties in the total consumptive WF of a crop as a result of combined key input uncertainties were on average $\pm 30 \%$ (at $95 \%$ confidence level).

\footnotetext{
${ }^{1}$ Chapter is based on: Zhuo, Mekonnen and Hoekstra (2014) Hydrology and Earth System Sciences 18 (6), 2219-2234
} 


\subsection{Introduction}

More than two billion people live in highly water stressed areas (Oki and Kanae, 2006), and the pressure on freshwater will inevitably be intensified by population growth, economic development and climate change in the future (Vörösmarty et al., 2000). The water footprint (WF) (Hoekstra, 2003) is increasingly recognized as a suitable indicator of human appropriation of freshwater resources and is becoming widely applied to get better understanding of the sustainability of water use. In the period 1996-2005, agriculture contributed $92 \%$ to the total WF of humanity (Hoekstra and Mekonnen, 2012).

Water footprints within the agricultural sector have been extensively studied, mainly focusing on the WF of crop production, at scales from a sub-national region (Aldaya and Llamas, 2008; Zeng et al., 2012; Sun et al., 2013a), and a country (Ma et al., 2006; Hoekstra and Chapagain, 2007a; Kampman et al., 2008; Liu and Savenije, 2008; Bulsink et al., 2010; Ge et al., 2011) to the globe (Hoekstra and Chapagain, 2007b; Liu and Yang, 2010; Siebert and Doll, 2010; Mekonnen and Hoekstra, 2011; Hoekstra and Mekonnen, 2012).The green or blue WF of a crop is normally expressed by a single volumetric number referring to an average value for a certain area and period. However, the WF of a crop is always estimated based on a large set of assumptions with respect to the modelling approach, parameter values, and datasets for input variables used, so that outcomes carry substantial uncertainties (Mekonnen and Hoekstra, 2010; Hoekstra et al., 2011).

Together with the carbon footprint and ecological footprint, the WF is part of the "footprint family of indicators" (Galli et al., 2012), a suite of indicators to track human pressure on the surrounding environment. Nowadays, it is not hard to find information in literature on uncertainties in the carbon footprint of food products (Röös et al., 2010; 2011) or uncertainties in the ecological footprint (Parker and Tyedmers, 2012). But there are hardly any sensitivity or uncertainty studies available in the WF field (Hoekstra et al., 2011), while only some subjective approximations and local rough assessments exist (Mekonnen and Hoekstra, 2010; 2011; Hoekstra et al., 2012; Mattila et al., 2012). Bocchiola et al. (2013) assessed the sensitivity of the WF of maize to potential changes of certain selected weather variables in Northern Italy. Guieysse et al. (2013) assessed the sensitivity of the WF of fresh 
algae cultivation to changes in methods to estimate evaporation.

In order to provide realistic information to stakeholders in water governance, analysing the sensitivity and the magnitude of uncertainties in the results of a WF Assessment in relation to assumptions and input variables would be useful (Hoekstra et al., 2011; Mekonnen and Hoekstra, 2011). Therefore, the objectives of this study are (1) to investigate the sensitivity of the WF of a crop to changes in input variables and parameters, and (2) to quantify the uncertainty in green, blue, and total consumptive WFs of crops due to uncertainties in input variables at scale of a river basin. The study focuses on the water footprint of producing maize, soybean, rice, and wheat in the Yellow River Basin, China, for each separate year in the period 1996-2005. Uncertainty in this study refers to the uncertainty in WF that accumulates due to the uncertainties in inputs that is propagated through the accounting process and is reflected in the resulting estimates (Walker et al., 2003).

\subsection{Study area}

The Yellow River Basin (YRB), drained by the Yellow River (or 'Huang He'), is the second largest river basin in China with a drainage area of $795 \times 10^{3} \mathrm{~km}^{2}$ (YRCC, 2011). The Yellow River is 5,464 km long, originates from the Bayangela Mountains of the Tibetan Plateau, flows through nine provinces (Qinghai, Sichuan, Gansu, Ningxia, Inner Mongolia, Shaanxi, Shanxi, Henan and Shandong), and finally drains into the Bohai Sea. The YRB is usually divided into three reaches: the upper reach (upstream of Hekouzhen, Inner Mongolia), the middle reach (upstream of Taohuayu, Henan province) and the lower reach (draining into the Bohai Sea) (Figure 2.1).

The YRB is vital for food production, natural resources and socioeconomic development of China (Cai et al., 2011). The cultivated area of the YRB accounts for $13 \%$ of the national total (MWR, 2015). In 2000, the basin accounted for 14\% of the country's crop production with about 7 million ha of irrigated land at a total agriculture area in the basin of 13 million ha (Ringler et al., 2010). The water of the Yellow River supports 150 million people with a per capita blue water availability of $430 \mathrm{~m}^{3}$ per year (Falkenmark and Widstrand, 1992). The YRB is a net virtual water exporter (Feng et al., 2012) and suffering severe water scarcity. 
The blue water footprint in the basin is larger than the maximum sustainable blue water footprint (runoff minus environmental flow requirements) during eight months a year (Hoekstra et al., 2012).

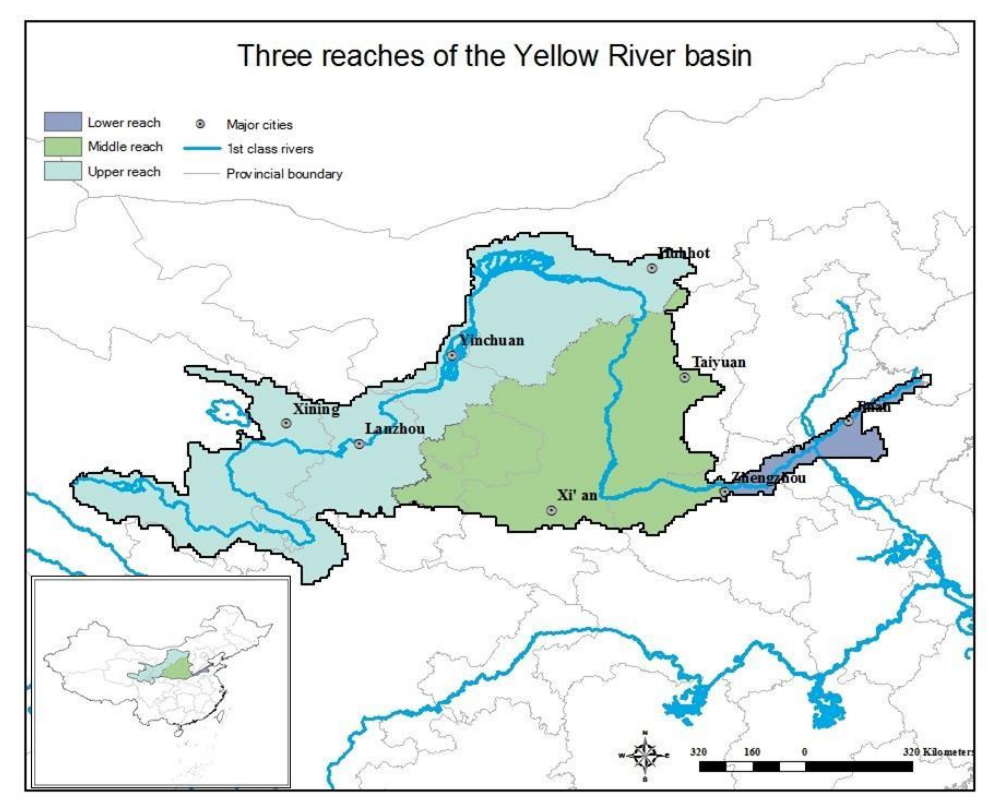

Figure 2.1 The three reaches of the Yellow River Basin.

\subsection{Method and data}

\subsubsection{Crop water footprint accounting}

Annual green and blue water footprints (WF) of producing maize, soybean, rice, and wheat in the YRB for the study period were estimated. The green and blue WF per unit mass of crop $\left(\mathrm{m}^{3} \mathrm{t}^{-1}\right)$ were calculated by dividing the green and blue crop water use (CWU, $\left.\mathrm{m}^{3} \mathrm{ha}^{-1}\right)$ by the crop yield $\left(\mathrm{Y}, \mathrm{t} \mathrm{ha}^{-1}\right)$, respectively(Hoekstra et al., 2011). The total WF refers to the sum of green and blue WF.

A grid-based dynamic water balance model, developed by Mekonnen and Hoekstra (2010; 2011), is used to compute different components of CWU according to the daily soil water balance. The model has a spatial resolution of 5 by 5 arc minute (about $7.4 \mathrm{~km} \times 9.3 \mathrm{~km}$ at 
the latitude of the YRB). The daily root zone soil water balance for growing a crop in each grid cell in the model can be expressed in terms of soil moisture $\left(\mathrm{S}_{[\mathrm{t}]}, \mathrm{mm}\right)$ at the end of the day (Mekonnen and Hoekstra, 2010):

$S_{[t]}=S_{[t-1]}+I_{[t]}+P R_{[t]}+C R_{[t]}-R_{[t]}-E_{[t]}-D_{[t]}$

where $\mathrm{S}_{[\mathrm{t}-1]}(\mathrm{mm})$ refers to the soil water content on day $(\mathrm{t}-1), \mathrm{I}_{[\mathrm{t}]}(\mathrm{mm})$ the irrigation water applied on day $\mathrm{t}, \mathrm{PR}_{[\mathrm{t}]}(\mathrm{mm})$ precipitation, $\mathrm{CR}_{[\mathrm{t}]}(\mathrm{mm})$ capillary rise from the groundwater, $\mathrm{RO}_{[\mathrm{t}]}(\mathrm{mm})$ water runoff, $\mathrm{ET}_{[\mathrm{t}]}(\mathrm{mm})$ actual evapotranspiration and $\mathrm{DP}_{[\mathrm{t}]}$ $(\mathrm{mm})$ deep percolation on day $\mathrm{t}$.

$\mathrm{CWU}_{\text {green }}$ and $\mathrm{CWU}_{\text {blue }}$ over the crop growing period (in $\mathrm{m}^{3} \mathrm{ha}^{-1}$ ) were calculated from the accumulated corresponding ET (mm day $\left.{ }^{-1}\right)$ :

$\mathrm{CWU}_{\text {green }}=10 \times \sum_{\mathrm{d}=1}^{\text {lgp }} \mathrm{ET}_{\text {green }}$

$\mathrm{CWU}_{\text {blue }}=10 \times \sum_{\mathrm{d}=1}^{\operatorname{lgp}} \mathrm{ET}_{\text {blue }}$

The accumulation was done over the growing period from the day of planting $(d=1)$ to the day of harvest (lgp, the length of growing period in days). The factor $10\left(\mathrm{~m}^{3} \mathrm{~mm}^{-1} \mathrm{ha}^{-1}\right)$ is applied to convert the $\mathrm{mm}$ to $\mathrm{m}^{3} \mathrm{ha}^{-1}$. The daily ET (mm day ${ }^{-1}$ ) was computed according to Allen et al. (1998) as:

$\mathrm{ET}=\mathrm{K}_{\mathrm{s}}[\mathrm{t}] \times \mathrm{K}_{\mathrm{c}}[\mathrm{t}] \times \mathrm{ET}_{0}[\mathrm{t}]$

where $K_{c}[t]$ is the crop coefficient, $K_{s}[t]$ a dimensionless transpiration reduction factor dependent on available soil water and $\mathrm{ET}_{0}[\mathrm{t}]$ the reference evapotranspiration $\left(\mathrm{mm} \mathrm{day}^{-1}\right)$. The crop calendar and $K_{c}$ values for each crop were assumed to be constant for the whole basin as shown in Table 2.1. $\mathrm{K}_{\mathrm{s}}[\mathrm{t}]$ is assessed based on a daily function of the maximum and actual available soil moisture in the root zone: 
$\mathrm{K}_{\mathrm{s}}[\mathrm{t}]=\left\{\begin{array}{cc}\frac{\mathrm{S}[\mathrm{t}]}{(1-\mathrm{p}) \times \mathrm{S}_{\max }[\mathrm{t}]}, & \mathrm{S}[\mathrm{t}]<(1-\mathrm{p}) \times \mathrm{S}_{\max }[\mathrm{t}] \\ 1, & \text { otherwise }\end{array}\right.$

where $S_{\max }[t]$ is the maximum available soil water in the root zone $(\mathrm{mm}$, when soil water content is at field capacity), and $p$ the fraction of $S_{\max }$ that a crop can extract from the root zone without suffering water stress, which is a function of $\mathrm{ET}_{0}$ and $\mathrm{K}_{\mathrm{c}}$.

WF of the four crops in the YRB was estimated covering both rain-fed and irrigated agriculture. In the case of rain-fed crop production, blue CWU is zero and green CWU $\left(\mathrm{m}^{3}\right.$ $\mathrm{ha}^{-1}$ ) was calculated by aggregating the daily values of ET over the length of the growing period. In the case of irrigated crop production, the green water use was assumed to be equal to the ET for the case without irrigation. The blue water use was estimated as the CWU simulated in the case with sufficient irrigation water applied minus the green CWU in the same condition but without irrigation (Mekonnen and Hoekstra, 2010; 2011).

The crop yield is influenced by water stress (Mekonnen and Hoekstra, 2010). The actual harvested yield $\left(\mathrm{Y}, \mathrm{t} \mathrm{ha}^{-1}\right)$ at the end of crop growing period for each grid cell was estimated using the equation proposed by Doorenbos and Kassam (1979):

$\mathrm{Y}=\mathrm{Y}_{\mathrm{m}} \times\left[1-\mathrm{K}_{\mathrm{y}}\left(1-\frac{\sum_{\mathrm{d}=1}^{\mathrm{lg}} \mathrm{ET}}{\mathrm{CWR}}\right)\right]$

where $Y_{m}$ is the maximum yield $\left(\mathrm{t} \mathrm{ha}^{-1}\right)$, obtained by multiplying the corresponding provincial average yield values by a factor of 1.2 (Reynolds et al., 2000). $\mathrm{K}_{\mathrm{y}}$ is the yield response factor obtained from Doorenbos and Kassan (1979). CWR refers to the crop water requirement for the whole growing period $\left(\mathrm{mm} \mathrm{period}^{-1}\right)\left(\right.$ which is equal to $\mathrm{K}_{\mathrm{c}} \times \mathrm{ET}_{0}$ ). 
Table 2.1 Crop characteristics for maize, soybean, rice and wheat in the Yellow River Basin.

\begin{tabular}{|c|c|c|c|c|c|c|c|c|c|}
\hline & \multicolumn{3}{|c|}{ Crop coefficients } & \multirow{2}{*}{$\begin{array}{l}\text { Planting } \\
\text { date }\end{array}$} & \multirow{2}{*}{$\begin{array}{l}\text { Growing } \\
\text { period } \\
\text { (days) }\end{array}$} & \multicolumn{4}{|c|}{ Relative crop growing stages } \\
\hline & $K_{c \_}$ini & $K_{c \_}$mid & $K_{c \_}$end & & & L_ini & L_dev & L_mid & L_late \\
\hline Maize & 0.70 & 1.20 & 0.25 & 1-Apr & 150 & 0.20 & 0.27 & 0.33 & 0.20 \\
\hline Soybean & 0.40 & 1.15 & 0.50 & 1-Jun & 150 & 0.13 & 0.17 & 0.50 & 0.20 \\
\hline Rice & 1.05 & 1.20 & 0.90 & 1-May & 180 & 0.17 & 0.17 & 0.44 & 0.22 \\
\hline Wheat & 0.70 & 1.15 & 0.30 & 1-Octobe & 335 & 0.48 & 0.22 & 0.22 & 0.07 \\
\hline
\end{tabular}

Sources: Allen et al. (1998); Chen et al. (1995); Chapagain and Hoekstra (2004).

\subsubsection{Sensitivity and uncertainty analysis}

The estimation of crop WF requires a number of input variables and parameters to the model, including: daily precipitation (PR), daily reference evapotranspiration $\left(\mathrm{ET}_{0}\right)$, crop coefficients $\left(\mathrm{K}_{\mathrm{c}}\right)$ in the different growing stages, crop calendar (planting date and length of the growing period), soil water content at field capacity $\left(S_{\max }\right)$, yield response factor $\left(\mathrm{K}_{\mathrm{y}}\right)$ and maximum yield $\left(\mathrm{Y}_{\mathrm{m}}\right)$. The one-at-a-time method (see below) was applied to investigate the sensitivity of CWU, Y and WF to changes in these inputs. The uncertainties in WF due to uncertainties in $\mathrm{PR}, \mathrm{ET}_{0}, \mathrm{~K}_{\mathrm{c}}$, and crop calendar were assessed through Monte Carlo simulations. We assumed that systematic errors in original climate observations at stations had been removed already. Uncertainties in variables $\mathrm{PR}, \mathrm{ET}_{0}$ and $\mathrm{K}_{\mathrm{c}}$ were assumed random, independent and close to a normal (Gaussian) distribution (Troutman, 1985; Meyer et al., 1989; Ahn, 1996; Droogers and Allen, 2002; Xu et al., 2006b).

\section{- Sensitivity analysis}

The 'one-at-a-time' or 'sensitivity curve' method is a simple but practical way of sensitivity analysis to investigate the response of an output variable to variation of input values (Hamby, 1994; Sun et al., 2012b). With its simplicity and intuitionism, the method is popular and has been widely used (Ahn, 1996; Goyal, 2004; Xu et al., 2006a; Xu et al., 2006b; Estevez et al., 2009). The method was performed by introducing fractional changes to one input variable while keeping other inputs constant. The 'sensitivity curve' of the resultant relative change 
in the output variable was then plotted against the relative change of the input variable. The sensitivity analysis was carried out for each year in the period 1996-2005. For each cropped grid cell, we varied each input variable within a certain range. Then, the annual average level of the responses in CWU, Y, and (green, blue, and total) WF of the crops for the basin as a whole were recorded. With respect to the input variables $\mathrm{PR}, \mathrm{ET}_{0}$ and $\mathrm{K}_{\mathrm{c}}$, we shifted each within the range of $\pm 2 \mathrm{SD}$ ( $2 \times$ standard deviation of input uncertainties), which represents the $95 \%$ confidence interval for uncertainties in the input variable. In terms of the crop calendar, we varied the planting date (D) within \pm 30 days with constant growing degree days (GDD) and relative length of crop growing stages (Allen et al., 1998) (Table 2.1). The cumulative GDD $\left({ }^{\circ} \mathrm{C}\right.$ day), measuring heat units during crop growth, has vastly improved expression and prediction of the crop's phenological cycle compared to other approaches such as time of the year or number of days (McMaster and Wilhelm, 1997). In the study, a crop's GDD was calculated per year, following the most widely used 'Method 1' (McMaster and Wilhelm, 1997), by summing the difference of the daily base temperature and the average air temperature over the reference crop growing period in days (Table 2.1). The base temperature is the temperature below which crop growth does not progress. The base temperature of each crop was obtained from FAO (Raes et al., 2011). Parameters $S_{\max }$, $\mathrm{K}_{\mathrm{y}}$ and $\mathrm{Y}_{\mathrm{m}}$ were varied within the range of $\pm 20 \%$ of the default value.

\section{- Uncertainty analysis}

The advantage of uncertainty analysis with Monte Carlo (MC) simulation is that the model to be tested can be of any complexity (Meyer, 2007). MC simulations were carried out at the basin level to quantify the uncertainties in estimated WF due to uncertainties in individual or multiple input variables. The uncertainty analysis was carried out separately for three years within the study period: 1996 (wet year), 2000 (dry year), and 2005 (average year). For each MC simulation, 1,000 runs were performed. Based on the set of WF estimates from those runs, the mean $(\mu)$ and standard deviation (SD) is calculated; with $95 \%$ confidence, WF falls in the range of $\mu \pm 2 \mathrm{SD}$. The SD will be expressed as a percentage of the mean.

\section{- Uncertainties in input variables and parameters}

Uncertainties in the Climate Research Unit Time Series (CRU-TS) (Harris et al., 2014) grid 
precipitation values used for WF accounting in this study come from two sources: the measurement errors inherent in station observations, and errors which occur during the interpolation of station data in constructing the grid database (Phillips and Marks, 1996; Fekete et al., 2004; Zhao and Fu, 2006). Zhao and $\mathrm{Fu}$ (2006) compared the spatial distribution of precipitation as in the CRU database with the corresponding observations over China and revealed that the differences between the CRU data and observations vary from $-20 \%$ to $20 \%$ in the area where the YRB is located. For this study, we assume a $\pm 20 \%$ range around the CRU precipitation data as the $95 \%$ confidence interval $(2 \mathrm{SD}=20 \%)$.

The uncertainties in the meteorological data used in estimating $\mathrm{ET}_{0}$ will be transferred into uncertainties in the $\mathrm{ET}_{0}$ values. The method used to estimate the CRU-TS $\mathrm{ET}_{0}$ dataset is the Penman-Monteith (PM) method (Allen et al., 1998). The PM method has been recommended for its high accuracy at station level within $\pm 10 \%$ from the actual values under all ranges of climates (Jensen et al., 1990). With respect to the gridded $\mathrm{ET}_{0}$ calculation, the interpolation may cause additional error (Phillips and Marks, 1996; Thomas, 2008b).

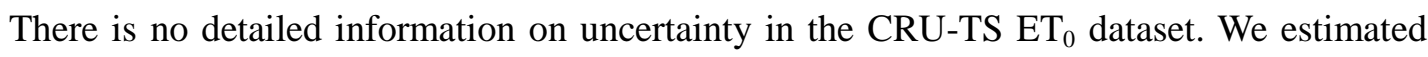
daily $\mathrm{ET}_{0}$ values $\left(\mathrm{mm} \mathrm{day}^{-1}\right.$ ) for the period 1996-2005 from observed climatic data at 24 meteorological stations spread out in the YRB (CMA, 2008) by the PM method. Then we compared, station by station, the monthly averages of those calculated daily $\mathrm{ET}_{0}$ values to the corresponding monthly $\mathrm{ET}_{0}$ values in the CRU-TS dataset (Figure2.2a). The differences between the station values and CRU-TS values ranged from -0.23 to $0.27 \mathrm{~mm}^{-1} \mathrm{day}^{-1}$ with a mean of $0.005 \mathrm{~mm} \mathrm{day}^{-1}$ (Figure 2.2b). The standard deviation (SD) of the differences was $0.08 \mathrm{~mm} \mathrm{day}^{-1}, 5 \%$ from the station values, which implies an uncertainty range of $\pm 10 \%$ (2SD) at $95 \%$ confidence interval. The locations of CMA stations were different from the stations used for generating the CRU dataset (Harris et al., 2014) (see Figure 2.2c), which was one of the sources of the uncertainty. We added the basin level uncertainty in monthly $\mathrm{ET}_{0}$ values due to uncertainties in interpolation $( \pm 10 \%$ at $95 \%$ confidence level $)$ and the uncertainty related to the application of the PM method (another $\pm 10 \%$ at $95 \%$ confidence level) to arrive at an overall uncertainty of $\pm 20 \%$ (2SD) for the $\mathrm{ET}_{0}$ data. We acknowledge that this is a crude estimate of uncertainty, but there is no better. 


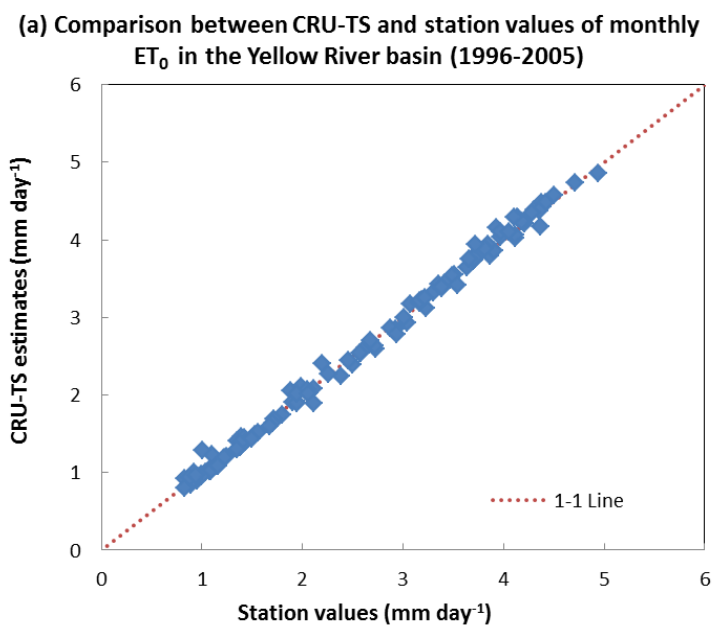

(b) Distribution of the differences between CRU-TS $\mathrm{ET}_{0}$ and station values

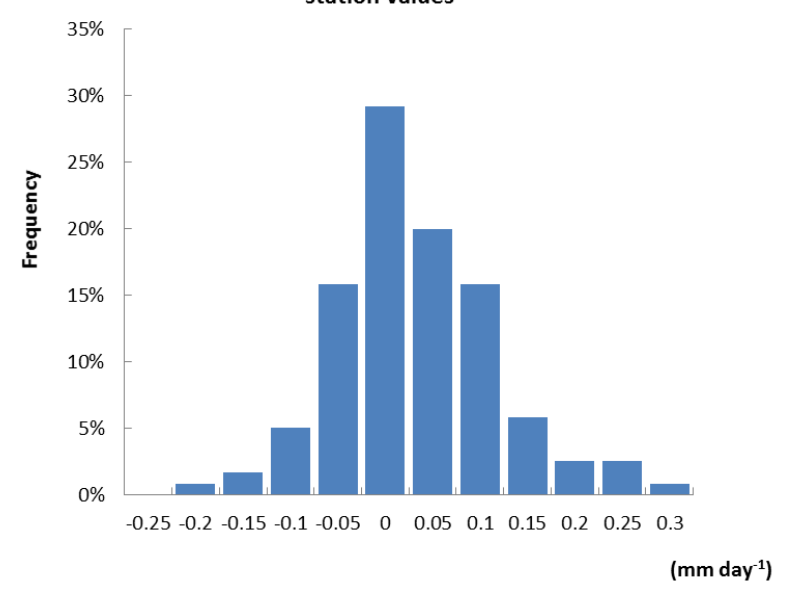

(c) The station locations for CMA data and CRU data.

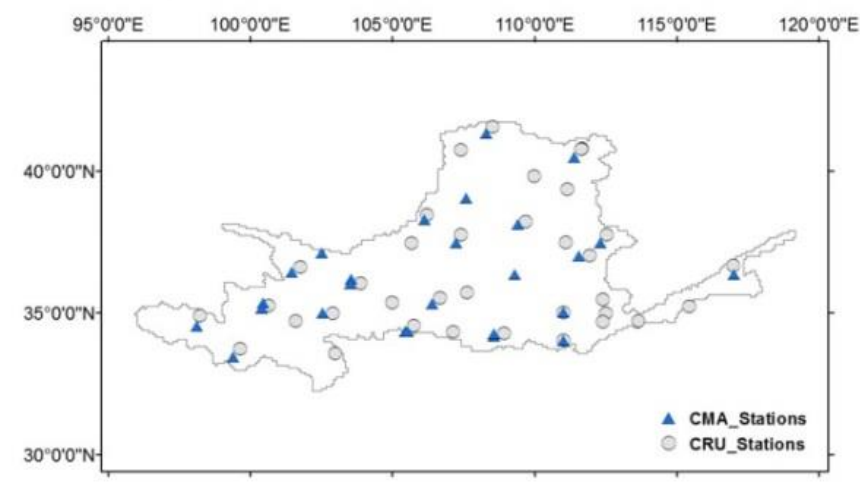

Figure 2.2 Differences between monthly averages of daily ET 0 data from CRU-TS and station-based values for the Yellow River Basin, 1996-2005. 
We used the $\mathrm{K}_{\mathrm{c}}$ values from Table 2.1 for the whole basin. According to Jagtap and Jones (1989), the $\mathrm{K}_{\mathrm{c}}$ value for a certain crop can vary by $15 \%$. We adopted this value and assumed the $95 \%$ uncertainty range falls within $\pm 15 \%$ (2SD) from the mean $\mathrm{K}_{\mathrm{c}}$ values. Referring to the crop calendar, we assumed that the planting date for each crop fluctuated within \pm 30 days from the original planting date used, holding the same length of GDD for each year. Table 2.2 summarises the uncertainty scenarios considered in the study.

Table 2.2 Input uncertainties for crop water footprint accounting in the Yellow River Basin.

\begin{tabular}{|c|c|c|c|}
\hline Input variable & Unit & $\begin{array}{l}95 \% \text { confidence interval } \\
\text { of input uncertainties }\end{array}$ & $\begin{array}{l}\text { Distribution of input } \\
\text { uncertainties }\end{array}$ \\
\hline Precipitation (PR) & $\mathrm{mm}$ day $^{-1}$ & $\pm 20 \%\left(2 S^{\star}\right)$ & Normal \\
\hline $\begin{array}{l}\text { Reference } \\
\text { evapotranspiration }\left(E T_{0}\right)\end{array}$ & $\mathrm{mm} \mathrm{day}^{-1}$ & $\pm 20 \%(2 S D)$ & Normal \\
\hline Crop coefficient $\left(K_{c}\right)$ & - & $\pm 15 \%(2 S D)$ & Normal \\
\hline Planting date (D) & days & \pm 30 & Uniform (discrete) \\
\hline
\end{tabular}

\subsubsection{Data}

The GIS polygon data for the YRB were extracted from the HydroSHEDS dataset (Lehner et al., 2008). Total monthly PR, monthly averages of daily $\mathrm{ET}_{0}$, number of wet days, and daily minimum and maximum temperatures at 30 by 30 arc minute resolution for 1996-2005 were extracted from CRU-TS-3.10.01 (Harris et al., 2014). Figure 2.3 shows PR and ET for $_{0}$ the YRB in the study period. Daily values of precipitation were generated from the monthly values using the CRU-dGen daily weather generator model (Schuol and Abbaspour, 2007). Daily $\mathrm{ET}_{0}$ values were derived from monthly average values by curve fitting to the monthly average through polynomial interpolation (Mekonnen and Hoekstra, 2011). Data on irrigated and rain-fed areas for each crop at a 5 by 5 arc minute resolution were obtained from the MIRCA2000 dataset (Portmann et al., 2010). Crop areas and yields within the 
YRB from MIRCA2000 were scaled to fit yearly agriculture statistics per province of China (NBSC, 2013). Total available soil water capacity at a spatial resolution of 5 by 5 arc minute was obtained from the ISRIC-WISE version 1.2 dataset (Batjes, 2012).
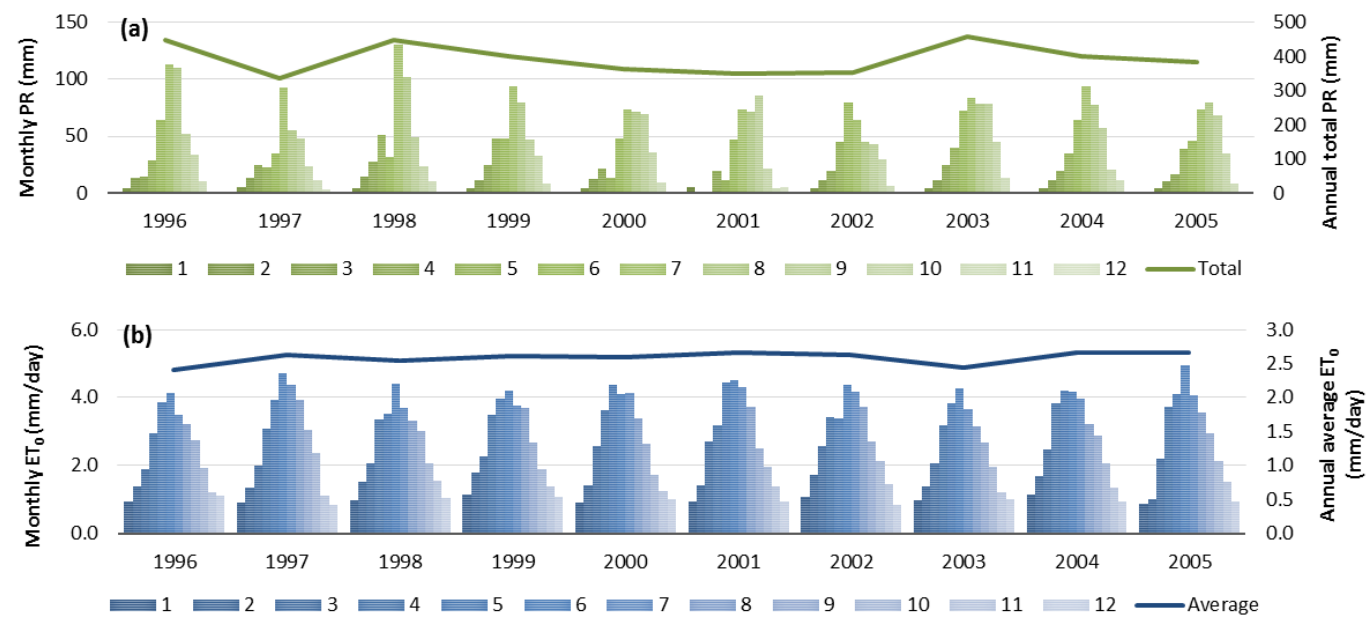

Figure 2.3 Monthly precipitation (PR) and monthly averages of daily $E T_{0}$ in the Yellow River Basin from the CRU-TS database, for the period 1996-2005.

\subsection{Results}

\subsubsection{Sensitivity of CWU, Y, and WF to variability of input variables}

- Sensitivity to variability of precipitation (PR)

The average sensitivities of CWU, Y, and WF to variability of precipitation for the study period were assessed by varying the precipitation between $\pm 20 \%$ as shown in Figure 2.4. An overestimation in precipitation leads to a small overestimation of green WF and a relatively large underestimation of blue WF. A similar result was found for maize in the Po valley of Italy by Bocchiola et al. (2013). The sensitivity of WF to input variability is defined by the combined effects on the CWU and Y. Figure 2.4 shows the overall result for the YRB, covering both rain-fed and irrigated cropping. 
For irrigated agriculture, a reduction in green CWU due to smaller precipitation will be compensated with an increased blue CWU, keeping total CWU and Y unchanged. Therefore, the changes in $\mathrm{Y}$ were due to the changes in the yields in rain-fed agriculture. The relative changes in total WF were always smaller than $\pm 5 \%$ because of the opposite direction of sensitivities of green and blue WF, as well as the domination of green WF in the total. In addition, in terms of wheat only, both Y and total WF reduced with less precipitation. Purposes of modern agriculture are mainly keeping or improving the crop production as well as reducing water use. The instance for wheat indicates that $\mathrm{Y}$ (mass of a crop per hectare) might decrease in certain climate situations in practice although the WF (referring to drops of water used per mass of crop) reduced. On the other hand, it can be noted that the sensitivity of CWU, Y, and WF to input variability differs across crop types, especially evident in blue WF. Regarding the four crops considered, blue WF of soybean is most sensitive to variability in precipitation and blue WF of rice is least sensitive. The explanation lies in the share of blue WF in total WF. At basin level, the blue WF of soybean accounted for about $9 \%$ of the total WF, while the blue WF of rice was around $44 \%$ of the total, which is the highest blue water fraction among the four crops. The larger sensitivity of the blue WF of soybean to change in precipitation compared to that of rice shows that the smaller the blue water footprint the larger its sensitivity to a marginal change in precipitation. 

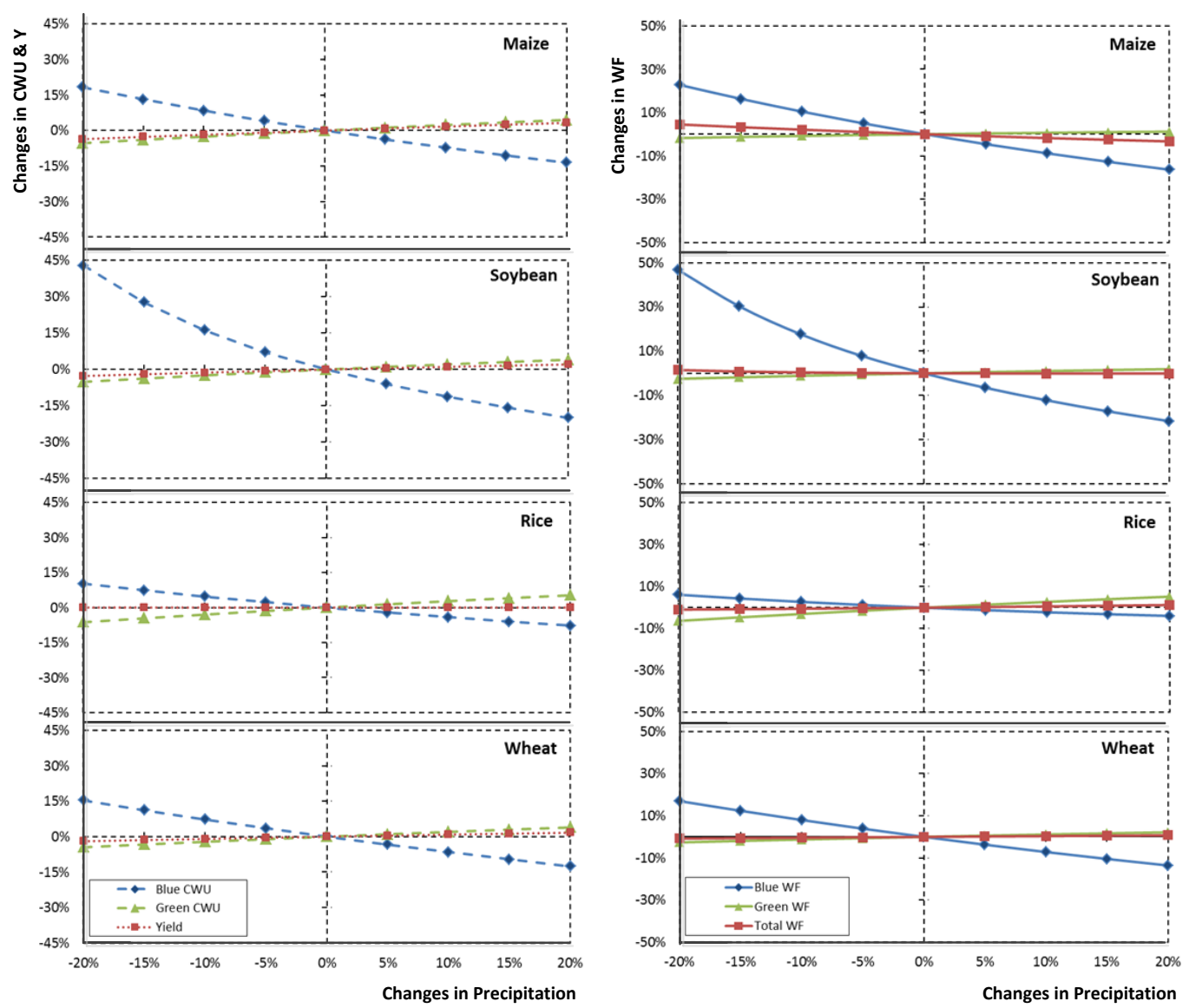

Figure 2.4 Sensitivity of CWU, Y and WF to changes in precipitation (PR), 1996-2005.

\section{- Sensitivity to variability of $E T_{0}$ and $\mathrm{Kc}$}

Figure 2.5 shows the average sensitivity of CWU, Y, and WF to changes in $\mathrm{ET}_{0}$ within a range of $\pm 20 \%$ from the mean for the period 1996-2005. The influences of changes in $\mathrm{ET}_{0}$ on WF are greater than the effect of changes in precipitation. Both green and blue CWU increase with the rising $\mathrm{ET}_{0}$. An increase in $\mathrm{ET}_{0}$ will increase the crop water requirement. For rain-fed crops, the crop water requirement may not be fully met, leading to crop water stress and thus lower Y. For irrigated crops under full irrigation, the crop will not face any water stress, so that the yield will not be affected. The decline in yield at increasing $\mathrm{ET}_{0}$ at basin level in Figure 2.5 is therefore due to yield reductions in rain-fed agriculture only.

Due to the combined effect of increasing CWU and decreasing $\mathrm{Y}$ at increasing $\mathrm{ET}_{0}$, an 
overestimation in $\mathrm{ET}_{0}$ leads to a larger overestimation of WF. The strongest effect of $\mathrm{ET}_{0}$ changes on blue WF was found for soybean, with a relative increase reaching up to $105 \%$ with a $20 \%$ increase in $\mathrm{ET}_{0}$, while the lightest response was found for the case of rice, with a relative increase in blue WF of 34\%. The sensitivities of green WF were similar among the four crops. The changes in total WF were always smaller and close to $\pm 30 \%$ in the case of a $\pm 20 \%$ change in $\mathrm{ET}_{0}$.

As shown in Eq.2.4, $\mathrm{K}_{\mathrm{c}}$ and $\mathrm{ET}_{0}$ have the same effect on crop evapotranspiration. Therefore, the effects of changes in $\mathrm{K}_{\mathrm{c}}$ on CWU, Y, and WF are exactly the same as the effects of $\mathrm{ET}_{0}$ changes. The changes in total WF were less than $\pm 25 \%$ in the case of a $\pm 15 \%$ change in $\mathrm{K}_{c}$ values.
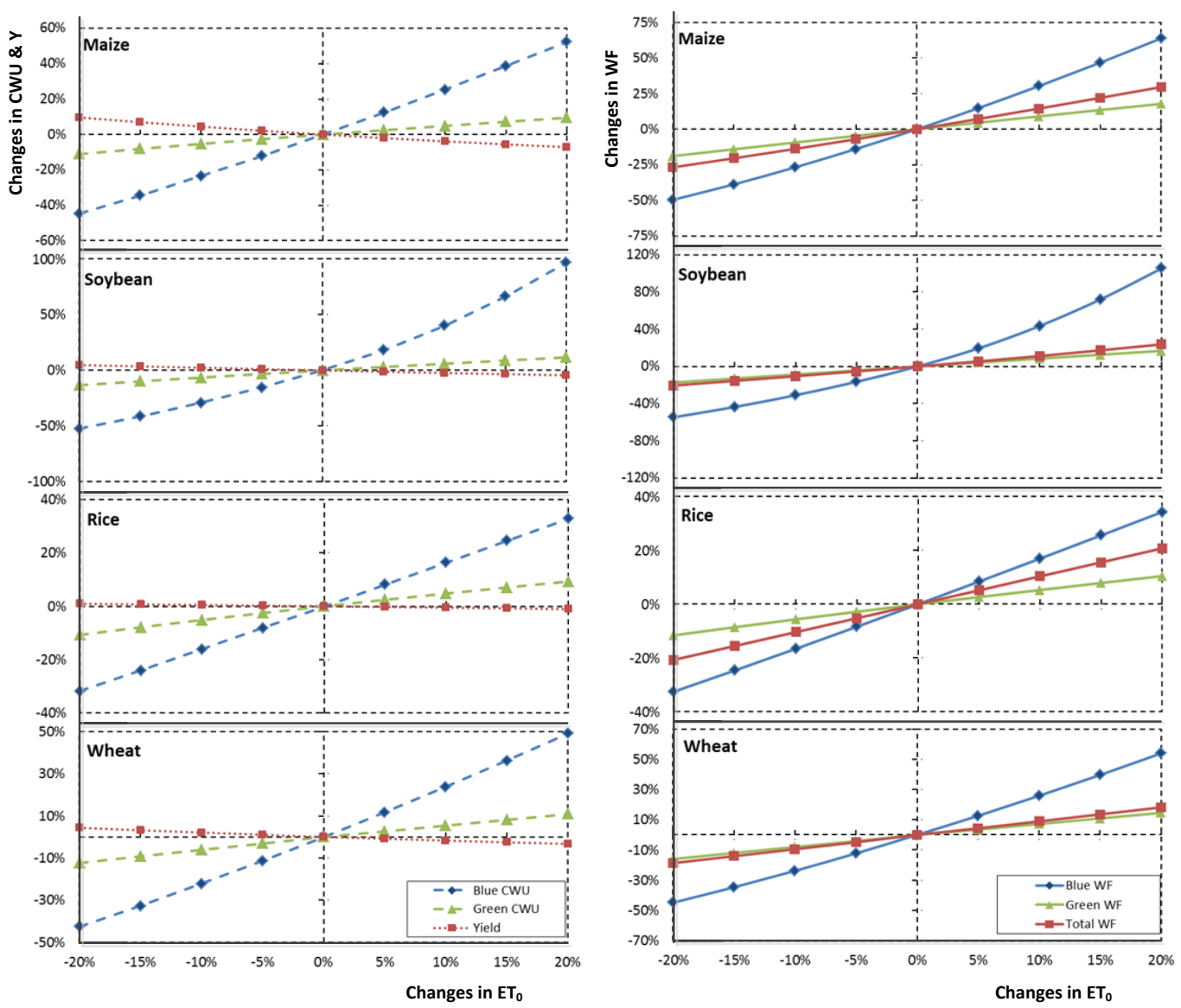

Figure 2.5 Sensitivity of CWU, $Y$ and WF to changes in reference evapotranspiration (ETo), 1996-2005. 


\section{- Sensitivity to changing crop planting date (D)}

The responses of CWU, Y, and WF to the change of crop planting date with constant GDD are plotted in Figure 2.6. There is no linear relationship between the cropping calendar and WF. Therefore, no generic information can be summarised for the sensitivity of WF of crops to a changing cropping calendar. But some interesting regularity can still be found. With the late sowing dates, the crop growing periods in days became longer for rice and soybean while shorter for maize and wheat. WF was smaller with late planting date for all four crops, which is mainly due to the decrease in the blue and green CWU for maize, rice and wheat, as well as relatively larger decrease of green CWU for soybean. Apparently, the reduction in CWU of maize and wheat was due to shortening of the growing period. Meanwhile, we found a reduced $\mathrm{ET}_{0}$ over the growing period with delayed planting of the rice and soybean, which led to a decrease in the crop water requirement. This is consistent with the result observed for maize in western Jilin Province of China by Qin et al. (2012) and North China (Sun et al., 2007; Jin et al., 2012) based on local field experiments. Late planting, particularly for maize, rice and wheat, could save water, particular blue water, while increasing Y. The response of wheat yield did not match with the field experiment results in North China by Sun et al. (2007). The difference was because they set a constant growing period when changing the sowing date of wheat, not taking the GDD into consideration. With late planting of soybean, the reduction of PR was larger than the reduction of crop water requirement of soybean, resulting in a larger blue WF. Since blue WF is more sensitive to $\mathrm{ET}_{0}$ and $\mathrm{PR}$ than green WF, the relative change in blue WF was always more than green WF. When planted earlier, both green and blue WF of maize increased because of increased CWU with longer growing period. Although growing periods for rice and soybean were shorter with earlier sowing, the increased rainwater deficit resulted in more blue CWU and less green CWU for irrigated fields and a slight increase in total WF with little change in Y. Meanwhile, a different response curve was observed for wheat with earlier planting. The explanation for the unique sensitivity curve for wheat is that the crop is planted in October after the rainy season (June to September) and the growing period lasts around 335 days (Table 2.1), which leads to a low sensitivity to the precise planting date. However, as interesting as the phenomenon found in the Figure 2.6, the Y and total WF both dropped (by 
$0.25 \%$ and $0.3 \%$ to 30 days earlier planting, respectively) when changing more than 15 days earlier than the reference sowing date of wheat. A similar instance also arose for rice with delaying the sowing date: reduction of Y by $0.2 \%$ and total WF by $9.3 \%$ with delaying the planting day by 30 days. As a comparison, we also show the responses of CWU, Y, and WF to the change of crop planting date with constant crop growing days in Figure 2.7. The same phenomenon shown in Figure 2.5 was also valid for maize, rice and soybean in Figure 2.7.
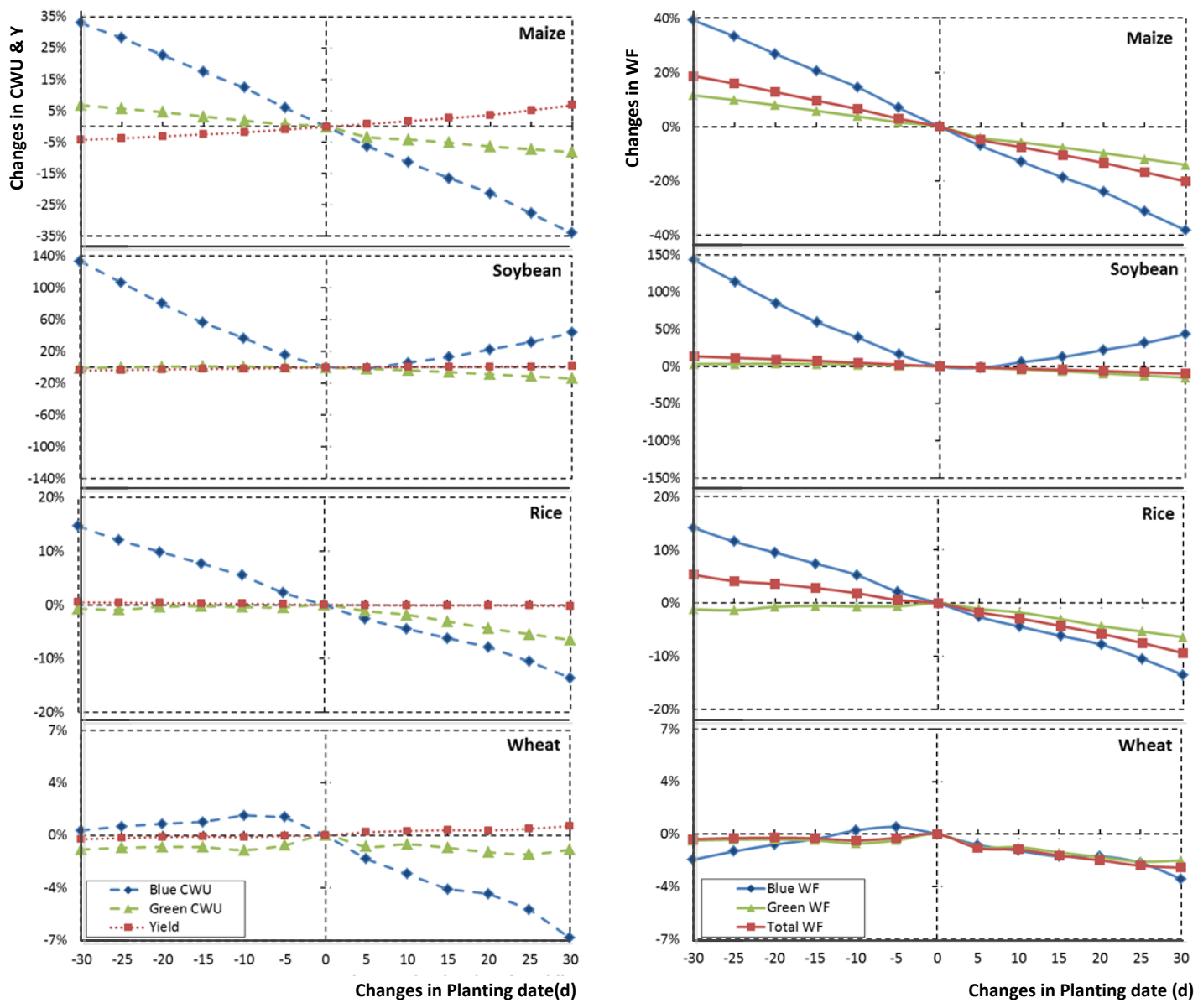

Figure 2.6 Sensitivity of CWU, Y and WF to changes in crop planting date (D) with constant growing degree days (GGD), 1996-2005. 

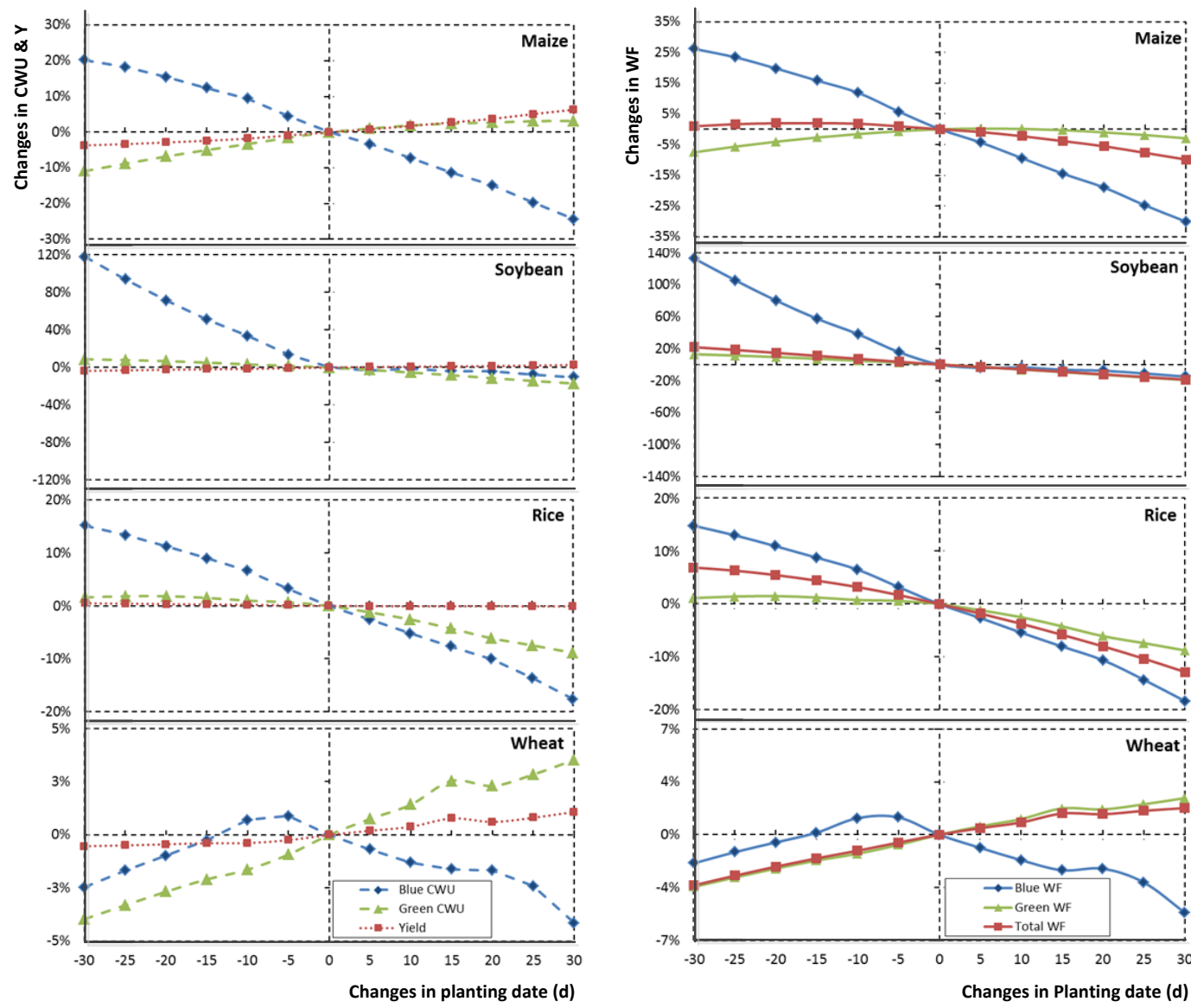

Figure 2.7 Sensitivity of CWU, Y and WF to changes in crop planting date (D) with constant crop growing days, 1996-2005.

Therefore from perspective of the agricultural practice, the response of both crop production and crop water consumption with change in the planting date should be considered in agricultural water saving projects. In general, the results show that the crop calendar is one of the factors affecting the magnitude of crop water consumption. A proper planning of the crop-growing period is, therefore, vital from the perspective of water resources use, especially in arid and semi-arid areas like the YRB. However, our estimate, which was based on a sensitivity analysis by keeping all other input parameters such as the initial soil water content constant, could be different from the actual cropping practice. There are techniques to maintain or increase the initial soil moisture, for instance by storing off-season 
rainfall (through organic matter) in the cropping field.

\section{- Sensitivity to changes of soil water content at field capacity $\left(S_{\max }\right)$}

The sensitivity curves of CWU, Y and WF to the changes of the $S_{\max }$ within $\pm 20 \%$ are shown in Figure 2.8. The total WF varied no more than $1.3 \%$ to changes in the $S_{\max }$. The maximum sensitivity was found for rice. But the responses of blue and green WF were different per crop type. Blue WF reduced while green WF increased with higher $S_{\max }$ for maize, soybean, and rice. For wheat we found opposite. Figure 2.8 shows that CWU and Y become smaller with higher $S_{\max }$. In the model, higher $S_{\max }$ with no change in the soil moisture defines a higher water stress in crop growth, resulting in smaller $\mathrm{K}_{\mathrm{s}}$, ET (Eq. 2.4 and 2.5), and thus lower Y (Eq. 2.6).
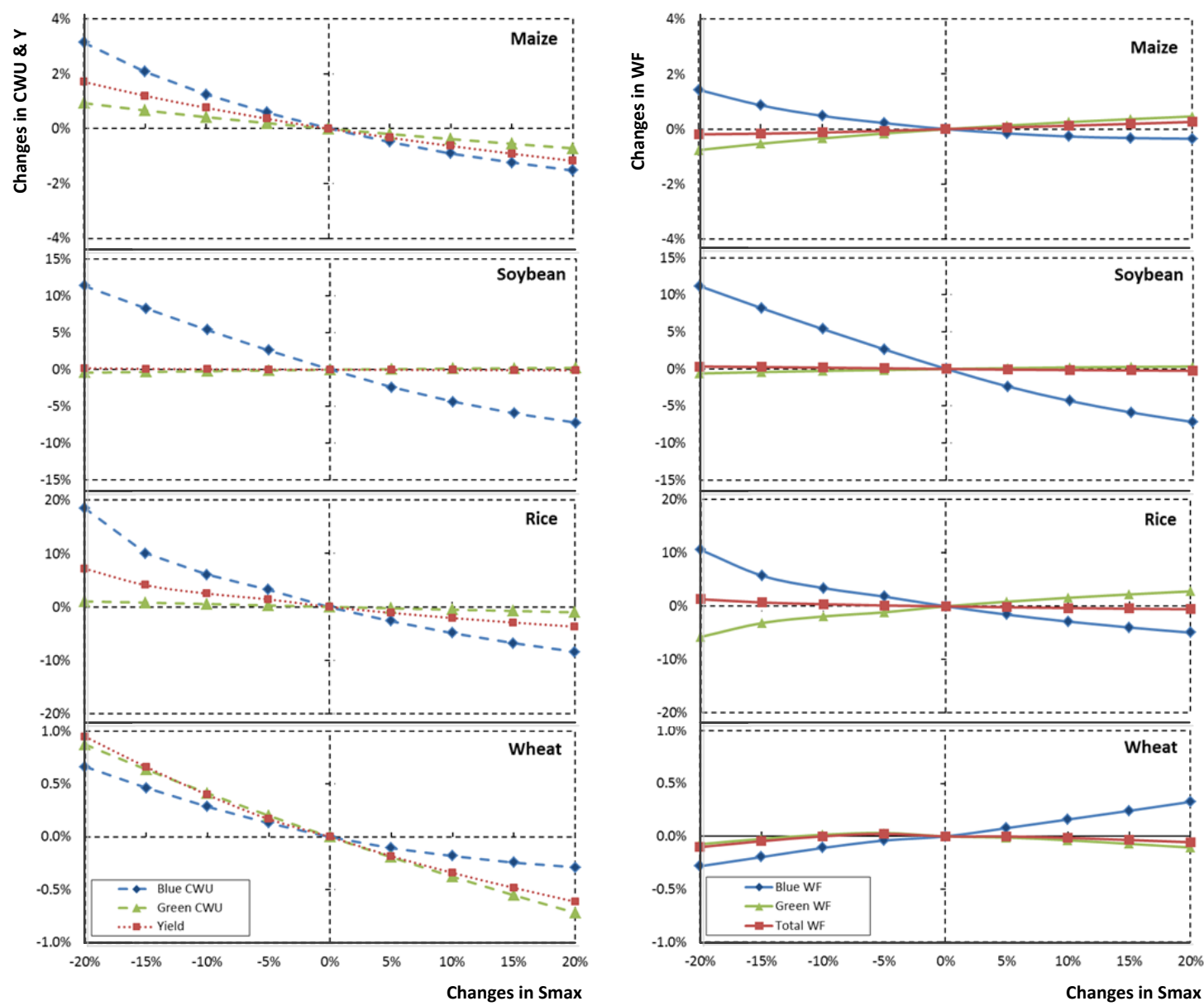
Figure 2.8 Sensitivity of CWU, $Y$ and WF to changes in the field capacity of the soil water $\left(S_{\text {max }}\right)$, 1996-2005.

\section{- Sensitivity to parameters for yield simulation}

The yield response factor $\left(\mathrm{K}_{\mathrm{y}}\right)$ and maximum yield $\left(\mathrm{Y}_{\mathrm{m}}\right)$ are important parameters defining the Y simulation (Eq.2.6). They are always set with a constant default value for different crop. It is clear from the equation that crop WF is negatively correlated to $\mathrm{Y}_{\mathrm{m}}$ : a $20 \%$ increase in $\mathrm{Y}_{\mathrm{m}}$ results in a $20 \%$ increase in $\mathrm{Y}$ and a $20 \%$ decrease in the WFs. Figure 2.9 shows the sensitivity of $Y$ and WF of each crop to changes in the values of $K_{y}$ within $\pm 20 \%$ of the default value. The figure shows that an increase in $\mathrm{K}_{\mathrm{y}}$ leads to a decrease in simulated $\mathrm{Y}$ and an increase in the WFs. Due to the difference in the sensitivity of crops to water stress, different crops have different default $\mathrm{K}_{\mathrm{y}}$ values, leading to different levels of sensitivity in $\mathrm{Y}$ and WF estimates to changes in $\mathrm{K}_{\mathrm{y}}$ with crop types. Among the four crops, maize had the highest while wheat had the lowest sensitivity in $\mathrm{Y}$ and $\mathrm{WF}$ to the variation of $\mathrm{K}_{\mathrm{y}}$.
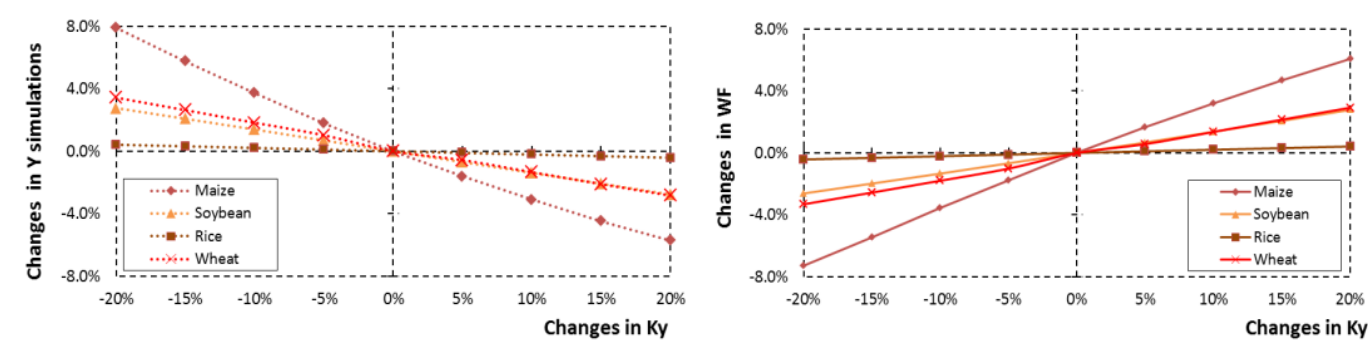

Figure 2.9 Sensitivity of $Y$ and WF to changes in yield response factor $\left(K_{y}\right), 1996-2005$.

\subsubsection{Annual variation of sensitivities in crop water footprints}

As an example of the annual variation of sensitivities, Table 2.3 presents the sensitivity of blue, green and total WF of maize to changes in $\mathrm{PR}, \mathrm{ET}_{0}, \mathrm{~K}_{\mathrm{c}}, \mathrm{D}, \mathrm{S}_{\max }$, and $\mathrm{K}_{\mathrm{y}}$ for each specific year in the period 1996-2005. As can be seen from the table, the sensitivity of green WF to the PR, $\mathrm{ET}_{0}, \mathrm{~K}_{\mathrm{c}}, \mathrm{D}$, and $\mathrm{S}_{\max }$ was relatively stable around the mean annual level. But there was substantial inter-annual fluctuation of sensitivity of blue WF for all four crops. For 
each year and each crop, the slope (S) of the sensitivity curve of change in blue WF versus change in $\mathrm{PR}, \mathrm{ET}_{0}$, and $\mathrm{K}_{\mathrm{c}}$ was computed, measuring the slope at mean values for $\mathrm{PR}, \mathrm{ET}_{0}$, and $\mathrm{K}_{\mathrm{c}}$. The slopes (representing the percentage change in blue WF over percentage change in input variable) are plotted against the corresponding blue WF (Figure 2.10). The results show that - most clearly for maize and rice -the smaller the annual blue WF, the higher the sensitivity to changes in $\mathrm{PR}, \mathrm{ET}_{0}$, or $\mathrm{K}_{\mathrm{c}}$. As shown by the straight curves through the data for maize (Figure 2.10), we can roughly predict the sensitivity of blue WF to changes in input variables based on the size of blue WF itself. The blue WF of a specific crop in a specific field will be more sensitive (in relative terms) to the three inputs in wet years than in dry years, simply because the blue WF will be smaller in a wet year.

Table 2.3 Sensitivity of annual water footprint (WF) of maize to input variability at the level of the Yellow River Basin, for the period 1996-2005.

\begin{tabular}{|c|c|c|c|c|c|c|c|c|c|c|c|c|c|}
\hline & \multirow{3}{*}{$\underset{\left(\mathrm{m}^{3} / \mathrm{t}\right)}{W F}$} & \multicolumn{12}{|c|}{ Changes in the $W F$ to variability of input variables (\%) } \\
\hline & & \multicolumn{2}{|c|}{$P R$} & \multicolumn{2}{|c|}{$E T_{0}$} & \multicolumn{2}{|c|}{ Kc } & \multicolumn{2}{|c|}{$D$} & \multicolumn{2}{|c|}{$S_{\max }$} & \multicolumn{2}{|c|}{$K_{y}$} \\
\hline & & $-20 \%$ & $20 \%$ & $-20 \%$ & $20 \%$ & $-15 \%$ & $15 \%$ & $-30 d$ & $30 d$ & $-20 \%$ & $20 \%$ & $-20 \%$ & $20 \%$ \\
\hline \multicolumn{14}{|c|}{ Blue WF } \\
\hline 1996 & 201 & 27 & -18 & -52 & 72 & -41 & 52 & 51 & -51 & -3.2 & 1.4 & -4.1 & 4.1 \\
\hline 1997 & 381 & 17 & -14 & -47 & 55 & -36 & 41 & 19 & -25 & 0.9 & 0.9 & -9.4 & 8.0 \\
\hline 1998 & 209 & 25 & -16 & -53 & 70 & -42 & 51 & 31 & -42 & 4.1 & -1.6 & -5.6 & 4.8 \\
\hline 1999 & 308 & 26 & -18 & -50 & 67 & -39 & 49 & 44 & -42 & 1.9 & -1.3 & -7.5 & 6.2 \\
\hline 2000 & 342 & 18 & -14 & -46 & 54 & -35 & 40 & 48 & -45 & 0.6 & 0.3 & -8.6 & 6.8 \\
\hline 2001 & 439 & 15 & -12 & -44 & 50 & -34 & 37 & 38 & -33 & 0.4 & 0.8 & -9.8 & 7.4 \\
\hline 2002 & 296 & 23 & -18 & -51 & 62 & -39 & 46 & 23 & -24 & 6.7 & -3.1 & -5.8 & 5.1 \\
\hline 2003 & 233 & 29 & -21 & -56 & 72 & -44 & 53 & 45 & -41 & 0.8 & 0.3 & -4.9 & 5.0 \\
\hline 2004 & 260 & 24 & -17 & -49 & 65 & -39 & 47 & 51 & -43 & 1.0 & -0.1 & -7.2 & 6.4 \\
\hline 2005 & 288 & 25 & -17 & -50 & 71 & -39 & 51 & 39 & -37 & 1.2 & -1.0 & -9.9 & 6.9 \\
\hline Mean & 295 & 23 & -16 & -50 & 64 & -39 & 47 & 39 & -38 & 1.4 & -0.3 & -7.3 & 6.1 \\
\hline \multicolumn{14}{|c|}{ Green WF } \\
\hline 1996 & 754 & -1.4 & 0.9 & -18 & 18 & -14 & 14 & 12 & -17 & -0.5 & 0.2 & -4.1 & 4.1 \\
\hline 1997 & 820 & -2.0 & 1.3 & -19 & 18 & -14 & 13 & 10 & -14 & -1.0 & 0.6 & -9.4 & 8.0 \\
\hline 1998 & 792 & -1.3 & 0.7 & -19 & 18 & -14 & 14 & 12 & -11 & -0.8 & 0.4 & -5.6 & 4.8 \\
\hline 1999 & 864 & -2.1 & 1.3 & -19 & 18 & -14 & 13 & 12 & -13 & -0.8 & 0.6 & -7.5 & 6.2 \\
\hline 2000 & 831 & -2.0 & 1.3 & -19 & 18 & -14 & 13 & 12 & -15 & -0.8 & 0.5 & -8.6 & 6.8 \\
\hline 2001 & 819 & -2.3 & 1.7 & -19 & 17 & -14 & 13 & 11 & -15 & -0.8 & 0.5 & -9.8 & 7.4 \\
\hline 2002 & 865 & -1.7 & 1.2 & -18 & 18 & -14 & 13 & 12 & -15 & -0.7 & 0.3 & -5.8 & 5.1 \\
\hline
\end{tabular}




\begin{tabular}{llllllllllllll}
2003 & 882 & -1.4 & 1.0 & -19 & 18 & -14 & 14 & 12 & -16 & -0.6 & 0.4 & -4.9 & 5.0 \\
2004 & 838 & -1.5 & 0.9 & -19 & 18 & -14 & 14 & 13 & -13 & -0.8 & 0.6 & -7.2 & 6.4 \\
2005 & 733 & -2.1 & 1.6 & -19 & 17 & -14 & 13 & 10 & -11 & -0.7 & 0.5 & -9.9 & 6.9 \\
\hline Mean & 820 & -1.8 & 1.2 & -19 & 18 & -14 & 13 & 12 & -14 & -0.8 & 0.5 & -7.3 & 6.1 \\
\hline Total WF & & & & & & & & & & & & & \\
1996 & 955 & 4.7 & -3.1 & -26 & 29 & -20 & 22 & 20 & -24 & -1.1 & 0.5 & -4.1 & 4.1 \\
1997 & 1200 & 3.9 & -3.6 & -28 & 30 & -21 & 22 & 13 & -18 & -0.4 & 0.7 & -9.4 & 8.0 \\
1998 & 1001 & 4.2 & -2.8 & -26 & 29 & -20 & 22 & 16 & -17 & 0.2 & 0.0 & -5.6 & 4.8 \\
1999 & 1172 & 5.3 & -3.7 & -27 & 31 & -21 & 23 & 20 & -21 & -0.1 & 0.1 & -7.5 & 6.2 \\
2000 & 1172 & 3.7 & -3.1 & -27 & 28 & -20 & 21 & 23 & -24 & -0.4 & 0.5 & -8.6 & 6.8 \\
2001 & 1257 & 3.6 & -3.1 & -27 & 28 & -21 & 21 & 20 & -21 & -0.4 & 0.6 & -9.8 & 7.4 \\
2002 & 1160 & 4.7 & -3.7 & -27 & 29 & -20 & 22 & 15 & -17 & 1.2 & -0.5 & -5.8 & 5.1 \\
2003 & 1116 & 4.9 & -3.5 & -26 & 30 & -20 & 22 & 19 & -21 & -0.4 & 0.3 & -4.9 & 5.0 \\
2004 & 1098 & 4.4 & -3.3 & -26 & 29 & -20 & 22 & 22 & -20 & -0.4 & 0.4 & -7.2 & 6.4 \\
2005 & 1021 & 5.4 & -3.6 & -28 & 32 & -21 & 24 & 18 & -19 & -0.2 & 0.1 & -9.9 & 6.9 \\
\hline Mean & 1115 & 4.5 & -3.3 & -27 & 30 & -20 & 22 & 19 & -20 & -0.2 & 0.3 & -7.3 & 6.1 \\
\hline
\end{tabular}
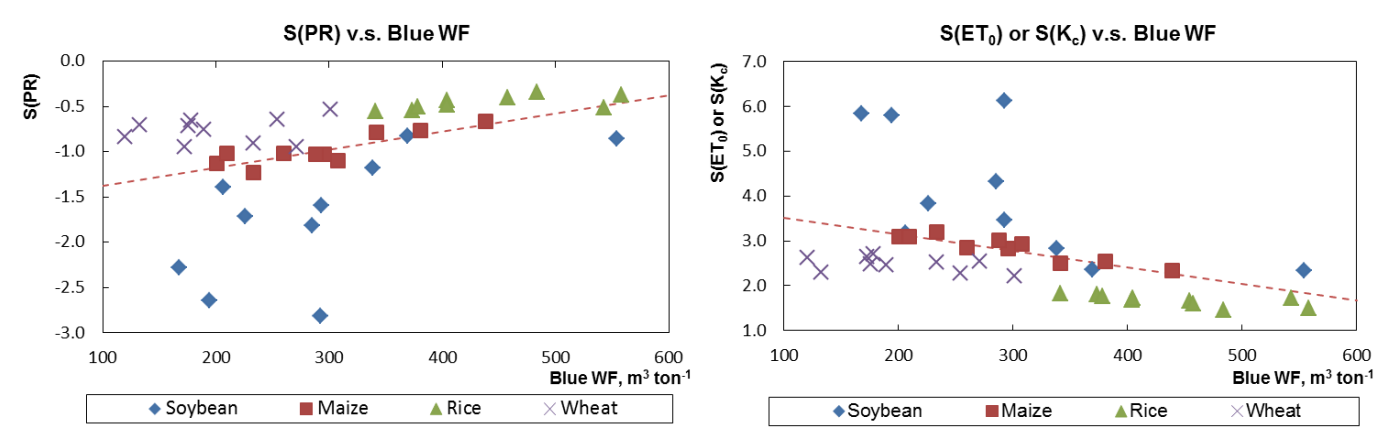

Figure 2.10 The slope (S) of the sensitivity curve for the blue WF for each crop for each year in the period 1996-2005 (vertical axis) plotted against the blue WF of the crop in the respective year ( $x$-axis). The graph on the left shows the relative sensitivity of blue WF to PR; the graph on the right shows the relative sensitivity of blue WF to $E T_{0}$ or $K_{c}$. The sensitivities to $E T_{0}$ and $K_{c}$ were the same. The trend lines in both graphs refer to the data for maize.

\subsubsection{Uncertainties in WF per tonne of crop due to input uncertainties}

In order to assess the uncertainty in WF (in $\mathrm{m}^{3} \mathrm{t}^{-1}$ ) due to input uncertainties, Monte Carlo (MC) simulations were performed at the basin level for 1996 (wet year), 2000 (dry year), and 2005 (average year). For each crop, we carried out a MC simulation for four input 
uncertainty scenarios, considering the effect of: (1) uncertainties in PR alone, (2) uncertainties in $\mathrm{ET}_{0}$ alone, (3) combined uncertainties in the two climatic input variables $\left(\mathrm{PR}+\mathrm{ET}_{0}\right)$, and (4) combined uncertainties in all four key input variables considered in this study $\left(\mathrm{PR}+\mathrm{ET}_{0}+\mathrm{K}_{\mathrm{c}}+\mathrm{D}\right)$. The uncertainty results in blue, green and total WF of the four crops for the four scenarios and three years are shown in Table 2.4.

The uncertainties are expressed in terms of values for 2SD as a percentage of the mean value; the range of $\pm 2 \mathrm{SD}$ around the mean value gives the $95 \%$ confidence intervals.

In general, for all uncertainty scenarios, blue WF shows higher uncertainties than green WF. Uncertainties in green WF are similar for the three different hydrologic years. Uncertainties in blue WF are largest (in relative sense) in the wet year, conform our earlier finding that blue WF is more sensitive to changes in input variables in wet years. The uncertainties in WF due to uncertainties in PR are much smaller than the uncertainties due to uncertainties in $\mathrm{ET}_{0}$. Uncertainties in PR hardly affect the assessment of total WF of crops in all three different hydrologic years. Among the four crops, soybean has the highest uncertainty in green and blue WF. The uncertainty in total WF for all crops is within the range of \pm 18 to $20 \%$ (at 95\% confidence interval) when looking at the effect of uncertainties in the two climate input variables only, and within the range of \pm 28 to $32 \%$ (again at $95 \%$ confidence interval) when looking at the effect of uncertainties in all four input variables considered. In all cases, the most important uncertainty source is the value of $\mathrm{ET}_{0}$. Figure 2.11 shows, for maize as an example, the probability distribution of the total WF (in $\mathrm{m}^{3} \mathrm{t}^{-1}$ ) given the uncertainties in the two climatic input variables and all four input variables combined. 
Table 2.4 Values of $2 \times$ Standard deviation for the probability distribution of the blue, green and total WF of maize, soybean, rice and wheat, expressed as \% of the mean value, from the Monte Carlo simulations.

\begin{tabular}{|c|c|c|c|c|c|c|c|c|c|c|}
\hline \multirow{2}{*}{ Crop } & \multirow{2}{*}{$\begin{array}{l}\text { Perturbed } \\
\text { inputs }\end{array}$} & \multicolumn{3}{|c|}{ 1996(wet year) } & \multicolumn{3}{|c|}{2000 (dry year) } & \multicolumn{3}{|c|}{ 2005(average year) } \\
\hline & & Blue WF & Green WF & Total WF & Blue WF & Green WF & Total WF & Blue WF & Green WF & Total WF \\
\hline \multirow{4}{*}{ Maize } & $P$ & 14 & 4 & 0.2 & 10 & 4 & 0.2 & 8 & 4 & 0 \\
\hline & $E T_{0}$ & 48 & 12 & 20 & 38 & 12 & 20 & 36 & 12 & 18 \\
\hline & $P+E T_{0}$ & 48 & 12 & 20 & 42 & 12 & 20 & 38 & 14 & 20 \\
\hline & $P+E T_{0}+K_{c}+D$ & 88 & 21 & 34 & 78 & 20 & 36 & 66 & 19 & 32 \\
\hline \multirow{4}{*}{ Soybean } & $P$ & 22 & 1.2 & 0.2 & 18 & 2 & 2 & 14 & 2 & 0.8 \\
\hline & $E T_{0}$ & 56 & 16 & 18 & 50 & 14 & 16 & 40 & 14 & 16 \\
\hline & $P+E T_{0}$ & 62 & 16 & 18 & 56 & 14 & 18 & 44 & 14 & 18 \\
\hline & $P+E T_{0}+K_{c}+D$ & 87 & 26 & 29 & 92 & 25 & 31 & 66 & 25 & 28 \\
\hline \multirow{4}{*}{ Rice } & $P$ & 10 & 6 & 0 & 8 & 6 & 0 & 7 & 6 & 0 \\
\hline & $E T_{0}$ & 34 & 12 & 20 & 30 & 12 & 20 & 30 & 12 & 20 \\
\hline & $P+E T_{0}$ & 34 & 12 & 20 & 32 & 12 & 20 & 32 & 13 & 20 \\
\hline & $P+E T_{0}+K_{c}+D$ & 70 & 18 & 31 & 66 & 21 & 32 & 61 & 19 & 29 \\
\hline \multirow{4}{*}{ Wheat } & $P$ & 14 & 2 & 0.4 & 14 & 2 & 0.4 & 16 & 2 & 0 \\
\hline & $E T_{0}$ & 48 & 16 & 20 & 46 & 16 & 18 & 52 & 16 & 18 \\
\hline & $P+E T_{0}$ & 52 & 16 & 20 & 48 & 16 & 18 & 54 & 16 & 18 \\
\hline & $P+E T_{0}+K_{c}+D$ & 85 & 24 & 26 & 83 & 24 & 31 & 88 & 22 & 30 \\
\hline
\end{tabular}



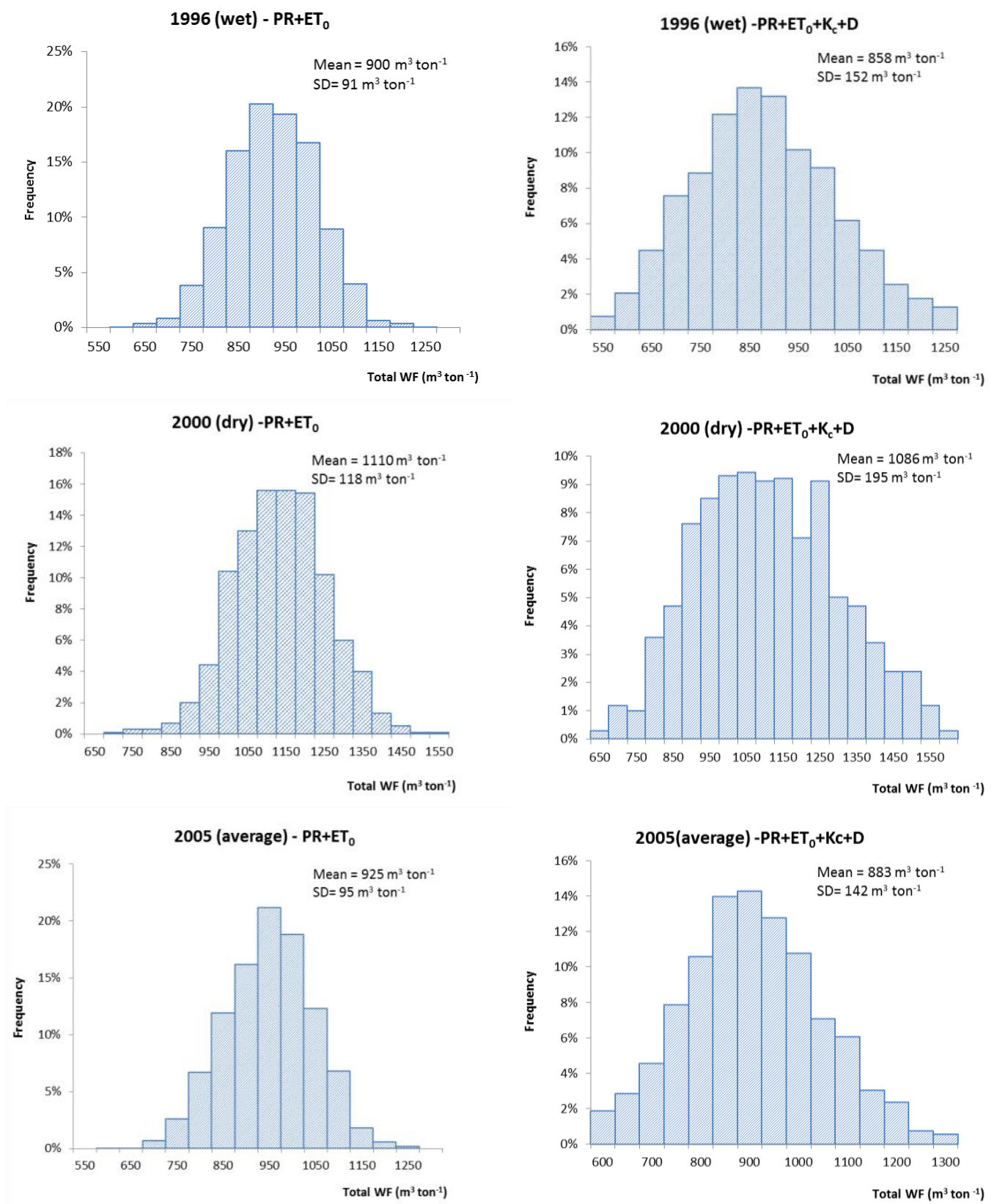

Figure 2.11 Probability distribution of the total WF of maize given the combined uncertainties in $P R$ and $E T_{0}$ (graphs at the left) and given the combined uncertainties in $P R, E T_{0}, K_{c}$ and $D$ (graphs at the right), for the years 1996, 2000 and 2005. 


\subsection{Conclusions and discussion}

This paper provides the first detailed study of the sensitivities and uncertainties in the estimation of green and blue water footprints of crop growing related to input variability and uncertainties at river basin level. The result shows that at the scale of the Yellow River Basin: (1) WF is most sensitive to errors in $\mathrm{ET}_{0}$ and $\mathrm{K}_{\mathrm{c}}$ followed by the crop planting date and PR, and less sensitive to changes of $S_{\max }, K_{y}$, and $Y_{m}$; (2) blue WF is more sensitive and has more uncertainty than green WF; (3) uncertainties in total (green + blue) WF as a result of climatic uncertainties are around $\pm 20 \%$ (at $95 \%$ confidence level) and dominated by effects from uncertainties in $\mathrm{ET}_{0}$; (4) uncertainties in total $\mathrm{WF}$ as a result of all uncertainties considered are on average $\pm 30 \%$ (at 95\% confidence level); (5) the sensitivities and uncertainties in WF estimation, particularly in blue WF estimation, differ across crop types and vary from year to year.

An interesting finding was that the smaller the annual blue WF (consumptive use of irrigation water), the higher the sensitivity of the blue WF to variability in the input variables $\mathrm{PR}, \mathrm{ET}_{0}$, and $\mathrm{K}_{\mathrm{c}}$. Furthermore, delaying the crop planting date was found to potentially contribute to a decrease of the WF of spring or summer planted crops (maize, soybean, rice). Optimizing the planting period for such crops could save irrigation water in agriculture, particularly for maize and rice. Although the conclusion closely matches the result from several experiments for maize carried out in some regions in North China (Sun et al., 2007; Jin et al., 2012; Qin et al., 2012), such information should be confirmed further by future field agronomic experiments.

The study confirmed that it is not enough to give a single figure of WF without providing an uncertainty range. A serious implication of the apparent uncertainties in Water Footprint Assessment is that it is difficult to establish trends in WF reduction over time, since the effects of reduction have to be measured against the background of natural variations and uncertainties.

The current study shows possible ways to assess the sensitivity and uncertainty in the WF of crops in relation to variability and errors in input variables and parameters. Not only can the 
outcomes of this study be used as a reference in future sensitivity and uncertainty studies on WF, but the results also provide a first rough insight in the possible consequences of changes in climatic variables like precipitation and reference evapotranspiration on the WF of crops. However, the study does not provide the complete picture of sensitivities and uncertainties in Water Footprint Assessment. Firstly, the study is limited to the assessment of the effects from only part of all input variables and parameters; uncertainties in other parameters were not considered, like for instance uncertainties around volumes and timing of irrigation, parameters affecting runoff and deep percolation. Secondly, there are several models available for estimating the WF of crops. Our result is only valid for the model used which is based on a simple soil water balance (Allen et al., 1998; Mekonnen and Hoekstra, 2010) and which considers water as the main factor in the yield estimation (Eq. 2.6). Thirdly, the quantification of uncertainties in the input variables considered is an area full of uncertainties and assumptions itself. Besides, the uncertainty range of an input variable, especially for climatic inputs, is location specific. Thus the level of input uncertainties will be different in different places, resulting in a different level of uncertainties in crop WFs. Therefore, the current result is highly valuable for the region of the YRB and should be referenced with caution at other regions. Furthermore, the uncertainties in water footprint estimation are scale dependent and decline with growing extent of the considered study region. Our study is carried out for the aggregated crop WF estimation for the whole basin scale. The result should be interpreted with caution at a higher resolution.

Therefore, in order to build up a more detailed and complete picture of sensitivities and uncertainties in Water Footprint Assessment, a variety of efforts needs to be made in the future. In particular, we will need to improve the estimation of input uncertainties, include uncertainties from other input variables and parameters, and assess the impact of using different models on WF outcomes. Finally, uncertainty studies will need to be extended towards other crops and other water using sectors, to other regions and at different spatial and temporal scales. 


\section{Inter- and Intra-annual Variation of Water Footprint of Crops and Blue Water Scarcity in the Yellow River Basin $(1961-2009)^{2}$}

\section{Abstract}

The Yellow River Basin (YRB), the second largest river basin of China, has experienced a booming agriculture over the past decades. But data on variability of and trends in water consumption, pollution and scarcity in the YRB are lacking. We estimate, for the first time, the inter- and intra-annual water footprint (WF) of crop production in the YRB for the period 1961-2009 and the variation of monthly blue water (ground and surface water) scarcity for 1978-2009, by comparing the blue WF of agriculture, industry and households in the basin to the maximum sustainable level. Results show that the average overall green (from rainfall) and blue (from irrigation) WFs of crops in the period 2001-2009 were 14\% and 37\% larger, respectively, than in the period 1961-1970. The annual nitrogen- and phosphorus-related grey WFs (water required to assimilate pollutants) of crop production grew by factors of 24 and 36, respectively. The green-blue WF per tonne of crop reduced significantly due to improved crop yields, while the grey WF increased because of the growing application of fertilizers. The ratio of blue to green WF increased during the study period resulting from the expansion of irrigated agriculture. In the period 1978-2009, the annual total blue WFs related to agriculture, industry and households varied between 19 and $52 \%$ of the basin's natural runoff. The blue WF in the YRB generally peaks around May-July, two months earlier than natural peak runoff. On average, the YRB faced moderate to severe blue water scarcity during seven months (January-July) per year. Even in the wettest month in a wet year, about half of the area of the YRB still suffered severe blue water scarcity, especially in the basin's northern part.

\footnotetext{
${ }^{2}$ Chapter is based on: Zhuo, Mekonnen, Hoekstra and Wada (2016b) Advances in Water Resources $87,29-41$.
} 


\subsection{Introduction}

The increasing demand for fresh water by humanity is challenging the sustainable water use in many river basins around the world (Vörösmarty et al., 2010; Wada et al., 2011; Hoekstra et al., 2012). The Yellow River Basin (YRB, or "Huang He"), the second largest river basin of China, with a drainage area of $795 \times 10^{3} \mathrm{~km}^{2}$ (YRCC, 2013), is well known as one of the world's basins facing severe water scarcity. The YRB is now responsible for producing $13 \%$ of national grain production with only $2 \%$ of the national water resources (YRCC, 2013). In the last half century, with a booming agriculture and burgeoning population, of the total blue water (ground and surface water) consumption in the YRB by agriculture, industry and households increased from $17.8 \times 10^{9} \mathrm{~m}^{3}$ in the 1960s (Liu and Zhang, 2002) to $39.3 \times 10^{9} \mathrm{~m}^{3}$ in 2009 (YRCC, 2011). Agriculture is by far the largest water user in the basin, accounting for $77 \%$ of the total blue water consumption, of which $91 \%$ is used for field irrigation (2009) (YRCC, 2011). In 2009, the total annual blue water withdrawal in the YRB for agriculture, industry and households reached $76.5 \%$ of the renewable water resources in the basin (YRCC, 2011). In recent years, competition among the different sectors over the limited water resources has intensified (Yunpeng et al., 2015). Meanwhile, when comparing the 1960s to 2000s, precipitation and evaporation showed downward trends in most areas within the YRB (Xu et al., 2007; Liu and McVicar, 2012). The yearly natural runoff of the YRB decreased constantly in the 1990s (Xu et al., 2010) and reached its lowest value in 2002 $\left(\sim 30.0 \times 10^{9} \mathrm{~m}^{3}\right)$, after which it increased again and remained fluctuating (at an average level of $\sim 57.5 \times 10^{9} \mathrm{~m}^{3}$ ) (YRCC, 2011). As a result of climatic variability, the inter-annual variability of natural water availability and water demand in the YRB are large, whereby demand in agriculture is typically high when availability is low.

Unfortunately, data on variability of and trends in water consumption, pollution and scarcity in the YRB are lacking. Another problem is that traditional statistics like 'annual gross water abstraction' per sector and 'irrigation efficiency' in the agricultural sector do not provide a comprehensive picture of water use and water scarcity. For understanding water scarcity at catchment or river basin level, we need to measure net water abstraction (consumptive water use) rather than gross water abstraction, because return flows can be reused and thus do not contribute to water scarcity (Hoekstra et al., 2011). A similar 
shortcoming exists with the indicator of irrigation efficiency, which measures losses between gross water abstraction and the volume of water that reaches the crop. Only a part of this so-called loss, namely the part that evaporates, is really lost to the catchment and will thus contribute to scarcity; a large part of the so-called loss refers to water that percolates and thus adds to the groundwater and remains available in the catchment (Perry, 2007). Another gap in traditional statistics is the focus on the use of blue water resources (ground and surface water), which is insufficient, given the fact that agriculture heavily relies on green water resources (rainwater) (Falkenmark and Rockström, 2004). Besides, water pollution and water scarcity are intricately linked, because the effect of pollutants becomes worse if groundwater and river flows get depleted. Finally, usual statistics on water use and scarcity are annual, while the key to understanding water use and scarcity is the recognition of intra-annual variability (Savenije, 2000). The water footprint (WF) - introduced by Hoekstra (2003) - is a comprehensive measure of human freshwater appropriation that addresses these shortcomings.

The WF is a multi-dimensional indicator that measures consumptive water use of both rainfall and ground-surface water (the green and blue WF, respectively) and the water required to assimilate anthropogenic loads of pollutants to freshwater bodies (the grey WF) (Hoekstra et al., 2011). In geographic applications, several soil-water-balance models have been applied in order to map WFs at high spatial levels so that one can see where they are located (Rost et al., 2008; Hanasaki et al., 2010; Liu and Yang, 2010; Siebert and Doll, 2010; Mekonnen and Hoekstra, 2011). Rost et al. (2008) estimated, using the LPJmL model at 30 arc min resolution level, total green and blue WFs of global crop production for 1971-2000. Hanasaki et al. (2010) evaluated, employing the H08 model at 30 arc min resolution level, global total green and blue WFs of major crops for 1985-1999. Liu and Yang (2010) estimated, based on the GEPIC model at 30 arc min resolution level, global total green and blue WFs of crop production for the year 2000. Siebert and Doll (2010) computed, with the GCWM model at 5 arc min resolution level, global total green and blue WFs of major crops worldwide for 1998-2002. Mekonnen and Hoekstra (2011) estimated, applying the Cropwat model at 5 arc min resolution level, the green, blue and grey WFs of crop production worldwide for 1996-2005. Cai et al. (2009) and Feng et al. (2012) applied an input-output 
model to evaluate the WF and regional virtual water trade for the YRB from a consumptive perspective for 2002 and 2007, respectively. Hoekstra et al. (2012) estimated blue water scarcity for the major river basins in the world over the period 1996-2005, by taking, per basin, the ratio of blue WF to the maximum sustainable blue WF. Mekonnen and Hoekstra (2015) estimated, at 5 arc min grid level, the global grey WF related to nitrogen for the period of 2002-2010. These studies show that the blue WF in the YRB is relatively large during several months per year (Rost et al., 2008; Hanasaki et al., 2010; Siebert and Doll, 2010; Hoekstra et al., 2012) and has the highest blue water proportion in total consumptive (green plus blue) water use among river basins around the world (Liu and Yang, 2010). Meanwhile, there is net virtual water export from the YRB (Cai et al., 2009; Feng et al., 2012). The YRB faces severe blue water scarcity for four months per year, as a long-term average, mostly in spring time when runoff is still low while water consumption for irrigation starts to increase (Hoekstra et al., 2012). The nitrogen-related grey WF in the YRB has been estimated to be about eight times the annual natural runoff, in which implies a very high water pollution level (Mekonnen and Hoekstra, 2015).

Although temporal and spatial variations in WFs are keys in understanding water scarcity, most existing geographic WF assessment studies consider one specific year or the average for a period of five to ten years. There are a few studies focusing on the long-term variability of green and blue WFs, for example, Zhuo et al. (2014) and Tuninetti et al. (2015) estimated WFs of four major crops in the YRB and globally, respectively, at 5 arc min grid level inter-annually over 1996-2005; Sun et al. (2012a) calculated WFs for grain production in the Hetao irrigation district over 1960-2008. But there are no water scarcity studies at a high temporal and spatial resolution for a series of years.

The current study aims at investigating (i) the temporal and spatial variability of green, blue and grey WFs of crop production in the YRB for the period of 1961-2009; and (ii) the temporal and spatial variability of blue water scarcity in the YRB for 1978-2009. The YRB is usually divided into three reaches: the upper reach (upstream of Hekouzhen, Inner Mongolia), the middle reach (upstream of Taohuayu, Henan Province) and the lower reach (draining into the Bohai Sea) (YRCC, 2013). In Chapter 2 we considered inter-annual 
variation of green and blue WFs of 4 major crops in the YRB over ten years (1996-2005). The current study improves upon the earlier study by assessing inter- and intra- annual variation of green, blue and grey WFs of 17 crops, and the blue water scarcity over several decades. Therefore, this is the first river basin study that combines a high temporal resolution (WF estimated per day; blue water scarcity estimated per month), a high spatial resolution $(5 \times 5$ arc min), and a multi-year record including both dry and wet years. In addition, the study is innovative in applying a combined soil-water-balance and crop-growth model in estimating the green and blue WFs in crop production. Most of earlier WF studies (Liu and Yang, 2010; Siebert and Doll, 2010; Mekonnen and Hoekstra, 2011; Zhuo et al., 2014) applied a soil-water-balance model in combination with an assumed simple linear relationship between yield and evapotranspiration (Doorenbos and Kassam, 1979). We applied, for the first time, the FAO crop water productivity model AquaCrop (Hsiao et al., 2009; Raes et al., 2009; Steduto et al., 2009) to estimate WF of crops. AquaCrop separately simulates crop transpiration ( $\mathrm{Tr}$ ) and soil evaporation $(\mathrm{E})$ and the daily $\operatorname{Tr}$ is used to derive the daily biomass gain via the normalized biomass water productivity of the crop (Steduto et al., 2009). Compared to other crop growth models, AquaCrop has a significantly smaller number of parameters and better balances between simplicity, accuracy and robustness (Steduto et al., 2007). The model performance regarding crop water use and yield simulation has been widely tested for a number of crops under diverse environments and types of water management (Farahani et al., 2009; Garcia-Vila et al., 2009; Andarzian et al., 2011; Stricevic et al., 2011; Abedinpour et al., 2012; Katerji et al., 2013; Yuan et al., 2013; Jin et al., 2014). This is the first time that the AquaCrop model is applied to simulate crop water use and yields for a whole river basin, by running the model per crop for each grid cell. Besides, we added a module that separates green and blue water evapotranspiration in order to be able to calculate green and blue WFs of crops.

\subsection{Method and data}

\subsubsection{Estimating green and blue water footprints in crop production}

The WFs related to the production of seventeen major crops (listed in Table 3.1) in the YRB during the period 1961-2009 were estimated year by year with a daily time step at a 5 by 5 arc min grid $(\sim 7.4 \mathrm{~km} \times 9.3 \mathrm{~km}$ at the latitude of the YRB) following the accounting 
framework of Hoekstra et al. (2011). The crops considered account for about $87 \%$ of the harvested area and 93\% of crop production in 2009 (NBSC, 2013). Per crop, the green WF of producing a crop within a grid cell (in $\mathrm{m}^{3} \mathrm{y}^{-1}$ ) was estimated by multiplying the green water evapotranspiration $\left(\mathrm{ET}, \mathrm{m}^{3} \mathrm{ha}^{-1}\right)$ over the growing period by the harvested area for the crop (in ha $\mathrm{y}^{-1}$ ). Similarly, the blue WF was estimated by multiplying the blue ET by the harvested area. The green or blue WF per unit of a crop (in $\mathrm{m}^{3} \mathrm{t}^{-1}$ ) was calculated per grid cell by dividing the green or blue ET over the growing period by the crop yield $\left(\mathrm{Y}, \mathrm{t} \mathrm{ha}^{-1}\right)$. The AquaCrop was used to simulate ET and Y for each type of crop per year per grid cell. Simulated Y per crop per year per grid cell was calibrated at provincial level, by scaling the model outputs in order to fit provincial crop yield statistics (NBSC, 2013). AquaCrop is a water-driven crop water productivity model with a dynamic daily soil water balance as Eq. 2.1 .

The daily runoff $\left(\mathrm{RO}_{[\mathrm{t}]}, \mathrm{mm}\right)$ is estimated through the Soil Conservation Service curve-number equation (Rallison, 1980):

$\mathrm{RO}_{[\mathrm{t}]}=\frac{\left(\mathrm{PR}_{[\mathrm{t}]}-0.2 \times \mathrm{S}\right)^{2}}{\mathrm{PR}_{[\mathrm{t}]}+\mathrm{S}-0.2 \times \mathrm{S}}$

where $\mathrm{PR}_{[\mathrm{t}]}$ refers to the precipitation on day $\mathrm{t}, \mathrm{S}(\mathrm{mm})$ to the potential maximum storage, which is a function of the soil curve number. The daily deep percolation $\left(\mathrm{DP}_{[\mathrm{t}]}, \mathrm{mm}\right)$ is defined by the drainage ability of the day given the actual soil water content between saturation and field capacity. The drainage ability is zero when the soil water content is lower than or equal to field capacity (Raes et al., 2011).

By tracking daily incoming and outgoing water fluxes at the boundaries of the root zone we were able to separate the green and blue soil water balances at a daily basis. The capillary rise from groundwater ( $\mathrm{mm}$ ) is assumed to be zero because the ground water depth is considered to be much larger than 1m (Allen et al., 1998). In order to obtain initial soil water content at the beginning of the growing period, following the method and assumption from (Siebert and Doll, 2010), the initial soil water moisture was simulated from the maximum soil water content through two years rain-fed fallow land prior to the planting 
date. The initial soil water moisture at the start of the growing period is assumed as green water.

The contribution of precipitation (green water) and irrigation (IRR) (blue water) to surface runoff is calculated based on the respective magnitudes of precipitation and irrigation to the total green plus blue water inflow. The green and blue components in DP and ET are calculated per day based on the fractions of green and blue water in the total soil water content at the end of the previous day. The green soil water content $\left(\mathrm{S}_{\text {green }}\right)$ and blue soil water content $\left(\mathrm{S}_{\text {blue }}\right)$ are thus calculated as:

$$
\left\{\begin{array}{c}
S_{\text {green }[\mathrm{t}]}=\mathrm{S}_{\text {green }[\mathrm{t}-1]}+\left(\mathrm{PR}_{[\mathrm{t}]}+\mathrm{IRR}_{[\mathrm{t}]}-\mathrm{RO}_{[\mathrm{t}]}\right) \times \frac{\mathrm{PR}_{[\mathrm{t}]}}{\mathrm{PR}_{[\mathrm{t}]}+\mathrm{IRR}_{[\mathrm{t}]}}-\left(\mathrm{DP}_{[\mathrm{t}]}+\mathrm{ET}_{[\mathrm{t}]}\right) \times \frac{\mathrm{S}_{\text {green }[\mathrm{t}-1]}}{\mathrm{S}_{[\mathrm{t}-1]}} \\
\mathrm{S}_{\text {blue }[\mathrm{t}]}=\mathrm{S}_{\text {blue }[\mathrm{t}-1]}+\left(\mathrm{PR}_{[\mathrm{t}]}+\mathrm{IRR}_{[\mathrm{t}]}-\mathrm{RO}_{[\mathrm{t}]}\right) \times \frac{\mathrm{IRR}_{[\mathrm{t}]}}{\mathrm{PR}_{[\mathrm{t}]}+\mathrm{IRR}_{[\mathrm{t}]}}-\left(\mathrm{DP}_{[\mathrm{t}]}+\mathrm{ET}_{[\mathrm{t}]}\right) \times \frac{\mathrm{S}_{\text {blue }[\mathrm{t}-1]}}{\mathrm{S}_{[\mathrm{t}-1]}}
\end{array}\right.
$$

In AquaCrop, the daily crop transpiration $\left(\operatorname{Tr}_{[\mathrm{t}]}, \mathrm{mm}\right)$ is used to derive the daily gain in above-ground biomass (B) via the normalized biomass water productivity of the crop (WP*, $\left.\mathrm{kg} \mathrm{m}^{-2}\right)$ :

$\mathrm{B}=\mathrm{WP}^{*} \times \sum \frac{\mathrm{Tr}_{[\mathrm{t}]}}{\mathrm{ET}_{0}[\mathrm{t}]}$

The WP* is normalized for the carbon dioxide $\left(\mathrm{CO}_{2}\right)$ concentration of the bulk atmosphere, the evaporative demand of the atmosphere $\left(\mathrm{ET}_{0}\right)$ and crop classes ( $\mathrm{C} 3$ or $\mathrm{C} 4$ crops). The normalization makes the model applicable to diverse locations and seasons (Raes et al., 2011). The harvestable portion (the crop yield $\mathrm{Y}, \mathrm{t} \mathrm{ha}^{-1}$ ) of $\mathrm{B}$ at the end of the growing period is determined as product of $\mathrm{B}$ and the harvest index (HI, \%):

$\mathrm{Y}=\mathrm{HI} \times \mathrm{B}$

$\mathrm{HI}$ is adjusted to water and temperature stress depending on the timing and extent of the stress by an adjustment factor $\left(\mathrm{f}_{\mathrm{HI}}\right)$ from the reference harvest index $\left(\mathrm{HI}_{0}\right)$ :

$\mathrm{HI}=\mathrm{f}_{\mathrm{HI}} \times \mathrm{HI}_{0}$ 
Vanuytrecht et al. (2014) examined the sensitivity of Y to inputs in the AquaCrop model, and found that simulated $\mathrm{Y}$ is particularly sensitive to the root and soil parameters. Therefore, before running AquaCrop, input parameters on crop calendar, maximum effective root depth and $\mathrm{HI}_{0}$ for each crop were carefully selected from different sources for the current study (Table 3.1). Values of other crop parameters used in the study are taken from Raes et al. (2011). Several studies (Araya et al., 2010; Abedinpour et al., 2012; Katerji et al., 2013; Iqbal et al., 2014) have verified that the model performs at acceptable accuracy level in $\mathrm{Y}$ simulations and the accuracy level was relatively higher for irrigated crops than rain-fed crops. This is due to the fact that if the soil water content reaches below the threshold affecting the canopy senescence in the model, the simulated canopy will die resulting in an underestimated or even zero Y (Raes et al., 2011; Katerji et al., 2013). Therefore, in order to avoid such modelling failures at rain-fed fields, we set the initial soil moisture such that the soil water threshold for canopy senescence for each crop is met.

\subsubsection{Estimating grey water footprints in crop production}

The grey WF related to crop production refers to the volume of water needed to assimilate the fertilizers and pesticides applied to the field that reach groundwater through leaching or surface water through runoff or soil erosion (Hoekstra et al., 2011). In the current study, we consider the effect of nitrogen $(\mathrm{N})$ and phosphorus $(\mathrm{P})$, thus excluding the effect of other nutrients and fertilizers. At a $5 \times 5$ arc-minute grid and annual basis, we estimated the grey WF of crop production related to $\mathrm{N}$ and $\mathrm{P}$ from both mineral and manure fertilizers during the period 1961-2009. The grey WF per unit of crop $\left(\mathrm{WF}_{\text {grey }}, \mathrm{m}^{3} \mathrm{t}^{-1}\right)$ was calculated following the formula (Hoekstra et al., 2011):

$$
\mathrm{WF}_{\text {grey }}=\frac{\alpha \times \mathrm{AR}}{\left(\mathrm{c}_{\text {max }}-\mathrm{c}_{\text {nat }}\right)} \frac{1}{\mathrm{Y}}
$$

where $\alpha$ represents the leaching-runoff fraction, $\mathrm{AR}\left(\mathrm{kg} \mathrm{ha}^{-1}\right)$ the application rate to the field (the sum of mineral and manure fertilizer), $\mathrm{c}_{\max }\left(\mathrm{mg} \mathrm{l}^{-1}\right)$ the maximum acceptable concentration of the nutrient in the receiving water body, and $\mathrm{c}_{\text {nat }}$ the natural concentration of the nutrient in the receiving water body. We used values for $c_{\max }$ and $c_{n a t}$ from China's 
national surface water quality standard (MEP, 2002) and average values for $\alpha$ as suggested in Franke et al. (2013): 0.1 for N, 0.03 for P.

The mineral and manure fertilizer application rates by crop and per grid cell were estimated following Liu et al. (2010). For both artificial fertilizer and manure, the fertilizer consumption volumes are expressed in terms of $\mathrm{N}$ and $\mathrm{P}$ amounts. The fertilizer volume per crop per year per grid cell was calculated from the total annual national fertilizer consumption for the crop times the production share of the grid cell. The correlated AR in a grid cell was calculated by dividing the crop-specific fertilizer volume by the harvested area of the crop. The manure input for a nutrient was calculated by multiplying the livestock density with animal specific excretion rates for the nutrient and excretion collection rates. Five types of livestock were considered: cattle, goats, sheep, pigs and poultry. Excreta can be produced in either stables or meadows (Liu et al., 2010). We only consider the excreta produced in a stable for manure supply. We used $90 \%$, the share of the manure for cropland use in developing countries suggested by Smil (1999). Part of the $\mathrm{N}$ in animal manure is lost through $\mathrm{NH}_{3}$ volatilization. Following the assumption from Bouwman et al. (2013), 60\% of the $\mathrm{N}$ in the manure is effective for fertilizer.

\subsubsection{Blue water footprints related to industry and municipal sectors}

The data on industrial and domestic water consumption for 1978-1997 are only available in the form of averages over five-year periods. The values for 1978-1982 and 1988-1992 for the YRB were directly available from YRCC (2006); the values for 1983-1987 and 1993-1997 were estimated based on national water withdrawal for industry and household obtained from FAO (2014a). In the latter case, we assumed the blue water consumption to be a fraction of blue water withdrawal, taking the fraction equal as the average for the years 1978-1992. Similarly, we assumed the blue water consumption in YRB to be a fraction of the national total equal as the average for the years 1978-1992. For the period 1998-2009, we use annual estimates for industrial and domestic water consumption from YRCC (2011).

The blue WFs related to the industrial and municipal sectors in the YRB were downscaled to grid level based on a population density map of the YRB, which was extracted from the 
2.5 arc min resolution population density map for China from CIESIN (2005). For downscaling industrial water use, it would have been preferred to use spatial data on industries within the basin, but in absence of such data we used the population density map, following Hoekstra et al. (2012). Monthly industrial and domestic water consumption was obtained by distributing the annual value equally over the 12 months without accounting for the possible variation.

\subsubsection{Blue water scarcity assessment}

Blue water scarcity in a catchment is defined as the ratio of the total blue WF $\left(\mathrm{m}^{3} \mathrm{y}^{-1}\right)$ to the maximum sustainable blue WF $\left(\mathrm{m}^{3} \mathrm{y}^{-1}\right)$ in that catchment during a specific time period (Hoekstra et al., 2011; Hoekstra et al., 2012). In this study, monthly blue water scarcity in the YRB during 1978-2009 was calculated at $5 \times 5$ arc min grid. The total blue WF was estimated by summing the crop-related blue WF as calculated in the current study and the blue WFs from the industrial and domestic sectors estimated based on YRCC (2011). The monthly maximum sustainable blue WF was calculated as the 'natural runoff' minus 'environmental flow requirement'. The monthly natural runoff for the study period was obtained from the hydrological model PCR-GLOBWB (Van Beek et al., 2011; Wada et al., 2011; Wada and Bierkens, 2014) at a spatial resolution of $6 \times 6 \operatorname{arc} \min (\sim 9 \mathrm{~km} \times 11 \mathrm{~km}$ in the YRB), which was resampled to a resolution of $5 \times 5$ arc min. The performance of the PCR-GLOBWB for the YRB is good in reproducing variability and magnitudes of monthly natural discharge (Van Beek et al., 2011). The 'environmental flow requirement' was estimated based on the presumptive standard proposed by Richter et al. (2012) and Hoekstra et al. (2011) and earlier applied by Hoekstra et al. (2012). According to this standard, 80\% of monthly natural runoff is allocated to the environment. The maximum sustainable blue WF per grid cell was calculated as $20 \%$ of the total natural runoff from that cell and upstream grid cells, minus the blue WF in upstream grid cells.

Blue water scarcity is classified into four levels (Hoekstra et al., 2012): 'low' when the blue WF is smaller than $20 \%$ of natural runoff, i.e. when the blue WF is smaller than the maximum sustainable blue WF; 'moderate' when the blue WF is between $20 \%$ and $30 \%$ of 
natural runoff; 'significant' when the blue WF is between $30 \%$ and $40 \%$ of natural runoff; and 'severe' when the blue WF exceeds $40 \%$ of natural runoff.

\subsubsection{Data}

For the period 1961-2009, monthly precipitation, $\mathrm{ET}_{0}$ and temperature data at 30 arc min resolution were extracted from CRU-TS-3.10.01(Harris et al., 2014). Data on irrigated and rain-fed area for each crop at 5 arc min resolution were obtained from Portmann et al. (2010). For crops not available in this database, we used the 5 arc min crop area map from Monfreda et al. (2008). Yearly harvested areas and yields for each crop within the YRB were scaled to fit the yearly agriculture statistics at province level of China obtained from NBSC (2013). For tomatoes, we used estimates of FAOSTAT (FAO, 2014b), because NBSC (2013) does not contain tomato-specific statistics. The data on crop calendar, maximum root depth and reference harvest index are presented in Table 3.1. Soil texture data were obtained from ISRIC Soil and Terrain database for China at a $10 \mathrm{~km}^{2}$ resolution (Dijkshoorn et al., 2008). For hydraulic characteristics for each type of soil, the indicative values provided by AquaCrop were used. Data on total soil water capacity (in \%vol) at a spatial resolution of 5 arc minute were obtained from Batjes (2012).

Annual chemical fertilizer use statistics for China for the study period 1961-2009 were obtained from IFA (2013). Total fertilizer use in the YRB was estimated based on the ratio of the crop area in the YRB to the crop area in China as a whole. Total fertilizer use in the YRB per year was downscaled to crop-specific fertilizer use based on the data on fertilizer use per crop in China as reported by FAO (2007). Livestock density data for the year 2000 were taken from Robinson et al. (2007). The livestock density data for other years were scaled with the yearly national stock statistics for different types of livestock obtained from NBSC (2013). The share of excretion produced in stables was obtained from Bouwman et al. (1997) and Liu et al. (2010) (Table 3.2). Following Bouwman et al. (2013), it was assumed that $90 \%$ of the manure was applied to crop fields and that $60 \%$ of the nutrients applied to the field in the form of manure is taken up by the plant. The livestock nutrient excretion rates by type of animal were obtained from the baseline data provided by Sheldrick et al. 
(2003) (Table 3.2). The values for $\mathrm{c}_{\max }$ and $\mathrm{c}_{\mathrm{nat}}$ for the calculation of grey WF were taken from the national surface water quality standard of China (MEP, 2002) (Table 3.3).

Table 3.1. Crop characteristics used in the current study ${ }^{a}$.

\begin{tabular}{|c|c|c|c|c|c|c|c|c|}
\hline \multirow{2}{*}{ Crop } & \multirow{2}{*}{ Planting date } & \multicolumn{4}{|c|}{ Relative crop growing stages } & \multirow{2}{*}{$\mathrm{HI}_{0}$} & \multicolumn{2}{|c|}{$\begin{array}{l}\text { Max. rooting depth } \\
\text { (m) }\end{array}$} \\
\hline & & $L_{\text {ini }}$ & $L_{d e v}$ & $L_{\text {mid }}$ & Llate & & Irrigated & Rain-fed \\
\hline Winter wheat & 15th October & 0.48 & 0.22 & 0.22 & 0.07 & $40 \%$ & 1.5 & 1.8 \\
\hline Spring wheat & 15th March & 0.15 & 0.19 & 0.44 & 0.22 & $39 \%$ & 1 & 1.5 \\
\hline Rice & 1st May & 0.20 & 0.20 & 0.40 & 0.20 & $43 \%$ & 0.5 & 1 \\
\hline Maize & 1st May & 0.20 & 0.27 & 0.33 & 0.20 & $44 \%$ & 1 & 1.7 \\
\hline Sorghum & 1st May & 0.15 & 0.27 & 0.35 & 0.23 & $39 \%$ & 1 & 2 \\
\hline Millet & 15th April & 0.14 & 0.21 & 0.39 & 0.25 & $38 \%$ & 1 & 2 \\
\hline Barley & 15th May & 0.13 & 0.21 & 0.42 & 0.25 & $39 \%$ & 1 & 1.5 \\
\hline Soybean & 1st June & 0.13 & 0.17 & 0.50 & 0.20 & $44 \%$ & 0.6 & 1.3 \\
\hline Potato & 1st May & 0.19 & 0.23 & 0.35 & 0.23 & $59 \%$ & 0.4 & 0.6 \\
\hline Sweet potato & 1st May & 0.13 & 0.20 & 0.40 & 0.27 & $69 \%$ & 1 & 1.5 \\
\hline Cotton & 1st April & 0.17 & 0.28 & 0.31 & 0.25 & $38 \%$ & 1 & 1.7 \\
\hline Sugar beet & 15th April & 0.28 & 0.22 & 0.28 & 0.22 & $71 \%$ & 0.7 & 1.2 \\
\hline Groundnut & 15th April & 0.25 & 0.32 & 0.25 & 0.18 & $43 \%$ & 0.5 & 1 \\
\hline Sunflower & 15th April & 0.19 & 0.27 & 0.35 & 0.19 & $31 \%$ & 0.8 & 1.5 \\
\hline Rapeseed & 15th March & 0.20 & 0.40 & 0.20 & 0.20 & $25 \%$ & 1 & 1.5 \\
\hline Tomato & 15th January & 0.22 & 0.30 & 0.30 & 0.19 & $40 \%$ & 0.7 & 1.5 \\
\hline Apple & 1st March & 0.13 & 0.21 & 0.54 & 0.13 & $20 \%$ & 0.7 & 1.5 \\
\hline
\end{tabular}

aSources: reference harvest indexes from Xie et al. (2011) and Zhang and Zhu (1990); planting dates from Chen et al. (1995); relative crop growing stages and maximum rooting depths from Allen et al. (1998) and Hoekstra and Chapagain (2007b). 
Table 3.2 Share of excretion produced in stables and excretion rates per livestock category a.

\begin{tabular}{lccc}
\hline \multirow{2}{*}{ Livestock } & $\begin{array}{c}\text { Share of excretion produced } \\
\text { in stables (\%) }\end{array}$ & \multicolumn{2}{c}{ Excretion rate $\left(\mathrm{kg}^{2}\right.$ nutrient head $\left.\mathrm{y}^{-1} \mathrm{y}^{-1}\right)$} \\
\cline { 3 - 4 } & 46 & $\mathrm{~N}$ & $\mathrm{P}$ \\
\hline Cattle & 10 & 50 & 10 \\
Goats & 10 & 10 & 2 \\
Sheep & 100 & 10 & 2 \\
Pigs & 100 & 12 & 4 \\
Poultry & 0.6 & 0.19 \\
\hline
\end{tabular}

aSources: shares of excretion produced in stables from Bouwman et al. (1997) and Liu et al. (2010); excretion rates from Sheldrick et al. (2003).

Table 3.3. Water quality parameters for grey water footprint estimation in Yellow River Basin $^{a}$.

\begin{tabular}{lcc}
\hline Chemical substance & $\mathrm{c}_{\max }\left(\mathrm{mg} \mathrm{l}^{-1}\right)$ & $\mathrm{c}_{\text {nat }}\left(\mathrm{mg} \mathrm{l}^{-1}\right)$ \\
\hline Phosphorous $(\mathrm{P})$ & 0.2 & 0.02 \\
Nitrogen $(\mathrm{N})$ & 1.0 & 0.2 \\
\hline
\end{tabular}

aSource: For $\mathrm{c}_{\mathrm{nat}}$, we took data for the best water quality level 'l' in MEP (2002).

\subsection{Results}

\subsubsection{The water footprint of crop production}

Over the period 1961-2009, the average annual total green-blue WF of crop production in the YRB was $48.8 \times 10^{9} \mathrm{~m}^{3} \mathrm{y}^{-1}$, of which $25 \%$ was blue WF $\left(12.4 \times 10^{9} \mathrm{~m}^{3} \mathrm{y}^{-1}\right)$. The average annual grey WF was $86.7 \times 10^{9} \mathrm{~m}^{3} \mathrm{y}^{-1}$ related to $\mathrm{N}$ and $37.8 \times 10^{9} \mathrm{~m}^{3} \mathrm{y}^{-1}$ related to $\mathrm{P}$. The annual variations of green, blue and grey WFs of crop production in the YRB over the study period are plotted in Figure 3.1. During the study period, the harvested area of crops considered in the YRB increased little (by about 5\%), but the crop production increased by almost five-fold. In order to reach the rising targets for crop production, the irrigated area in the YRB has been expanded 1.5 times relative to the level in the 1960s, which resulted in a $37 \%$ larger blue WF in the $2000 \mathrm{~s}\left(14.4 \times 10^{9} \mathrm{~m}^{3} \mathrm{y}^{-1}\right)$ compared to the $1960 \mathrm{~s}\left(10.5 \times 10^{9} \mathrm{~m}^{3} \mathrm{y}^{-1}\right)$. The increase in the green WF was less: it was $14 \%$ larger in the $2000 \mathrm{~s}\left(38.4 \times 10^{9} \mathrm{~m}^{3} \mathrm{y}^{-1}\right)$ 
compared to the $1960 \mathrm{~s}\left(33.7 \times 10^{9} \mathrm{~m}^{3} \mathrm{y}^{-1}\right)$. As can be seen from Figure 3.1, annual green and blue WFs fluctuated inversely, i.e., with an increase in green WF the blue WF decreased. The intensification of crop production and fertilizer application has been one of main reasons for the severe water pollution in the YRB (Yunpeng et al., 2015). According to our estimates, the fertilizer-related grey WFs increased over the study period by 24 and 36 times for $\mathrm{N}$ and $\mathrm{P}$, respectively. The large increase is not surprising considering the fact that over the period 1961-2009 total fertilizer use on crop land in China increased 38 and 90 times for $\mathrm{N}$ and $\mathrm{P}$, respectively (IFA, 2013).

The relative contribution of crops to the total green plus blue WF changed due to changes in cropping patterns in the YRB. In the period 1961-1965, the five biggest contributors to the green plus blue WF related to crop production were winter wheat (48\%), spring wheat (8.9\%), millet (8.8\%), maize (8.3\%), and soybean $(6.1 \%)$, while for 2006-2009 these were winter wheat $(41 \%)$, maize $(21 \%)$, spring wheat $(7.1 \%)$, apples $(6.7 \%)$ and potatoes $(5.2 \%)$. Over the study period, crops with increasing green-blue WF of production were winter wheat, rice, maize, potatoes, sunflower, groundnuts, sugar beet, rapeseed, tomatoes and apples. Crops with decreasing green-blue WF were spring wheat, sorghum, millet, barley, soybean, sweet potatoes and cotton (Table 3.4). Sunflower has the strongest increase in its total WF of production during the study period, which is driven by the huge extension of sunflower planting areas in the YRB (from $1.3 \mathrm{k}$ ha in 1961 to $203 \mathrm{k}$ ha in 2009). Sorghum has the largest decrease in the total WF of production, which relates to the decrease in sorghum planting area by $90 \%$.

In the 2000s, about $62 \%\left(8.9 \times 10^{9} \mathrm{~m}^{3} \mathrm{y}^{-1}\right)$ of the crop-related blue WF in the YRB was for wheat production and $21 \%\left(3.0 \times 10^{9} \mathrm{~m}^{3} \mathrm{y}^{-1}\right)$ for producing maize. The blue WF of maize production increased nearly five-fold, from $0.65 \times 10^{9} \mathrm{~m}^{3} \mathrm{y}^{-1}$ in the $1960 \mathrm{~s}$ to $3.0 \times 10^{9} \mathrm{~m}^{3} \mathrm{y}^{-1}$ in the 2000s. On the other hand, the blue WF of cotton, one of the biggest blue water consumers in the $1960 \mathrm{~s}$, dropped from $0.86 \times 10^{9} \mathrm{~m}^{3} \mathrm{y}^{-1}$ in the $1960 \mathrm{~s}$ to $0.63 \times 10^{9} \mathrm{~m}^{3} \mathrm{y}^{-1}$ in the 2000s, due to the decline in its irrigated area ( $\sim 307 \mathrm{k}$ ha in the 1960 s to $\sim 201 \mathrm{kha}$ in the 2000s). Regarding the green WF, wheat and maize accounted for about $62 \%$ in the $2000 \mathrm{~s}$ ( $43 \%$ from wheat, $19 \%$ from maize). For rapeseed, which is one of the fully rain-fed crops, 
the green WF share increased from 1\% (1960s) to 5\% (2000s). Among the crops, maize had the largest grey WF related to both $\mathrm{N}(60 \%$ of the total) and P (48\% of the total), followed by soybean ( $5 \%$ of total related to $\mathrm{N}, 12 \%$ of total related to $\mathrm{P})$.

The variation of the total crop-related green-blue WF at basin level is mainly caused by the increase in irrigated area and variation in climatic conditions (like PR and $\mathrm{ET}_{0}$ ). The increase of the irrigated area caused the overall increasing trend of the annual blue WF in the YRB, while climate variability contributed to the inter-annual fluctuation of the blue WF. We found that the blue WF decreases with increased PR and increases with increased $\mathrm{ET}_{0}$, which confirms the finding in Chapter 2 (Zhuo et al., 2014) that the blue WF of crop production is more sensitive to $\mathrm{ET}_{0}$ than to $\mathrm{PR}$.

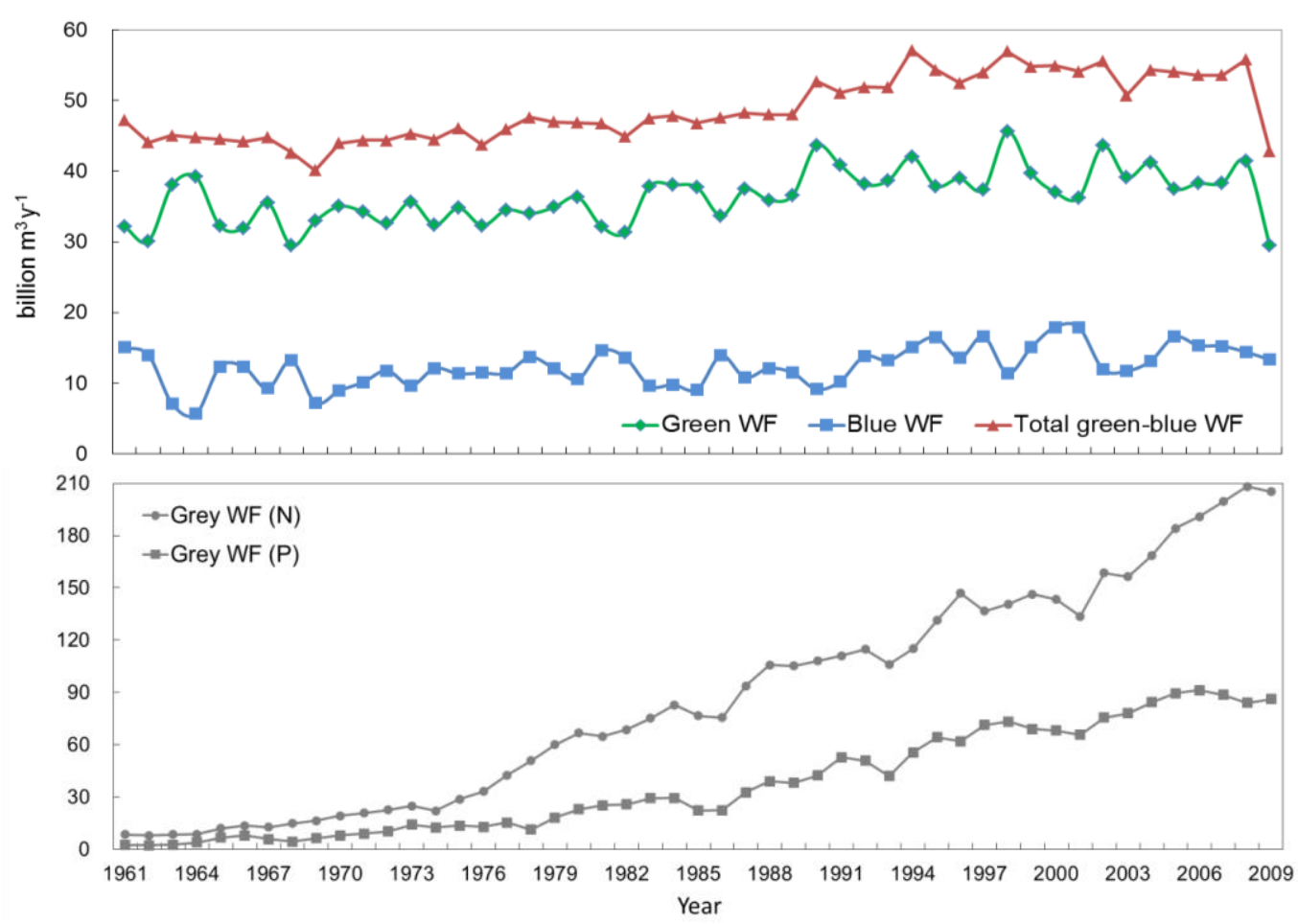

Figure 3.1 Annual variability of green, blue and grey water footprints of crop production in the Yellow River Basin. Period: 1961-2009. 
The upper, middle and lower reaches accounted for $23 \%, 49 \%$ and $28 \%$, respectively, of the annual average green-blue WF of crop production in the YRB in the 2000s. Over the study period, the increase of the basin's total blue WF mainly happened in the upper reach, while the increase in the total green WF was mainly in the lower reach. Figure 3.2 shows the relative contribution of the three reaches to the annual blue and green WFs of crop production in the basin over the period 1961-2009. Over the whole period, the middle reach had the largest share in both the blue and green WF in the basin as a whole, because of its larger share in the basin's total cultivated area ( $59 \%$ in 2009$)$. With the construction and expansion of main irrigation zones (e.g. Qingtongxia and Hetao irrigation districts) in the arid and semi-arid upper reach, the crop-related WF in this reach as well as the share in the basin total constantly increased and doubled during the five decades. The share of the upper reach in the total blue WF in the YRB reached 37\% in 2009. The blue WF in the lower reach fluctuated but remained more or less constant over the study period, although the share in the basin's total blue WF diminished. The green WF in the relatively wet lower reach increased almost two times due to increased cultivation of rain-fed crops such as rapeseed.

The spatial distribution of the total green-blue WF of crops in the YRB (Figure 3.3a) follows the distribution of the harvested crop area. The blue share in the total green-blue WF (Figure 3.3b) is obviously large in the places where the irrigated areas are most concentrated (Figure 3.3c). Also, blue WFs are larger in the drier area of the upper reach $(>60 \%$ of the total) than in the semi-arid middle reach and relatively wet lower reach ( $40 \%$ of the total). The lower reach has high levels of both $\mathrm{PR}$ and $\mathrm{ET}_{0}$. In this region, there is a large potential to improve productivity in rain-fed agriculture. Increased production in the lower reach can contribute to the lessening of the need to produce in the drier regions of the basin and thus to the reduction of irrigation and blue WF in these regions. 

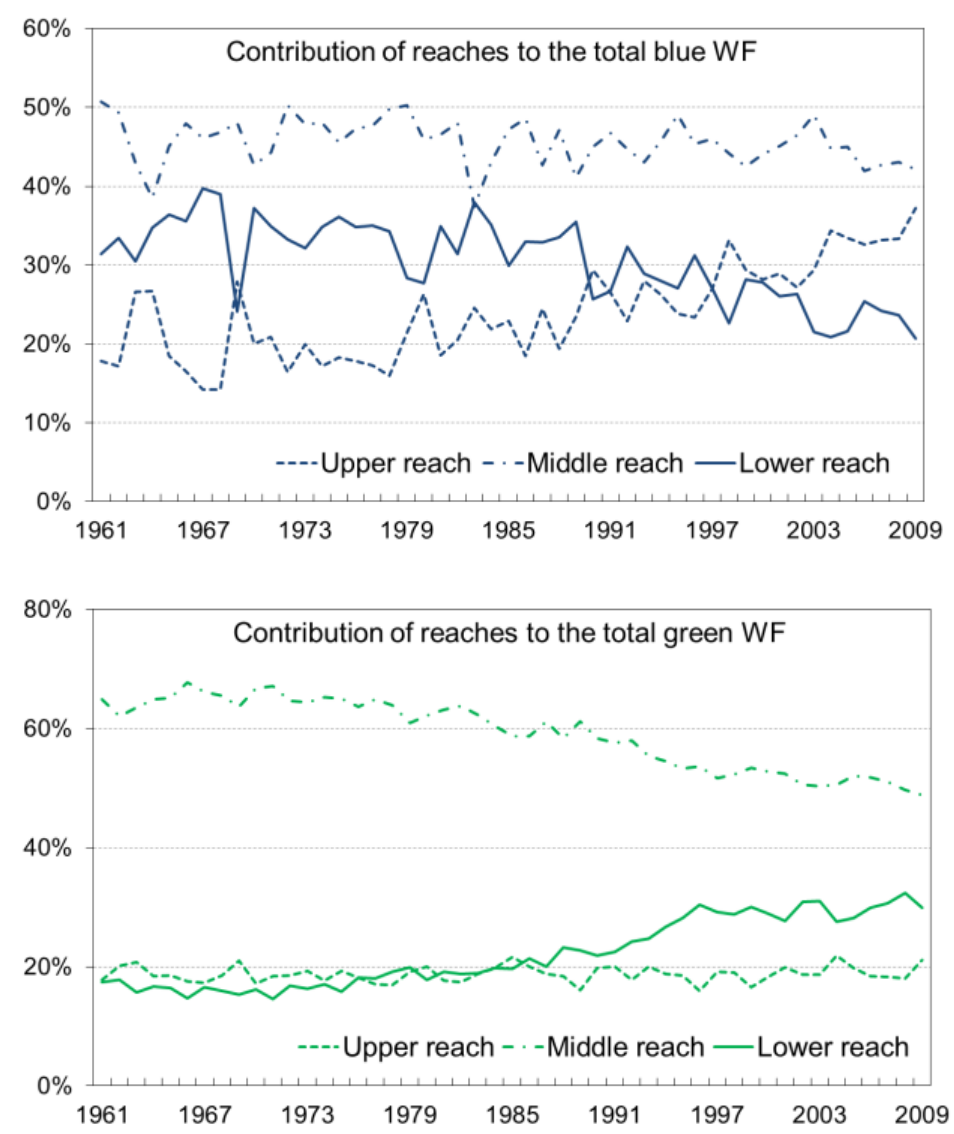

Figure 3.2 The relative contribution of the upper, middle and lower reaches to the annual blue (upper graph) and green (lower graph) water footprints of crop production in the Yellow River Basin. Period: 1961-2009. 
(a)

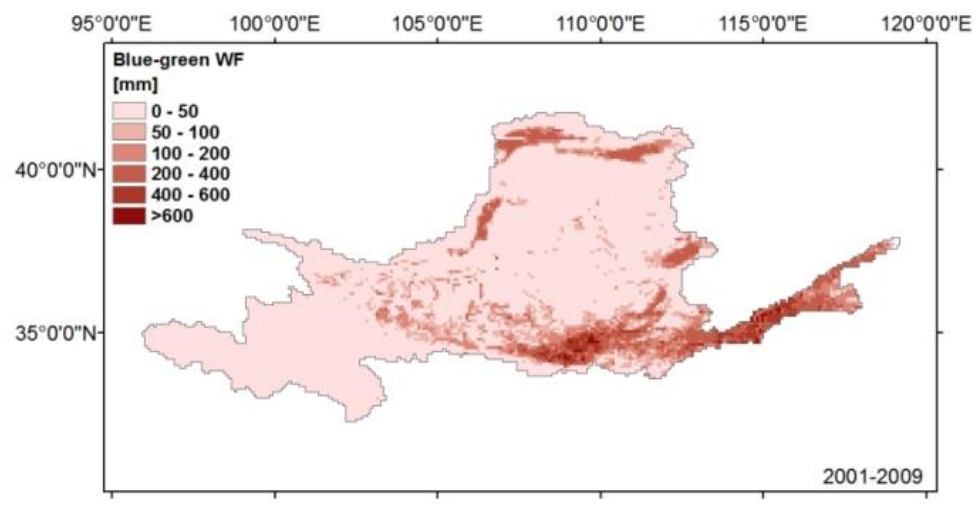

(b)

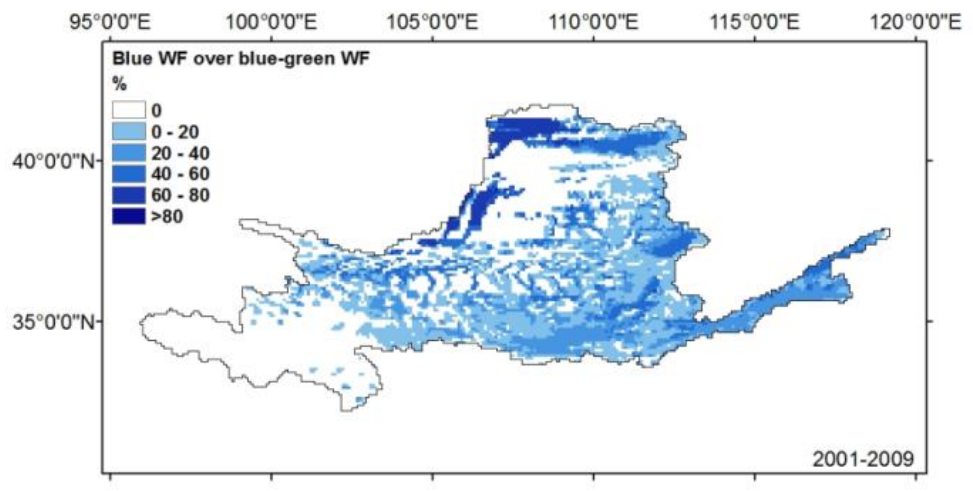

(c)

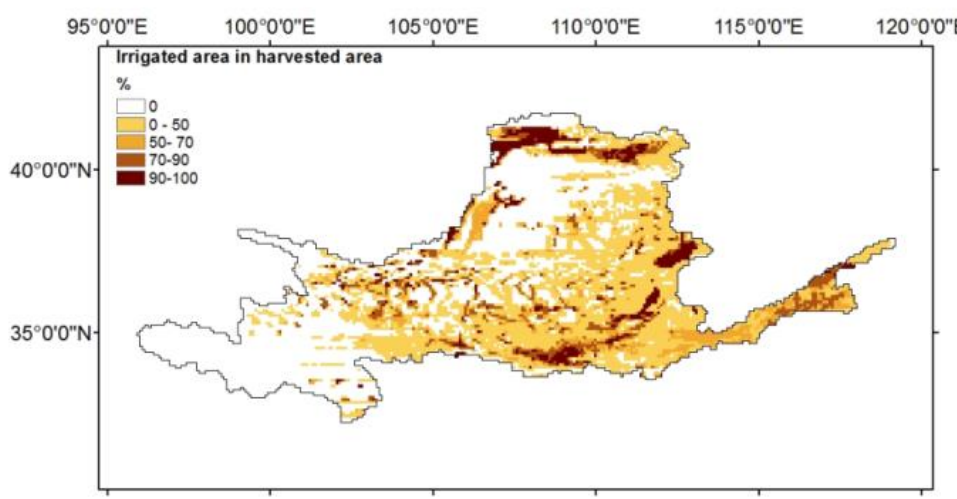

Figure 3.3 The spatial distributions of: (a) the average annual green-blue water footprint (WF) of crop production ( $\mathrm{mm}$ ), (b) the share of the blue WF in the total green-blue WF (\%), and (c) the share of irrigated area in total harvested area (\%) in the Yellow River Basin. Period: 2001-2009. 


\subsubsection{The water footprint per tonne of crop}

Over the period 1961-2009, the green and blue WF per tonne of crop in the YRB reduced significantly, while the grey WF increased. This is shown for the case of cereal crops (wheat, rice, maize, sorghum, millet and barley) in Figure 3.4. The average green-blue WF of cereal crops in the YRB decreased from $6540 \mathrm{~m}^{3} \mathrm{t}^{-1}$ in the $1960 \mathrm{~s}$ to $1570 \mathrm{~m}^{3} \mathrm{t}^{-1}$ in the $2000 \mathrm{~s}$. The sharp reduction of the green and blue WFs per tonne of cereals is a result of the improved crop yields. The land use for crop production within the YRB, adding up to around 10 million hectare for the crops considered in this study, changed little during the five decades studied, but crop production increased by a factor five. Due to the expansion of the irrigated area, the ratio of blue to green WF increased. Meanwhile, the grey WF per tonne of cereals rose because of the increasing application rates of artificial fertilizer. Figure 3.4 shows how the reduction in consumptive water use (the green plus blue WF) was offset by an increase in degradative water use (the grey WF). The overall grey WF was determined by the $\mathrm{N}$-related grey WF, which was generally bigger than the P-related grey WF. Among the crops studied, the grey WF of sorghum showed the strongest increase (Table 3.4).

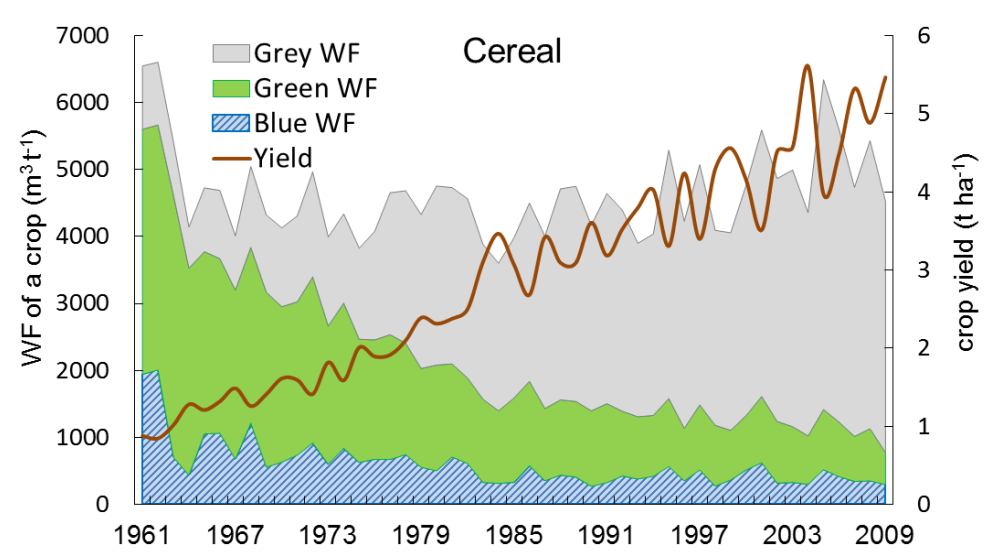

Figure 3.4 The green, blue and grey water footprint per tonne of cereal $\left(m^{3} t^{-1}\right)$ and cereal yield ( h $\left.^{-1}{ }^{-1}\right)$ in the Yellow River Basin. Period: 1961-2009. 
Figure 3.5 shows the spatial variation in the green-blue WF per tonne of cereal for five different decades. The WF within the YRB reduced from $>3000 \mathrm{~m}^{3} \mathrm{t}^{-1}$ in most areas in the 1960 s to about $500-2000 \mathrm{~m}^{3} \mathrm{t}^{-1}$ in the 2000s. But some regions in the western part of the basin still have low water productivity (large WF per ton). The reason is that there is low precipitation and no or little irrigation in this region (see Figure 3.3c), causing high water stress and low crop yields. It is worth noting, though, that there is little cultivation activity in this region. In the 2000s, rapeseed had the largest consumptive water use $\left(2678 \mathrm{~m}^{3} \mathrm{t}^{-1}\right)$ among the crops considered, followed by soybean $\left(2214 \mathrm{~m}^{3} \mathrm{t}^{-1}\right)$.
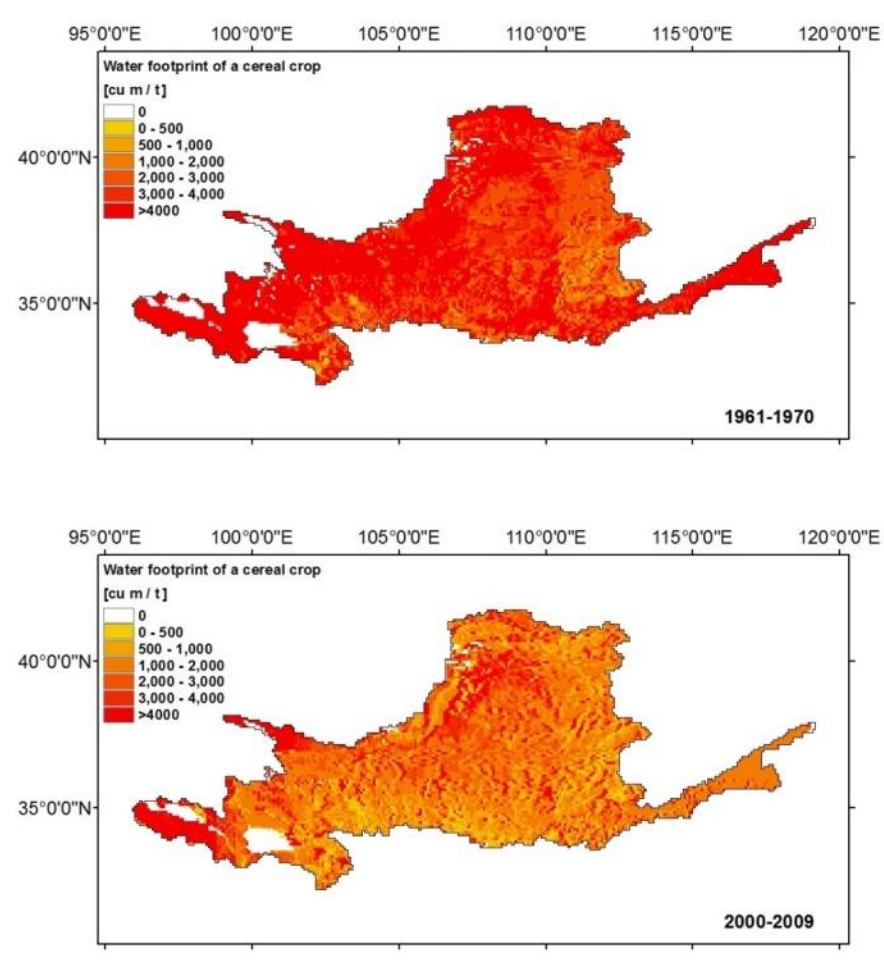

Figure 3.5 Spatial distribution of the decadal average green-blue water footprint $\left(\mathrm{m}^{3} t^{-1}\right)$ of cereal crops in the Yellow River Basin in the period: 1961-1970 (left) and 2000-2009 (right). 
Table 3.4 Percentage increases in water footprint of crop production in the Yellow River Basin from the period 1961-1970 to the period 2001-2009.

\begin{tabular}{|c|c|c|c|c|c|c|c|c|}
\hline \multirow[b]{2}{*}{ Crop } & \multicolumn{4}{|c|}{ Increase in total WF (\%) } & \multicolumn{4}{|c|}{ Increase in WF per tonne of crop (\%) } \\
\hline & Green & Blue & Grey & $\begin{array}{c}\text { Total } \\
\text { green-blue }\end{array}$ & Green & Blue & Grey & $\begin{array}{c}\text { Total } \\
\text { green-blue }\end{array}$ \\
\hline Winter wheat & -1 & 18 & 280 & 4 & -77 & -73 & -12 & -76 \\
\hline Spring wheat & -27 & 25 & 333 & -2 & -52 & -18 & 184 & -36 \\
\hline Rice & 121 & 167 & 1320 & 135 & -56 & -46 & 225 & -53 \\
\hline Maize & 125 & 362 & 1890 & 165 & -80 & -59 & 76 & -77 \\
\hline Sorghum & -83 & -86 & 1210 & -83 & -59 & -66 & 3080 & -60 \\
\hline Millet & -79 & -77 & 809 & -79 & -42 & -36 & 2470 & -43 \\
\hline Barley & -73 & -58 & 787 & -73 & -66 & -46 & 1030 & -65 \\
\hline Soybean & -37 & -40 & 811 & -38 & -53 & -46 & 662 & -51 \\
\hline Potato & 46 & 196 & 1590 & 51 & -66 & -31 & 295 & -65 \\
\hline Sweet potato & -41 & -37 & 1170 & -8 & -45 & -41 & 1080 & -46 \\
\hline Cotton & -17 & -27 & 634 & -20 & -64 & -69 & 217 & -67 \\
\hline Sugar beet & 76 & - & 3490 & 76 & -63 & - & 645 & -63 \\
\hline Groundnut & 266 & 409 & 1370 & 282 & -66 & -52 & 37 & -64 \\
\hline Sunflower & 9110 & 14900 & 14100 & 9630 & -44 & -8 & -13 & -41 \\
\hline Rapeseed & 385 & - & 2510 & 385 & -77 & - & 25 & -77 \\
\hline Tomato & 251 & 357 & 1640 & 258 & -57 & -44 & 113 & -56 \\
\hline Apple & 1248 & 1700 & 2310 & 1290 & -69 & -58 & -44 & -68 \\
\hline
\end{tabular}

\subsubsection{Blue water scarcity within the Yellow River Basin}

The annual blue WF of crop production in the YRB accounts for $73 \%$ of the long-term average total blue WF in the basin (including the WF of the industrial and municipal sectors). Blue water scarcity in the YRB during the period 1978-2009 was assessed by comparing the total blue WF from agriculture, industry and households to the maximum sustainable blue WF. According to our estimate, the annual blue WF in the YRB as a whole accounted for $19-52 \%$ of the natural runoff, with $31 \%$ as the multi-year average, which is higher than the maximum sustainable level ( $20 \%$ of the natural runoff). Figure 3.6 compares, at an annual basis, the total blue WF and the blue WF of crop production alone to the maximum sustainable blue WF and also shows the annual precipitation at the YRB over the study period. The results show that, at yearly scale, relatively large total blue WFs 
(resulting from additional water demands in agriculture) occur in relatively dry years, when the maximum sustainable blue WF is relatively small, thus enlarging the blue water scarcity.

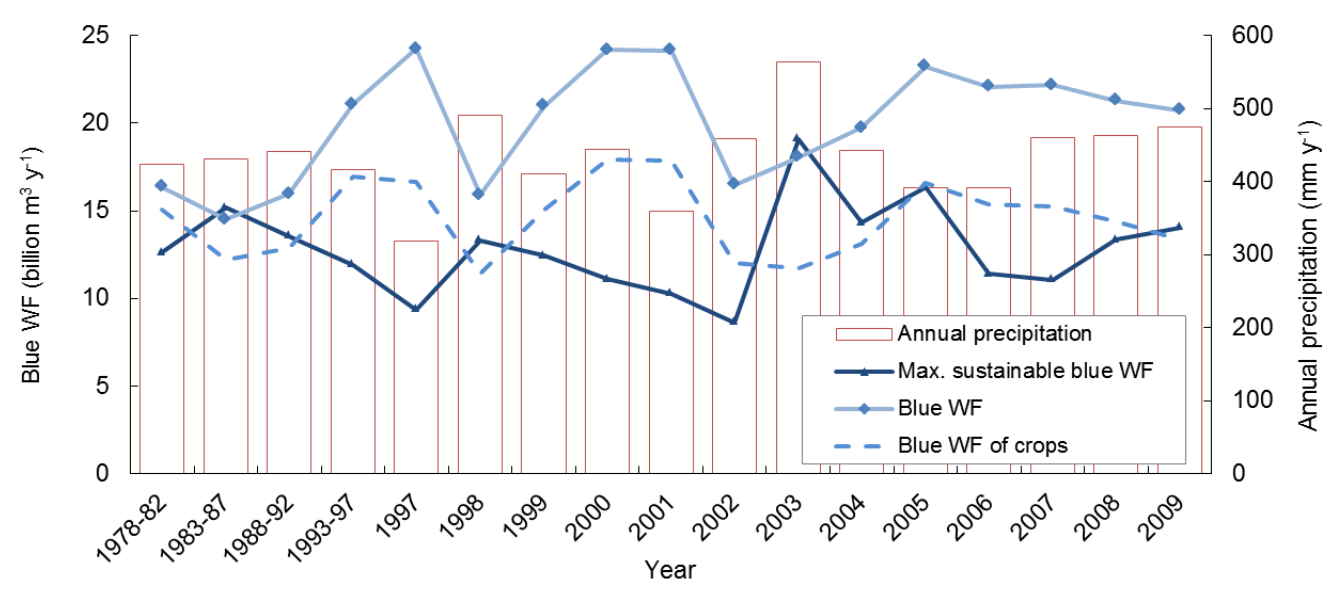

Figure 3.6 The total annual blue water footprint (WF), the annual blue WF of crop production, the maximum sustainable blue WF, and annual precipitation in the Yellow River Basin. Five-year averages for 1978-1997 and year-by-year for 1997-2009.

In order to assess the monthly variability of the blue water scarcity in the YRB, Figure 3.7 shows the monthly natural runoff, maximum sustainable blue WF, and blue WF for 1978-2009. The peak of monthly blue WF within a year is asynchronous with the flood season in the basin. The blue WF generally peaks about two months earlier (May-July) than the natural runoff (July-September), which was also observed by (Hoekstra et al., 2012). Natural runoff is generally largest from June to October, following the rain season, while the blue WF is largest with the crop growing period from March to July and decreases with higher precipitation after July. As a long-term average, the basin experiences moderate to severe blue water scarcity for seven months per year (January-July), of which on average five months severe (generally March-July). 


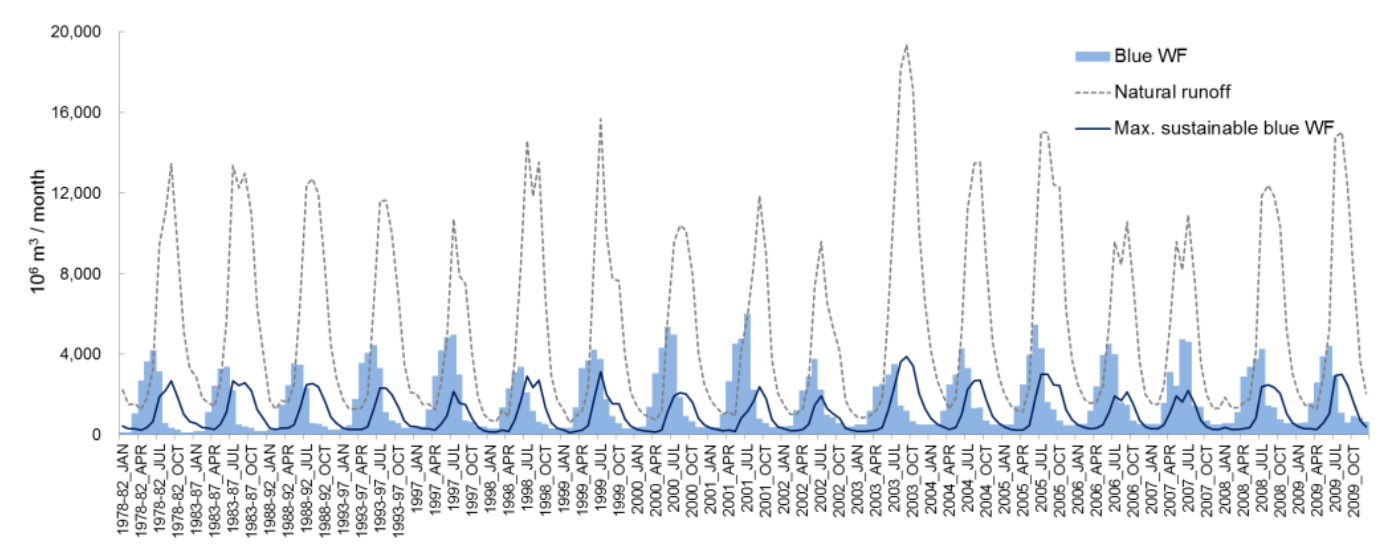

Figure 3.7 Monthly blue water footprint (WF) vs. maximum sustainable blue WF and natural runoff within the Yellow River Basin. Five-year averages for 1978-1997 and year-by-year for 1997-2009.

Figure 3.8 zooms in on the monthly blue water scarcity in the YRB for selected wet (2003), dry $(2000,2007)$ and average (2005) years in the most recent decade of the study period. Monthly blue WF generally peaks in May-July, but the peak in the wet year is much lower than in the average and dry years. Even in the wet year though, the basin experienced moderate to severe blue water scarcity during seven months per year. In the dry year of 2007, there were eleven months in which the blue WF exceeded the maximum sustainable level. Within the study period, the highest value of the monthly blue water scarcity index was 20, observed in April 2000. Although water use for irrigation is the main cause of high blue water scarcity in the YRB, it incidentally happens that moderate to severe blue water scarcity occurs outside the cropping season, in the period November-February, due to the WF of industries and household. 

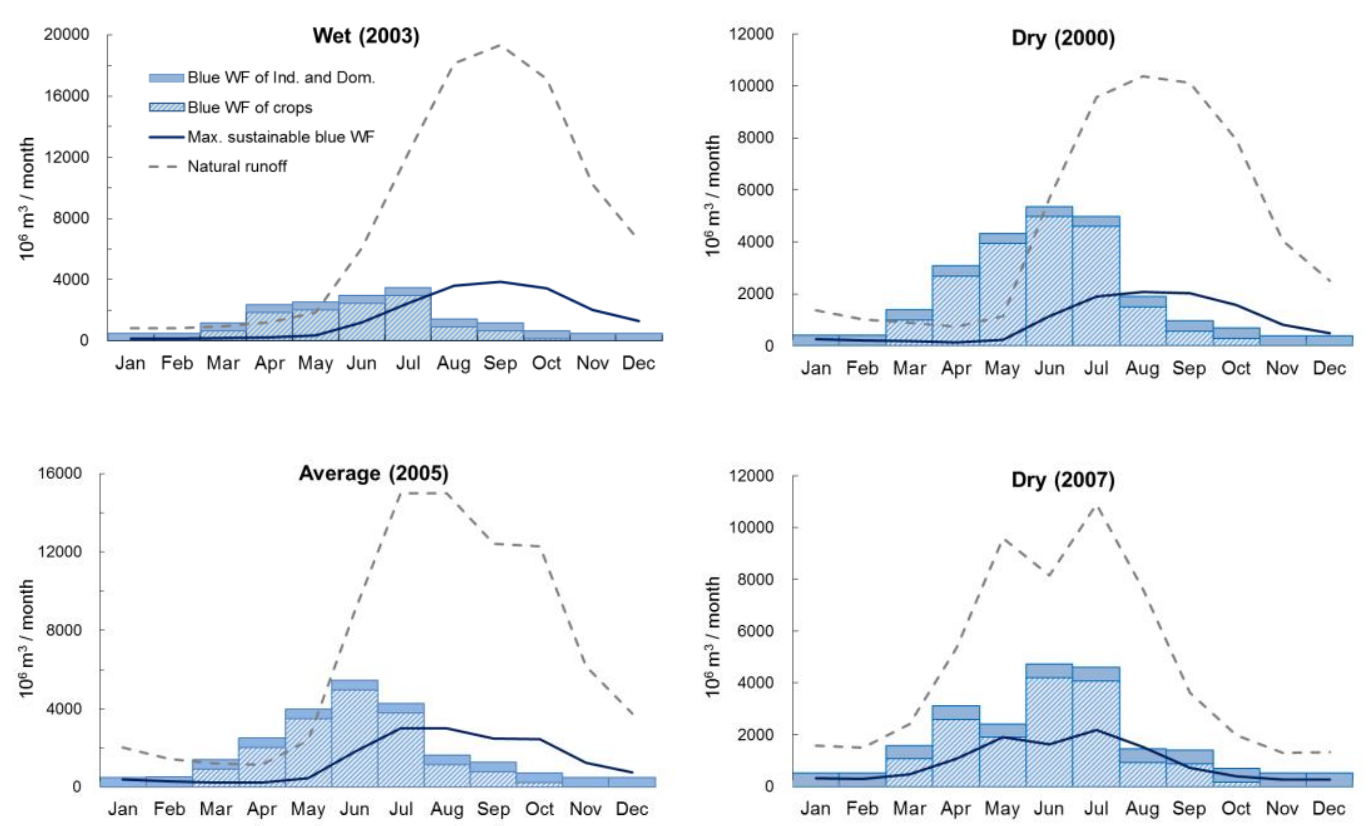

Figure 3.8 Monthly blue water footprint (WF) vs. maximum sustainable blue WF and natural runoff within the Yellow River Basin of selected wet (2003), dry (2000, 2007) and average (2005) years.

The spatial distributions of monthly blue water scarcity in the YRB in a dry year (2000) and a wet year (2003) are illustrated in Figure 3.9 for January, April (when blue WFs are growing while blue water availability is still low), July (when both water footprints and blue water availability are high) and October. The eastern part of the upper reach, the northern part of the middle reach, and most of the lower reach suffer severe blue water scarcity throughout the year. In both dry and wet years, about $90 \%$ of the basin is likely to face severe blue water scarcity till the start of the flooding season around June. During the last half of the year, the part located in the Tibetan Plateau (western part of the upper reach) has low blue water scarcity because of the absence of irrigation activities and because most of the total basin runoff is generated here. Due to the uneven distribution of the blue WF and available blue water resources across the YRB, about half of the basin still experiences severe blue water scarcity even in the flood season of the wet year even though the blue 
water scarcity for the basin as a whole is low. This shows the relevance of considering blue water scarcity at a finer spatial scale than river basin level as is usually done.
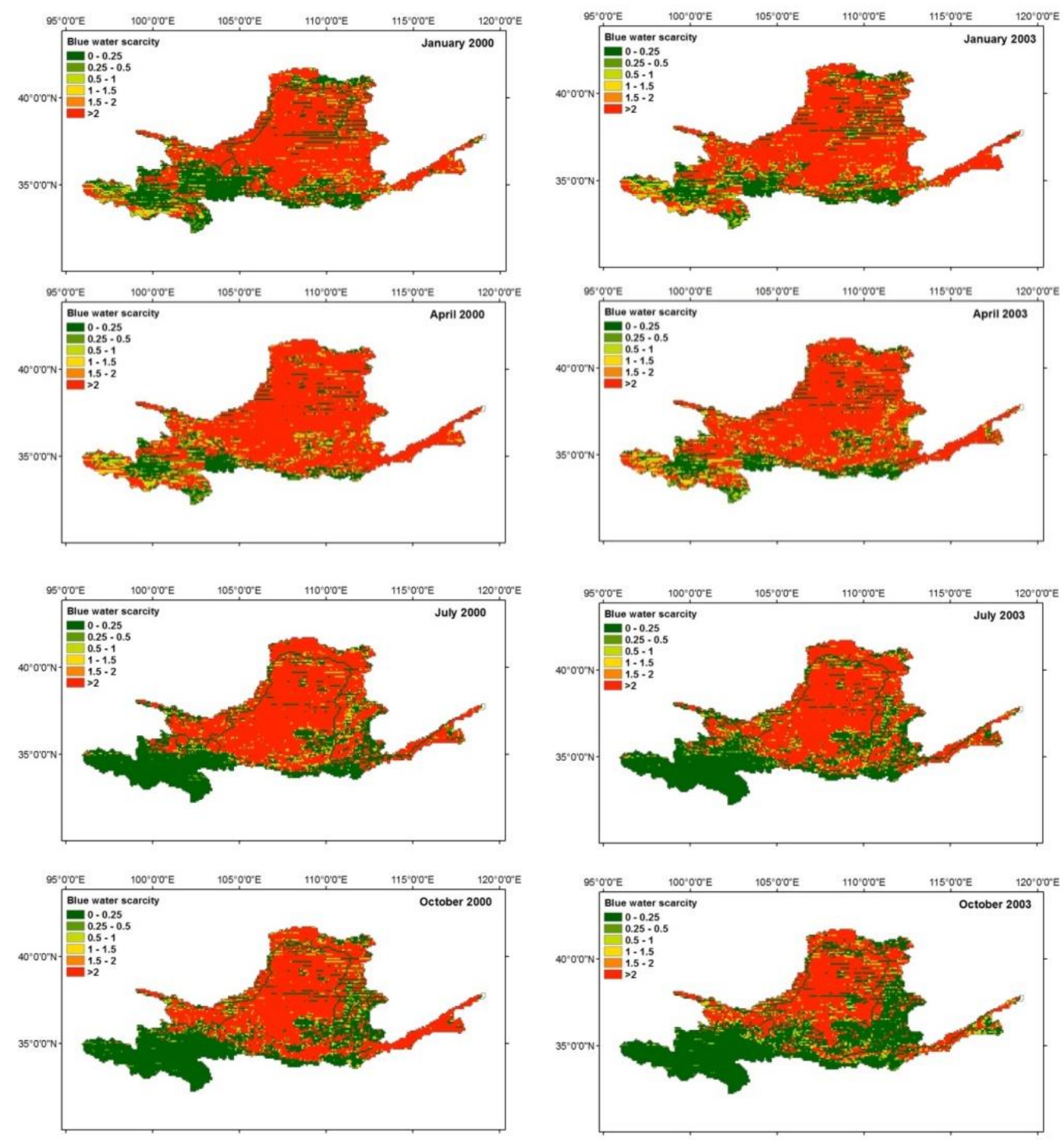

Figure 3.9 Monthly blue water scarcity in the Yellow River Basin in the months of January, April, July and October in a dry year (2000) and a wet year (2003). 


\subsubsection{Discussion}

The current study has been able to assess the inter- and intra-annual variation of the WF of crop production and the blue water scarcity over a few decades at a high spatial resolution in the YRB. Comparing the estimated blue and green WFs in total terms (in $\mathrm{m}^{3} \mathrm{y}^{-1}$ ) (averaged for the period 1996-2005) with Mekonnen and Hoekstra (2011) shows that the blue WF estimated in the current study agrees better (by 3\% lower) to the estimations by Mekonnen and Hoekstra (2011) than the green (by 33\% lower) and total WF (26\% lower). The current total blue WF in the YRB is 4\% higher than the assessment by Cai and Rosegrant (2004) (for the year 1995). Green-blue WFs per tonne of crop were compared with three studies on the YRB (Cai et al., 2011; Mekonnen and Hoekstra, 2011; Zhuo et al., 2014) as shown in Figure 3.10. Differences are mostly within the range of $\pm 30 \%$, which has been reported as the uncertainty range for WF estimates generated from input uncertainties (Zhuo et al., 2014). The comparison between current study with Mekonnen and Hoekstra (2011) and Zhuo et al. (2014) on green, blue and grey WFs of considered crops in the YRB were listed in Table 3.5. The models used and assumptions made in different studies may enhance the level of differences among WF studies. For example, our estimation on the green WF of rapeseed was more than two times the value from Mekonnen and Hoekstra (2011), because they calibrated the crop yield at national level while in the current study the calibration was at provincial level, and the rapeseed productivity in the YRB is lower than the national average level. Although we used the same input climate data sources as Zhuo et al. (2014), our estimates on the consumptive WF per unit of crop are lower because of the different assumptions on initial soil water content: Zhuo et al. (2014) assumed initial soil water content to be at its maximum, i.e. at soil water holding capacity, while in the current study we estimated initial soil water content based on the soil history before planting. The grey WF of crops presented in current study was much larger than values in the previous study (Mekonnen and Hoekstra, 2011), which can be explained by the fact that (i) we considered manure fertilizer in grey WF estimation, which was not considered in the the previous study and (ii) we used a very stricter assumption on the difference between the maximum allowable and natural $\mathrm{N}$ concentration ("c $\mathrm{c}_{\max }-\mathrm{c}_{\text {nat }}$ " in Eq.3.6) of $0.8 \mathrm{mg}^{-1}$ in current study versus $10 \mathrm{mg} \mathrm{l}^{-1}$ in Mekonnen and Hoekstra (2011). The current total grey WF of $193 \mathrm{~m}^{3} \mathrm{y}^{-1}$ 
(2002-2009) of was 53\% smaller than the estimate by Mekonnen and Hoekstra (2015) (2002-2010), given that we used a smaller leaching-runoff fraction of $\mathrm{N}$ (" $\alpha$ " in Eq.3.6) of 0.1 instead of 0.18 (Mekonnen and Hoekstra, 2015) and we only focus on agriculture while the previous study also included industry and domestic sector.

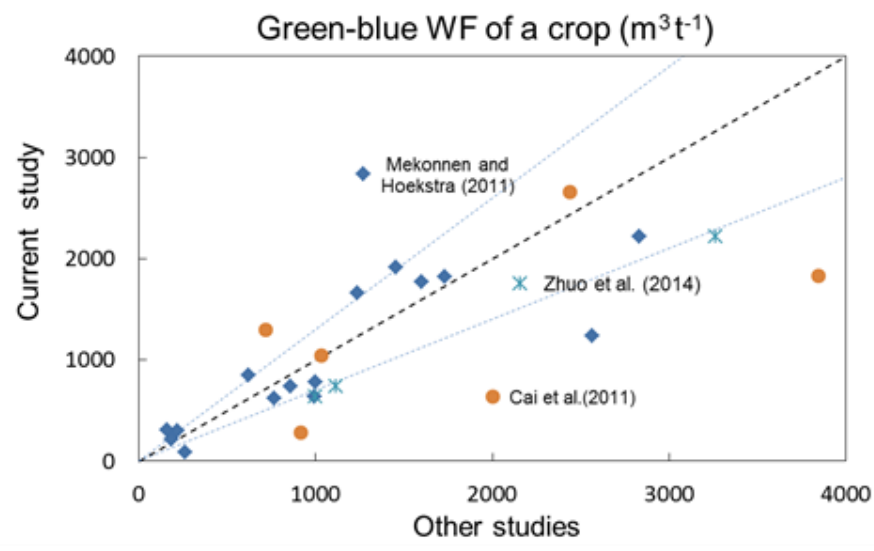

Figure 3.10 Comparison of estimated water footprints (WF) of crops with results from previous studies. Each data point refers to the WF of a crop. Period: 1996-2005 for Mekonnen and Hoekstra (2011) and Zhuo et al. (2014), and 2000-2009 for Cai et al. (2011).

Table 3.5 Comparison between current study and previous studies on green, blue and grey water footprint of crops in the Yellow River Basin. Period: 1996-2005.

\begin{tabular}{|c|c|c|c|c|c|c|c|c|}
\hline \multirow[b]{2}{*}{ Crop } & \multicolumn{2}{|c|}{ Green $W F\left(m^{3} t^{-1}\right)$} & \multicolumn{3}{|c|}{ Blue WF $\left(m^{3} t^{-1}\right)$} & \multicolumn{3}{|c|}{ Grey WF $\left(m^{3} t^{-1}\right)$} \\
\hline & $\begin{array}{l}\text { Current } \\
\text { study }\end{array}$ & $\begin{array}{c}\text { Mekonnen } \\
\text { and } \\
\text { Hoekstra } \\
(2011)\end{array}$ & $\begin{array}{l}\text { Zhuo } \\
\text { et al. } \\
\text { (2014) }\end{array}$ & $\begin{array}{l}\text { Current } \\
\text { study }\end{array}$ & $\begin{array}{c}\text { Mekonnen } \\
\text { and } \\
\text { Hoekstra } \\
(2011)\end{array}$ & $\begin{array}{l}\text { Zhuo } \\
\text { et al. } \\
\text { (2014) }\end{array}$ & $\begin{array}{c}\text { Current } \\
\text { study }\end{array}$ & $\begin{array}{c}\text { Mekonnen } \\
\text { and } \\
\text { Hoekstra } \\
(2011)\end{array}$ \\
\hline Wheat & 1241 & 702 & 1955 & 510 & 532 & 203 & 463 & 313 \\
\hline Rice & 414 & 510 & 558 & 225 & 482 & 440 & 5164 & 215 \\
\hline Maize & 542 & 745 & 816 & 195 & 113 & 294 & 7682 & 293 \\
\hline Sorghum & 731 & 960 & & 45 & 35 & & 10771 & 113 \\
\hline Millet & 1383 & 1568 & & 89 & 30 & & 4993 & 222 \\
\hline Barely & 789 & 587 & & 61 & 32 & & 2245 & 143 \\
\hline Soybean & 1626 & 2370 & 2130 & 482 & 459 & 163 & 11075 & 241 \\
\hline Potato & 279 & 205 & & 15 & 15 & & 1002 & 102 \\
\hline Sweet potato & 36 & 257 & & 57 & 5 & & 1265 & 64 \\
\hline Cotton & 1205 & 1386 & & 494 & 343 & & 3366 & 601 \\
\hline
\end{tabular}




\begin{tabular}{lcccccc} 
Sugar beet & 306 & 159 & 0 & 0 & 1578 & 97 \\
Groundnut & 1621 & 1347 & 296 & 108 & 1080 & 262 \\
Sunflower & 1096 & 2301 & 145 & 264 & 6106 & 467 \\
Rapeseed & 2832 & 1272 & 0 & 0 & 6617 & 532 \\
Tomato & 198 & 179 & 19 & 5 & 1631 & 106 \\
Apple & 563 & 745 & 72 & 23 & 645 & 286 \\
\hline
\end{tabular}

The current study focused on the YRB, but the method used, combining data from climate observations, hydrological models and national statistics, can be applied to other basins as well. Of course, our study is based on a number of limitations. First of all, not all crops were included, although the crops included were responsible for $93 \%$ of total crop production in 2009. Also, the WF of forestry and animal husbandry is not included in our simulations. On the other hand, the effects of reservoirs and inter-basin water transfers (the South to North Water Transfer Project) on the temporal and spatial patterns of blue water availability were not considered in the current assessment. Given the fact that blue water withdrawal from reservoirs or transfer projects can make up the blue water shortage in dry months, the maximum sustainable blue WF may have been under-estimated and the blue water scarcity over-estimated for some places and months within the basin. However, the presented results on blue water scarcity under natural background condition, at high spatial and temporal resolution, provide valuable information for improving blue water management (i.e. how to distribute the withdrawals from reservoirs and water transfer projects). By focussing on blue water scarcity, we excluded an assessment of green water scarcity and the effect of grey WFs on resultant water pollution levels throughout the basin.

Even though based on the most recent insights (Richter et al., 2012), the assumed environmental flow requirement ( $80 \%$ of natural runoff) may seem too strict and be the reason for the high water scarcity in the basin. We tested the sensitivity of our water scarcity result by computing scarcity also when assuming an environmental flow requirement of $37 \%$ of natural runoff (Cai and Rosegrant, 2004; Smakhtin et al., 2004a) or 55\% of natural runoff (Yang et al., 2009). We found that although the number of months facing moderate to severe blue water scarcity reduced from the current seven months (January-July) to four months 
(March-June) with the lowest standard (37\%), the spatial distribution of blue water scarcity did not change much even in the wettest month in a wet year, with more than half of the basin was still under significant to severe blue water scarcity.

\subsection{Conclusions}

We assessed the inter-annual variation of WF of crops in the YRB for 1961-2009 with a daily time step, as well as the blue water scarcity for the period 1978-2009 at monthly basis. The total blue WF of crop production, contributing $25 \%$ to the total green-blue WF as a long-term average, increased by $37 \%$ from the 1960s till the 2000s, while the green WF grew by $14 \%$. The $\mathrm{N}$ - and P-related grey WFs increased by factors of 24 and 36, respectively, along with the increased use of fertilizers. Blue WFs of crop production were larger in years with lower water availability. The increase of the basin's total blue WF in the study period mainly happened in the upper reach, and the share of the upper reach in the basin's total blue WF exceeds the share of the lower reach since 1998. Green and blue WFs of crops per tonne reduced significantly (with a factor four for cereal crops) due to improved yields, but the benefits of increased water productivity were completely offset by the five-fold increase in crop production. Related to the expansion of the irrigated area, the proportion of the blue WF in the total green-blue WF increased. Grey WFs per hectare grew quicker than yields, with the net effect that grey WFs per tonne of crop increased.

The analysis of blue water scarcity in the YRB showed that the assessment of water scarcity gives more insight when carried out at high spatial resolution level and monthly basis than when done at basin scale and annual basis. But even at basin scale, the annual total blue WF was 19 to $52 \%$ of annual natural runoff, and $31 \%$ as a long-term average. The annual figures, however, hide the fact that the period with relatively large blue WF (March-July) does not coincide with the period with largest runoff (June-October). On average, the basin faces moderate to severe blue water scarcity during seven months of the year (January-July), of which five months severe (generally March-July). The detailed spatial analysis reveals that the eastern part of the upper reach, the northern part of the middle reach, and most of the lower reach suffer severe blue water scarcity throughout the year. Even in the wettest month in a wet year, about half of the area of the YRB still suffered severe blue water scarcity, 
especially in the basin's northern part.

Despite the severe water scarcity in the YRB, the Chinese government plans to expand the irrigated cropland area by $12 \%$ of the current till the year of 2030 (YRCC, 2013). Therefore the basin is bound to continue facing severe water scarcity in the years to come. Further improvements in crop water productivity will be necessary to prevent aggravation of the water scarcity problem. Water productivities can be improved through increasing yields, reducing non-beneficial evapotranspiration and enhancing effective use of rainfall (Mekonnen and Hoekstra, 2014). Other options include optimizing crop planting dates and choosing crops and varieties that yield more nutritional value per drop of water. Reducing fertilizer use through precision farming will be key in reducing water pollution. In addition, increasing crop imports instead of producing locally within the YRB during dry years will also help saving water (Chapagain et al., 2006; Konar et al., 2011). 


\title{
4. The Effect of Inter-annual Variability of Consumption, Production, Trade and Climate on Crop-related Green and Blue Water Footprints and Inter-regional Virtual Water Trade in China (1978-2008)
}

\begin{abstract}
Previous studies into the relation between human consumption and indirect water resources use have unveiled the remote connections in virtual water (VW) trade networks, which show how communities externalize their water footprint (WF) to places far beyond their own region, but little has been done to understand variability in time. This study quantifies the effect of inter-annual variability of consumption, production, trade and climate on WF and VW trade, using China over the period 1978-2008 as a case study. Evapotranspiration, crop yields and green and blue WFs of crops are estimated at a $5 \times 5$ arc min resolution for 22 crops, for each year in the study period, thus accounting for climate variability. The results show that crop yield improvements during the study period helped to reduce the national average WF of crop consumption per capita by $23 \%$, with a decreasing contribution to the total from cereals and increasing contribution from oil crops. The total consumptive WFs of national crop consumption and crop production, however, grew by $6 \%$ and $7 \%$, respectively. By 2008, 28\% of total water consumption in crop fields in China served the production of crops for export to other regions and, on average, 35\% of the crop-related WF of a Chinese consumer was outside its own province. Historically, the net VW within China was from the water-rich South to the water-scarce North, but intensifying North-to-South crop trade reversed the net VW flow since 2000, which amounted 6\% of North's WF of crop production in 2008. South China thus gradually became dependent on food supply from the water-scarce North. Besides, during the whole study period, China's domestic inter-regional VW flows went dominantly from areas with a relatively large to areas with a relatively small blue WF per unit of crop, which in 2008 resulted in a trade-related blue water loss of $7 \%$ of
\end{abstract}

3 Chapter is based on: Zhuo, Mekonnen and Hoekstra (2016a) Water Research 94, 73-85. 
the national total blue WF of crop production. The case of China shows that domestic trade, as governed by economics and governmental policies rather than by regional differences in water endowments, determines inter-regional water dependencies and may worsen rather than relieve the water scarcity in a country. 


\subsection{Introduction}

Since the beginning of this millennium the body of scientific literature on water footprint and virtual water trade assessment is expanding exponentially, as witnessed by the number of papers published on the topic in Web of Science. The water footprint (WF), as a multi-dimensional measure of freshwater used both directly and indirectly by a producer or a consumer, enables to analyse the link between human consumption and the appropriation of water to produce the products consumed(Hoekstra, 2013). The consumptive WF of producing a crop includes a green and blue component, referring to consumption of rainfall and irrigation water respectively, thus enabling the broadening of perspective on water resources as proposed by (Falkenmark and Rockström, 2004). The consumptive WF is distinguished from the degradative WF, the so-called grey WF, which represents the volume of water required to assimilate pollutants entering freshwater bodies. The WF of human consumption within a certain geographic area consists of an internal WF, referring to the WF within the area itself for making products that are consumed within the area, and an external WF, referring to the WF in other areas for making products imported by and consumed within the geographic area considered (Hoekstra et al., 2011). Thus, trade in water-intensive commodities like crops results into so-called virtual water (VW) flows between exporting and importing regions (Hoekstra, 2003). Crop trade saves water resources for an administrative region if it imports water-intensive crops instead of producing them domestically (Chapagain et al., 2006).

WF and VW trade studies have been carried out for geographies at different scales, from the city (Zhang et al., 2011) to the globe (Hoekstra and Mekonnen, 2012). Despite the vast body of literature, little attention has been paid to the annual variability and long-term changes of WFs and VW flows as a result of climate variability and structural changes in the economy. Most work thus far focussed on employing different models and techniques to assess WFs and VW flows, considering a specific year or short period of years. The effects of long-term changes in spatial patterns of production, consumption, trade and climate on WFs and VW flows have hardly been studied. This is paramount, though, for understanding how human pressure on water resources develops over time and how changing trade patterns influence inter-regional water dependencies. 
The objective of the current study is to quantify the effect of inter-annual variability of consumption, production, trade and climate on crop-related green and blue WFs and inter-regional VW trade, using China over the period 1978-2008 as a case study. First, we assess the historical development of the green and blue WFs related to crop consumption in China, per province. Second, we estimate, accounting for the climate variability within the period considered, the green and blue WFs related to crop production, at a $5 \times 5$ arc min resolution, year by year, crop by crop. Third, we quantify the annual inter-regional VW flows based on provincial crop trade balances for each crop. Finally, we estimate national water savings as a result of international and inter-regional crop trade. We consider twenty-two primary crops (Table 4.2), which covered $83 \%$ of national harvested crop area in 2009 (NBSC, 2013) and 97\% and 78\% of the total blue and green WF of Chinese crop production in the period 1996-2005, respectively (Mekonnen and Hoekstra, 2011). In this study we exclude the grey WF of crops because of our focus on inter-annual variability and the fact that variability in climate plays a role particularly in estimating green and blue WFs, not in estimating grey WFs. We focus on the direct green and blue WF of crop growing in the field, thus excluding the indirect WF of other inputs into crop production, like the WF of machineries and energy used. The study area is Mainland China, which consists of 31 provinces and can be grouped into eight regions (Figure 4.1).

China is facing severe water scarcity (Jiang, 2009). Since the economic reforms in 1978, the Chinese people consume increasing levels of oil crops, sugar crops, vegetables and fruits (Liu and Savenije, 2008). Chinese crop consumption per capita rose by a factor 2.1 over the period 1978-2008 (FAO, 2014b), while China's population grew from 0.96 to 1.31 billion (NBSC, 2013). In order to meet the increasing food demand, China's crop production grew by a factor 2.8 from 1978 to 2008 (FAO, 2014b), with an increase of only 4\% in total harvested area, but a $31 \%$ growth in irrigated area. The expansion of the irrigated area occurred mainly $(77 \%)$ in the water-scarce North, which now has $51 \%$ of the national arable land, but only $19 \%$ of the national blue water resources (Zhang et al., 2009; Wu et al., 2010). Agriculture is the biggest water user in China, responsible for $63 \%$ of national total blue water withdrawals (MWR, 2014) and $88 \%$ of the total WF within China (Hoekstra and Mekonnen, 2012). Currently, the Yellow River basin in the North suffers moderate to severe 
blue water scarcity during seven months of the year, mostly driven by agricultural water use (Zhuo et al., 2016b). The Yongding He Basin in northern China, a densely populated basin serving water to Beijing, faces severe water scarcity all year long (Hoekstra et al., 2012). It is estimated that about $64 \%$ of China's total population, mainly from the North, regularly faces severe blue water scarcity (Mekonnen and Hoekstra, 2016). The competition between different sectors over water resources has become severe (Zhu et al., 2013), which has led to the adoption of the No. 1 Document by the State Council of China (SCPRC, 2010), announcing a four trillion CNY ( US\$600 billion) investment over ten years to guarantee water supplies through the improvement of water supply infrastructure. This includes the construction of new reservoirs, drilling of wells, and implementation of inter-basin water transfer projects (Gong et al., 2011; Yu et al., 2011), as well as targets to increase water productivity.

Today, China is the country with the largest WF related to crop consumption and the second largest WF related to crop production (Hoekstra and Mekonnen, 2012). Furthermore, China has substantive VW import through crop imports (Dalin et al., 2014). At present, net VW trade through crop trade is from the drier North to the wetter South (Ma et al., 2006; Cao et al., 2011). In 2005, China's domestic food trade resulted in national net water saving overall, but a net loss of blue water (Dalin et al., 2014), as a result of differences in WF of crops $\left(\mathrm{m}^{3}\right.$ $\mathrm{t}^{-1}$ ) among trading provinces (Mekonnen and Hoekstra, 2011).

There have been quite a number of previous studies on the WF of Chinese crop consumption (Hoekstra and Chapagain, 2007b; Hoekstra and Chapagain, 2008; Liu and Savenije, 2008; Ge et al., 2011; Mekonnen and Hoekstra, 2011; Hoekstra and Mekonnen, 2012; Cao et al., 2015), the WF of Chinese crop production (Hoekstra and Chapagain, 2007b; Hoekstra and Chapagain, 2008; Fader et al., 2010; Liu and Yang, 2010; Siebert and Doll, 2010; Ge et al., 2011; Mekonnen and Hoekstra, 2011; Cao et al., 2014b; a), on China's international VW imports and exports associated with crop trade (Hoekstra and Hung, 2005; Hoekstra and Chapagain, 2007b; Liu et al., 2007; Hoekstra and Chapagain, 2008; Fader et al., 2011; Dalin, 2012; Hoekstra and Mekonnen, 2012; Chen and Chen, 2013; Shi et al., 2014)and on VW trade flows within China (Ma et al., 2006; Guan and Hubacek, 2007; Wu et al., 2010; Cao et 
al., 2011; Han and Sun, 2013; Sun et al., 2013b; Dalin et al., 2014; Feng et al., 2014; Wang et al., 2014; Zhang and Anadon, 2014; Zhao and Chen, 2014; Fang and Chen, 2015; Jiang et al., 2015; Zhao et al., 2015). Despite all those studies, analyses of inter-annual variability and long-term changes in spatial WF and VW trade patterns are rare, not only in studies for China but in general. While in Chapter 3 we show the inter-annual variations in WFs of crop production as well as inter-annual variation of blue water scarcity (with a focus on the Yellow River basin), in the current study we also consider inter-annual variability in WFs of crop consumption and in inter-regional and international VW trade (for China as a whole).

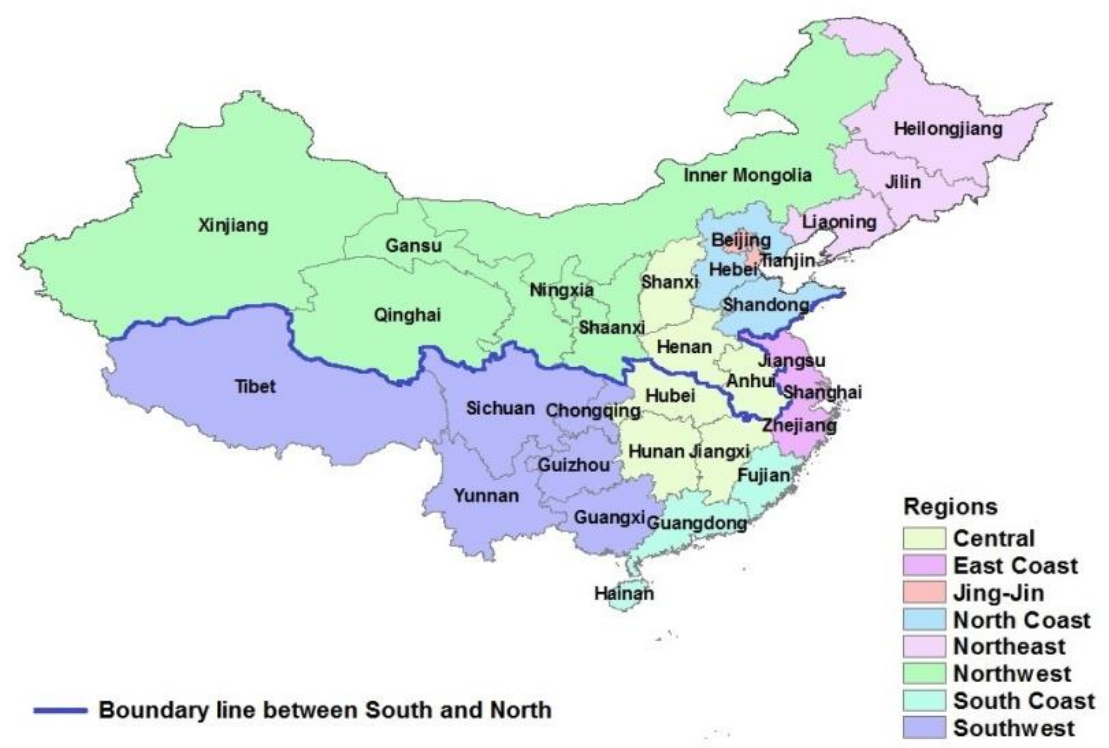

Figure 4.1 Provinces and regions of mainland China.

\subsection{Method and data}

The annual green and blue WFs of crop consumption (in $\mathrm{m}^{3} \mathrm{y}^{-1}$ ) were estimated per crop per year at provincial level based on the bottom-up approach (Hoekstra et al., 2011). The WF related to consumption of a crop $\left(\mathrm{m}^{3} \mathrm{y}^{-1}\right)$ was calculated per year by multiplying the provincial crop consumption volume $\left(\mathrm{t} \mathrm{y}^{-1}\right)$ with the WF of the crop for the province $\left(\mathrm{m}^{3} \mathrm{t}^{-1}\right)$. Crop consumption volumes per capita were obtained from the Supply and Utilization Accounts expressed in crops primary equivalent of FAO (2014b). We assumed consumption 
per capita data the same for all provinces. For edible crops, we took the sum of the "food" and "food manufactured" columns and added an amount representing seed and waste. Regarding the latter amount, we took a part of the utilization for seed and waste based on the utilization of crops for food and food manufactured relative to the utilization of crops for feed. For cotton and tobacco, we took the "other use" column as consumed quantities. The WF of crops per province was calculated as:

$\mathrm{WF}_{\text {prov }}[p]=\frac{\mathrm{P}_{\text {prov }}[p] \times \mathrm{WF}_{\text {prod,prov }}[p]+\sum_{\mathrm{e}}\left(\mathrm{I}_{\mathrm{e}}[p] \times \mathrm{WF}_{\text {prod, } \mathrm{e}}[p]\right)}{\mathrm{P}_{\text {prov }}[p]+\sum_{\mathrm{e}} \mathrm{I}_{\mathrm{e}}[p]}$

in which $\mathrm{P}_{\text {prov }}[p]\left(\mathrm{t} \mathrm{y}^{-1}\right)$ represents the production quantity of crop $p, \mathrm{I}_{\mathrm{e}}[p]\left(\mathrm{t}^{-1}\right)$ the imported quantity of crop $p$ from exporting place $e$ (other regions in China or other countries), $\mathrm{WF}_{\text {prod,prov }}[p]\left(\mathrm{m}^{3} \mathrm{t}^{-1}\right)$ the specific WF of crop production in the province, and $\mathrm{WF}_{\text {prod,e }}[p]\left(\mathrm{m}^{3}\right.$ $\left.\mathrm{t}^{-1}\right)$ the WF of the crop as produced in exporting place $e$.

The green and blue WFs of crop production were estimated year by year at $5 \times 5$ arc min

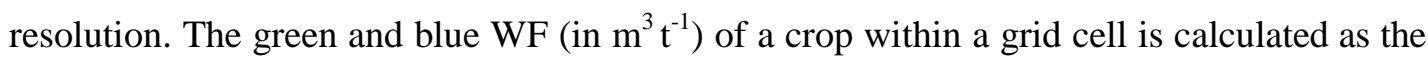
actual green and blue evapotranspiration $\left(\mathrm{ET}, \mathrm{m}^{3} \mathrm{ha}^{-1}\right)$ over the growing period divided by the crop yield $\left(\mathrm{Y}, \mathrm{t} \mathrm{ha}^{-1}\right)$. ET and $\mathrm{Y}$ were simulated per crop per grid per year at daily basis using the plug-in version of FAO's crop water productivity model AquaCrop version 4.0 (Steduto et al, 2009; Reas et al., 2009; Hsiao et al., 2009). The separation of green and blue ET was carried out by tracking the daily green and blue soil water balances based on the contribution of rainfall and irrigation, respectively, following Chapter 3.

Inter-regional VW flows $\left(\mathrm{m}^{3} \mathrm{y}^{-1}\right)$ related to crop trade were calculated per year by multiplying the inter-regional crop trade flows $\left(\mathrm{t}^{-1}\right)$ with the WF of the crop $\left(\mathrm{m}^{3} \mathrm{t}^{-1}\right)$ in the exporting region. Since inter-regional crop trade statistics are not available, we took the following steps:

1) The provincial crop trade balance or net import of a crop $\left(\mathrm{t} \mathrm{y}^{-1}\right)$ was estimated as the total provincial crop utilization minus the provincial crop production. The national use of a crop for direct and manufactured food as given by FAO (2014b) was distributed 
over the provinces based on provincial populations. The national use of a crop for feed was distributed over provinces proportional to the national livestock units (LU) per province. $\mathrm{LU}$ is a reference unit which facilitates the aggregation of different livestock types to a common unit, via the use of a 'livestock unit coefficient' obtained by converting the livestock body weight into the metabolic weight by an exchange ratio (FAO, 2005). We used the livestock unit coefficients for East Asia from Chilonda and Otte (2006): 0.65 for cattle, 0.1 for sheep and goats, 0.25 for pigs, 0.5 for asses, 0.65 for horses, 0.6 for mules, 0.8 for camels, and 0.01 for chickens. Finally, we downscale national variations in crop stock to provincial level by assuming provincial stock variations proportional to the provincial share in national production.

2) We assume that international crop imports and exports relate to the provinces with deficit and surplus of the crop, respectively (following Ma et al., 2006). Further we assume that crop-deficit provinces primarily receive from crop-surplus provinces within the same region and subsequently - if insufficient surplus within the region itself - from other crop-surplus regions.

3) A crop-deficit region is assumed to import the crop preferentially from the crop-surplus region which has the highest agricultural export values to the crop-deficit region, according to the multi-regional input-output tables of the agricultural sector for the years 1997 (SIC, 2005), 2002 and 2007(Zhang and Qi, 2011). How source regions supply deficit regions is determined in a few subsequent rounds. The source regions per region per allocation round are listed in Table 4.1. We assume that in each round the crop source regions supply crops to the deficit regions proportionally to their deficit.

The total crop-related net VW import $\left(\mathrm{m}^{3} \mathrm{y}^{-1}\right)$ of a province is equal to the international net VW import plus the inter-regional net VW import of the province. The WFs $\left(\mathrm{m}^{3} \mathrm{t}^{-1}\right)$ of crops imported from abroad were obtained from Mekonnen and Hoekstra (2011), assuming constant green and blue WFs of imported crops per source country. The provincial net VW export related to a certain crop export is calculated by multiplying the net crop export volume $\left(\mathrm{t}^{-1}\right)$ with the WF $\left(\mathrm{m}^{3} \mathrm{t}^{-1}\right)$ of the crop in the province. 
Water savings through crop trade were estimated using the method of Chapagain et al. (2006). The international crop trade-related water saving of a province $\left(\mathrm{m}^{3} \mathrm{y}^{-1}\right)$ was calculated by multiplying the net international import volume of the province $\left(\mathrm{t}^{-1}\right)$ by the WF per tonne of the crop in the province $\left(\mathrm{m}^{3} \mathrm{t}^{-1}\right)$. The inter-regional crop trade-related water saving was estimated similarly, by multiplying the net inter-regional import volume of the province $\left(\mathrm{t}^{-1}\right)$ with the WF per tonne of the crop in the province $\left(\mathrm{m}^{3} \mathrm{t}^{-1}\right)$. If a specific crop is imported and not grown in the province itself at all, the national average WF per tonne of the crop was used. Overall trade-related water savings follow from the difference in the WF of a crop in the importing and exporting province (Hoekstra et al., 2011). When calculated trade-related water savings are negative, we talk about trade-related 'water losses', which refer to cases whereby crops are traded from a region with relatively low water productivity to a region with relatively high water productivity.

The GIS polygon for Chinese provinces was obtained from NASMG (2010). Provincial population statistics over the study period and numbers of the different livestock types were obtained from NBSC (2013), and data on China's international trade per crop (in $\mathrm{t}^{-1}$ ) from FAO (2014b). Data on monthly precipitation, reference evapotranspiration and temperature at $30 \times 30$ arc minute resolution were taken from Harris et al. (2014). Figure 4.2 shows the inter-annual variation of national average precipitation and reference evapotranspiration $\left(\mathrm{ET}_{0}\right)$ across China over the period 1978-2008. Data on irrigated and rain-fed areas for each crop at $5 \times 5$ arc-minute resolution were taken from Portmann et al. (2010). For crops not available in this source, we used Monfreda et al. (2008). Harvested areas and yields for each crop were scaled per year to fit the annual agriculture statistics at province level obtained from NBSC (2013). For crops not reported in NBSC (2013), we used FAO (2014b). Soil texture data were obtained from Dijkshoorn et al. (2008). For hydraulic characteristics for each type of soil, the indicative values provided by AquaCrop were used. Data on total soil water capacity were obtained from Batjes (2012). 
Table 4.1 Crop source regions per region for mainland China.

\begin{tabular}{|c|c|c|c|c|c|c|c|c|c|}
\hline & \multirow{2}{*}{ Region* } & \multirow{2}{*}{ Provinces } & \multicolumn{7}{|c|}{ Crop source regions per allocation round } \\
\hline & & & 1 & 2 & 3 & 4 & 5 & 6 & 7 \\
\hline $\mathrm{R} 1$ & Northeast (N) & Heilongjiang, Jilin, Liaoning & R3 & $\mathrm{R} 7$ & $\mathrm{R} 6$ & $\mathrm{R} 8$ & R5 & $\mathrm{R} 4$ & $\mathrm{R} 2$ \\
\hline $\mathrm{R} 2$ & Jing-Jin (N) & Beijing, Tianjin & R3 & $\mathrm{R} 7$ & $\mathrm{R} 1$ & $\mathrm{R} 6$ & $\mathrm{R} 8$ & R5 & $\mathrm{R} 4$ \\
\hline R3 & North Coast $(\mathrm{N})$ & Hebei, Shandong & $\mathrm{R} 7$ & $\mathrm{R} 1$ & R6 & $\mathrm{R} 8$ & $\mathrm{R} 2$ & R5 & $\mathrm{R} 4$ \\
\hline R4 & East Coast (S) & Jiangsu, Shanghai, Zhejiang & R6 & $\mathrm{R} 7$ & $\mathrm{R} 3$ & $\mathrm{R} 1$ & $\mathrm{R} 8$ & R5 & $\mathrm{R} 2$ \\
\hline R5 & South Coast (S) & Fujian, Guangdong, Hainan & $\mathrm{R} 6$ & $\mathrm{R} 8$ & $\mathrm{R} 7$ & R3 & $\mathrm{R} 1$ & R4 & $\mathrm{R} 2$ \\
\hline R6 & Central & $\begin{array}{l}\text { Shanxi (N), Henan (N), Anhui } \\
(\mathrm{N}) \text {, Hubei }(\mathrm{S}) \text {, Hunan (S), } \\
\text { Jiangxi (S) }\end{array}$ & R3 & $\mathrm{R} 7$ & $\mathrm{R} 1$ & R8 & R5 & R4 & $\mathrm{R} 2$ \\
\hline R7 & Northwest (N) & $\begin{array}{l}\text { Inner Mongolia, Shaanxi, } \\
\text { Ningxia, Gansu, Qinghai, } \\
\text { Xinjiang }\end{array}$ & R6 & R3 & $\mathrm{R} 8$ & $\mathrm{R} 1$ & R5 & R4 & $\mathrm{R} 2$ \\
\hline R8 & Southwest (S) & $\begin{array}{c}\text { Sichuan, Chongqing, } \\
\text { Guangxi, Yunnan, Guizhou, } \\
\text { Tibet }\end{array}$ & $\mathrm{R} 7$ & $\mathrm{R} 1$ & $\mathrm{R} 6$ & R3 & R5 & $\mathrm{R} 4$ & $\mathrm{R} 2$ \\
\hline
\end{tabular}

${ }^{*} \mathrm{~N}=$ North China; $\mathrm{S}=$ South China.

Inter-annual variation of precipitation \& $\mathrm{ET}_{0}$ in China (1978-2008)

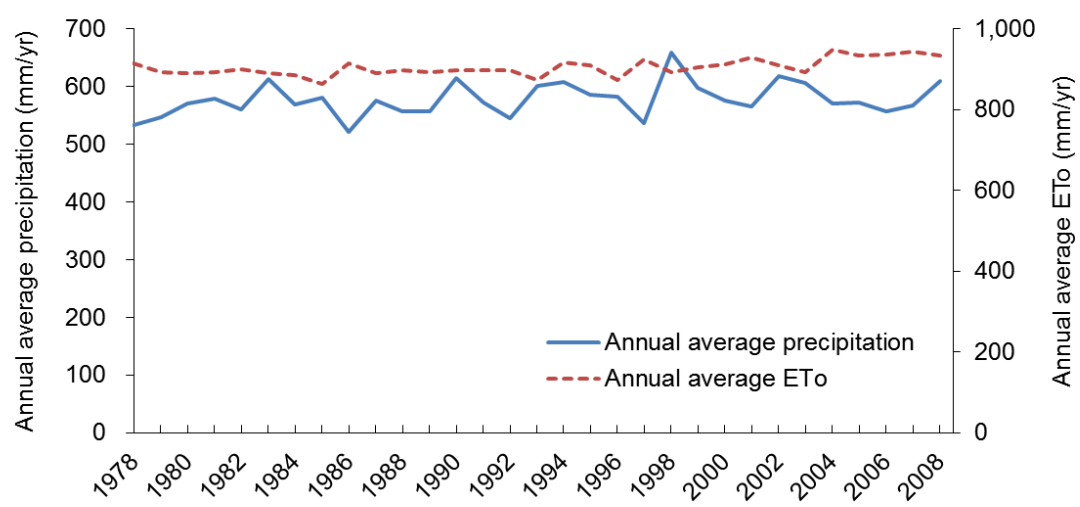

Figure 4.2 Inter-annual variation of national average precipitation and reference evapotranspiration (ETo) across China over the period 1978-2008. Data source: Harris et al. (2014). 


\subsection{Results}

\subsubsection{Water footprint of crop consumption}

Over the study period 1978-2008, Chinese annual per capita consumption of the 22 considered crops has grown by a factor 1.4 , from 391 to $559 \mathrm{~kg} \mathrm{cap}^{-1}$. The national average WF per capita related to crop consumption reduced by $23 \%$, from $625 \mathrm{~m}^{3} \mathrm{cap}^{-1}\left(149 \mathrm{~m}^{3} \mathrm{cap}^{-1}\right.$ blue WF) in 1978 to $481 \mathrm{~m}^{3} \mathrm{cap}^{-1}\left(94 \mathrm{~m}^{3} \mathrm{cap}^{-1}\right.$ blue WF) in 2008 (Figure 4.3), which was mainly due to the decline in the WF per tonne of crops (Table 4.2). The decline in the WF per tonne of crop resulted from improved crop yields within China as well as the expanded international import of crops from other countries with relatively small WF. The share of the WF related to the consumption of oil crops (soybean, groundnuts, sunflower and rapeseed) in the total consumptive WF per capita grew from $8 \%$ in 1978 to $21 \%$ in 2008 (Figure 4.3), as a result of the increased proportion of oil crops in Chinese consumption.

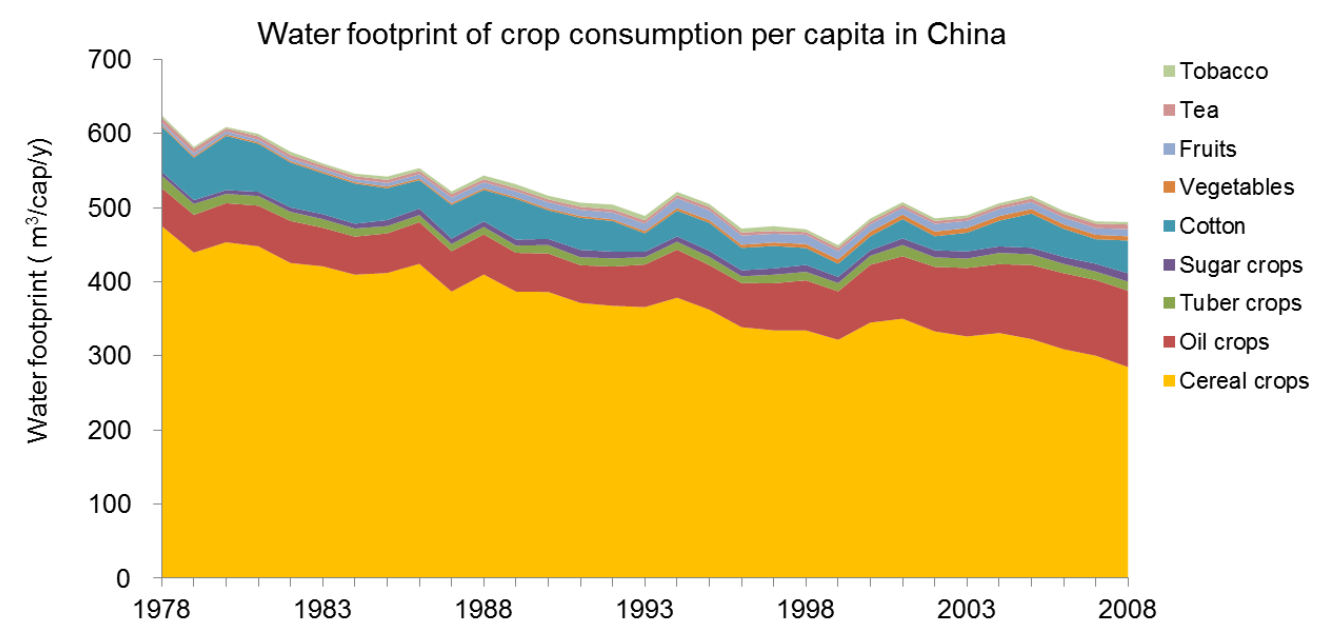

Figure 4.3 National average water footprint per capita $\left(m^{3} \operatorname{cap}^{-1} y^{-1}\right)$ related to crop consumption in China by crop group (lower graph). Period: 1978-2008. The figures represent crop consumption for food, thus excluding crop consumption for feed. 
Table 4.2 National average water footprint per tonne of crop consumed in China for the years 1978 and 2008.

\begin{tabular}{|c|c|c|c|c|c|c|}
\hline & \multicolumn{3}{|c|}{1978} & \multicolumn{3}{|c|}{2008} \\
\hline & Green WF & Blue WF & Total WF & Green WF & Blue WF & Total WF \\
\hline & $m^{3} t^{-1}$ & $m^{3} t^{-1}$ & $m^{3} t^{-1}$ & $m^{3} t^{-1}$ & $m^{3} t^{-1}$ & $m^{3} t^{-1}$ \\
\hline Wheat & 2080 & 817 & 2897 & 839 & 312 & 1151 \\
\hline Maize & 1412 & 121 & 1534 & 754 & 66 & 819 \\
\hline Rice & 1486 & 615 & 2101 & 961 & 384 & 1345 \\
\hline Sorghum & 1080 & 88 & 1168 & 714 & 45 & 759 \\
\hline Barley & 839 & 558 & 1397 & 832 & 198 & 1030 \\
\hline Millet & 2042 & 184 & 2225 & 1811 & 133 & 1945 \\
\hline Potato & 264 & 7 & 271 & 189 & 7 & 196 \\
\hline Sweet potato & 74 & 40 & 114 & 67 & 21 & 88 \\
\hline Soybean & 3718 & 677 & 4395 & 2024 & 110 & 2134 \\
\hline Groundnut & 3165 & 395 & 3560 & 1345 & 191 & 1536 \\
\hline Sunflower seed & 2177 & 289 & 2466 & 1087 & 184 & 1270 \\
\hline Rapeseed & 4292 & 0 & 4292 & 1736 & 0 & 1736 \\
\hline Seed cotton & 5093 & 539 & 5632 & 1278 & 503 & 1781 \\
\hline Sugar cane & 208 & 3 & 211 & 120 & 1 & 121 \\
\hline Sugar beet & 372 & 0 & 372 & 66 & 0 & 66 \\
\hline Spinach & 100 & 8 & 107 & 79 & 4 & 83 \\
\hline Tomato & 126 & 3 & 129 & 68 & 2 & 70 \\
\hline Cabbage & 181 & 15 & 196 & 130 & 7 & 137 \\
\hline Apple & 1367 & 157 & 1524 & 314 & 39 & 353 \\
\hline Grape & 1011 & 304 & 1314 & 316 & 104 & 421 \\
\hline Tea & 33518 & 226 & 33744 & 8517 & 144 & 8662 \\
\hline Tobacco & 2381 & 84 & 2465 & 1633 & 13 & 1646 \\
\hline
\end{tabular}

National averages are calculated weighing the water footprints of domestically produced and imported crops.

Due to differences in the WF (in $\mathrm{m}^{3} \mathrm{t}^{-1}$ ) of the consumed crops in the different provinces, there were differences among provinces in terms of WFs per capita, ranging from 367 to $604 \mathrm{~m}^{3} \mathrm{cap}^{-1} \mathrm{y}^{-1}$ for the total consumptive WF and from 29 to $228 \mathrm{~m}^{3} \mathrm{cap}^{-1} \mathrm{y}^{-1}$ for the blue 
WF in the year 2008. Fourteen provinces, mostly located in Southwest, Northeast, North Coast and East Coast, have a WF per capita below the national average (Figure 4.4). The three provinces with the largest WF per capita related to crop consumption in 2008 were Ningxia $\left(604 \mathrm{~m}^{3}\right.$ cap $\left.^{-1} \mathrm{y}^{-1}\right)$, Guangxi $\left(587 \mathrm{~m}^{3} \mathrm{cap}^{-1} \mathrm{y}^{-1}\right)$ and Guangdong (586 $\left.\mathrm{m}^{3} \mathrm{cap}^{-1} \mathrm{y}^{-1}\right)$. Chongqing had the smallest WF per capita $\left(367 \mathrm{~m}^{3} \mathrm{cap}^{-1} \mathrm{y}^{-1}\right)$. Provinces with a blue WF per capita smaller than the national average are mostly located in Southwest, Northeast and East Coast. The three provinces with the largest blue WF per capita in 2008 are all located in the semi-arid Northwest: Inner Mongolia $\left(228 \mathrm{~m}^{3} \operatorname{cap}^{-1} \mathrm{y}^{-1}\right)$, Xinjiang $\left(214 \mathrm{~m}^{3} \mathrm{cap}^{-1} \mathrm{y}^{-1}\right)$ and Ningxia $\left(213 \mathrm{~m}^{3} \operatorname{cap}^{-1} \mathrm{y}^{-1}\right)$. Anhui had the smallest blue WF per capita $\left(29 \mathrm{~m}^{3} \operatorname{cap}^{-1} \mathrm{y}^{-1}\right)$.
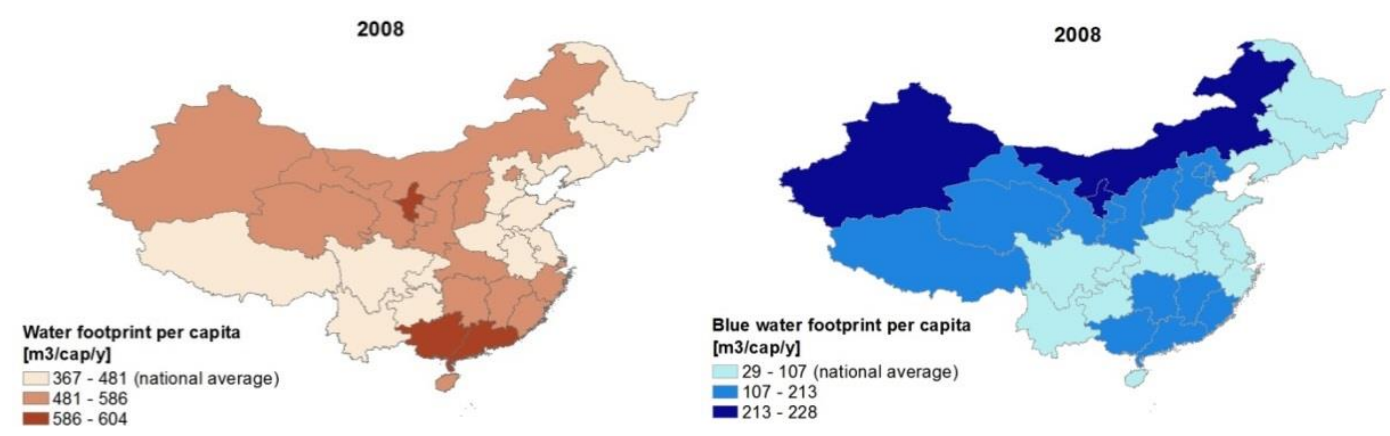

Figure 4.4 China's provincial average total and blue water footprints per capita $\left(m^{3} \operatorname{cap}^{-1} y^{-1}\right)$ related to crop consumption in the year of 2008. The figures refer to crop consumption for food, thus excluding crop consumption for feed.

Although the total consumption of the 22 considered crops doubled between 1978 and 2008, with $37 \%$ of population growth in China, the national WF related to crop consumption increased only by $6 \%$, from 599 to 632 billion $\mathrm{m}^{3} \mathrm{y}^{-1}$ (Figure 4.5), thanks to the decline in the WF of crops $\left(\mathrm{m}^{3} \mathrm{t}^{-1}\right)$. The share of North China in the total national consumptive WF of crop consumption decreased from 48 to $44 \%$ over the study period, amongst other driven by the slightly faster population growth in the South. At provincial level, Shanghai had the largest increase in the WF of crop consumption, a 2.3 times increase over the study period 
(from 4.6 to 10.5 billion $\mathrm{m}^{3} \mathrm{y}^{-1}$ ), followed by Beijing with a 2.0 times increase (from 4.4 to 8.6 billion $\mathrm{m}^{3} \mathrm{y}^{-1}$ ). This was mainly driven by the doubling of the population in these two megacities (from 11.0 to 21.4 million in Shanghai and from 8.7 to 17.7 million in Beijing).
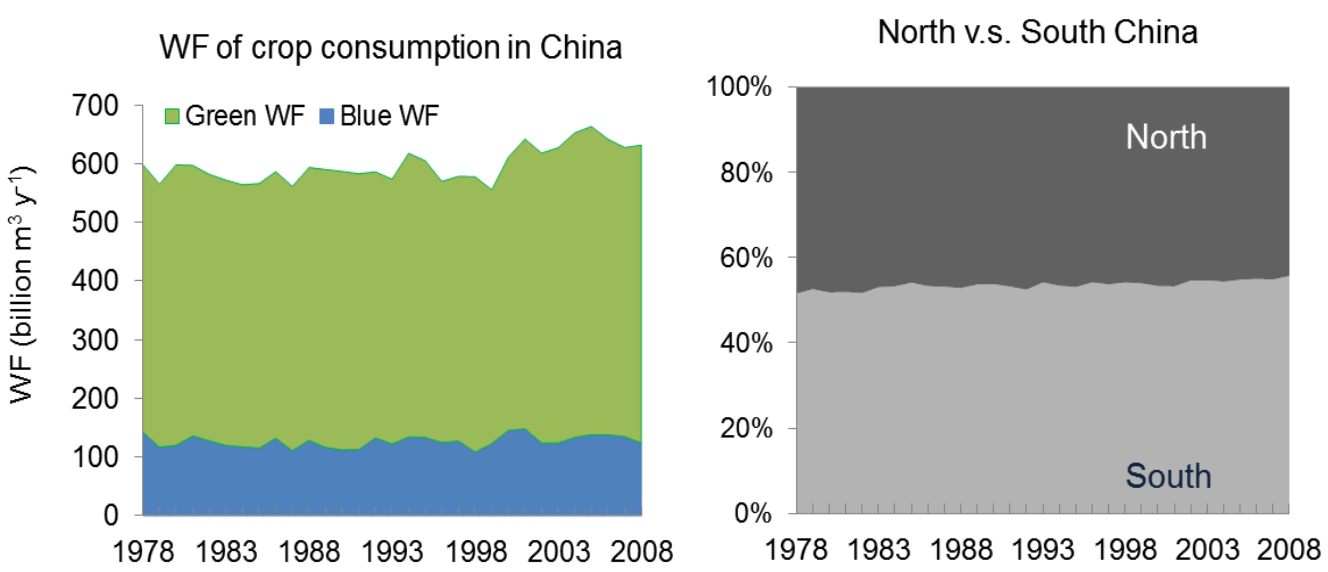

Figure 4.5 Water footprint of crop consumption in China (left), and the relative contributions of North and South China to the total (right). Period: 1978-2008. The figures refer to crop consumption for food, thus excluding crop consumption for feed.

\subsubsection{Water footprint of crop production}

The total green plus blue WF in China of producing the 22 crops considered increased over the period $1978-2008$ by $7 \%$, from 682 billion $\mathrm{m}^{3} \mathrm{y}^{-1}$ (23\% of blue) to 730 billion $\mathrm{m}^{3} \mathrm{y}^{-1}(19 \%$ of blue) (Figure 4.6), while total production of those crops grew by a factor 2.2. The relatively modest growth of the WF can be attributed to a significant decrease in the WFs per tonne of crop, which in turn result from an increase in crops yield. The national average WF of cereals (wheat, rice, maize, sorghum, millet, and barley), for example, decreased by $46 \%$, from $2136 \mathrm{~m}^{3} \mathrm{t}^{-1}$ (540 $\mathrm{m}^{3} \mathrm{t}^{-1}$ blue WF) to $1146 \mathrm{~m}^{3} \mathrm{t}^{-1}$ (249 $\mathrm{m}^{3} \mathrm{t}^{-1}$ blue WF), due to an almost two-fold increase in cereal yield (from 2.9 to $5.6 \mathrm{t} \mathrm{ha}^{-1}$ ) (Figure 4.7). These findings correspond to long-term decreases in WFs per tonne found in a case study for the Yellow River basin in Chapter 3. Inter-annual climatic variability contributed to the fluctuations in 
consumptive WFs $\left(\mathrm{m}^{3} \mathrm{t}^{-1}\right)$ over the years. When comparing the fluctuations in the average green and blue WFs of a cereal crop in China over the period 1978-2008 (as shown in Figure 4.7) to the variations in annual precipitation and $\mathrm{ET}_{0}$ over the same period (Figure 4.2), we find that the blue WF inversely relates to precipitation, and that the green and total consumptive WFs show a weak positive relation to $\mathrm{ET}_{0}$. In years with relatively large precipitation, the ratio of blue to total consumptive WF is generally smaller, a finding that could be expected because irrigation requirements will generally be less.
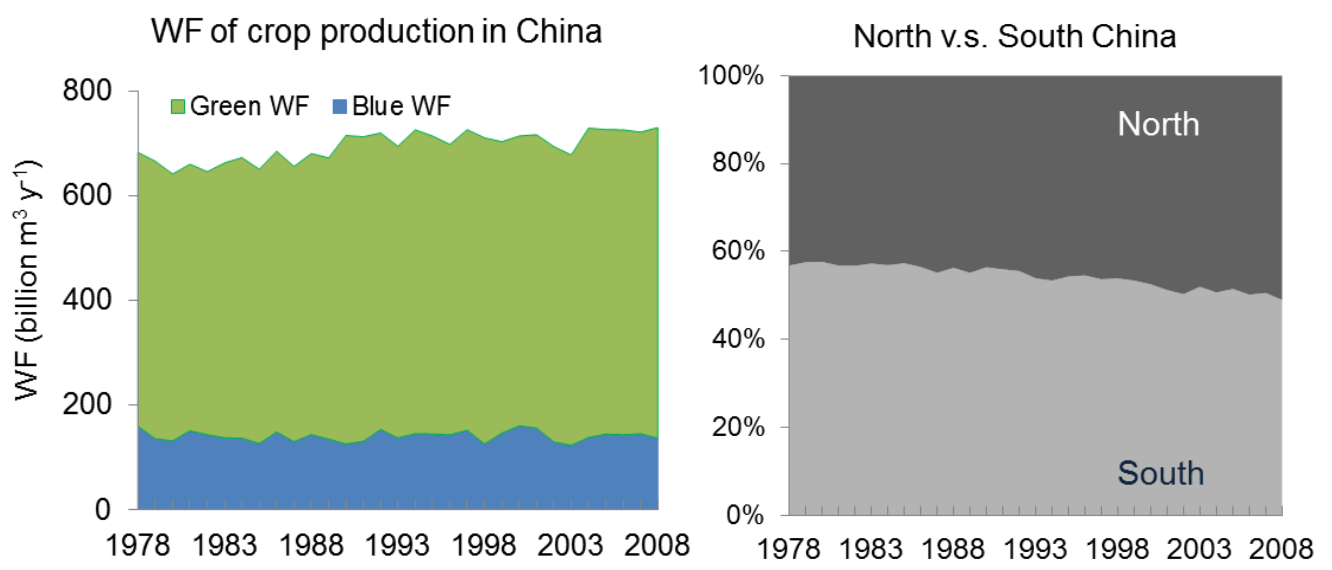

Figure 4.6 Consumptive water footprint of crop production in China, and the relative contributions of North and South China to the total. Period: 1978-2008.

The total harvested area of the considered crops increased by $16 \%$ in the North and decreased by $13 \%$ in the South. The harvested area and the total consumptive WF of crop production decreased in the provinces that have relatively high urbanization levels (Beijing, Tianjin, Shanghai, Chongqing, Zhejiang, Fujian, Hubei, and Guangdong) and are mostly located in the water-rich South. The most significant drop in the total consumptive WF of crop production (a 65\% decrease) was in Shanghai and Zhejiang, with halved harvested areas. At the same time, the other provinces mostly located in the water-scarce North, experienced increases in the total consumptive WF of crop production. The most significant 
increase (fivefold) in the total consumptive WF was observed in Inner Mongolia, which is located in the semi-arid Northwest, where the harvested area expanded by a factor 3.5 and the irrigated area by a factor 2. The contribution of the water-scarce North to the WF of national crop production increased from $43 \%$ in 1978 to $51 \%$ in 2008 as a result of increasing cropping area in the North compared to the South and increased irrigation in the North (Figure 4.6).

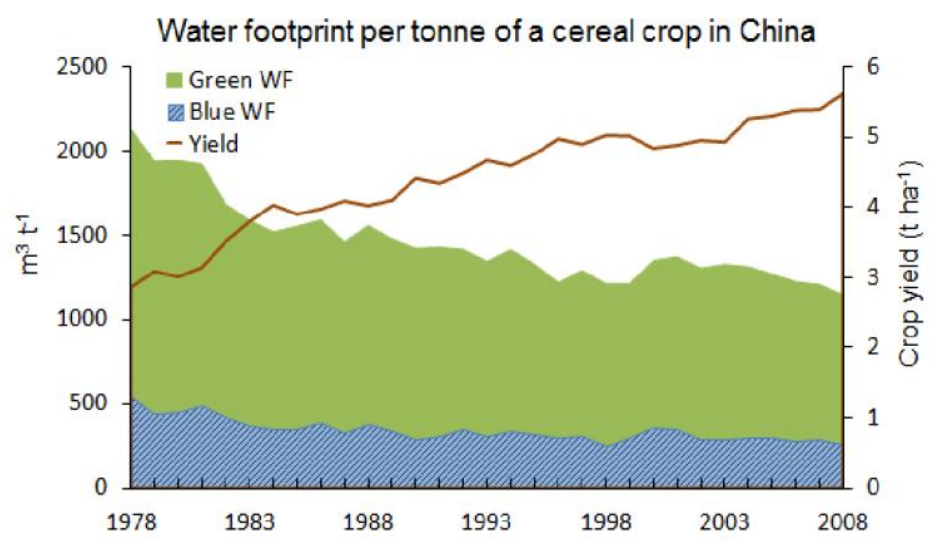

Figure 4.7 Green and blue water footprint per tonne of a cereal crop $\left(m^{3} t^{-1}\right)$ and cereal crop yield ( $t \mathrm{ha}^{-1}$ ) in China over the period 1978-2008.

Figure 4.8 shows the spatial distribution of the total consumptive WF (in $\mathrm{mm} \mathrm{y}^{-1}$ ) of crop production, as well as the share of blue in the total, averaged over the period 1999-2008. Large total consumptive WFs correlate with large overall harvested areas and/or the production of relatively water-intensive crops, while a large share of blue WF in the total reflects the presence of intensive irrigated agriculture. In the semi-arid Northwest and North Coast, blue WF shares exceed 40\%, with Xinjiang having the highest share (54\%), followed by Hebei $(43 \%)$ and Ningxia $(35 \%)$.

Cereals (wheat, maize, rice, sorghum, millet and barley) accounted for $74 \%$ of the overall consumptive WF of the 22 crops considered, $87 \%$ of the blue WF, and $71 \%$ of the green WF. 
More than half of the total blue WF within China was from rice fields (51\%), followed by wheat $(28 \%)$. Rice $(32 \%)$ and wheat $(20 \%)$ together also shared half of the total green WF.

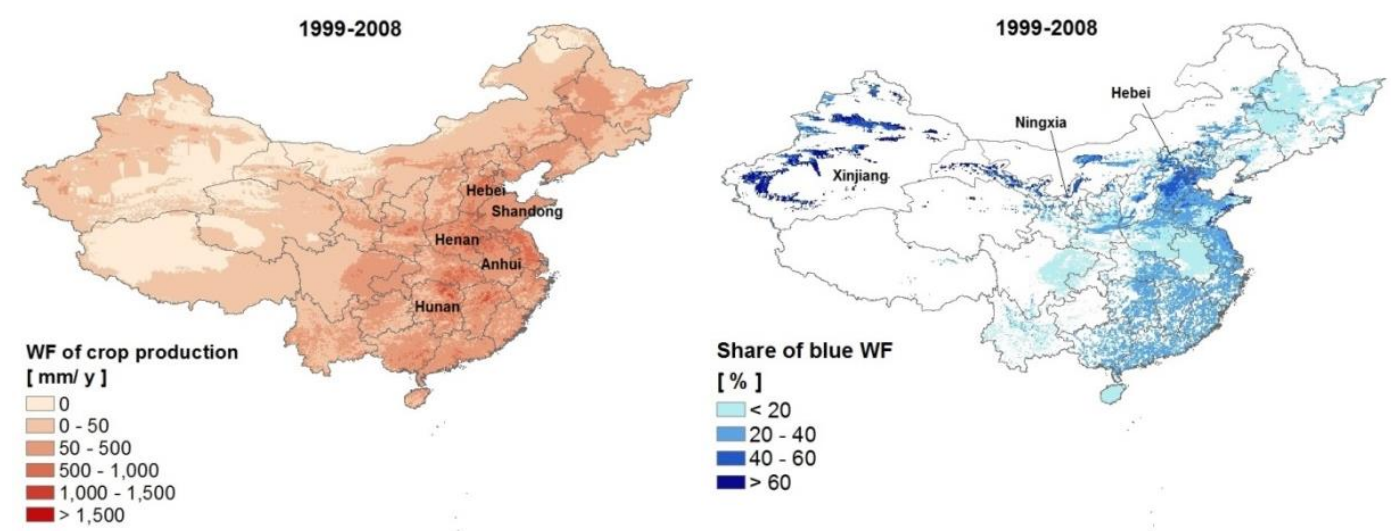

Figure 4.8 Spatial distribution of consumptive water footprints [mm $\left.y^{-1}\right]$ of crop production (left) and the share of the blue water footprint in the total (right) in China. Period: 1999-2008.

\subsubsection{Crop-related inter-regional VW flows in China}

China's annual net VW import from abroad nearly tripled over the period 1978-2008 (from 34 to 95 billion $\mathrm{m}^{3} \mathrm{y}^{-1}$ ). The external WF related to crop consumption in China as a whole was $6 \%$ of the total in 1978 and $13 \%$ in 2008. The inter-regional VW flows within China were larger than the country's international VW flow. The sum of China's inter-regional VW flows was relatively constant over the period 1978-2000 (with an average of 187 billion $\mathrm{m}^{3}$ $\mathrm{y}^{-1}$ ), and rose to a bit higher level during the period 2001-2008 (average 207 billion $\mathrm{m}^{3} \mathrm{y}^{-1}$ ) (Figure 4.9). With a total consumptive WF of Chinese crop production in 2008 of 730 billion $\mathrm{m}^{3} \mathrm{y}^{-1}$ and a total gross inter-regional VW trade of 207 billion $\mathrm{m}^{3} \mathrm{y}^{-1}$, we find that $28 \%$ of total water consumption in crop fields in China serves the production of crops for export to other regions. When we consider blue water consumption specifically, we find the same value of $28 \%$. Further we find that, on average, in $2008,35 \%$ of the crop-related WF of a Chinese consumer is outside its own province. For some provinces we find much larger 
external WFs in 2008: $92 \%$ for Tibet (83\% in other provinces, $10 \%$ abroad), $88 \%$ for Beijing (68\% in other provinces, $20 \%$ abroad) and $86 \%$ for Shanghai $(66 \%$ in other provinces, $20 \%$ abroad).

The estimated inter-regional trade of the crops considered increased by a factor 2.3 over the study period, but the sum of inter-regional VW trade flows increased only modestly due to the general decline in WFs per tonne of crops traded. Trade in rice is responsible for the largest component in the inter-regional VW trade flows, although its importance is declining: rice-trade related inter-regional VW flows contributed $48 \%$ to the total inter-regional VW flows in China in 1978, but $30 \%$ in 2008 . More and more rice was transferred from the Central region, which has a relatively large WF per tonne of rice, to deficit regions. Rice production in Central accounted for 38\% of total national rice production in 1978 and $44 \%$ in 2008. The South Coast became a net rice importer since 2005 due to its increased rice consumption (11\% of national rice consumption in 2008) and reduced rice production (from $15 \%$ of national rice production in 1978 to $9 \%$ in 2008). Wheat- and maize-related inter-regional VW flows increased over the period $1978-2008$ by $62 \%$ and $60 \%$, respectively, due to the estimated increased inter-regional trade volumes of the two staple crops (from 9 to 36 million $\mathrm{t} \mathrm{y}^{-1}$ for wheat, and from 17 to 51 million $\mathrm{t}^{-1}$ for maize), driven by North China's increased share in national crop production but decreased share in national crop consumption. 


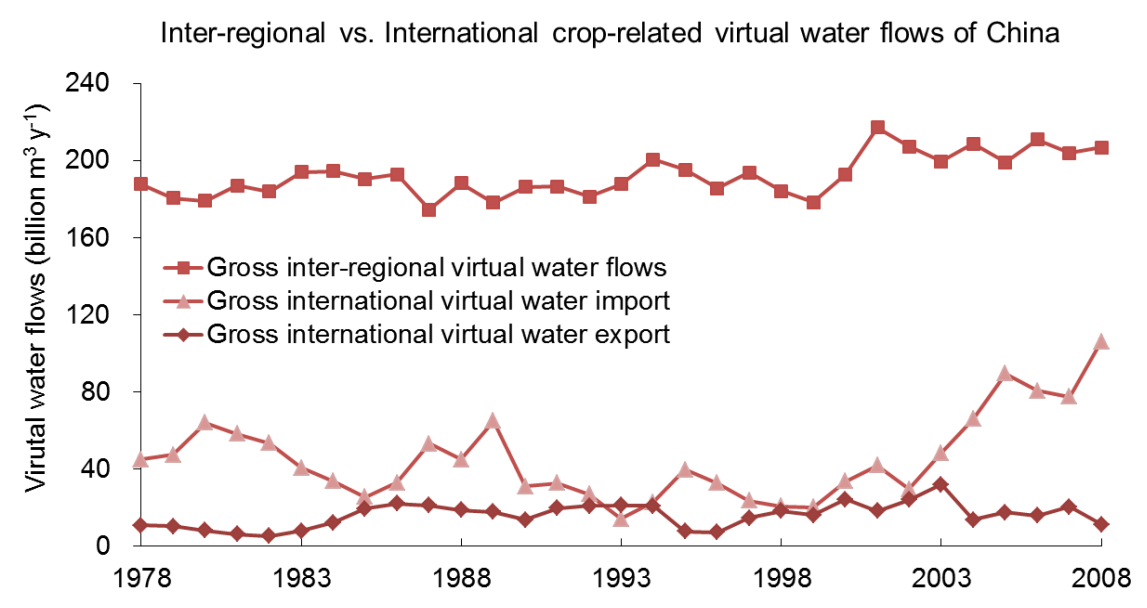

Figure 4.9 China's inter-regional vs. international virtual water flows. Period: 1978-2008.

Historically, VW flows within China went from South to North, but over time the size of this flow declined and since the year 2000 the VW flow - related to the 22 crops studied here - goes from North to South (Figure 4.10). In 2008, the North-to-South VW flow is related to twelve of the twenty-two considered crops (wheat, maize, sorghum, millet, barley, soybean, cotton, sugar beet, groundnuts, sunflower seed, apples and grapes). Still, other crops, most prominently rice, go from South to North. The main driving factor of the reversed VW flow is the faster increase of production in the North and the faster increase of consumption in the South. By 2008, the crop-related net VW flow from North to South has reached 27 billion $\mathrm{m}^{3} \mathrm{y}^{-1}$, equal to $7 \%$ of the total consumptive WF of crop production in the North. 


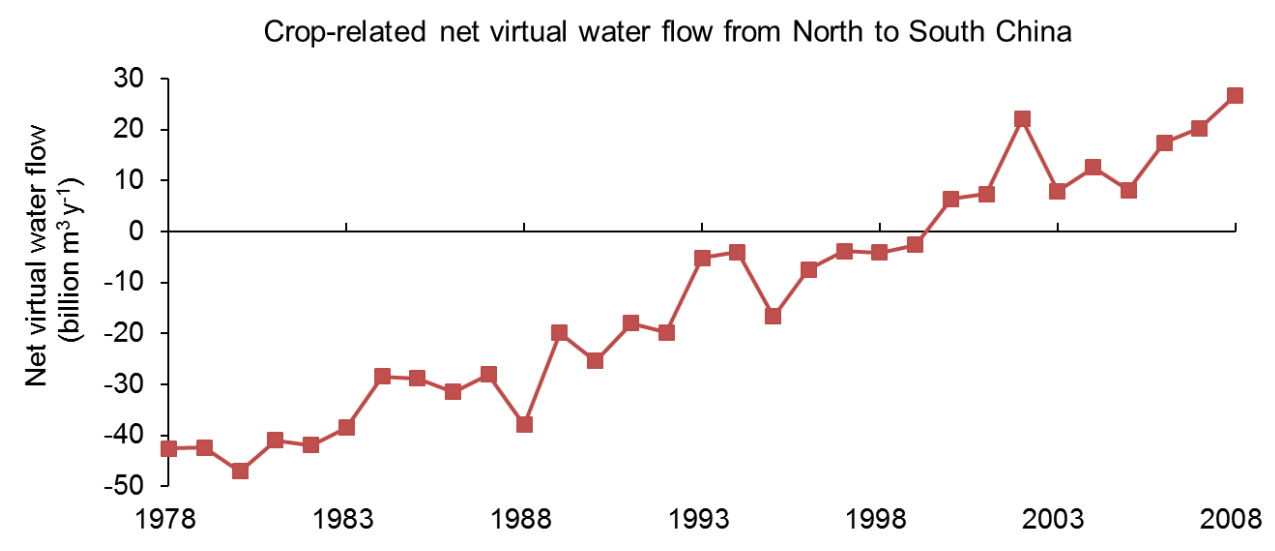

Figure 4.10 Net virtual water transfer from North to South China resulting from inter-regional crop trade. Period: 1978-2008.

Figure 4.11 presents the net VW trade balances of all provinces for the years 1978 and 2008, for total VW trade as well as for blue and green VW trade separately, with positive balances reflecting net VW import and negative balances indicating net VW export. The figure also shows total, blue and green net VW flows between North and South and the international net VW flows towards the North and South. International net VW imports to both North and South increased. With regard to blue water, China was a net VW exporter to other countries in the 1978, which was mainly from the South and mostly related to rice exports. With the increased crop consumption of the Chinese population, China as a whole became a net blue VW importer in 1990 and remained since.

Over the whole study period, we find a blue VW flow from South to North. It is the green VW flow, and with that the total VW flow, that reversed direction in the study period. This is the first study that shows this, because previous studies didn't distinguish between the green and blue components in the VW flow between North and South. The reason for the continued blue VW flow from South to North is the continued trade of rice in this direction.

The provinces Zhejiang, Guangdong and Fujian, all located in the South, have changed from net VW exporters to net VW importers, in the years 1999, 1987 and 1981, respectively. By 
2008, Guangdong was the largest net VW importing province (36 billion $\mathrm{m}^{3} \mathrm{y}^{-1}$ ), followed by Sichuan (18 billion $\left.\mathrm{m}^{3} \mathrm{y}^{-1}\right)$ and Zhejiang (15 billion $\left.\mathrm{m}^{3} \mathrm{y}^{-1}\right)$. In the meantime, the provinces Henan and Shandong in the North became net VW exporters, in 1993 and 1983, respectively. In 2008, the three largest crop-related net VW exporters were Heilongjiang (21 billion $\left.\mathrm{m}^{3} \mathrm{y}^{-1}\right)$, Jiangxi (12 billion $\left.\mathrm{m}^{3} \mathrm{y}^{-1}\right)$ and Anhui (10 billion $\left.\mathrm{m}^{3} \mathrm{y}^{-1}\right)$. 
(a)

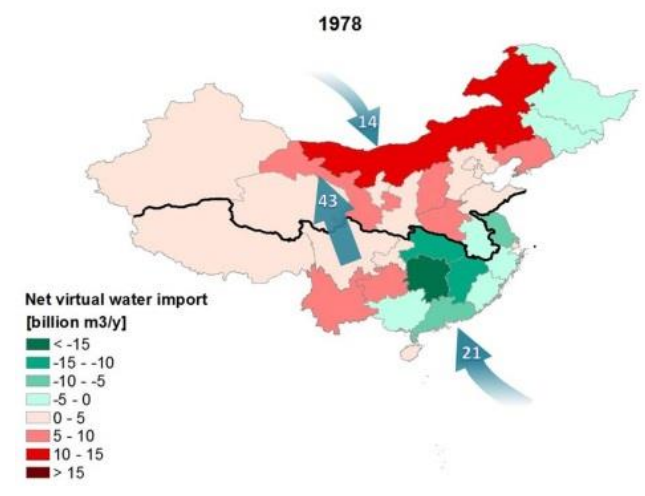

(b)

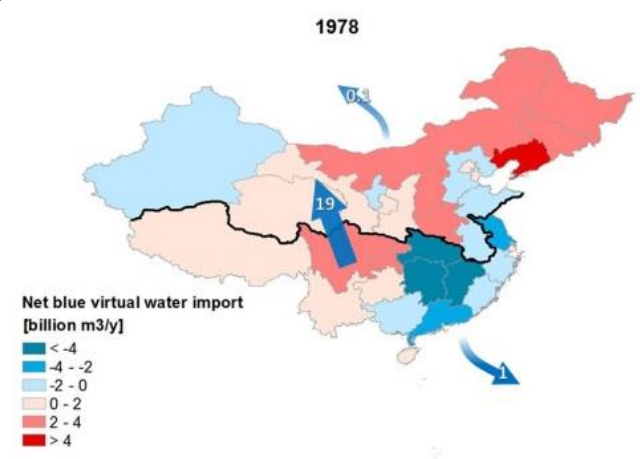

(c)

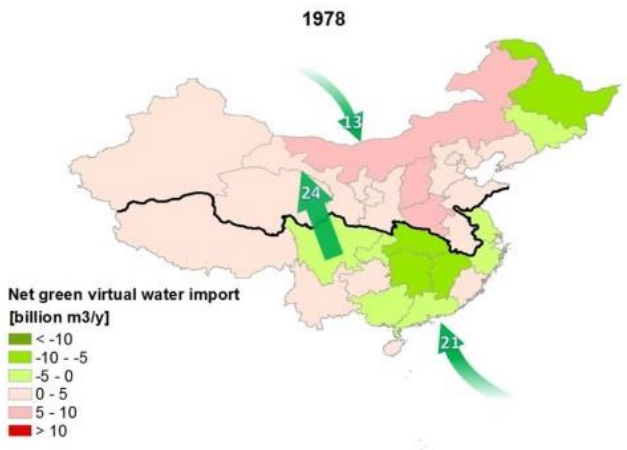

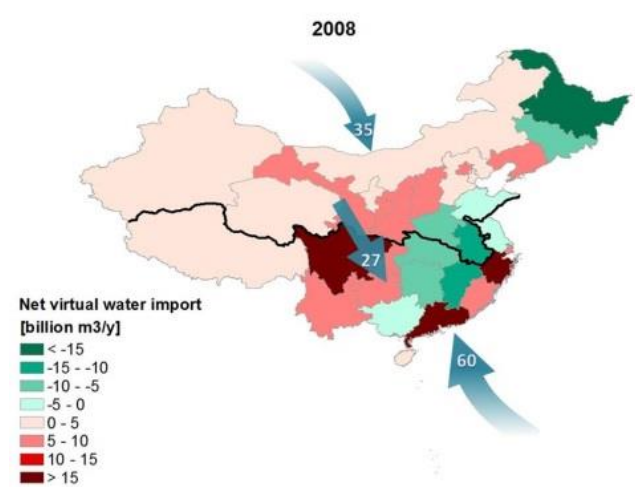
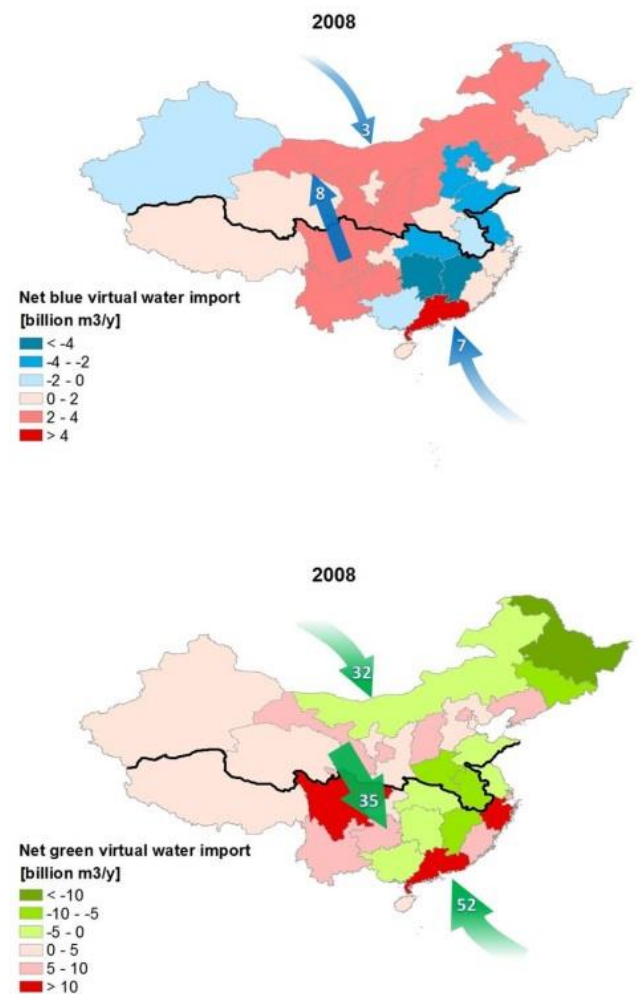

Figure 4.11 China's provincial crop-related total (a), green (b) and blue (c) net virtual water imports for 1978 (left) and 2008 (right). The net virtual water flows between the North and South and the international net virtual water flows of the North and South are shown by arrows, with the numbers indicating the size of net virtual water flows in billion $m^{3} y^{-1}$. 
The inter-regional VW network related to crop trade has changed significantly over the study period (Figure 4.12). The Jing-Jin, Northwest, and Southwest regions were all-time net VW importers. The net VW import of Jing-Jin, where Beijing is located, from other regions has more than doubled, from 4.5 to 9.7 billion $\mathrm{m}^{3} \mathrm{y}^{-1}$, which can be explained by the $84 \%$ growth of its population. Central was net VW exporter over the whole study period, with a net VW export increasing from 28 to 52 billion $\mathrm{m}^{3} \mathrm{y}^{-1}$. East Coast and South Coast have changed from net VW exporter in 1978 to net VW importer in 2008, while North Coast reversed in the other direction. The direction of the net VW flow from South Coast to Northeast has been reversed during the study period due to a reversed direction of rice trade between the two regions. While Northeast shifted from a net importer of rice to a net exporter, the reverse happened in South Coast.
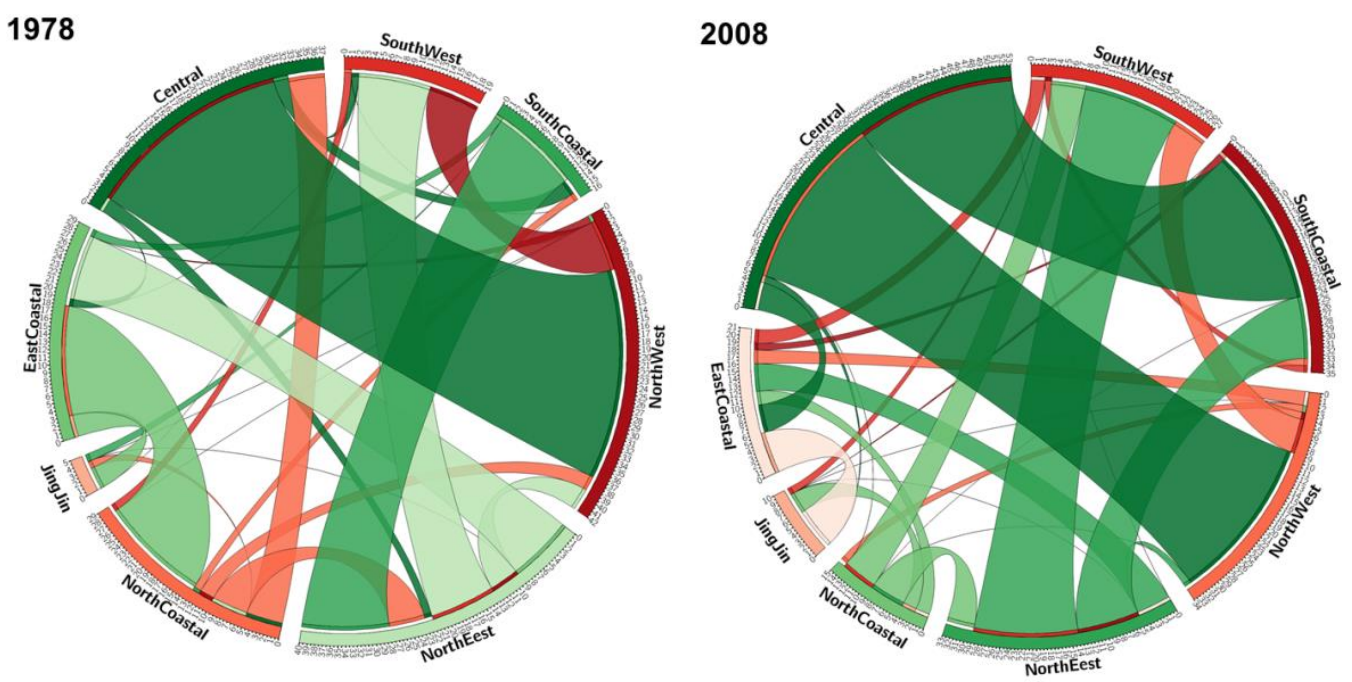

Figure 4.12 Inter-regional virtual water flows in China as a result of the trade in 22 crops for 1978 and 2008. The widths of the ribbons are scaled by the volume of the virtual water flow. The colour of each ribbon corresponds to the export region. The net virtual water exporters are shown in green segments, the net virtual water importers are shown in red segments. 


\subsubsection{National water saving related to international and inter-regional crop trade}

As shown in Figure 4.13, China's total national water saving as a result of international crop trade highly fluctuated, amounting to 41 billion $\mathrm{m}^{3} \mathrm{y}^{-1}$ (6\% of total national WF of crop production) in 1978 and 108 billion $\mathrm{m}^{3} \mathrm{y}^{-1}$ (15\% of total national WF of crop production) in 2008. From 1981 onwards, inter-regional crop trade in China started to save increasing amounts of water for the country in total, reaching to 121 billion $\mathrm{m}^{3} \mathrm{y}^{-1}$ (17\% of the total national WF of crop production) by 2008. Inter-regional crop trade in China did not lead to an overall saving of blue water; instead, the trade pattern increased the blue WF in China as a whole, due to the fact that blue WFs per tonne of crop in the exporting regions were often larger than in the importing regions. The blue water loss resulting from inter-regional trade was 20 billion $\mathrm{m}^{3} \mathrm{y}^{-1}$ (13\% of national blue WF of crop production) in 1978 and 9 billion $\mathrm{m}^{3}$ $\mathrm{y}^{-1}$ (6\% of national blue WF of crop production) in 2008 . The decrease was the result of the increased blue water productivity over the years.

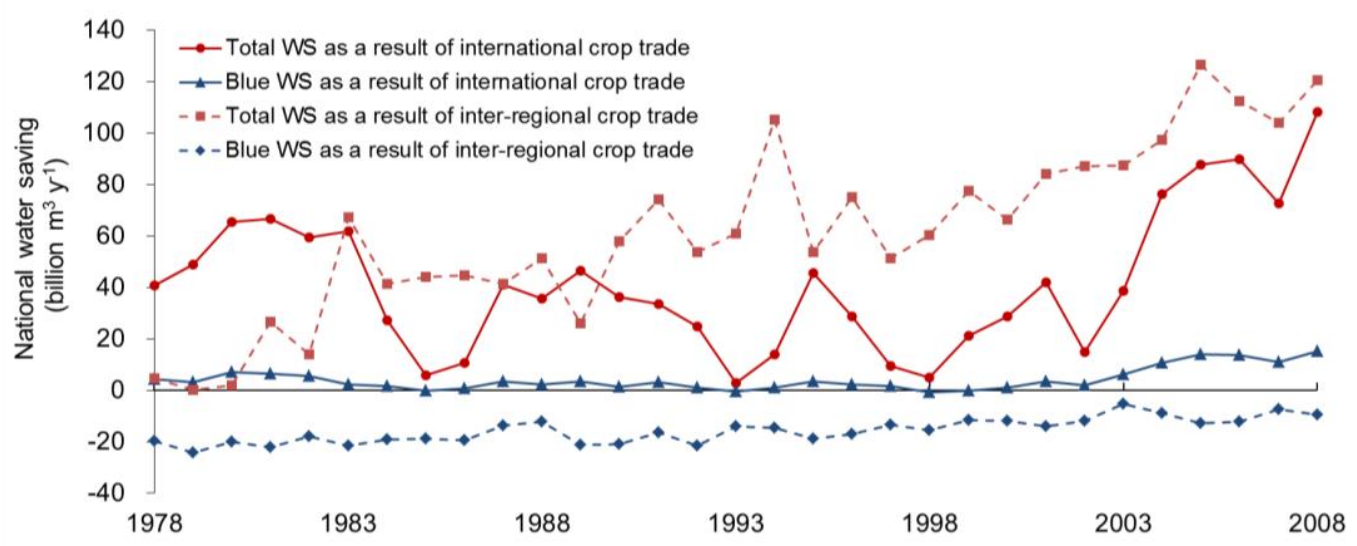

Figure 4.13 National water saving (WS) as a result of China's international and inter-regional crop trade over the period 1978-2008.

Table 4.3 lists the national water saving related to international and inter-regional trade of China, per crop, for both 1978 and 2008. In recent years, soybean plays the biggest role in the national water saving of China through international crop trade, which confirms earlier 
findings (Liu et al., 2007; Shi et al., 2014; Chapagain et al., 2006; Dalin et al., 2014). We found that before 1997 the largest national water saving related to international trade was for wheat trade. In 2008, international trade of only four of the 22 crops considered (soybean, rapeseed, cotton and barley) resulted in national water saving for China. The international export of tea led to the greatest national water loss in 2008.

Most of the national water saving related to inter-regional crop trade in 2008 was due to trade in rapeseed, wheat and groundnuts. Due to the increasing inter-regional trade of rapeseed (from 0.8 million $\mathrm{t}^{-1}$ in 1978 to 5 million $\mathrm{t}^{-1}$ in 2008), the generated water saving increased by a factor 4.5 over the study period. The biggest contributor to the national water loss through inter-regional crop trade was rice, with a national water loss of 29 billion $\mathrm{m}^{3} \mathrm{y}^{-1}$ (11\% of total consumptive WF of rice production) in 2008. Particularly inter-regional trade in rice and wheat led to blue water losses.

Table 4.3 National water saving (WS) through international and inter-regional crop trade of China.

\begin{tabular}{|c|c|c|c|c|c|c|}
\hline & \multicolumn{2}{|c|}{$\begin{array}{l}\text { National WS through } \\
\text { international crop trade } \\
\quad\left(\text { billion } \mathrm{m}^{3} \mathrm{y}^{-1}\right)\end{array}$} & \multicolumn{2}{|c|}{$\begin{array}{l}\text { National WS through } \\
\text { inter-regional crop } \\
\text { trade } \\
\left.\text { (billion } \mathrm{m}^{3} \mathrm{y}^{-1}\right)\end{array}$} & \multicolumn{2}{|c|}{$\begin{array}{c}\text { Blue WS through } \\
\text { inter-regional crop } \\
\text { trade } \\
\text { (billion } \mathrm{m}^{3} \mathrm{y}^{-1} \text { ) }\end{array}$} \\
\hline & 1978 & 2008 & 1978 & 2008 & 1978 & 2008 \\
\hline Wheat & 33.8 & -0.6 & 23.9 & 59.6 & -10.4 & -3.2 \\
\hline Maize & 1.6 & -0.9 & 13.2 & 3.5 & 3.6 & -0.6 \\
\hline Rice & -4.9 & -1.6 & -55.7 & -28.9 & -17.2 & -10.7 \\
\hline Sorghum & 0.0 & -0.1 & -1.1 & 0.0 & 0.2 & 0.1 \\
\hline Barley & -0.0 & 0.3 & 0.0 & -0.0 & -0.0 & -0.0 \\
\hline Millets & -0.1 & -0.0 & 3.7 & 0.7 & 1.2 & 0.3 \\
\hline Potato & -0.0 & -0.1 & 0.7 & 0.2 & 0.2 & 0.1 \\
\hline Sweet potato & -0.0 & -0.0 & 0.3 & 0.2 & -0.5 & 0.1 \\
\hline Soybean & 0.4 & 86.1 & 1.7 & -1.3 & 1.0 & 0.7 \\
\hline Groundnut & -0.1 & -0.9 & 3.5 & 10.2 & 1.8 & 4.3 \\
\hline Sunflower & -0.0 & -0.2 & 0.1 & 0.1 & 0.1 & 0.1 \\
\hline
\end{tabular}




\begin{tabular}{lcccccc} 
Rapeseed & -0.0 & 20.4 & 13.7 & 64.9 & 0.0 & 0.0 \\
Sugar beet & 0.0 & -0.0 & -0.1 & 0.2 & -0.0 & -0.0 \\
Sugar cane & 0.0 & 0.0 & -0.0 & 3.0 & 0.1 & 0.3 \\
Cotton & 12.9 & 9.4 & 0.1 & 0.0 & 0.2 & -0.3 \\
Spinach & -0.0 & -0.0 & 0.0 & 0.1 & 0.0 & 0.0 \\
Tomato & -0.0 & -0.0 & 0.8 & 7.3 & 0.0 & 0.1 \\
Cabbage & -0.0 & -0.1 & -0.0 & -0.0 & -0.0 & -0.0 \\
Apple & -0.1 & -0.9 & -0.4 & 0.6 & -0.0 & -0.1 \\
Grape & -0.0 & -0.0 & -0.0 & -0.2 & -0.0 & -0.5 \\
Tea & -2.7 & -2.5 & -0.0 & 0.3 & 0.0 & 0.0 \\
Tobacco & -0.0 & -0.2 & 0.4 & 0.2 & 0.1 & 0.1 \\
\hline Total & 40.7 & 108.1 & 4.6 & 120.6 & -19.6 & -9.3 \\
\hline
\end{tabular}

\subsubsection{Discussion}

We compared the national average WF of each crop (in $\mathrm{m}^{3} \mathrm{t}^{-1}$ ) as estimated in the current study with three previous studies that gave average values for different periods: Mekonnen and Hoekstra (2011) for 1996-2005, Liu et al. (2007) for 1999-2007 and Shi et al. (2014) for 1986-2008 (Figure 4.14). Our estimates of crop WFs match well with previous reported values, with R-square values of $0.96,0.89$ and 0.98 for the three studies, respectively.

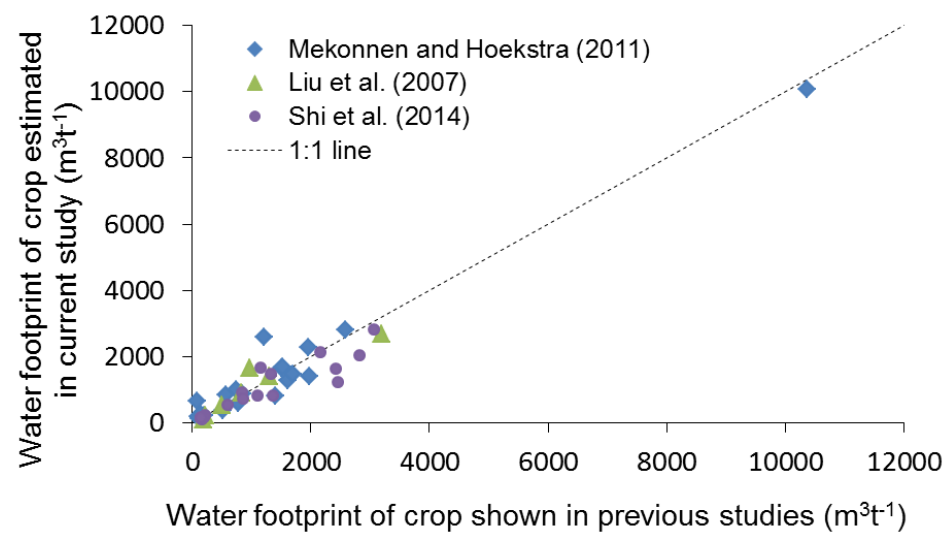

Figure 4.14 Comparison of current estimates of national average consumptive water footprint of each crop (in $\mathrm{m}^{3} t^{-1}$ ) with results from Mekonnen and Hoekstra (2011), Liu et al. (2007) and Shi et al. (2014). 
A number of limitations should be taken into account when interpreting the results of this study. First, in simulating WFs of crops, a number of crop parameters, such as harvest index, cropping calendar and the maximum root depth for each type of crop, were taken constant over the whole period of analysis. Second, the annual variation of the initial soil water content for each crop (at the beginning of the growing season) in each grid cell was not taken into consideration. Third, we assumed, per crop, that the changes in cropping area over the study period only happened in grid cells where a harvested area for that crop existed around the year 2000 according to the database used (Monfreda et al., 2008; Portmann et al., 2010). Fourth, in estimating WFs of crop consumption, the spatial variation of per capita crop consumption levels (e.g. urban vs. rural) was ignored due to lack of data. Finally, the specific trade flows between crop surplus and crop deficit regions were estimated assuming static multi-regional input-output tables as explained in the method section.

The various assumptions that have been taken by lack of more accurate data translate to uncertainties in the results. The assumptions on harvest indexes and maximum root depths mainly affect the magnitude of modelled crop yield levels; the effect of uncertainties in these model parameters has been minimized by the fact that we calibrated the simulated yields in order to match provincial yield statistics. Regarding assumed cropping calendars and initial soil water content values, a detailed sensitivity analysis to these two variables has been carried out by Zhuo et al. (2014) for the Yellow River basin, the core of Chinese crop production, and by Tuninetti et al. (2015) at global level. By varying the crop planting date by \pm 30 days, Zhuo et al. (2014) found that the consumptive WF of crops generally decreased by less than $10 \%$ with late planting date due to decreased crop ET and that crop yields hardly changed. By changing the initial soil water content by $\pm 1 \mathrm{~mm} \mathrm{~m}^{-1}$, Tuninetti et al. (2015) showed that an increment in the initial soil water content resulted in decreases in consumptive WF due to higher yield. Again, the effects on yield simulations were diminished by calibration to fit yield statistics. Since none of the factors mentioned can influence the order of magnitude of the outcomes, the broad conclusions with respect to declining WFs of crops $\left(\mathrm{m}^{3} \mathrm{t}^{-1}\right)$, declining WFs per capita $\left(\mathrm{m}^{3} \mathrm{y}^{-1} \mathrm{cap}^{-1}\right)$, increasing total WFs of consumption and production $\left(\mathrm{m}^{3} \mathrm{y}^{-1}\right)$ and the reversing of the VW flow between South 
and North China, are solid.

\subsection{Conclusions}

For China as a whole, even though the per capita consumption of considered crops grew by a factor of 1.4 over the study period, China's average WF per capita $\left(\mathrm{m}^{3} \mathrm{cap}^{-1} \mathrm{y}^{-1}\right)$ related to crop consumption decreased by $23 \%$, owing to improved yields. Due to the population growth $(37 \%)$, the total consumptive WF $\left(\mathrm{m}^{3} \mathrm{y}^{-1}\right)$ of Chinese crop consumption increased by $6 \%$, with a tripled net VW import as a result of importing crops from other countries. The production of the 22 crops considered doubled, while the harvested area increased only marginally (4\%). The increased crop yields in China have led to significant reductions in the WF of crops (e.g. halving the WF per tonne of cereals), resulting in a slight increase (7\%) in the total consumptive WF of crop production. About $28 \%$ of total consumptive water use in crop fields in China serves the production of crops for export to other regions. About $35 \%$ of the crop-related WF of a Chinese consumer is outside its own province. By 2000, the North has become net VW exporter through crops to the South. This is in line with the findings in earlier studies (e.g. Ma et al., 2006; Cao et al., 2011; Dalin et al., 2014), but we add the nuance that the North-South VW flow concerns green water. There is still a blue VW flow from the South to the North, although this flow more than halved over the study period.

If these trends continue, this will put an increasing pressure on the North's already limited water resources. The on-going South-North Water Transfer Project (SNWTP) may alleviate this pressure to a certain extent, but might be insufficient (Barnett et al., 2015). The Middle Route of the South-North Water Transfer project, which is operational since late 2014, is transferring 3 billion $\mathrm{m}^{3}$ of blue water per year to support agriculture, with the aim to increase irrigated land by 0.6 million ha in the drier North (SCPRC, 2014a). The Government's plan to expand irrigated agriculture by using the transferred water for irrigation will stimulate crop export from the North and thus further increase the blue VW transfer from North to South. The blue water supply through the SNWTP will thus not significantly reduce the pressure on water resources in the North, but rather support agricultural expansion. Efforts to reduce water demand will be needed to address the growing water problems in China. 
Crop yield improvements have led to a drop in the WF of crops $\left(\mathrm{m}^{3} \mathrm{t}^{-1}\right)$, but further reduction in the WF is possible. Setting WF benchmark values for the different crops, taking into account the agro-ecological conditions of the different regions, formulating targets to reduce the WFs of crops to benchmark levels and making proper investments to reach these targets will be important steps toward further reduction of the WF (Hoekstra, 2013). As the economy grows, the per capita consumption of water-intensive goods such as animal products and oil crops will increase, putting further pressure on China's already scarce water resources (Liu and Savenije, 2008). Thus, efforts are necessary to influence the food preferences of the population in order to curb the increasing consumption of meat, dairy and water-intensive crops, which is useful from a health perspective as well (Du et al., 2004).

The case of China shows that domestic trade, as governed by economics and governmental policies rather than by regional differences in water endowments, determines inter-regional water dependencies and may worsen rather than relieve the water scarcity in a country. 
Appendix 4A An example of assessing the water footprint related to crop consumption in China: wheat in the year 2006.

\begin{tabular}{|c|c|c|c|c|c|c|c|c|c|c|c|c|c|c|c|c|c|c|c|c|c|c|c|c|c|c|c|c|c|c|}
\hline \multirow[t]{2}{*}{ Province } & \multirow[t]{2}{*}{$\begin{array}{l}\text { Population } \\
\left(10^{4}\right)^{8}\end{array}$} & \multirow[t]{2}{*}{$\begin{array}{l}\text { Livestock } \\
\left(10^{4} \text { LU) }\right.\end{array}$} & \multicolumn{5}{|c|}{ Utilization $\left(10^{3} \mathrm{t}\right)$} & \multicolumn{5}{|c|}{ Supply $\left(10^{3} \mathrm{t}\right)$} & \multicolumn{3}{|c|}{$\begin{array}{l}\text { WF of crop production } \\
\left(10^{6} \mathrm{~m}^{3} / \mathrm{y}\right)\end{array}$} & \multicolumn{3}{|c|}{$\begin{array}{l}\text { Net virtual water import } \\
\text { as result of International } \\
\text { crop trade }\left(10^{6} \mathrm{~m}^{3} / \mathrm{y}\right)\end{array}$} & \multicolumn{3}{|c|}{$\begin{array}{l}\text { Net virtual water import } \\
\text { as result of Inter-regional } \\
\text { crop trade }\left(10^{6} \mathrm{~m}^{3} / \mathrm{y}\right) \\
\end{array}$} & \multicolumn{3}{|c|}{$\begin{array}{l}\text { Virtual water trade } \\
\text { balance }\left(10^{6} \mathrm{~m}^{3} / \mathrm{y}\right)\end{array}$} & \multicolumn{3}{|c|}{$\begin{array}{l}\text { WF of consumed crop } \\
\left(\mathrm{m}^{3} / \mathrm{t}\right)\end{array}$} & \multicolumn{3}{|c|}{$\begin{array}{l}\text { WF of food consumption } \\
\left(10^{6} \mathrm{~m}^{3} / \mathrm{y}\right)\end{array}$} \\
\hline & & & Food $^{E}$ & Feed & Seed & Waste & Otheruse & Production & Stock var. & $\begin{array}{l}\text { International } \\
\text { trade }^{c}\end{array}$ & $\begin{array}{l}\text { Inter-regional } \\
\text { trade }\end{array}$ & $\begin{array}{l}\text { Crop trade } \\
\text { balance } e^{D}\end{array}$ & Blue & Green & Total & Blue & Green & Total & Blue & Green & Total & Blue & Green & Total & Blue & Green & Total & Blue & Green & Total \\
\hline Beiling & 1601 & 61 & 1109 & 15 & 49 & 31 & 28 & 300 & -8 & 12 & 928 & 940 & 177 & 74 & 251 & 0.5 & 23 & 23 & 533 & 578 & 1111 & 534 & 601 & 1134 & 574 & 680 & 1254 & 681 & 646 & 1327 \\
\hline Tianjin & 1075 & 62 & 745 & 15 & 33 & 21 & 19 & 499 & -13 & 5 & 342 & 347 & 335 & 165 & 500 & 0.2 & 8 & 9 & 197 & 213 & 410 & 197 & 222 & 419 & 629 & 501 & 1130 & 502 & 365 & 866 \\
\hline Hebei & 6898 & 1102 & 4778 & 274 & 219 & 141 & 120 & 11897 & -307 & -231 & -5827 & -6058 & 9030 & 5320 & 14350 & -175.3 & -103 & -279 & -4423 & -2606 & -7028 & -4598 & -2709 & -7307 & 729 & 3726 & 4455 & 3885 & 2289 & 6174 \\
\hline Shanxi & 3375 & 322 & 2338 & 80 & 105 & 68 & 59 & 2271 & -59 & 6 & 431 & 437 & 1570 & 1540 & 3110 & 0.2 & 11 & 11 & 77 & 480 & 557 & 77 & 490 & 568 & 609 & 1522 & 2130 & 1524 & 1878 & 3402 \\
\hline Inner Mongolia & a 2415 & 1241 & 1673 & 308 & 86 & 55 & 42 & 1722 & -44 & 6 & 481 & 487 & 1940 & 549 & 2489 & 0.2 & 12 & 12 & 303 & 349 & 652 & 303 & 361 & 664 & 1016 & 1817 & 2833 & 1820 & 738 & 2558 \\
\hline Liaoning & 4271 & 712 & 2959 & 177 & 136 & 88 & 74 & 31 & -1 & 44 & 3359 & 3403 & 17 & 16 & 33 & 1.7 & 82 & 84 & 1931 & 2092 & 4023 & 1933 & 2174 & 4107 & 568 & 1799 & 2367 & 1800 & 2022 & 3822 \\
\hline Jilin & 2723 & 670 & 1886 & 166 & 89 & 57 & 47 & 3 & 0 & 29 & 2214 & 2243 & 3 & 2 & 5 & 1.1 & 54 & 55 & 1273 & 1379 & 2652 & 1274 & 1433 & 2708 & 569 & 1148 & 1717 & 1149 & 1292 & 2440 \\
\hline Heilongjiang & 3823 & 783 & 2648 & 194 & 123 & 79 & 67 & 930 & -24 & 29 & 2177 & 2206 & 483 & 504 & 987 & 1.1 & 53 & 54 & 1252 & 1356 & 2608 & 1253 & 1409 & 2662 & 554 & 1569 & 2123 & 1570 & 1731 & 3302 \\
\hline Shanghai & 1964 & 35 & 1360 & 9 & 59 & 38 & 34 & 113 & -3 & 18 & 1372 & 1390 & 65 & 138 & 203 & 0.7 & 34 & 34 & 213 & 1744 & 1957 & 214 & 1777 & 1991 & 186 & 270 & 456 & 270 & 1856 & 2126 \\
\hline Jiangsu & 7656 & 533 & 5303 & 132 & 236 & 152 & 133 & 9016 & -233 & -108 & -2719 & -2827 & 1210 & 12700 & 13910 & -14.5 & -152 & -166 & -365 & -3830 & -4195 & -379 & -3982 & -4361 & 132 & 748 & 880 & 762 & 8003 & 8765 \\
\hline Zhejiang & 5072 & 287 & 3513 & 71 & 155 & 100 & 88 & 157 & -4 & 49 & 3726 & 3775 & 13 & 281 & 294 & 1.9 & 91 & 93 & 578 & 4734 & 5312 & 580 & 4825 & 5405 & 151 & 569 & 720 & 568 & 4887 & 5455 \\
\hline Anhui & 6110 & 487 & 4232 & 121 & 189 & 122 & 106 & 10390 & -268 & -204 & -5148 & -5352 & 978 & 18300 & 19278 & -19.2 & -359 & -379 & -485 & -9067 & -9551 & -504 & -9426 & -9930 & 90 & 409 & 499 & 427 & 7986 & 8413 \\
\hline Fujian & 3585 & 369 & 2483 & 92 & 112 & 72 & 62 & 16 & 0 & 37 & 2769 & 2805 & 0 & 35 & 35 & 1.4 & 68 & 69 & 496 & 3081 & 3577 & 497 & 3149 & 3646 & 177 & 470 & 647 & 469 & 3002 & 3471 \\
\hline Jiangxi & 4339 & 503 & 3006 & 125 & 136 & 88 & 76 & 20 & -1 & 44 & 3365 & 3409 & 0 & 95 & 95 & 1.7 & 82 & 84 & 603 & 3744 & 4347 & 604 & 3827 & 4431 & 177 & 568 & 745 & 568 & 3682 & 4249 \\
\hline Shandong & 9309 & 1387 & 6448 & 345 & 294 & 190 & 162 & 20130 & -520 & -464 & -11707 & -12171 & 9730 & 14300 & 24030 & -224.3 & -330 & -554 & -5659 & -8316 & -13975 & -5883 & -8646 & -14529 & 455 & 3140 & 3595 & 3339 & 4907 & 8247 \\
\hline Henan & 9392 & 2191 & 6506 & 544 & 305 & 197 & 163 & 29365 & -758 & -797 & -20094 & -20891 & 5900 & 27800 & 33700 & -160.1 & -754 & -914 & -4037 & -19023 & -23061 & $\begin{array}{l}-4197 \\
\end{array}$ & -19778 & -23975 & 182 & 1267 & 1449 & 1400 & 6598 & 7999 \\
\hline Hubei & 5693 & 793 & 3944 & 197 & 179 & 116 & 99 & 3111 & -80 & 20 & 1485 & 1504 & 134 & 8540 & 8674 & 0.8 & 36 & 37 & 266 & 1652 & 1918 & 267 & 1688 & 1955 & 87 & 367 & 454 & 367 & 9363 & 9730 \\
\hline Hunan & 6342 & 1219 & 4393 & 303 & 203 & 131 & 110 & 29 & -1 & 67 & 5046 & 5113 & 0 & 86 & 86 & 2.6 & 124 & 126 & 904 & 5616 & 6520 & 907 & 5739 & 6646 & 177 & 831 & 1008 & 830 & 5331 & 6161 \\
\hline Guangdon & 9442 & 665 & 6541 & 165 & 291 & 187 & 164 & 3 & 0 & 96 & 7249 & 734 & 0 & 8 & 8 & 3.7 & 177 & 181 & 1299 & 8067 & 9366 & 1302 & 8245 & 9547 & 178 & 1244 & 1422 & 1242 & 7869 & 9111 \\
\hline Guangxi & 4719 & 903 & 3269 & 224 & 151 & 98 & 82 & 6 & 0 & 50 & 3769 & 3818 & 2 & 24 & 26 & 1.9 & 92 & 94 & 2009 & 2692 & 4701 & 2011 & 2784 & 4795 & 527 & 1843 & 2370 & 1844 & 2571 & 4415 \\
\hline Hainan & 836 & 143 & 579 & 36 & 27 & 17 & 15 & 0 & 0 & 9 & 664 & 673 & 0 & 0 & 0 & 0.3 & 16 & 17 & 119 & 739 & 858 & 119 & 755 & 875 & 178 & 110 & 288 & 110 & 696 & 806 \\
\hline Chongqing & 2808 & 447 & 1945 & 111 & 89 & 57 & 49 & 476 & -12 & 23 & 1765 & 1788 & 4 & 1070 & 1074 & 0.9 & 43 & 44 & 941 & 1260 & 2201 & 942 & 1304 & 2245 & 418 & 870 & 1288 & 870 & 2185 & 3055 \\
\hline Sichuan & 8169 & 2189 & 5659 & 544 & 269 & 173 & 142 & 4436 & -114 & 32 & 2433 & 2465 & 250 & 7930 & 8180 & 1.2 & 60 & 61 & 1297 & 1738 & 3035 & 1299 & 1797 & 3096 & 225 & 1359 & 1584 & 1360 & 8545 & 9905 \\
\hline Guizhou & 3690 & 838 & 2556 & 208 & 120 & 77 & 64 & 451 & -12 & 34 & 2552 & 2586 & 28 & 1520 & 1548 & 1.3 & 62 & 64 & 1361 & 1823 & 3184 & 1362 & 1885 & 3247 & 458 & 1252 & 1710 & 1253 & 3070 & 4323 \\
\hline Yunnan & 4483 & 1292 & 3105 & 321 & 148 & 96 & 78 & 930 & -24 & 37 & 2806 & 2843 & 514 & 2730 & 3244 & 1.4 & 69 & 70 & 1496 & 2004 & 3500 & 1497 & 2073 & 3570 & 534 & 1772 & 2306 & 1774 & 4235 & 6008 \\
\hline Tibet & 285 & 639 & 197 & 159 & 15 & 10 & 5 & 265 & -7 & 2 & 126 & 128 & 72 & 134 & 206 & 0.1 & 3 & 3 & 67 & 90 & 158 & 67 & 93 & 161 & 355 & 75 & 430 & 75 & 122 & 197 \\
\hline Shaanxi & 3699 & 430 & 2562 & 107 & 116 & 75 & 64 & 3901 & -101 & -33 & -843 & -877 & 1670 & 6050 & 7720 & -14.3 & -52 & -66 & -361 & -1308 & -1669 & -375 & -1359 & -1735 & 423 & 1160 & 1584 & 1175 & 4257 & 5432 \\
\hline Gansu & 2547 & 691 & 1764 & 172 & 84 & 54 & 44 & 2607 & -67 & -16 & -405 & -421 & 1590 & 3720 & 5310 & -9.8 & -23 & -33 & -247 & -578 & -826 & -257 & -601 & -858 & 605 & 1143 & 1748 & 1153 & 2697 & 3850 \\
\hline Qinghai & 548 & 543 & 380 & 135 & 22 & 14 & 10 & 594 & -15 & 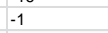 & -17 & -18 & 131 & 617 & 748 & -0.2 & -1 & -1 & -4 & -18 & -22 & -4 & -19 & -23 & 220 & 89 & 310 & 90 & 422 & 512 \\
\hline Ningxia & 604 & 137 & 418 & 34 & 20 & 13 & 11 & 833 & -22 & -12 & -304 & -316 & 951 & 473 & 142 & $\begin{array}{l}-0.4 \\
-13.8\end{array}$ & -7 & -21 & -347 & $\begin{array}{l}-173 \\
-173\end{array}$ & -520 & -361 & -180 & -541 & 1115 & 499 & 1614 & 512 & 255 & 766 \\
\hline Xinjiang & 2050 & 865 & 1420 & 215 & 71 & 46 & 36 & 3962 & -102 & -79 & -1994 & -2073 & 2560 & 1020 & 3580 & -51.1 & -20 & -71 & -1288 & -513 & -1801 & -1339 & -534 & -1873 & 619 & 940 & 1559 & 983 & 392 & 1374 \\
\hline China $\mathrm{A}^{\mathrm{A}}$ & 129523 & 22539 & 89721 & 5600 & 4130 & 2665 & 2254 & 108466 & -2800 & -1296 & 0 & -1296 & 39358 & 115740 & 155098 & -657 & -600 & -1257 & 0 & 0 & 0 & -657 & -600 & -1257 & 355 & 1081 & 1436 & 34371 & 103891 & 1138263 \\
\hline
\end{tabular}

A. National total crop utilization and supply accounts are obtained from FAO (2014).

B. Statistics on provincial population and livestock are obtained from NBSC (2013).

C. Positive value means import. Negative value means export.

D. Provincial "crop trade balance" refers to net crop import.

E. "Food" is equal to the sum of "food directly" and "food manufactured" obtained from FAO (2014). 


\title{
5. Consumptive Water Footprint and Virtual Water Trade Scenarios for China with a Focus on Crop Production, Consumption and Trade ${ }^{4}$
}

\begin{abstract}
The study assesses green and blue water footprints (WFs) and virtual water (VW) trade in China under alternative scenarios for 2030 and 2050, with a focus on crop production, consumption and trade. We consider five driving factors of change: climate, harvested crop area, technology, diet, and population. Four scenarios (S1-S4) are constructed by making use of three of IPCC's shared socio-economic pathways (SSP1-SSP3) and two of IPCC's representative concentration pathways (RCP 2.6 and RCP 8.5) and taking 2005 as the baseline year. Results show that, across the four scenarios and for most crops, the green and blue WFs per tonne will decrease compared to the baseline year, due to the projected crop yield increase, which is driven by the higher precipitation and $\mathrm{CO}_{2}$ concentration under the two RCPs and the foreseen uptake of better technology. The WF per capita related to food consumption decreases in all scenarios. Changing to the less-meat diet can generate a reduction in the WF of food consumption of $44 \%$ by 2050 . In all scenarios, as a result of the projected increase in crop yields and thus overall growth in crop production, China will reverse its role from net VW importer to net VW exporter. However, China will remain a big net VW importer related to soybean, which accounts for $5 \%$ of the WF of Chinese food consumption (in S1) by 2050. All scenarios show that China could attain a high degree of food self-sufficiency while simultaneously reducing water consumption in agriculture. However, the premise of realizing the presented scenarios is smart water and cropland management, effective and coherent policies on water, agriculture and infrastructure, and, as in scenario $\mathrm{S} 1$, a shift to a diet containing less meat.
\end{abstract}

\footnotetext{
${ }^{4}$ The Chapter has been submission to Environment International and being under review.
} 


\subsection{Introduction}

Intensified competition for finite water resources among different sectors is challenging the sustainability of human society. Agriculture is the biggest water consumer, accounting for $92 \%$ of global water consumption (Hoekstra and Mekonnen, 2012). In China, the world's most populous country, agriculture was responsible for $64 \%$ of the total blue water withdrawal in 2014 (MWR, 2015). About $81 \%$ of the nation's water resources are located in the south, but $56 \%$ of the total harvested crop area is located in the north (Piao et al., 2010; NBSC, 2013; Jiang, 2015). China is a net virtual water importer related to agricultural products (Hoekstra and Mekonnen, 2012). Local overuse of water threatens the sustainability of water resources in China (Hoekstra et al., 2012). China's agricultural water management will be increasingly challenged by climate change, population growth, and socio-economic development (NDRC, 2007; Piao et al., 2010; Jiang, 2015).

The Chinese government pursues self-sufficiency in major staple foods (wheat, rice and maize) (NDRC, 2008; SCPRC, 2014b) and has set the 'three red lines' policy on sustainable agricultural blue water use, which sets targets regarding total maximum national blue water consumption ( 670 billion $\mathrm{m}^{3} \mathrm{y}^{-1}$ ), improving irrigation efficiency (aiming at $55 \%$ at least) and improving water quality (SCPRC, 2010). However, risks to water security arise not only from blue water scarcity, but also from scarcity of green water (rainwater stored in soil), which limits the national food production potential (Falkenmark, 2013). An important question is whether China can pull off the political plan to attain both food and water security under climate change combined with population growth and socio-economic development. A question relevant for the world as a whole is how the development of Chinese food consumption and production, given future socio-economic changes and climate change, will impact on the country's net crop trade and related net virtual water trade.

This study assesses green and blue water footprints (WFs) and virtual water (VW) trade in China under alternative scenarios for 2030 and 2050, with a focus on crop production, consumption and trade. We consider five driving factors of change: climate, harvested crop area, technology, diet, and population. We consider 22 primary crops, covering $83 \%$ of 
national harvested crop area (2009) (NBSC, 2013) and 97\% and 78\% of China's total blue and green WFs of crop production (1996-2005), respectively (Mekonnen and Hoekstra, 2011). We take the year 2005 as the baseline. The spatial resolution of estimating the WF of crop production is 5 by 5 arc min.

WF is an indicator of water use in relation to production or consumption in the economy (Hoekstra, 2003). In the agricultural sector, the WF of crop production measures the consumption of rainfall at croplands over the crop growing period (the green WF), the consumption of groundwater and surface water as a result of irrigation (the blue WF), and the water pollution that results from the leaching and runoff of fertilizers and pesticides from croplands (the grey WF) (Hoekstra et al., 2011; Hoekstra, 2013). The green and blue WFs together are called the consumptive WF, while the grey WF is also called the degradative WF. In the current study, we focus on analysing the consumptive (green and blue) WF. The WF of the consumption in a country consists of an internal and external component. The internal WF refers to the WF within the country itself for making products that are consumed within the country. The external WF of national consumption refers to the WF in other areas for making products that are imported by and consumed within the country (Hoekstra et al., 2011).

A number of WF and VW trade scenario studies are available, some at global level (Fader et al., 2010; Pfister et al., 2011; Hanasaki et al., 2013a; Hanasaki et al., 2013b; Konar et al., 2013; Liu et al., 2013; Haddeland et al., 2014; Wada and Bierkens, 2014), others focussing on China (Thomas, 2008a; Mu and Khan, 2009; Xiong et al., 2010; Dalin et al., 2015; Zhu et al., 2015). Several studies suggest that blue water scarcity in China will increase as a result of a growing blue WF of crop production and a decreasing blue water availability in the course of the $21^{\text {st }}$ century (Mu and Khan, 2009; Xiong et al., 2010; Pfister et al., 2011; Hanasaki et al., 2013a; Hanasaki et al., 2013b; Haddeland et al., 2014; Wada and Bierkens, 2014). However, the scenario analyses generally exclude the potential decrease of consumptive WFs per unit of crop under the combined effect of climate and technological progress. Besides, regarding the consumptive WF of crop production in climate change scenarios, the findings of several studies contradict each other. Zhu et al. (2015) find a 
significant increased total blue WF for croplands in northwest, southeast and southwest China as a result of climate change under IPCC SRES B1, A1B and A2 scenarios by 2046-2065. On the contrary, Liu et al. (2013) find that both blue and total consumptive WFs will decrease in the North China Plain and southern parts of China and increase in the other parts of the country under the IPCC SRES A1FI and B2 scenarios. Thomas (2008a) finds a decreased blue WF in north and northwest China by 2030, based on a climate change scenario extrapolated from a regression trend derived from the time series for 1951-1990. Fader et al. (2010) and Zhao et al. (2014) project a decline in consumptive WF per tonne of crops in China as a result of climate change under the IPCC SRES A2 scenario, owing to increased crop yields because of increased $\mathrm{CO}_{2}$ fertilization. By considering five socio-economic driving factors for 2050, Ercin and Hoekstra (2014) developed four global WF scenarios from both production and consumption perspectives. Under two of the global WF scenarios, China's WF of agricultural production will increase, while it will decrease in the other two WF scenarios. Dalin et al. (2015) assess future VW trade of China related to four major crops and three livestock products by 2030 under socio-economic development scenarios. They find that the VW import of China related to major agricultural products tends to increase given socio-economic growth by 2030. Konar et al. (2013) assess future global VW trade driven by both climate change and socio-economic developments for 2030, and find that China will remain the dominant importer of soybean. But they consider only three crops (rice, wheat and soybean) and neglected changes in crop yield to climate changes. By taking a more comprehensive approach - studying 22 crops, looking at production, consumption as well as trade, and considering climate change as well as socio-economic driving factors - the current study aims to achieve a broader understanding of how the different driving forces of change may play out

\subsection{Method and data}

\subsubsection{Scenario set-up}

Scenarios are sets of plausible stories, supported with data and simulations, about how the future might unfold from current conditions under alternative human choices (Polasky et al., 2011). In the current study we build on the 5th IPCC Assessment Report (IPCC, 2014), 
which employs a new generation of scenarios (Moss et al., 2010), including socio-economic narratives named shared socio-economic pathways (SSPs) (O'Neill et al., 2012) and emission scenarios named representative concentration pathways (RCPs) (van Vuuren et al., 2011).

Five SSPs (SSP1-SSP5) were developed within a two-dimensional space of socio-economic challenges to mitigation and adaptation outcomes (O’Neill et al., 2012) (Figure 5.1a). From SSP1 to SSP3, socio-economic conditions increasingly pose challenges and difficulties to mitigate and adapt to climate change. In order to cover the full range from the best to the worst possible future conditions of China, we choose to consider the two extreme scenarios SSP1 and SSP3. SSP1 represents a world with relatively low challenges to both climate change mitigation and adaptation, and SSP3 represents a world with relatively large challenges in both respects. In addition, we consider the middle of the road scenario SSP2 with an intermediate level of challenges. In sustainability scenario SSP1, the world makes relatively good progress towards sustainability: developing countries have relatively low population growth as well as rapid economic growth; increasingly developed technology is put towards environmentally friendly processes including yield-enhancing technologies for land; the consumption level of animal products is low. In middle-of-the-road scenario SSP2, the typical trends of recent decades continue, with a relatively moderate growth in population; most economics are stable with partially functioning and globally connected markets. In fragmentation scenario SSP3, the world is separated into regions characterized by extreme poverty, pockets of moderate wealth and a bulk of countries that struggle to maintain living standards for a strongly growing population, and slow technology development.

In this study, we constructed scenarios S1 to S4 by combining certain socio-economic scenarios with certain climate scenarios (Figure 5.1b). The assumptions for the four scenarios S1-S4 are summarised in Table 5.1. The five driving factors of change considered in this study have been quantified per scenario as will be discussed below. 
(a)

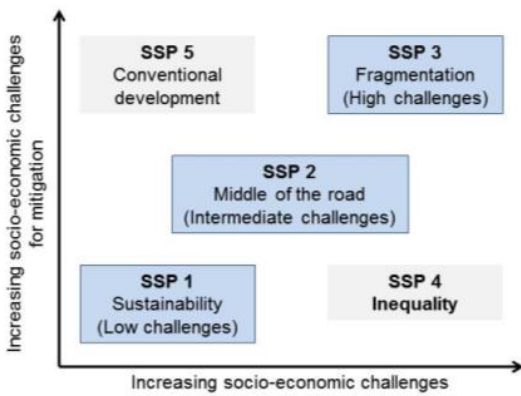

for adaptation

Figure 5.1 (a) SSPs in the conceptual space of socio-economic challenges for mitigation and adaptation. Source: O'Neill et al. (2012). (b) Definition of scenarios S1-4 used in the current study in the matrix of SSPS and RCPS.

Table 5.1 Summary of the four scenarios S1-4 in the current study.

\begin{tabular}{lcccc}
\hline & $S 1$ & $S 2$ & $S 3$ & S4 \\
\hline Shared socio-economic pathway & SSP1 & SSP2 & SSP2 & SSP3 \\
$\begin{array}{l}\text { Population growth } \\
\text { Diet }\end{array}$ & Relatively low & Medium & Medium & Relatively high \\
$\begin{array}{l}\text { Yield increase through technology } \\
\text { development }\end{array}$ & High & Medium & Medium & Low \\
$\begin{array}{l}\text { Representative concentration pathway } \\
\text { climate outcomes (GCMs) }\end{array}$ & Current trend & Current trend & Current trend \\
Harvested crop area (IAM) & CanESM2, GFDL-CM3, GISS-E2-R and MPI-ESM-MR \\
\hline
\end{tabular}

Population. The SSPs of the IPCC consist of quantitative projections of population growth as given by IIASA (2013) (Table 5.2). 
Table 5.2 Population projections for China under SSP1 to SSP3.

\begin{tabular}{lcccccccc}
\hline & \multirow{2}{*}{2005} & \multicolumn{3}{c}{2030} & & \multicolumn{3}{c}{2050} \\
\cline { 3 - 4 } & & $S S P 1$ & $S S P 2$ & $S S P 3$ & & SSP 1 & SSP 2 & SSP 3 \\
\hline $\begin{array}{l}\text { Population } \\
\text { (million) }\end{array}$ & 1307.59 & 1359.51 & 1380.65 & 1398.88 & & 1224.52 & 1263.14 & 1307.47 \\
\hline
\end{tabular}

Source: IIASA (2013).

Climate. The IPCC distinguishes four RCPs (RCP 2.6, 4.5, 6 and 8.5) based on different radiative forcing levels by 2100 (from 2.6 to $8.5 \mathrm{~W} / \mathrm{m}^{2}$ ) (van Vuuren et al., 2011). In this study, we consider the two climate change scenarios RCP2.6 (also called RCP 3PD) (van Vuuren et al., 2007) and RCP8.5 (Riahi et al., 2007). RCP2.6 represents pathways below the $10^{\text {th }}$ percentile and RCP8.5 pathways below the $90^{\text {th }}$ percentile of the reference emissions range (Moss et al., 2010). By combining the RCPs and SSPs, a matrix framework was proposed showing that an increased level of mitigation efforts corresponds to a decreased level of climate hazard (Kriegler et al., 2010). For the purpose of our study we constructed two scenarios S1 and S2 by combining climate scenarios forced by RCP2.6 with socio-economic scenarios SSP1 and SSP2, respectively. In addition we constructed two scenarios S3 and S4 that combine climate outcomes forced by RCP8.5 with SSP2 and SSP3, respectively (Figure 5.1b). Climate change projections by four Global Climate Models (GCMs) within the Coupled Model Intercomparison Project (CMIP5) (Taylor et al., 2012) were used: CanESM2 (Canadian Centre for Climate Modelling and Analysis), GFDL-CM3 (NOAA Geophysical Fluid Dynamics Laboratory), GISS-E2-R (NASA Goddard Institute for Space Studies), and MPI-ESM-MR (Max Planck Institute for Meteorology). The models were selected from nineteen GCMs in such a way that the outcomes of the selected GCMs span the full range of projections for China on precipitation $(\mathrm{mm})$ for spring and summer (March to July), when most crops grow. The projections by CanESM2 and GFDL-CM3 represent relatively wet conditions and the projections by GISS-E2-R and MPI-ESM-MR relatively dry conditions (Table 5.3). 
Table 5.3 Projected changes in national average precipitation (PR), maximum temperature $\left(T_{\text {max }}\right)$, minimum temperature $\left(T_{\text {min }}\right)$, reference evapotranspiration $\left(E T_{0}\right)$ and $\mathrm{CO}_{2}$ concentration in China for the four selected GCMs for RCP2.6 and RCP8.5 by the years 2030 and 2050 compared to 2005.

\begin{tabular}{|c|c|c|c|c|c|c|c|c|}
\hline \multirow[b]{2}{*}{$\begin{array}{l}\text { Changes in climate } \\
\text { variables }\end{array}$} & \multicolumn{4}{|c|}{ RCP2.6 } & \multicolumn{4}{|c|}{$R C P 8.5$} \\
\hline & $\begin{array}{l}\text { Can } \\
\text { ESM } \\
2 \\
\end{array}$ & $\begin{array}{l}\text { GFDL- } \\
\text { CM3 }\end{array}$ & $\begin{array}{l}\text { GISS } \\
-E 2-R\end{array}$ & $\begin{array}{l}\text { MPI-E } \\
\text { SM-M } \\
\text { R } \\
\end{array}$ & $\begin{array}{l}\text { Can } \\
\text { ESM } \\
2 \\
\end{array}$ & $\begin{array}{l}\text { GFDL- } \\
\text { CM3 }\end{array}$ & $\begin{array}{l}\text { GISS- } \\
\text { E2-R }\end{array}$ & $\begin{array}{l}\text { MPI-E } \\
\text { SM-M } \\
\text { R }\end{array}$ \\
\hline \multicolumn{9}{|l|}{ Year: 2030} \\
\hline $\begin{array}{l}\text { Relative changes in annual } \\
\text { PR }\end{array}$ & $15 \%$ & $12 \%$ & $1 \%$ & $4 \%$ & $16 \%$ & $8 \%$ & $2 \%$ & $7 \%$ \\
\hline Increase in $\mathrm{T}_{\max }\left({ }^{\circ} \mathrm{C}\right)$ & 1.9 & 2.4 & 0.9 & 1.2 & 2.2 & 2.6 & 1.4 & 1.6 \\
\hline Increase in $\mathrm{T}_{\min }\left({ }^{\circ} \mathrm{C}\right)$ & 1.7 & 2.0 & 0.5 & 0.9 & 2.1 & 2.2 & 1.1 & 1.4 \\
\hline $\begin{array}{l}\text { Relative changes in annual } \\
\mathrm{ET}_{0} \\
\text { Relative changes in } \mathrm{CO}_{2} \\
\text { concentration }\end{array}$ & $3 \%$ & \multicolumn{2}{|c|}{$13 \%$} & $2 \%$ & \multicolumn{4}{|c|}{$18 \%$} \\
\hline \multicolumn{9}{|l|}{ Year: 2050} \\
\hline $\begin{array}{l}\text { Relative changes in annual } \\
\text { PR }\end{array}$ & $19 \%$ & $20 \%$ & $3 \%$ & $5 \%$ & $24 \%$ & $20 \%$ & $6 \%$ & $7 \%$ \\
\hline Increase in $\mathrm{T}_{\max }\left({ }^{\circ} \mathrm{C}\right)$ & 2.2 & 3.1 & 0.9 & 1.3 & 3.5 & 4.3 & 2.2 & 2.7 \\
\hline Increase in $T_{\min }\left({ }^{\circ} \mathrm{C}\right)$ & 2.1 & 2.5 & 0.5 & 1.0 & 3.5 & 3.7 & 1.8 & 2.6 \\
\hline $\begin{array}{l}\text { Relative changes in annual } \\
\mathrm{ET}_{0}\end{array}$ & $3 \%$ & $8 \%$ & $2 \%$ & $2 \%$ & $6 \%$ & $11 \%$ & $5 \%$ & $5 \%$ \\
\hline $\begin{array}{l}\text { Relative changes in } \mathrm{CO}_{2} \\
\text { concentration }\end{array}$ & \multicolumn{4}{|c|}{$17 \%$} & \multicolumn{4}{|c|}{$42 \%$} \\
\hline
\end{tabular}

Harvested crop area. We use the harmonized land use (HLU) scenarios provided at a resolution of 30 by 30 arc min from (Hurtt et al., 2011). We downscale the original data to a 5 by 5 arc min resolution. The changes in cropland area, provided as a fraction of each grid cell, were obtained from the IMAGE model (van Vuuren et al., 2007) for the RCP2.6 pathway and the MESSAGE model (Rao and Riahi, 2006; Riahi et al., 2007) for the RCP8.5 pathway. We apply the projected relative changes in the cropland area per crop and grid cell to the current cropland area per crop and grid cell as provided by Portmann et al. (2010) and (Monfreda et al., 2008). The total harvested crop area for the selected crops in China is projected to increase by $19 \%$ from 2005 to 2050 in RCP2.6 and by $4 \%$ in RCP8.5. 
Crop yield increase through technology development. According to a recent global yield gaps analysis for major crops (Mueller et al., 2012), it is possible to increase yields by $45 \%-70 \%$ for most crops. For China's case, studies are available only for wheat, maize and rice. Meng et al. (2013) reported that experimental attainable maize yield was $56 \%$ higher than the average (7.9 $\mathrm{t} \mathrm{ha}^{-1}$ ) farmer's yield in China for 2007-2008. Lu and Fan (2013) found that the yield gap for winter wheat is $47 \%$ of the actual yield in the North China Plain. Zhang et al. (2014) estimated that the national average yield gap for rice is $26 \%$ of the actual yield. With limited land and water resources available to expand the acreage of croplands, the only way to enlarge production is by yield increase (Huang et al., 2002). In a scenario analysis on potential global yield increases, De Fraiture et al. (2007) conclude that yield growth can reach $20-72 \%$ for rain-fed cereals and $30-77 \%$ for irrigated cereals as compared to the year 2000. Due to a lack of quantitative data on crop yield growth under each SSP, we took the values from De Fraiture et al. (2007) as a starting point by assuming a yield increase of $72 \%$ from 2000 to 2050 in SSP1, 46\% in SSP2, and 20\% in SSP3. Assuming a linear increase in the crop yield over time, corresponding yield increases over the period 2005-2030 are 34\% in SSP1, 22\% in SSP2, and 10\% in SSP3, and corresponding yield increases over the period 2005-2050 are 60\% in SSP1, 40\% in SSP2, and 18\% in SSP3.

Diet. We make use of the two diet scenarios for East Asia for 2050 by Erb et al. (2009). We assume the less-meat scenario for SSP1 and the current-trend scenario for SSP2 and SSP3. We assume that the conversion factor from the kilocalorie intake to kilogram consumption of each type of crop per capita remains constant over the years. As shown in Table 5.4, the share of animal products in the Chinese diet will decrease by $37 \%$ in the less-meat scenario and increase by $4.4 \%$ in the current-trend scenario, compared to baseline year 2005 .

Table 5.4 Two diet scenarios for China.

\begin{tabular}{lccc}
\hline \multirow{2}{*}{$\begin{array}{l}\text { Consumption per capita } \\
\text { in kcal/day per category }\end{array}$} & $2005^{\mathrm{a}}$ & & \multicolumn{2}{c}{2050} \\
\cline { 3 - 4 } & & Current-trend scenario $^{\mathrm{b}}$ & Less-meat scenario \\
\hline Cereal & 1458 & $1552(6.4 \%)$ & $1709(17.2 \%)$ \\
Roots & 187 & $149(-20.6 \%)$ & $201(7.6 \%)$ \\
Sugar crops & 60 & $85(41.7 \%)$ & $124(106.7 \%)$
\end{tabular}




\begin{tabular}{lccc} 
Oil crops & 246 & $288(17.1 \%)$ & $265(7.8 \%)$ \\
Vegetables and fruits & 247 & $205(-16.9 \%)$ & $219(-11.2 \%)$ \\
Other crops & 95 & $66(-30.4 \%)$ & $82(-13.5 \%)$ \\
Animal products & 586 & $612(4.4 \%)$ & $372(-36.5 \%)$ \\
\hline Total & 2879 & $2956(2.8 \%)$ & $2973(3.3 \%)$ \\
\hline
\end{tabular}

a. Source: FAO (2014b);

b. Values were generated according to the scenarios for East Asia by Erb et al. (2009), with relative changes from 2005 level in brackets.

\subsubsection{Estimating water footprints and virtual water trade}

Following Hoekstra et al. (2011), green and blue WFs of producing a crop $\left(\mathrm{m}^{3} \mathrm{t}^{-1}\right)$ are calculated by dividing the total green and blue evapotranspiration $\left(\mathrm{ET}_{[\mathrm{t}]}, \mathrm{m}^{3} \mathrm{ha}^{-1}\right)$ over the crop growing period, respectively, by the crop yield $\left(\mathrm{Y}, \mathrm{t} \mathrm{ha}^{-1}\right)$. Daily ET and $\mathrm{Y}$ were simulated, at a resolution level of 5 by 5 arc min, with the FAO crop water productivity model AquaCrop (Hsiao et al., 2009; Raes et al., 2009; Steduto et al., 2009). Following Chapter 3, the daily green and blue ET were derived based on the relative contribution of precipitation and irrigation to the daily green and blue soil water balance of the root zone, respectively. We considered multi-cropping of rice (i.e. twice a year in southern China) and assumed single cropping for other crops. The simulated $\mathrm{Y}$ of each crop for the baseline year was scaled to match provincial statistics (NBSC, 2013). The projected Y under climate scenarios was obtained by multiplying the scaled baseline $\mathrm{Y}$ by the ratio of the simulated future $\mathrm{Y}$ to the simulated baseline $\mathrm{Y}$.

The water footprint of food consumption ( $\left.\mathrm{WF}_{\text {cons, food }}, \mathrm{m}^{3} \mathrm{y}^{-1}\right)$ includes the WF related to the consumption of crops and crop products as well as the WF related to the consumption of animal products. The WF related to crop consumption $\left(\mathrm{m}^{3} \mathrm{y}^{-1}\right)$ under each scenario was obtained, per crop, by multiplying the crop consumption volume $\left(\mathrm{C}_{\text {crop } \text {, food }}, \mathrm{t}^{-1}\right)$ by the WF per tonne of the crop $\left(\mathrm{WF}_{\text {cons, unit crop }}, \mathrm{m}^{3} \mathrm{t}^{-1}\right)$. The WF related to the consumption of animal products $\left(\mathrm{m}^{3} \mathrm{y}^{-1}\right)$ was estimated by multiplying total animal products consumption $\left(\mathrm{C}_{\text {animal, }}\right.$, food, $\left.\mathrm{kcal}^{-1}\right)$ by the WF per kilocalorie of animal products $\left(\mathrm{WF}_{\text {cons, unit animal }}, \mathrm{m}^{3} \mathrm{kcal}^{-1}\right)$.

$\mathrm{C}_{\text {crop, food }}$ was calculated, per crop, as the crop consumption per capita (in $\mathrm{kg} \mathrm{cap}^{-1} \mathrm{y}^{-1}$ ) times the projected population. We consider the seed and waste as part of the food consumption. 
The fraction of seed and waste in the crop consumption is assumed to be constant in the coming decades and calculated as the ratio of total waste and seed to the total crop use in the

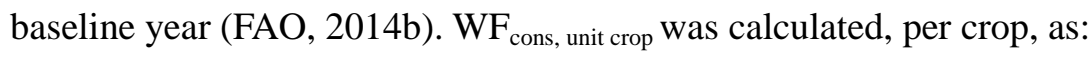

$W F_{\text {cons,unit crop }}=\frac{P_{\text {crop }} \times W F_{\text {prod }}+I_{\text {crop }} \times W F i_{\text {prod }}}{P_{\text {crop }}+I_{\text {crop }}}$

where $\mathrm{P}_{\text {crop }}\left(\mathrm{t} \mathrm{y}^{-1}\right)$ is the total national production of the crop, $\mathrm{I}_{\text {crop }}\left(\mathrm{t} \mathrm{y}^{-1}\right)$ the total import of the crop from outside the country; $\mathrm{WF}_{\text {prod }}\left(\mathrm{m}^{3} \mathrm{t}^{-1}\right)$ the water footprint of the crop produced domestically, and $\mathrm{WFi}_{\text {prod }}\left(\mathrm{m}^{3} \mathrm{t}^{-1}\right)$ the water footprint of the imported crop, taken as the global average WF of the crop as reported by Mekonnen and Hoekstra (2011). Under each scenario, $\mathrm{I}_{\text {crop }}$ equals to the sum of the crop consumption for food $\left(\mathrm{C}_{\text {crop, food }}\right)$ and the crop consumption for feed $\left(\mathrm{C}_{\text {crop, feed }}, \mathrm{t}^{-1}\right)$ minus the national production of the crop $\left(\mathrm{P}_{\text {crop }}\right)$. A negative value for $\mathrm{I}_{\text {crop }}$ means export. The crop import $\mathrm{I}_{\text {crop }}$ multiplied with $\mathrm{WFi}_{\text {prod }}$ refers to the net VW import related to trade in the crop $\left(\mathrm{m}^{3} \mathrm{y}^{-1}\right)$.

$\mathrm{C}_{\text {crop, feed }}$ changes with animal products consumption, which is driven by population growth, personal income growth and diet changes (Rosegrant et al., 1999; Du et al., 2004; Bouwman et al., 2005; Keyzer et al., 2005; Liu and Savenije, 2008; Trostle, 2008; Nonhebel and Kastner, 2011; Shiferaw et al., 2011; Hoekstra and Mekonnen, 2012; Hoekstra and Wiedmann, 2014). Here we assume that the relative change in $\mathrm{C}_{\text {crop } \text {, feed }}$ under each scenario is the same as the relative changes in the total consumption of animal products, which is driven by corresponding diet changes (Table 5.4) and population growth. $\mathrm{C}_{\text {crop, feed }}$ in China for the baseline year 2005 was obtained from FAO (2014b).

Values for $\mathrm{WF}_{\text {cons, unit animal }}$ in China in the baseline year were obtained from Hoekstra and Mekonnen (2012). The WF of animal feed contributes $98 \%$ to the WF of animal products (Mekonnen and Hoekstra, 2012). Animal productivity was assumed to grow in the future as a result of higher offtake rates and higher carcass weights or milk or egg yields (Bruinsma,

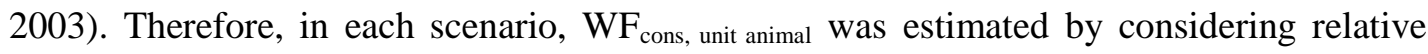
changes in the WF of animal feed $\left(\Delta \mathrm{WF}_{\text {feed }}, \%\right)$ and potential improvements in animal productivity (i.e. animal production output per unit mass of feed) $\left(\Delta_{\text {productivity }} \%\right)$ : 
$W F_{\text {cons,unit animal }}=\frac{W F_{\text {cons,unit animal }[2005]} \times\left(1+\Delta \mathrm{WF}_{\text {feed }}\right)}{\left(1+\Delta_{\text {productivity }}\right)}$

$\Delta \mathrm{WF}_{\text {feed }}$ Was calculated as a weighted average of changes in the WF of feed crops $(\Delta \mathrm{WF}$ feed crops, \%) and changes in the WF of other feed ingredients (i.e. pasture, crop residues and other roughages) $\left(\Delta \mathrm{WF}_{\text {feed other, }} \%\right)$, given their corresponding shares in the total WF of animal feed in China $\left(\mathrm{pct}_{\text {feed crops }}\right.$ and $\left.\mathrm{pct}_{\text {feed other }}, \%\right)$ :

$\Delta \mathrm{WF}_{\text {feed }}=\Delta W F_{\text {feed crops }} \times p c t_{\text {feed crops }}+\Delta W F_{\text {feed other }} \times p c t_{\text {feed other }}$

We assume that the composition of the animal feed in China stays constant. Currently, the selected crops account for $75 \%$ of the total feed crop consumption in quantity (FAO, 2014b) and contribute $70 \%$ and $86 \%$ to the green and blue WFs of feed crops consumed in China, respectively (Hoekstra and Mekonnen, 2012). For the feed crops that are not included in the current study, the $\Delta \mathrm{WF}_{\text {feed other }}$ was assumed in line with the assumed crop yield increase under each scenario. The values of $\mathrm{pct}_{\text {feed crops }}$ and $\mathrm{pct}_{\text {feed others }}$ for green and blue WFs were obtained from Mekonnen and Hoekstra (2012). We use the projections on $\Delta_{\text {productivity }}$ for the various types of animal products by Bouwman et al. (2005) for East Asia from 1995 to 2030, assuming a linear increase. We took a weighted average based on production of each type of animal product in the baseline year (NBSC, 2013), which implies an animal productivity increase of $4 \%$ by 2030 and $8 \%$ by 2050 compared to the baseline year 2005 .

China's international virtual water trade was estimated per crop by considering the difference between the WF of crop production and the WF of crop consumption (in the form of food, feed, seed or waste) within China.

\subsubsection{Data}

The GIS polygon data for China were obtained from NASMG (2010). Climate data for baseline year 2005 on monthly precipitation (PR), reference evapotranspiration $\left(\mathrm{ET}_{0}\right)$, maximum temperature $\left(\mathrm{T}_{\max }\right)$ and minimum temperature $\left(\mathrm{T}_{\min }\right)$ at a resolution of 30 by 30 arc min were taken from Harris et al. (2014). The downscaled GCM outputs at 5 by 5 arc min grid level for China on monthly $\mathrm{PR}, \mathrm{T}_{\max }$ and $\mathrm{T}_{\min }$ were obtained from Ramirez-Villegas 
and Jarvis (2010). Since this dataset does not included data on $\mathrm{ET}_{0}$, we calculated monthly $\mathrm{ET}_{0}$ with inputs on temperature through the Penman-Monteith method introduced in Allen et al. (1998) for the baseline year 2005 and each climate scenario. Then the monthly $\mathrm{ET}_{0}$ under each climate scenario was corrected by adding the absolute changes in the calculated $\mathrm{ET}_{0}$ from 2005 to the values of 2005 in CRU-TS database. The projected $\mathrm{CO}_{2}$ concentrations (in ppm) under the two RCPs were obtained from IIASA (2009). Data on irrigated and rain-fed areas for each crop at 5 by 5 arc min resolution were obtained from the MIRCA2000 dataset (Portmann et al., 2010). For crops not available in this database, we used the 5 by 5 arc min crop area map by Monfreda et al. (2008). Crop yield statistics at province level for the baseline year were taken from NBSC (2013). For crops not reported in NBSC (2013), we used national average values from FAOSTAT (FAO, 2014b). Soil texture data were obtained from the ISRIC Soil and Terrain database for China(Dijkshoorn et al., 2008). Data on total soil water capacity (in \% vol) at a spatial resolution of 5 by 5 arc min were obtained from the ISRIC-WISE version1.2 dataset (Batjes, 2012).

\subsection{Results}

\subsubsection{Water footprint of crop production}

For most of the crops studied, consumptive WFs per tonne of crop were projected to decrease across all scenarios. Taking cereal crops (wheat, rice, maize, sorghum, millet and barley) as an example, compared to the baseline year 2005, the consumptive WF per tonne of cereal crops reduced by 41\%, 35\%, 36\% and 24\% till 2050 under S1, S2, S3 and S4, respectively, averaged across the four GCMs. From Figure 5.2 we can see that the reductions in the WFs of cereal crops were mainly driven by significant increases in crop yields, which have larger impact than the relatively small changes in ET under each scenario. The effects of climate change on WF of crops can be observed by comparing scenarios S2 and S3 under the same SSP and different RCPs. Positive effects on crop yields by increased $\mathrm{CO}_{2}$ fertilization have been widely reported (Yao et al., 2007; Tao and Zhang, 2011; Wada et al., 2013; Zhao et al., 2014), which is also shown in the current result. With relatively small differences in $\mathrm{ET}_{0}$ and precipitation for RCP 2.6 and RCP8.5 (see Table 5.3), scenario $\mathrm{S} 3$ for RCP8.5 with significant higher $\mathrm{CO}_{2}$ concentration had higher cereal yields than 
scenario S2 for RCP 2.6 (Figure 5.2). The effect of the application of better technology on the WF can be observed by comparing S1 versus S2 (both RCP2.6) and S3 versus S4 (both RCP8.5). The scenarios with a higher level of technology development (S1 and S3) have a higher yield increase and a lower WF per tonne of crop. The increase in irrigated cereal yields is around $20 \%$ higher than the increase in rain-fed cereal yields under each scenario, which reflects the limits on yield increases by water stress on rain-fed fields. The reduction of the blue WF per tonne of cereal crop is higher than for the green WF under each scenario. This is because of the decrease in irrigation requirements and thus in blue ET as a result of projected increases in precipitation across the GCM scenarios for both RCP2.6 and RCP 8.5. The relative changes in the WF per tonne for the selected crops under the four scenarios are listed in Appendix 5C.

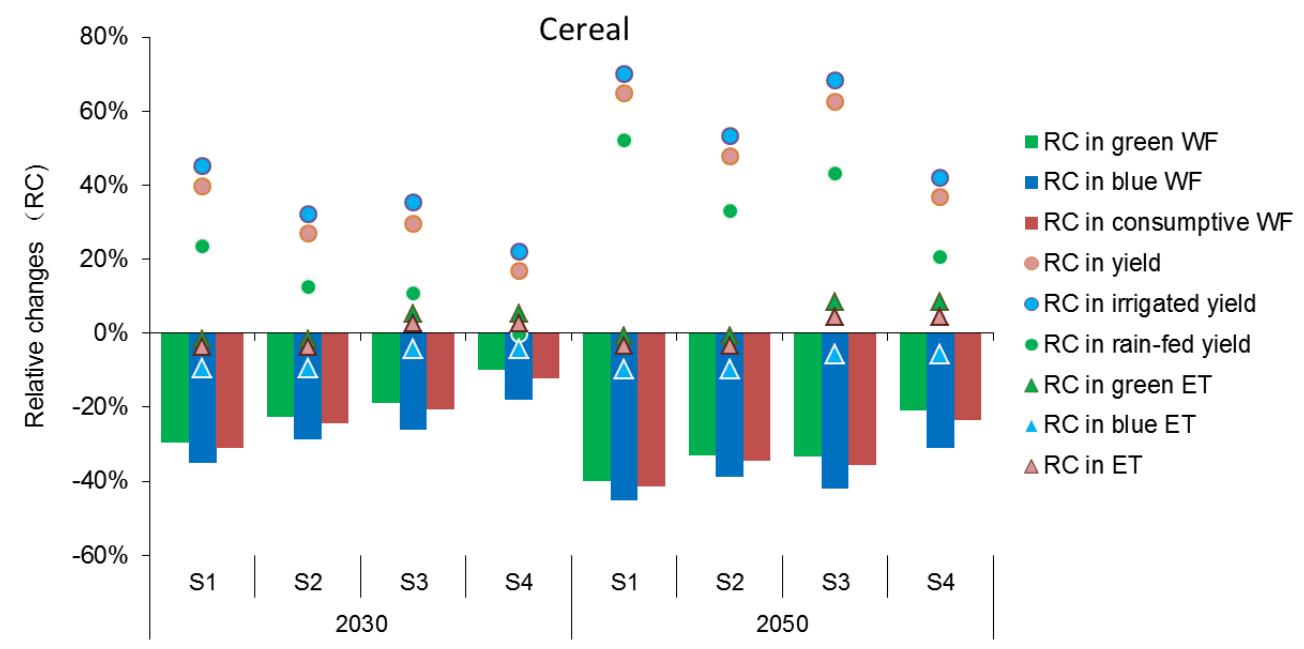

Figure 5.2 Relative changes (RC) in water footprint (WF) per tonne of a cereal crop, cereal yield and average ET at cereal croplands in China across scenarios as compared to the baseline year 2005 .

Figure 5.3 shows maps of multi-GCM averaged projected changes in green, blue and total consumptive WF per tonne of cereal crop over the period 2005-2050 under RCP8.5. Under 
this RCP, the national average green, blue and total consumptive WFs of cereal crops are projected to decrease by $7 \%, 19 \%$ and $10 \%$, respectively. Reductions in both green and blue WFs of cereal crops larger than $40 \%$ were mostly located in Northwest China, which includes the upper and middle reaches of the severely water stressed Yellow River Basin, due to the projected increases in annual precipitation by more than $60 \%$ across GCM scenarios (see Appendix 5A). The projected wetter climate in the Northwest helps to reduce the water stress on rain-fed fields and the resulted yield loss. In most areas in the Northeast, the green and blue WF per tonne of crops was projected to increase by more than $40 \%$ as a result of the projected increase in $\mathrm{ET}_{0}$ and decrease in precipitation in the Northeast across the GCM scenarios (Appendix 5A, 5B).

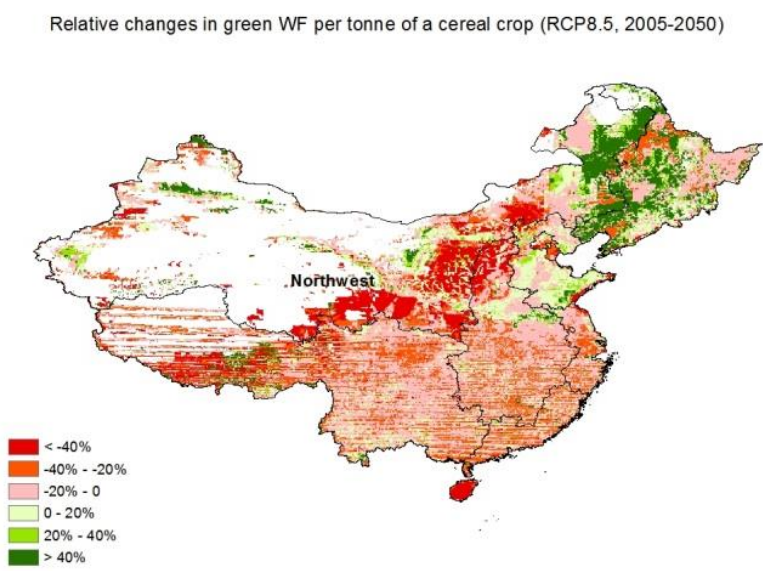

Relative changes in blue WF per tonne of a cereal crop (RCP 8.5, 2005-2050)

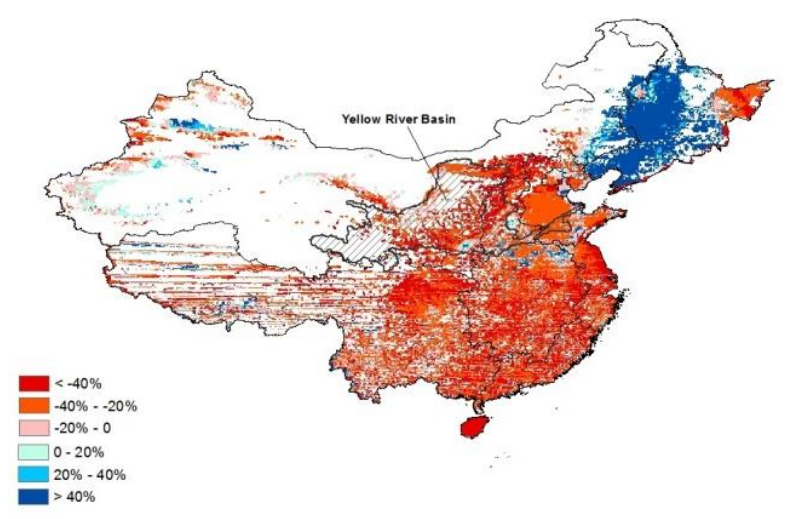




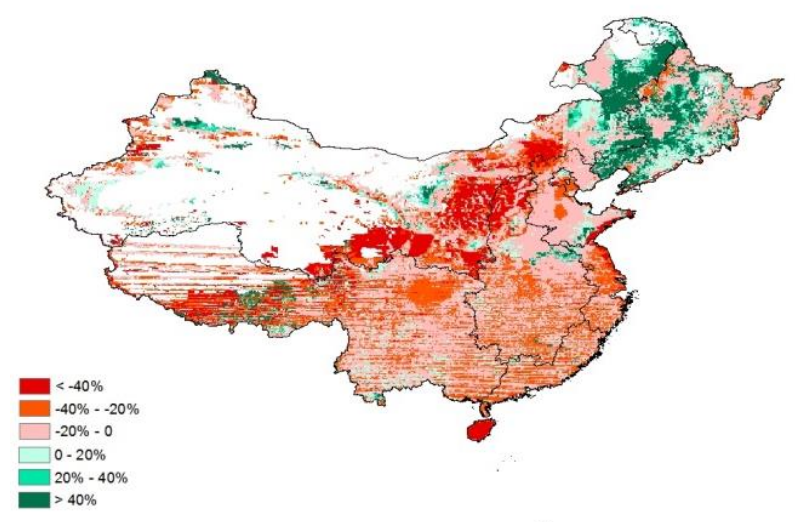

Figure 5.3 Changes in green, blue and overall consumptive water footprint (WF) per tonne of cereal crop in China over the period 2005-2050 under RCP8.5.

In Figure 5.4 we plotted the relative changes in WF per tonne of the crops studied against the corresponding relative changes in crop yield under each scenario. A reference line indicates the relative changes in WFs when only yields change (thus without the effect of changing ET on WFs). The vertical deviation of the dots from the line shows the impact of changing ET on WFs. The dots below the line, which is the majority, show the positive impact of reduced ET on reducing the WF per unit mass of crops.

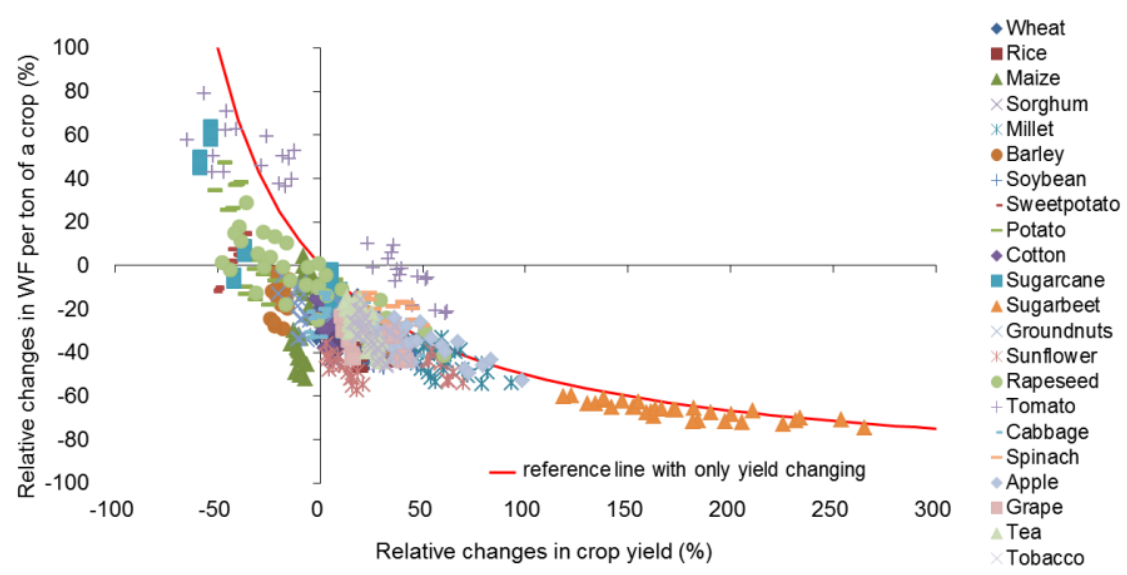

Figure 5.4 Relationship between relative changes in crop yields and relative changes in corresponding water footprint per tonne of crop. One dot refers to the projection for one crop under one GCM for one scenario for one year. 
Over the period 2005-2050, the total national consumptive WF (in $\mathrm{m}^{3} \mathrm{y}^{-1}$ ) of crop production increases by $18 \%$ under RCP2.6 (S1 and S2), and by $0.8 \%$ under RCP8.5 (S3 and S4), as a result of the combined effect of climate change and projected changes in harvested crop area. The impact of projected changes in harvested crop area under each RCP (19\% increase from 2005 to 2050 under RCP2.6 and 4\% decrease under RCP8.5) on the total WF was significant, because average ET per hectare over croplands increases by only $3.1 \%$ from 2005 to 2050 for RCP2.6 and by $5.6 \%$ for RCP8.5. The total green WF of crop production increases under both RCPs (by $21 \%$ from 2005 to 2050 under RCP2.6 and by 4\% under RCP8.5). The total blue WF increases under RCP2.6 (by $4.3 \%$ to 2050) and decreases under RCP8.5 (by $10 \%$ to 2050 ).

\subsubsection{Water footprint of food consumption}

The water footprint of food consumption per capita in China decreases across all scenarios as compared to the baseline year $\left(927 \mathrm{~m}^{3} \mathrm{cap}^{-1} \mathrm{y}^{-1}\right)$, driven by the decreased WF per tonne of most crops. The largest decrease in the WF of food consumption per capita (by $44 \%$ to 2050) is observed under scenario S1 (Figure 5.5). This large decrease is due to the less-meat diet combined with the largest decrease in consumptive WF per unit of crops and animal products. S4 shows the most modest decrease in the WF of food consumption per capita (20\% to 2050), which is due to diet type (current-trend diet) and a relatively low reduction level in the WFs per unit of crop and animal product compared to the other scenarios. In "current trend" diet scenarios (S2-4), animal product consumption was the largest contributor $(\sim 41-46 \%)$ to WF of food consumption followed by cereal consumption $(\sim 31-32 \%)$ and oil crop consumption $(\sim 14-18 \%)$. In the "less meat" scenario (S1), the WF of animal product consumption decreased significantly (by $65 \%$ from 2005 to 2050) and became the second largest contributor, after cereal consumption, to total WF of Chinese food consumption. This reduction was driven by decreases in both animal product consumption (by $37 \%$ to 2050) and WF per unit calorie of animal products (by $43 \%$ to 2050). 


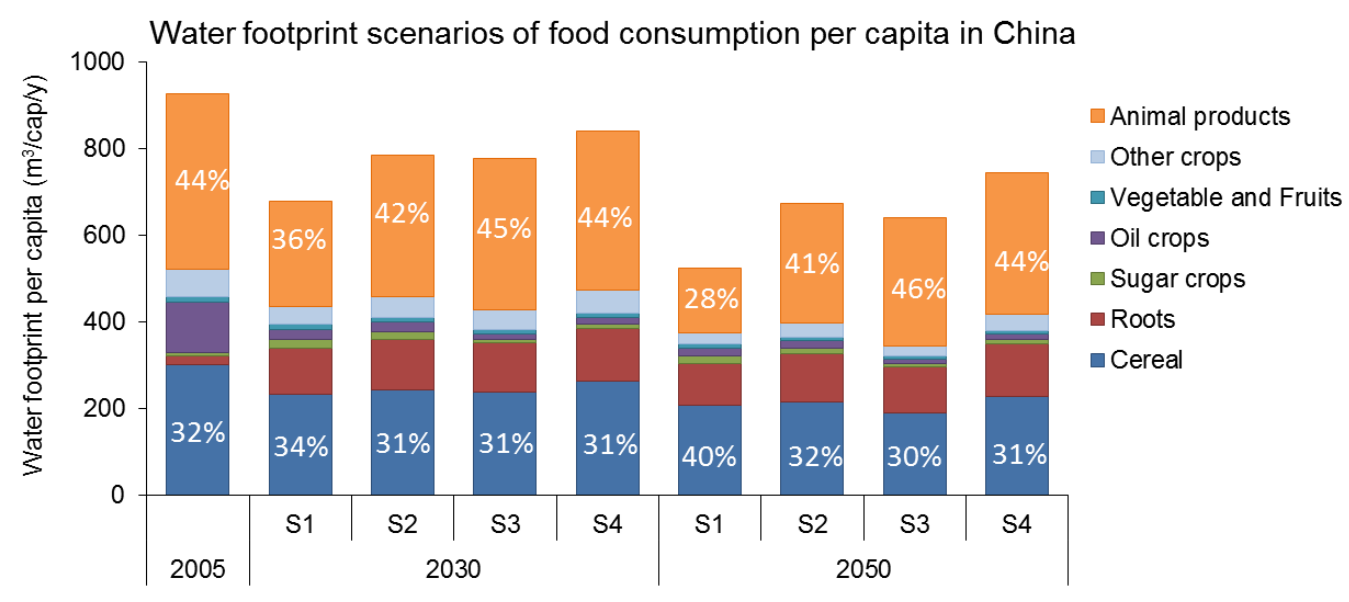

Figure 5.5 Water footprint of food consumption per capita under the four scenarios of China.

The total national consumptive WF of food consumption is projected to decrease across all scenarios, compared to the baseline level of 2005 (1212 billion $\mathrm{m}^{3} \mathrm{y}^{-1}$ ) (Figure 5.6). Even under an increased population by 2030 , we observe a decrease in the total WF of consumption. The main reason for this decrease is the decrease in WF per unit of consumed crop and animal products, and the fact that the population increase to 2030 remains modest. The more significant decrease by 2050 is a combination of the projected declining population and the further decrease in WFs per unit of crops and animal products. In S1, with the smallest population size and the largest decrease in WF per capita, the total WF of food consumption drops most, decreasing on average by $24 \%$ and $47 \%$ by 2030 and 2050 , respectively. With the current-trend diet, the smaller decrease in the WF of food consumption in S4 compared to $\mathrm{S} 2$ and $\mathrm{S} 3$ results from the relatively large size of the population and the relatively high WFs per unit of crops and animal products.

The reductions in blue WFs are higher than those in green WFs across all scenarios, in line with the higher reductions in the blue WFs per unit of production, which result from climate change and yield improvements through technology. The reduction in the green WF of food consumption in S1 is higher than in the other scenarios, as a result of larger share of roots and sugar crops in the diet and the low fraction of blue WF in the total consumptive WF per unit for roots and sugar crops ( 2-3\% for root crops and $\sim 0-8 \%$ for sugar crops). 


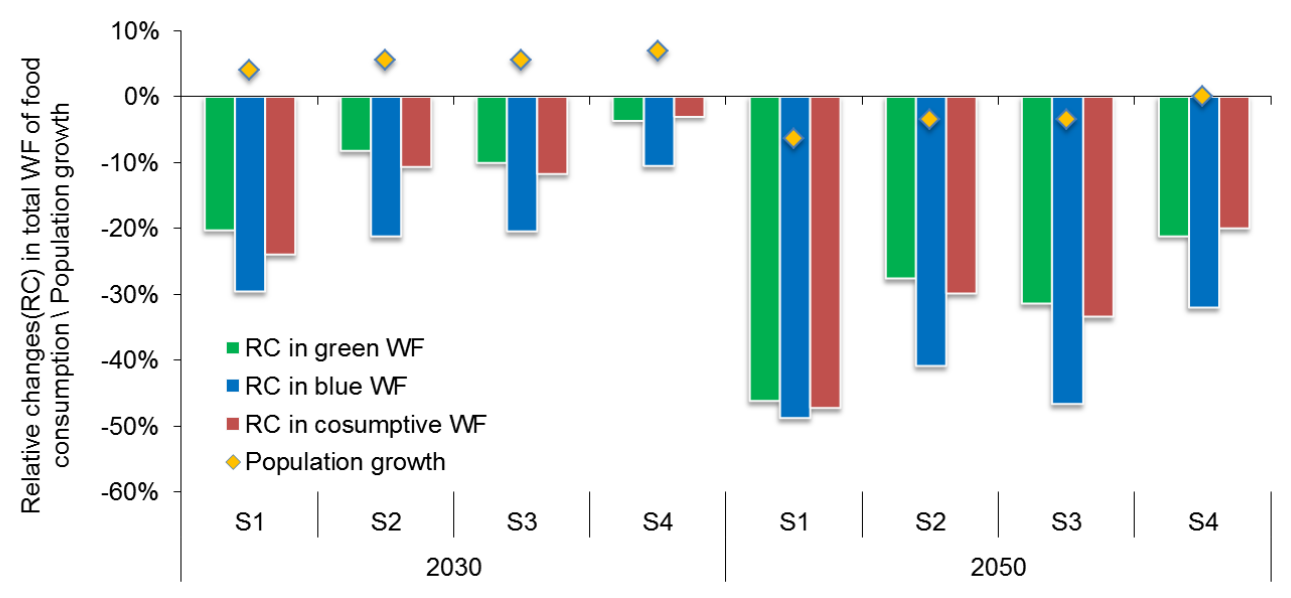

Figure 5.6 Changes in China's green, blue and total consumptive water footprint of food consumption across scenarios, as compared to the baseline year 2005. The green, blue and overall consumptive water footprints in 2005 are 1030, 183, and 1212 billion $\mathrm{m}^{3} \mathrm{y}^{-1}$, respectively.

\subsubsection{National virtual water trade related to crop products}

While in the baseline year 2005 China was a net virtual water importer (with respect to trade in the crops considered in this study), the country will have become net virtual water exporter by 2050 , in all scenarios. In scenarios S1-S3 this is already the case in 2030. The potential reversal of China's role in the global VW trade network was also reported by Ercin and Hoekstra (2014), but contradicts the projected increase in net VW import of major agricultural products by Dalin et al. (2015). However, the result of Dalin et al. (2015) was based on a totally different scenario, with decreasing irrigation area and reduced exports of crops. The current result shows an enhanced self-sufficiency in food supply and a potential contribution to the global VW trade network as an exporter. Table 5.5 presents the multi-GCM averaged net VW import related to crop trade across scenarios. The VW export of China under S1 is larger than in the other scenarios, with the net VW export as high as $38 \%$ of the total consumptive WF of crop production. This is the result of the relatively high increase in crop production, by the relatively high crop yield and expansion of harvested 
crop area, and smaller crop consumption due to the projected population decrease and less-meat diet. In S4, China is still a net VW importer by 2030, due to the VW import related to the large soybean import, which is larger than the total VW export through all exported crops.

Table 5.5 Net virtual water import of China related to trade in considered crops, for the baseline year 2005 and for 2030 and 2050 in the four scenarios.

\begin{tabular}{|c|c|c|c|c|c|c|c|c|c|}
\hline \multirow{2}{*}{$\begin{array}{l}\text { Net virtual water } \\
\text { import }\left(10^{9} \mathrm{~m}^{3} \mathrm{y}^{-1}\right)\end{array}$} & \multirow{2}{*}{2005} & \multicolumn{4}{|c|}{2030} & \multicolumn{4}{|c|}{2050} \\
\hline & & S1 & S2 & S3 & S4 & S1 & S2 & S3 & S4 \\
\hline Green water & 82 & -133 & -70 & -3 & 65 & -267 & -192 & -139 & -40 \\
\hline Blue water & 14 & -39 & -26 & -9 & 9 & -71 & -59 & -48 & -23 \\
\hline Total & 97 & -172 & -96 & -12 & 73 & -338 & -250 & -187 & -62 \\
\hline
\end{tabular}

Figure 5.7 shows the multi-GCM averaged net VW import of China related to different crops under the four scenarios. China's shift from net VW importer to net VW exporter occurs most in particular through the projected export of rice and wheat. In the baseline year, export of maize contributes most to China's virtual water export, responsible for $86 \%$ of the crop-related VW exports of China. In the future, rice export is expected to become the biggest contributor to China's virtual water export, accounting for $38 \%$ of total VW export in 2050 in $\mathrm{S} 1,42 \%$ in $\mathrm{S} 2,33 \%$ in S3, and 32\% in S4. In S1, the net VW export related to rice export even becomes $53 \%$ of the total WF of rice production in China by 2050 . China will remain a big VW importer related to soybean in all scenarios. According to Konar et al. (2013), China could become world's largest VW importer through soybean trade in the future. In the baseline year, $61 \%$ of Chinese soybean consumption depends on import. By 2050 , the projected dependency on soybean imports is $24 \%, 37 \%, 45 \%$ and $55 \%$ in $\mathrm{S} 1, \mathrm{~S} 2$, $\mathrm{S} 3$ and $\mathrm{S} 4$, respectively.

The fraction of the external WF in the total WF of crop consumption decreases in all scenarios, most in S1 and least in S4 (Table 5.6). 


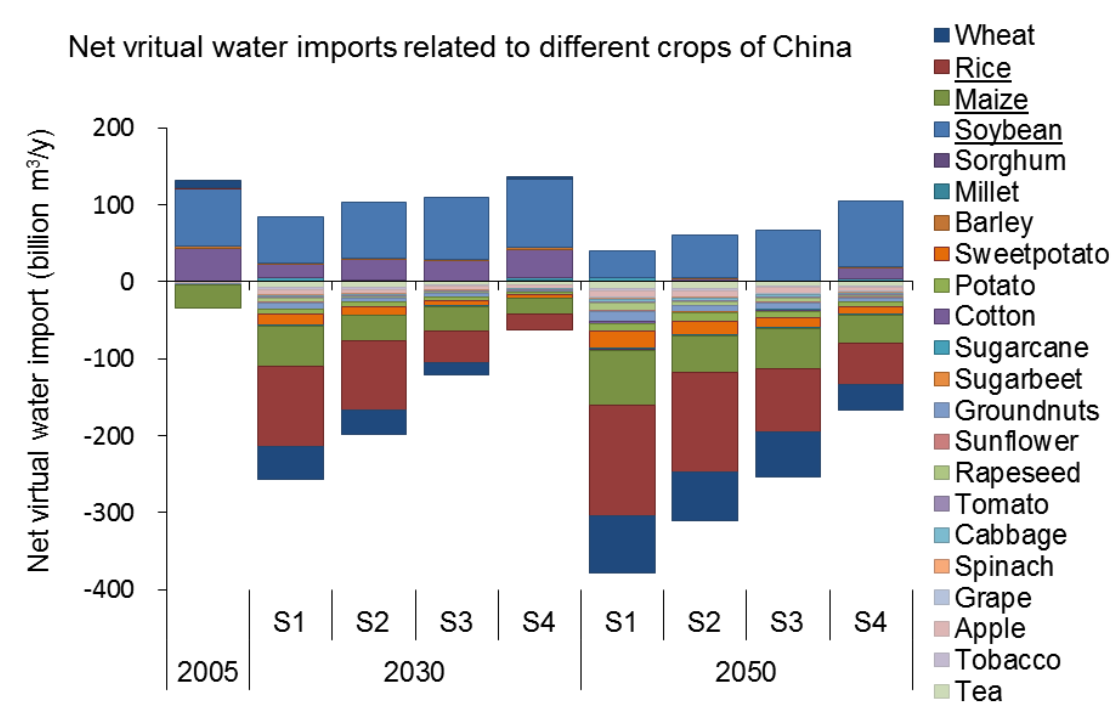

Figure 5.7 Net virtual water import of China related to its trade in different crops, for the baseline year 2005 and for 2030 and 2050 in the four scenarios.

Table 5.6 Fraction of the external water footprint (WF) in the total water footprint of Chinese crop consumption, in the baseline year and in 2030 and 2050 under the four scenarios.

\begin{tabular}{|c|c|c|c|c|c|c|c|c|c|}
\hline \multirow{2}{*}{$\begin{array}{l}\text { Fraction of external WF in } \\
\text { total WF of crop } \\
\text { consumption }\end{array}$} & \multirow{2}{*}{2005} & \multicolumn{4}{|c|}{2030} & \multicolumn{4}{|c|}{2050} \\
\hline & & S1 & $\mathrm{S} 2$ & S3 & S4 & $\mathrm{S} 1$ & $\mathrm{~S} 2$ & S3 & S4 \\
\hline Green WF & $17 \%$ & $10 \%$ & $12 \%$ & $15 \%$ & $17 \%$ & $5 \%$ & $8 \%$ & $10 \%$ & $14 \%$ \\
\hline Blue WF & $11 \%$ & $6 \%$ & $7 \%$ & $8 \%$ & $11 \%$ & $1 \%$ & $2 \%$ & $1 \%$ & $6 \%$ \\
\hline Consumptive WF & $15 \%$ & $9 \%$ & $11 \%$ & $13 \%$ & $16 \%$ & $5 \%$ & $7 \%$ & $9 \%$ & $13 \%$ \\
\hline
\end{tabular}

\subsubsection{Discussion}

In Table 5.7 we compare the current results with the results from earlier studies where possible. The relative changes in WF per tonne of wheat and maize in China in the current study are in the same direction but much larger than the global average values as suggested by (Fader et al., 2010). The differences in magnitude originate from the different geographic scopes of the studies, but also from the fact that different climate scenarios and crop models are used. The relative changes in total blue WF at the current irrigated cropland in China 
from the current study, which considers the impacts of both changing precipitation and $\mathrm{ET}_{0}$, are smaller than the estimates for Asia provided by Pfister et al. (2011), who considers the impact of changing precipitation only. The changes in WF of crop production in China found in the current study are much smaller than the figures presented by Ercin and Hoekstra (2014). The decrease in total WF of food consumption in scenario S1 in the current study is greater than the decrease in scenarios S3 and S4 in Ercin and Hoekstra (2014), which are based on the same less-meat diet scenario, but exclude the effect of reduced WFs per unit of food products by climate change that has been included in the current study. The relative changes in VW import related to soybean for S3 in the current study agree best with the result for the low-yield scenario in Konar et al. (2013). 
Table 5.7 Comparison between the results from the current study and previous studies.

\begin{tabular}{|c|c|c|c|c|c|c|c|c|}
\hline & Current study & Year & Scenarios & Other studies & Year & Scenarios & Scope & Sources \\
\hline \multirow{4}{*}{$\begin{array}{l}\text { Changes in } \\
\text { consumptive WF } \\
\text { per tonne of } \\
\text { consumed crops } \\
(\%)\end{array}$} & $-27 /-36$ & \multirow[t]{4}{*}{$2005-50$} & RCP2.6 & $-0.43 /-0.45$ & \multirow[t]{4}{*}{$2041-70$} & SRES A2 & \multirow{4}{*}{$\begin{array}{l}\text { Global } \\
\text { Wheat }\end{array}$} & \multirow{4}{*}{$\begin{array}{l}\text { Fader et } \\
\text { al.(2010) }\end{array}$} \\
\hline & $-26 /-39$ & & RCP8.5 & \multirow{3}{*}{$-0.35 /-0.44$} & & & & \\
\hline & $-44 /-50$ & & RCP2.6 & & & & & \\
\hline & $-7 /-23$ & & RCP8.5 & & & & & \\
\hline \multirow{2}{*}{$\begin{array}{l}\text { Changes in total } \\
\text { blue WF at } \\
\text { current irrigated } \\
\text { area }(\%)\end{array}$} & -8 & & RCP2.6 & \multirow{2}{*}{-11} & \multirow{2}{*}{$2000-50$} & Precipitation & \multirow{2}{*}{ Asia } & \multirow[t]{2}{*}{$\begin{array}{l}\text { Pfister et al. } \\
(2011)\end{array}$} \\
\hline & -2 & & RCP8.5 & & & SRES A1B & & \\
\hline $\begin{array}{l}\text { Changes in total } \\
\text { WF of production } \\
(\%)\end{array}$ & $17 / 17 / 0.8 / 0.8$ & & $\mathrm{~S} 1 / \mathrm{S} 2 / \mathrm{S} 3 / \mathrm{S} 4$ & $89 / 127 /-22 /-22$ & $\begin{array}{l}2000-50 \\
\mathrm{~S} 1 / \mathrm{S} 2 / \mathrm{S} 3 / \mathrm{S} \\
4\end{array}$ & $\begin{array}{l}\text { Global } \\
\text { socio-econom } \\
\text { ic scenarios }\end{array}$ & China & $\begin{array}{l}\text { Ercin and } \\
\text { Hoekstra (2014) }\end{array}$ \\
\hline $\begin{array}{l}\text { Changes in total } \\
\text { WF of } \\
\text { consumption (\%) }\end{array}$ & $-47 /-30 /-33 /-20$ & & & 79/117/-29/-25 & & & China & $\begin{array}{l}\text { Ercin and } \\
\text { Hoekstra (2014) }\end{array}$ \\
\hline \multirow{2}{*}{$\begin{array}{l}\text { Net virtual water } \\
\text { import }\left(10^{9} \mathrm{~m}^{3} / \mathrm{y}\right)\end{array}$} & $\begin{array}{l}60(-19 \%) / 71 \\
(-3 \%) / 81(11 \%) / \\
90(21 \%)\end{array}$ & 2030 & $\mathrm{~S} 1 / \mathrm{S} 2 / \mathrm{S} 3 / \mathrm{S} 4$ & $\begin{array}{l}25(-11 \%) / 32 \\
(13 \%)\end{array}$ & $\begin{array}{l}2030 \text { (low } \\
\text { yield/ high } \\
\text { yield) }\end{array}$ & SRES A2 & Soybean & $\begin{array}{l}\text { Konar et al. } \\
(2013)\end{array}$ \\
\hline & $\begin{array}{l}-338 /-250 /-187 /-6 \\
2\end{array}$ & 2050 & $\mathrm{~S} 1 / \mathrm{S} 2 / \mathrm{S} 3 / \mathrm{S} 4$ & $\begin{array}{l}-171 /-152 / \\
-101 /-63\end{array}$ & $\begin{array}{l}2050 \\
\text { S1/S2/S3/S } \\
4\end{array}$ & & $\begin{array}{l}\text { Agricultural } \\
\text { products }\end{array}$ & $\begin{array}{l}\text { Ercin and } \\
\text { Hoekstra (2014) }\end{array}$ \\
\hline
\end{tabular}


The current study has a number of limitations with regard to assumptions in modelling the WF of crops. First, we assumed a constant cropping calendar (planting date and length of cropping period) for each crop considered, which neglects the potential impact of temperature changes on the crop growing period as reported in previous studies (Yao et al., 2007; Hatfield et al., 2011; Tao and Zhang, 2011). Second, we assumed constant initial soil water content at each grid among different scenarios. Third, we assumed a constant irrigated ratio for each grid cell because of lack of quantitative information in the harmonized land use projections that we used (Hurtt et al., 2011), which may cause over- or underestimation of the blue WF of crop production in China under different scenarios. Finally, we did not include the impacts of potential changes in fertilizer or pesticide inputs on crop production, neither did we consider water pollution as indicated by the grey WF. By focusing on the impact of water stress on crop growth in modelling, ignoring the potential impact of temperature stress (e.g. cold or heat stress) and biotic stress from weeds, insects and disease, we may overestimate crop production (Hatfield et al., 2011; Mueller et al., 2012).

In addition, there are inherent uncertainties in scenario studies. All scenarios are based on assumptions regarding climate change and socio-economic developments like population growth, changes in diets, technological improvements and land use changes. Different GCMs result in different climate projections for a given emission scenario, which can be addressed by using the projections from multiple GCMs (Semenov and Stratonovitch, 2010), as we did in the current study, although we considered four GCMs only. Finally, the crop model used, the Aquacrop model in our study, and parameter values chosen, will inevitably result in different yield predictions when compared to studies based other models and parameter sets (Asseng et al., 2013).

\subsection{Conclusion}

The study provides a comprehensive analysis of the consumptive WF and VW trade of China by 2030 and 2050, focusing on the agricultural sector, developing four alternative scenarios forced by different levels of population growth and by changes in production, consumption and climate. The four scenarios differ in assumptions and outcomes, but the projected futures share a few commonalities: 
(i) On average, the WF of producing a tonne of crop decreases due to the combined effect of climate change and technology improvements on yield increase. Wetter climate projections in Northwest China potentially reduce the local blue WF of crop production that can help to reduce the high blue water stress from the agriculture sector;

(ii) The WF of food consumption per capita decreases, up to $44 \%$ by 2050 if diets change to less meat (scenario S1). The total national WF of food consumption also decreases across all scenarios;

(iii) China will shift from net VW importer through crop trade to net VW exporter. However, China will remain depending on soybean imports.

The results suggest that the target of the Chinese government to achieve higher self-sufficiency in food supply while simultaneously reducing the WF of crop production (SCPRC, 2010; MOA et al., 2015) is feasible. However, the premise of realizing the presented scenarios is smart water and cropland management, effective and coherent policies on water, agriculture and infrastructure, and, in scenario S1, a successful shift to a diet containing less meat. 
Appendix 5A Relative changes in annual precipitation in China from 2005 to 2050 across GCMs for RCP2.6 (left) and RCP8.5 (right).
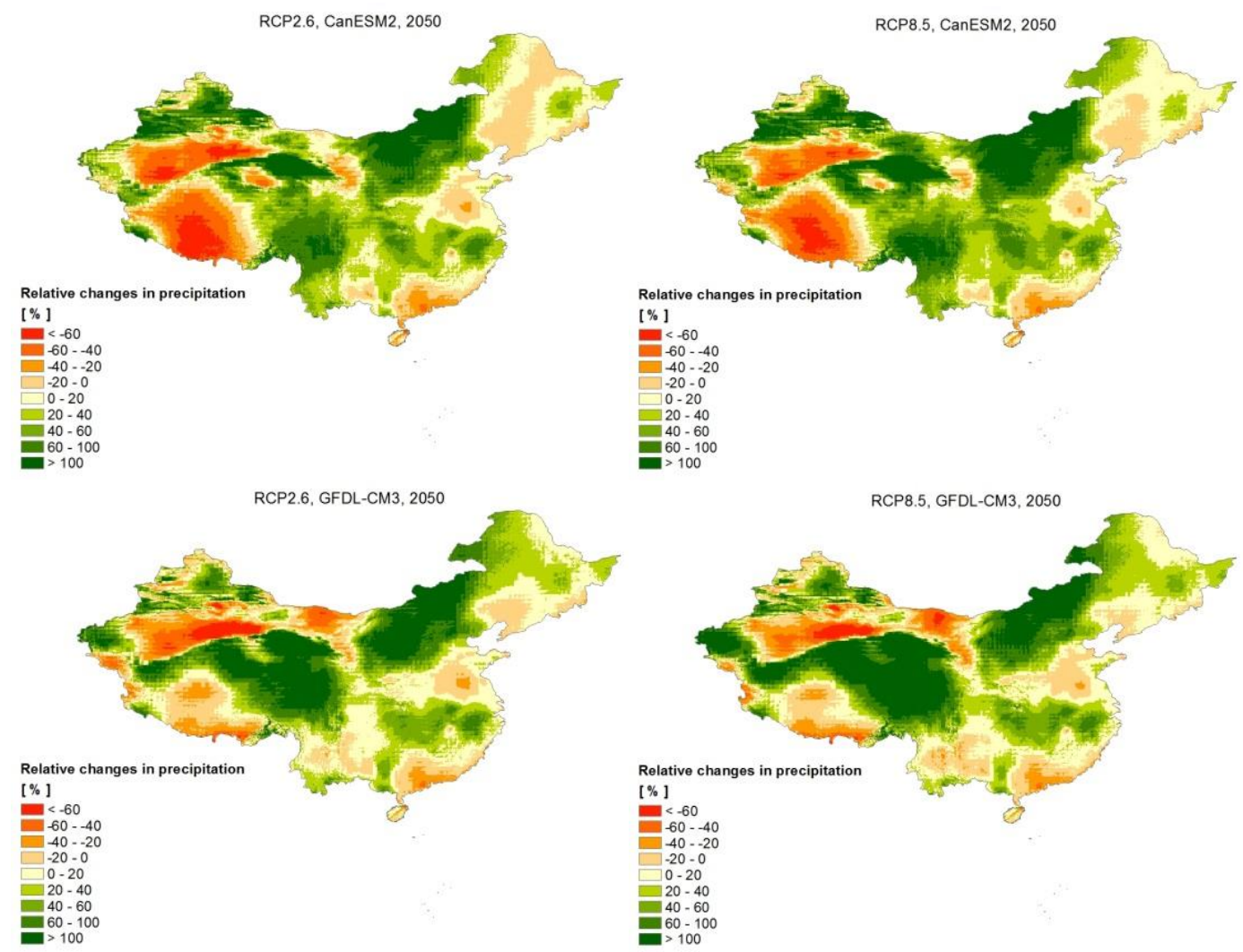

Projected changes in precipitation (RCP2.6, GISS-E2-R, 2050)

Relative changes in precipitation

[\%]

$<-60$
$-60-40$

$-40--20$

$-20-0$
$\quad 0-20$

$20-40$
$40-60$

$60-100$
$>100$

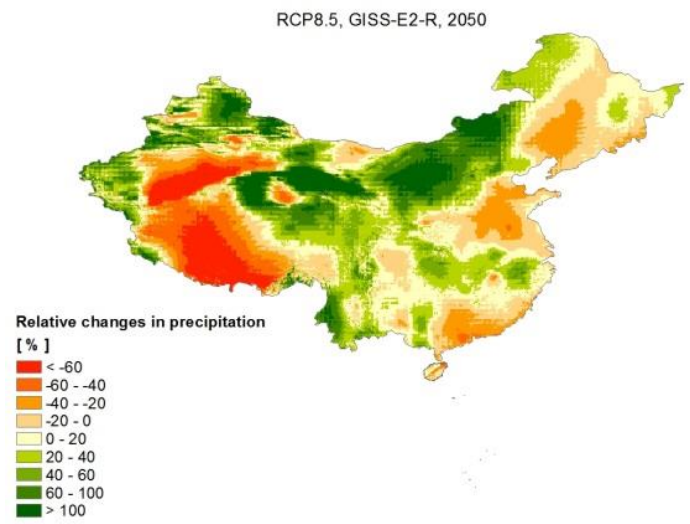

[\%

$<-60$
$-60-$

$-40--20$

$-20-0$
$0-20$

$=20-40$

$40-60$
$-60-100$ 

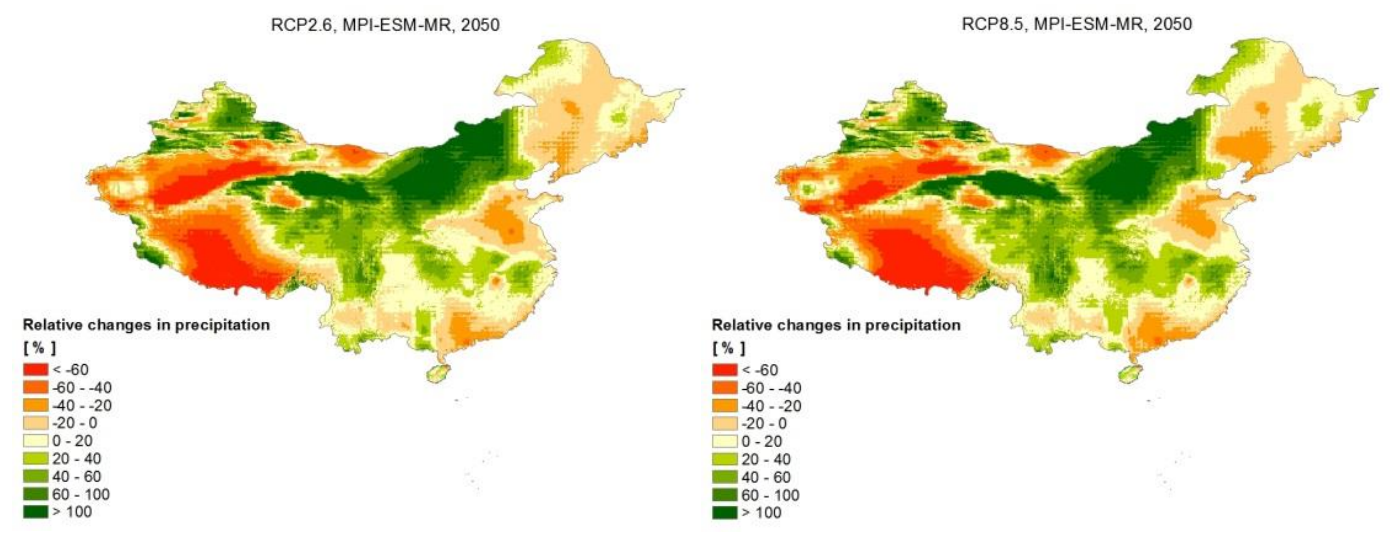
Appendix 5B Relative changes in annual reference evapotranspiration in China from 2005 to 2050 across GCMs for RCP2.6 (left) and RCP8.5 (right).

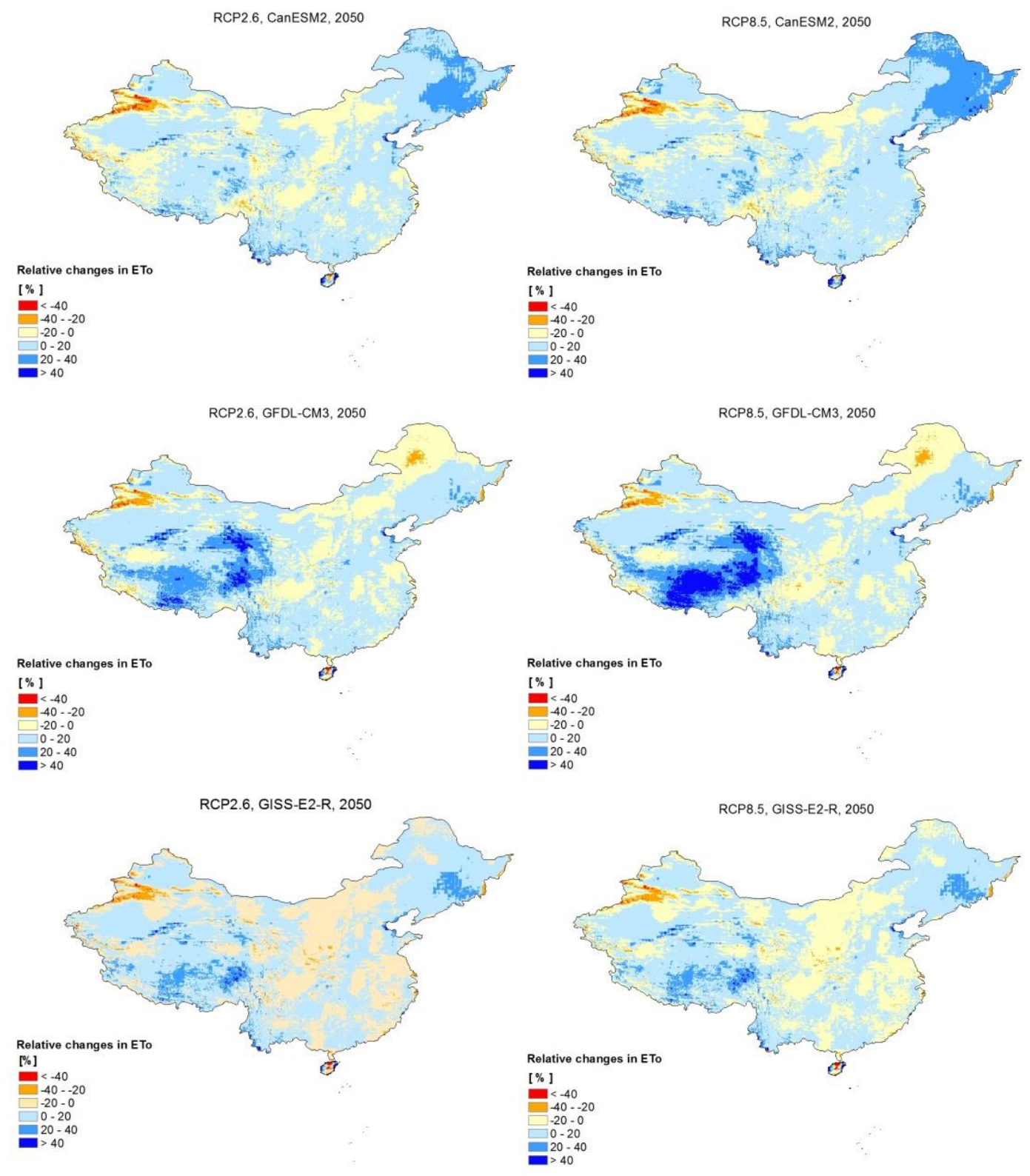



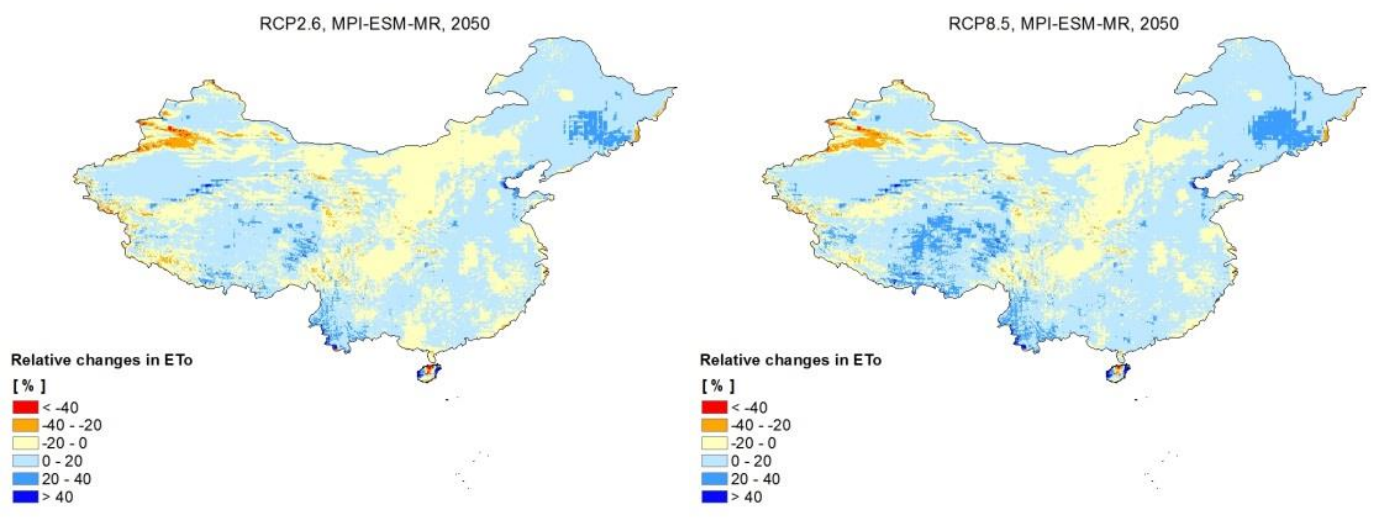
Appendix 5C Relative changes in the green, blue and total consumptive water footprint $\left(\mathrm{m}^{3}\right.$ $\mathrm{t}^{-1}$ ) of the 22 considered crops in China across scenarios, compared to the baseline year 2005.

\begin{tabular}{|c|c|c|c|c|c|c|c|c|c|}
\hline \multirow{2}{*}{ Crop } & \multirow{2}{*}{$\begin{array}{l}\text { Relative } \\
\text { changes in WF } \\
\text { of a crop }\end{array}$} & \multicolumn{2}{|c|}{ S1 } & \multicolumn{2}{|c|}{ S2 } & \multicolumn{2}{|c|}{ S3 } & \multicolumn{2}{|c|}{$S 4$} \\
\hline & & 2030 & 2050 & 2030 & 2050 & 2030 & 2050 & 2030 & 2050 \\
\hline \multirow[t]{3}{*}{ Wheat } & Green & -20 & -31 & -12 & -21 & -18 & -35 & -9 & -23 \\
\hline & Blue & -31 & -43 & -24 & -34 & -23 & -44 & -15 & -33 \\
\hline & Total & -25 & -36 & -17 & -27 & -20 & -38 & -11 & -27 \\
\hline \multirow[t]{3}{*}{ Rice } & Green & -33 & -44 & -26 & -36 & -28 & -42 & -20 & -31 \\
\hline & Blue & -38 & -48 & -32 & -40 & -30 & -44 & -22 & -33 \\
\hline & Total & -34 & -45 & -27 & -37 & -28 & -42 & -20 & -31 \\
\hline \multirow[t]{3}{*}{ Maize } & Green & -37 & -49 & -30 & -42 & -4 & -17 & 6 & -2 \\
\hline & Blue & -45 & -57 & -40 & -51 & -35 & -46 & -28 & -36 \\
\hline & Total & -38 & -51 & -32 & -43 & -10 & -22 & 0 & -8 \\
\hline \multirow[t]{3}{*}{ Sorghum } & Green & -34 & -44 & -28 & -36 & -22 & -32 & -14 & -19 \\
\hline & Blue & -18 & -33 & -10 & -24 & -12 & -25 & -2 & -11 \\
\hline & Total & -33 & -43 & -27 & -35 & -22 & -32 & -13 & -19 \\
\hline \multirow[t]{3}{*}{ Millet } & Green & -43 & -52 & -37 & -46 & -41 & -50 & -34 & -41 \\
\hline & Blue & -37 & -50 & -30 & -43 & -37 & -50 & -30 & -41 \\
\hline & Total & -42 & -52 & -37 & -45 & -41 & -50 & -34 & -41 \\
\hline \multirow[t]{3}{*}{ Barley } & Green & -9 & -25 & 0 & -15 & -21 & -39 & -13 & -27 \\
\hline & Blue & -34 & -46 & -28 & -39 & -35 & -52 & -28 & -43 \\
\hline & Total & -11 & -27 & -2 & -16 & -22 & -40 & -14 & -28 \\
\hline \multirow[t]{3}{*}{ Soybean } & Green & -33 & -45 & -26 & -37 & -28 & -42 & -21 & -32 \\
\hline & Blue & -47 & -60 & -41 & -54 & -35 & -50 & -28 & -40 \\
\hline & Total & -33 & -46 & -27 & -38 & -29 & -43 & -21 & -32 \\
\hline \multirow[t]{3}{*}{ Sweet potato } & Green & 7 & -9 & 17 & 3 & -26 & -41 & -18 & -30 \\
\hline & Blue & -31 & -42 & -24 & -34 & -34 & -52 & -26 & -43 \\
\hline & Total & 5 & -11 & 15 & 2 & -27 & -42 & -19 & -31 \\
\hline \multirow[t]{3}{*}{ Potato } & Green & 29 & -13 & 42 & -1 & -19 & -36 & -10 & -24 \\
\hline & Blue & -27 & -44 & -20 & -35 & -27 & -46 & -19 & -35 \\
\hline & Total & 27 & -14 & 40 & -2 & -19 & -36 & -11 & -24 \\
\hline \multirow[t]{3}{*}{ Cotton } & Green & -26 & -38 & -18 & -29 & -28 & -43 & -20 & -32 \\
\hline & Blue & -20 & -36 & -12 & -27 & -28 & -46 & -20 & -36 \\
\hline & Total & -25 & -37 & -17 & -28 & -28 & -43 & -20 & -33 \\
\hline \multirow[t]{3}{*}{ Sugarcane } & Green & 47 & -6 & 62 & 7 & -15 & -27 & -6 & -13 \\
\hline & Blue & 12 & -9 & 23 & 4 & -45 & -57 & -39 & -49 \\
\hline & Total & 47 & -6 & 61 & 7 & -15 & -27 & -6 & -14 \\
\hline \multirow[t]{3}{*}{ Sugar beet } & Green & -66 & -72 & -62 & -68 & -67 & -73 & -63 & -68 \\
\hline & Blue & 13 & -10 & 24 & 3 & -69 & -75 & -66 & -70 \\
\hline & Total & -66 & -72 & -62 & -68 & -67 & -73 & -63 & -68 \\
\hline \multirow[t]{3}{*}{ Groundnut } & Green & -16 & -33 & -8 & -23 & -25 & -41 & -17 & -30 \\
\hline & Blue & -25 & -41 & -17 & -32 & -26 & -46 & -18 & -36 \\
\hline & Total & -17 & -34 & -9 & -24 & -25 & -41 & -17 & -31 \\
\hline \multirow[t]{3}{*}{ Sunflower } & Green & -46 & -55 & -41 & -49 & -39 & -52 & -32 & -43 \\
\hline & Blue & -38 & -51 & -32 & -43 & -38 & -53 & -31 & -44 \\
\hline & Total & -46 & -55 & -40 & -49 & -39 & -52 & -32 & -43 \\
\hline Rape seed & Green & 3 & -9 & 13 & 4 & -13 & -31 & -4 & -19 \\
\hline & Blue & & & & & & & & \\
\hline & Total & 3 & -9 & 13 & 4 & -13 & -31 & -4 & -19 \\
\hline Tomato & Green & 40 & 49 & 54 & 71 & -3 & -19 & 8 & -4 \\
\hline & Blue & -21 & -26 & -14 & -16 & -42 & -62 & -36 & -55 \\
\hline
\end{tabular}




\begin{tabular}{llllllllll} 
& Total & 39 & 48 & 53 & 69 & -4 & -20 & 7 & -5 \\
\hline Cabbage & Green & -20 & -30 & -13 & -20 & -26 & -41 & -18 & -29 \\
& Blue & -38 & -75 & -32 & -71 & -32 & -44 & -25 & -33 \\
& Total & -21 & -32 & -14 & -23 & -26 & -41 & -18 & -30 \\
\hline \multirow{2}{*}{ Gpinach } & Green & -36 & -43 & -29 & -35 & -39 & -41 & -33 & -30 \\
& Blue & -47 & -56 & -42 & -50 & -43 & -58 & -37 & -51 \\
& Total & -38 & -46 & -32 & -38 & -40 & -44 & -33 & -34 \\
\hline Grape & Green & -31 & -42 & -24 & -33 & -29 & -43 & -21 & -33 \\
& Blue & -29 & -42 & -22 & -33 & -24 & -41 & -16 & -30 \\
& Total & -30 & -42 & -23 & -33 & -28 & -43 & -20 & -32 \\
\hline \multirow{2}{*}{ Apple } & Green & -31 & -41 & -24 & -32 & -33 & -48 & -26 & -38 \\
& Blue & -46 & -55 & -40 & -49 & -43 & -59 & -37 & -52 \\
& Total & -32 & -42 & -25 & -34 & -34 & -49 & -27 & -39 \\
\hline Tea & Green & -27 & -42 & -20 & -34 & -24 & -34 & -16 & -21 \\
& Blue & -51 & -65 & -46 & -60 & -52 & -57 & -46 & -49 \\
& Total & -27 & -42 & -20 & -34 & -25 & -34 & -17 & -22 \\
\hline \multirow{2}{*}{ Tobacco } & Green & -34 & -45 & -27 & -37 & -28 & -42 & -20 & -31 \\
& Blue & -39 & -53 & -32 & -47 & -31 & -48 & -23 & -38 \\
& Total & -34 & -45 & -27 & -37 & -28 & -42 & -20 & -31 \\
\hline
\end{tabular}




\title{
6. Benchmark Levels for the Consumptive Water Footprint of Crop Production for Different Environmental Conditions: a Case Study for Winter Wheat in China $^{5}$
}

\begin{abstract}
Meeting growing food demands while simultaneously shrinking the water footprint (WF) of agricultural production is one of the greatest societal challenges. Benchmarks for the WF of crop production can serve as a reference and be helpful in setting WF reduction targets. The consumptive WF of crops, the consumption of rainwater stored in the soil (green WF) and the consumption of irrigation water (blue WF) over the crop growing period, varies spatially and temporally depending on environmental factors like climate and soil. The study explores which environmental factors should be distinguished when determining benchmark levels for the consumptive WF of crops. Hereto we determine benchmark levels for the consumptive WF of winter wheat production in China for all separate years in the period 1961-2008, for rain-fed versus irrigated croplands, for four different soil classes and for two different climate zones. We simulate consumptive WFs of winter wheat production with the crop water productivity model AquaCrop at a 5 by 5 arc min resolution, accounting for water stress only. The results show that (i) benchmark levels determined for individual years for the country as a whole remain within a range of $\pm 20 \%$ around long-term mean levels over 1961-2008; (ii) the WF benchmarks for irrigated winter wheat are 8-10\% larger than those for rain-fed winter wheat; (iii) WF benchmarks for wet years are 1-3\% smaller than for dry years, (iv) WF benchmarks for warm years are 7-8\% smaller than for cold years, (v) WF benchmarks differ by about $10-12 \%$ across different soil texture classes; and (vi) WF benchmarks for the humid zone are $26-31 \%$ smaller than for the arid zone, which has relatively higher $\mathrm{ET}_{0}$ in general and lower yields in rain-fed fields. We conclude that when determining benchmark levels for the consumptive WF of a crop, it is useful to primarily distinguish between different climate zones. If actual consumptive WFs of winter wheat
\end{abstract}

\footnotetext{
5 The Chapter has been submitted to Hydrology and Earth System Sciences.
} 
throughout China were reduced to the benchmark levels set by the best $25 \%$ of Chinese winter wheat production (1224 $\mathrm{m}^{3} \mathrm{t}^{-1}$ for arid areas and $841 \mathrm{~m}^{3} \mathrm{t}^{-1}$ for humid areas), the water saving in an average year would be $53 \%$ of the current water consumption at winter wheat fields in China. The majority of the yield increase and associated improvement in water productivity can be achieved in southern China. 


\subsection{Introduction}

Half of the large river basins in the world face severe blue water scarcity for at least one month a year (Hoekstra et al., 2012). Agriculture is the largest consumer of water in the world and therefore responsible for a large part of the water scarcity in the world. Still, global food demand continues to increase, due to growing populations and changing diets. Meeting growing food demands and simultaneously reducing the water footprint (WF) of agricultural production is therefore one of the greatest societal challenges of our time (Foley et al., 2011; Hoekstra and Wiedmann, 2014). Increasing water productivity ( $\left.\mathrm{t} \mathrm{m}^{-3}\right)$ in croplands, i.e. reducing the WF of crops $\left(\mathrm{m}^{3} \mathrm{t}^{-1}\right)$, is recognized as an important way of producing more with the same water (or producing the same with less water). In order to know what is a reasonable production level given a certain amount of water consumption (or what is a reasonable volume of water consumption given a certain production level), we need reference values that indicate reasonable WF levels. (Hoekstra, 2013; 2014) has proposed to develop WF benchmarks for this purpose, which can be used for setting WF reduction targets. Such benchmarks could be global, but would preferably be context-specific, given the fact that the WF of growing a crop varies as a function of environmental factors such as climate and soil (Siebert and Doll, 2010; Mekonnen and Hoekstra, 2011; Tuninetti et al., 2015).

The WF of a crop is determined by both environmental conditions (e.g. climate, soil texture, $\mathrm{CO}_{2}$ concentration in the air, groundwater level) and managerial factors (e.g. application of fertilizers and pesticides, irrigation technology and strategy, mulching practice) (Zwart et al., 2010; Mekonnen and Hoekstra, 2011; Brauman et al., 2013). Benchmarks for the WF of growing a crop can, for example, be set by looking at what WF level is not exceeded by the best $20-25 \%$ of the total production in an area. Alternatively, benchmarks can be determined by estimating the WF associated with best-available technology and management practice (Hoekstra, 2013; 2014). Mekonnen and Hoekstra (2014) followed the first approach, by establishing global benchmarks for both the consumptive (green plus blue) WF and the degradative (grey) WF for a large number of crops, based on estimated WF values for 1996-2005 at a spatial resolution of 5 by 5 arc minute. Chukalla et al. (2015) followed the second approach and explored reduction potentials of consumptive WFs for a few crops by 
applying different alternative irrigation techniques and strategies and different alternative mulching practices. They found that the highest reduction $(\sim 29 \%)$ in the consumptive WF of a crop could be achieved when applying drip/subsurface drip irrigation in combination with deficit irrigation and synthetic mulching.

Research in developing benchmark levels for the consumptive WF of crop production is still in its infancy. An important question that has been insufficiently addressed is which environmental factors should play a role when developing WF benchmarks. It is nice to have one global benchmark for the consumptive WF per crop, as a global reference, like the ones developed by Mekonnen and Hoekstra (2014), but it remains unclear whether it is reasonable to expect the same water productivity under different environmental conditions. In their global analysis, Mekonnen and Hoekstra (2014) found that a crop in a temperate climate generally has a smaller WF than the same crop in a tropical climate, but this can still be due to other factors (e.g. better management practices in temperate climates), so that this is not a sufficient finding to diversify benchmark levels based on the distinction between temperate and tropical. Besides, even though Mekonnen and Hoekstra (2014) found a difference between different climates, for each crop considered it was found that the $10 \%$ best global production (e.g. with smallest WFs) were always at least partly in the tropics as well. In other words, a WF benchmark developed in the temperate part of the world still offers a reference value that can be achieved in the tropics as well. Next to climate also soil affects evapotranspiration and yield and thus the WF of a crop. (Tolk and Howell, 2012), for example, analyse the variation of consumptive WFs of sunflower in relation to different types of soils. There has not been yet, though, a systematic study looking at how environmental factors influence the consumptive WFs of crops and to which extent it makes sense to diversify WF benchmark levels based on specific environmental factors.

The current study aims to contribute to this discussion through an explorative study for winter wheat in China. We explore which environmental factors should be distinguished when determining benchmark levels for the consumptive WF of crops. We subsequently determine benchmark levels for the consumptive WF of winter wheat production in China for all separate years in the period 1961-2008, for rain-fed versus irrigated croplands, for 
wet versus dry years, for warm versus cold years, for four different soil classes and for two different climate zones. Winter wheat in China accounts for $95 \%$ of total wheat production in China, which is the world biggest wheat producer (FAO, 2014b). Winter wheat covers 96\% of China's harvested wheat area and occurs across China's different climate zones (NBSC, 2013). In order to avoid interference from managerial factors that cause differences in evapotranspiration and yield, we simulate WFs by means of the water productivity model AquaCrop, at a resolution of 5 by 5 arc minute, considering only water stress and not taking into account other stresses such as from soil fertility, salinity, frost, or pest and diseases.

\subsection{Method and data}

The consumptive WF of growing a crop $\left(\mathrm{m}^{3} \mathrm{t}^{-1}\right)$ equals the total actual evapotranspiration $\left(E T, \mathrm{~m}^{3} \mathrm{ha}^{-1}\right)$ over the cropping period divided by the crop yield $\left(\mathrm{t} \mathrm{ha}^{-1}\right)$. The soil water balance and crop growth were simulated at daily basis, at 5 by 5 arc minute resolution, with FAO's crop water productivity model AquaCrop (Hsiao et al., 2009; Raes et al., 2009; Steduto et al., 2009), run for the whole period 1961-2008. Compared to other crop growth models, AquaCrop has a significantly smaller number of parameters and better balances between simplicity, accuracy and robustness (Steduto et al., 2007). The model performance regarding crop water use and yield simulation has been widely tested for a number of crops under diverse environments and types of water management (Farahani et al., 2009; Garcia-Vila et al., 2009; Andarzian et al., 2011; Stricevic et al., 2011; Abedinpour et al., 2012; Katerji et al., 2013; Yuan et al., 2013; Jin et al., 2014). We used the same input data sources and crop parameters as reported in Chapter 4. In order to avoid the effects of non-environmental factors (e.g. technology, fertilization) on crop growth, only water stress is considered, which is determined by the water availability in the root zone. For irrigated fields, we assume that the applied irrigation volumes are equal to the net irrigation requirement. We simulated winter wheat production per grid cell over the years based on the harvested areas of around the year 2000 (Portmann et al., 2010); see Figure 6.1) in order to avoid in the simulations the effects of changes in where how much wheat is grown. 


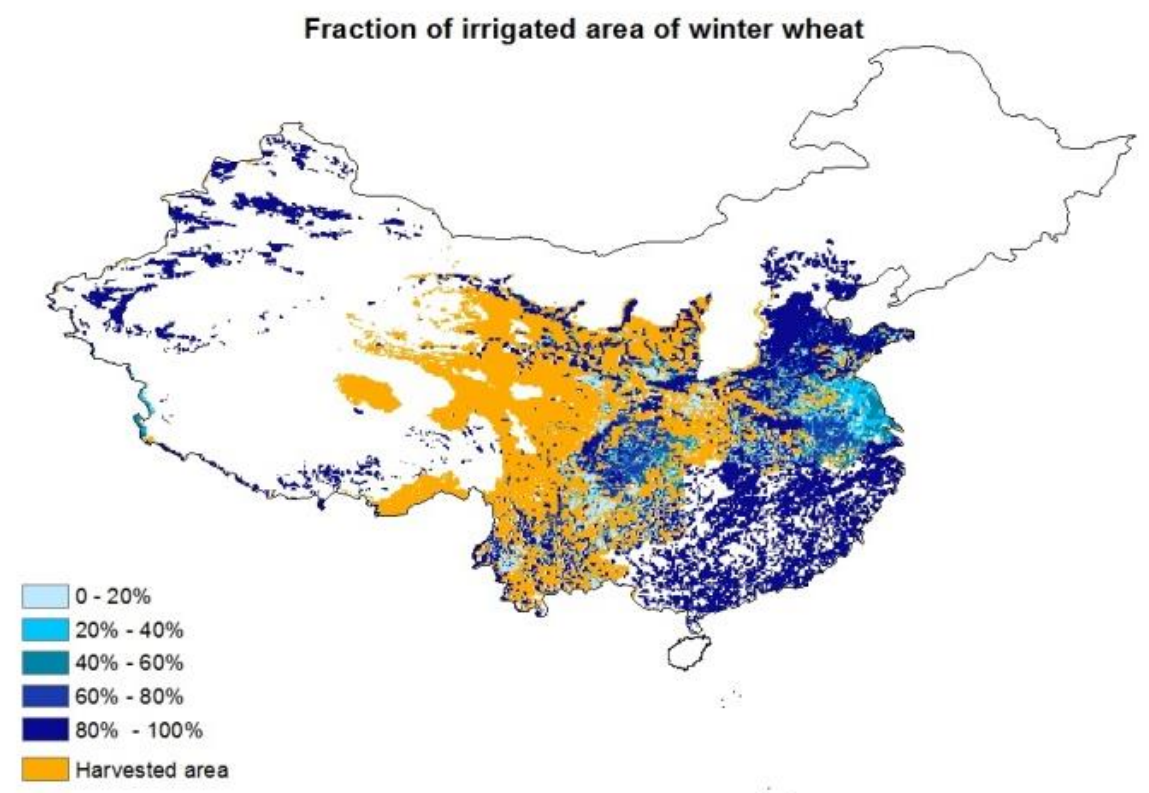

Figure 6.1 Harvested winter wheat areas in China in the year 2000 and fractions of the harvested areas irrigated. Data source: Portmann et al. (2010).

Following Mekonnen and Hoekstra (2014), benchmark levels for the consumptive WF of crop production were determined by ranking the grid-level WF values from the smallest to the largest against the corresponding cumulative percentage of total crop production.

In order to analyse differences in consumptive WFs in relatively dry versus relatively wet years, we evenly group the forty-eight considered years (1961-2008) into relative dry, average and relatively wet years. We ranked the years based on the annual precipitation over the cropping area of winter wheat in China (Figure 6.2a) and classified the sixteen years with the lowest precipitation into the group of dry years and the sixteen years with the highest precipitation into the group of wet years, with the other sixteen years remaining for the group of average years. The average annual precipitation levels of the relatively dry, average and relatively wet years are 760,799 and $850 \mathrm{~mm} \mathrm{y}^{-1}$, respectively.

We also grouped the years considered into relatively cold, average and relatively warm years based on annual mean temperature (Figure 6.2b) and into years with relatively low, average and high $\mathrm{ET}_{0}$ (Figure 6.2c). The average annual mean temperatures of the relative 
cold, average and warm years are $10.7,11.2$ and $11.8{ }^{\circ} \mathrm{C}$, respectively. The average annual $\mathrm{ET}_{0}$ values in the three categories of years are 874, 896 and $927 \mathrm{~mm} \mathrm{y}^{-1}$.
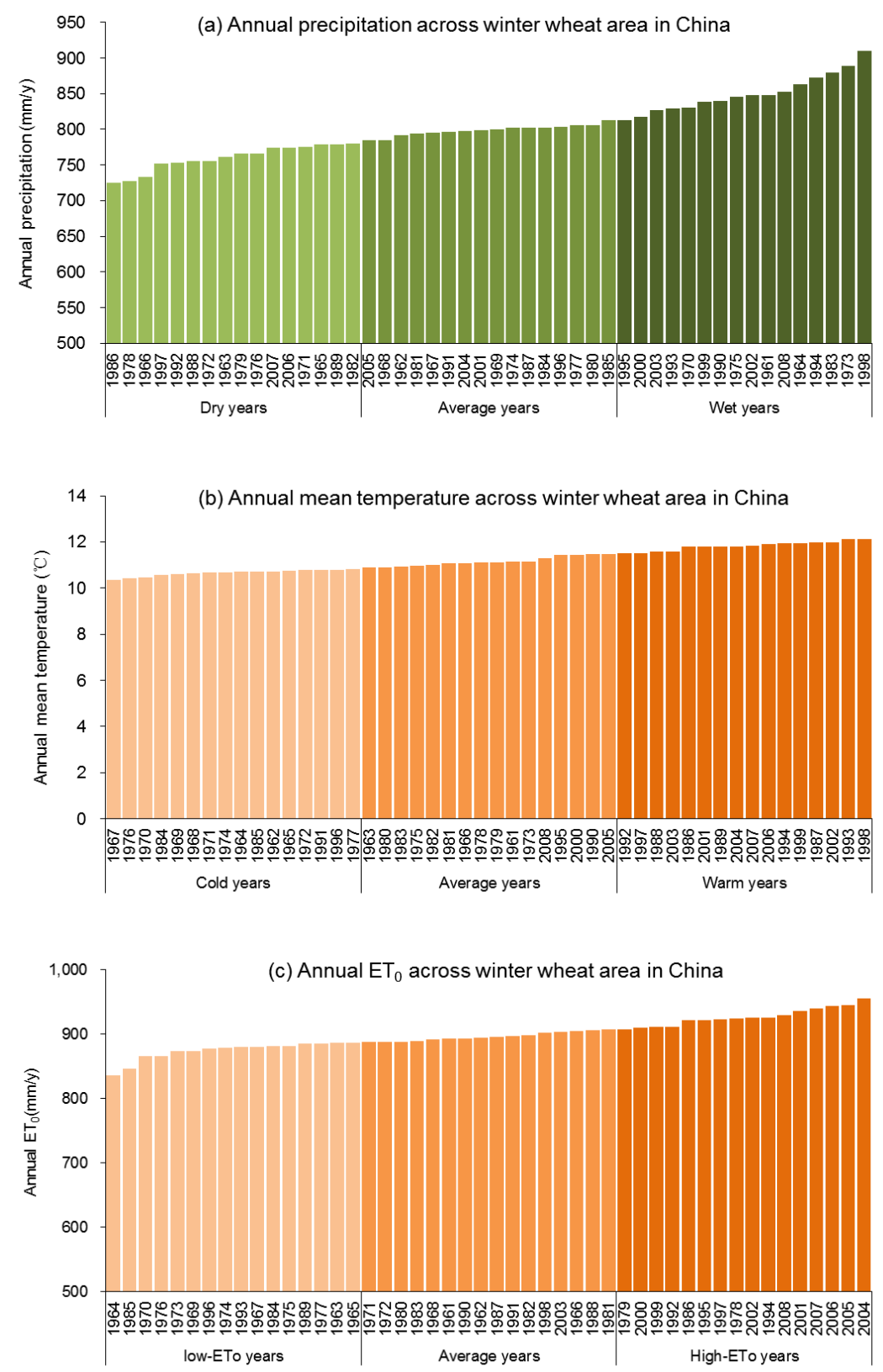

Figure 6.2 Annual precipitation (a), mean temperature (b), and $E T_{0}(c)$ over the cropping area of winter wheat in China for the years in the period 1961-2008, ranked from lowest to 
highest values.

For determining WF benchmarks for different soil texture classes, the soil types in the USDA (U.S. Department of Agriculture) soil texture triangles were grouped into four soil classes (Raes et al., 2011): sandy soils, loamy soils, sandy clayey soils, and silty clayey soils. Each soil class has different ranges of field capacity, permanent wilting point and saturated water content (Table 6.1). The difference between soil water content and permanent wilting point defines the total available soil water content in the root zone. Given certain soil water content, a soil with a higher field capacity has less deep percolation. With the same water input from precipitation or irrigation and the same soil water content, soils with a smaller saturated soil water content will generate more surface runoff (Raes et al., 2011). Figure 6.3 shows the spatial distribution of the four soil classes across mainland China (Dijkshoorn et al., 2008).

Table 6.1 Soil classes.

\begin{tabular}{|c|c|c|c|c|}
\hline \multirow[b]{2}{*}{ Soil class } & \multirow[b]{2}{*}{ Soil types } & \multicolumn{3}{|c|}{ Soil water content (vol \%) } \\
\hline & & Field capacity & $\begin{array}{c}\text { Permanent wilting } \\
\text { point }\end{array}$ & $\begin{array}{c}\text { Saturatio } \\
\mathrm{n}\end{array}$ \\
\hline Sandy & $\begin{array}{l}\text { Sand, loamy sand, sandy } \\
\text { loam }\end{array}$ & $9-28$ & $4-15$ & $32-51$ \\
\hline Loamy & Loam, silt loam, silt & $23-42$ & $6-20$ & $42-55$ \\
\hline Sandy clayey & $\begin{array}{l}\text { Sandy clay, sandy clay } \\
\text { loam, clay loam }\end{array}$ & $25-45$ & $16-34$ & $40-53$ \\
\hline Silty clayey & $\begin{array}{l}\text { Silty clay loam, silty clay, } \\
\text { clay }\end{array}$ & $40-58$ & $20-42$ & $49-58$ \\
\hline
\end{tabular}

Source: Raes et al. (2011). 


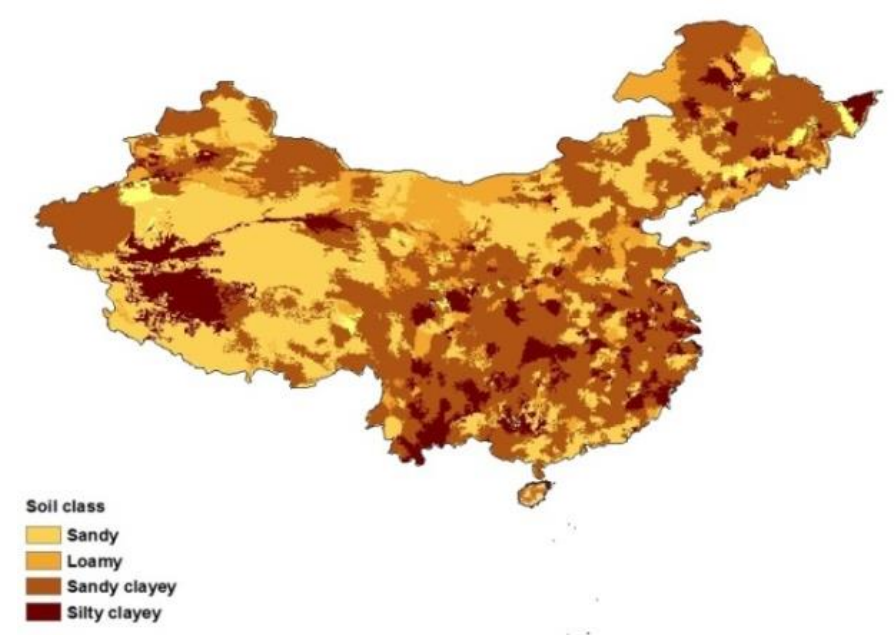

Figure 6.3 Soil classes across mainland China, generated from the ISRIC Soil and Terrain database for China. Data source: Dijkshoorn et al. (2008).

For determining WF benchmarks for different climate zones, we classify climate based on UNEP's aridity index (AI) (Middleton and Thomas, 1992; 1997). The AI is an indicator of dryness, defined as the ratio of precipitation to reference evapotranspiration, with five levels of aridity: hyper-arid ( $\mathrm{AI}<0.05)$, arid $(0.05<\mathrm{AI}<0.2)$, semi-arid $(0.2<\mathrm{AI}<0.5)$, dry sub humid $(0.5<\mathrm{AI}<0.65)$, and humid ( $\mathrm{AI}>0.65)$. To determine the geographic spread of the five climate zones in China we used the data on annual precipitation and $\mathrm{ET}_{0}$ averaged over the period 1961-2008 at 30 by 30 arc minute resolution from the CRU-TS-3.10.01 database (Harris et al., 2014) (Figure 6.4). In the current study, we group the five climate zones into two broad zones: the arid-semi-arid (Arid) zone $(\mathrm{AI}<0.5)$ and the humid-semi-humid (Humid) zone (AI >0.5). 


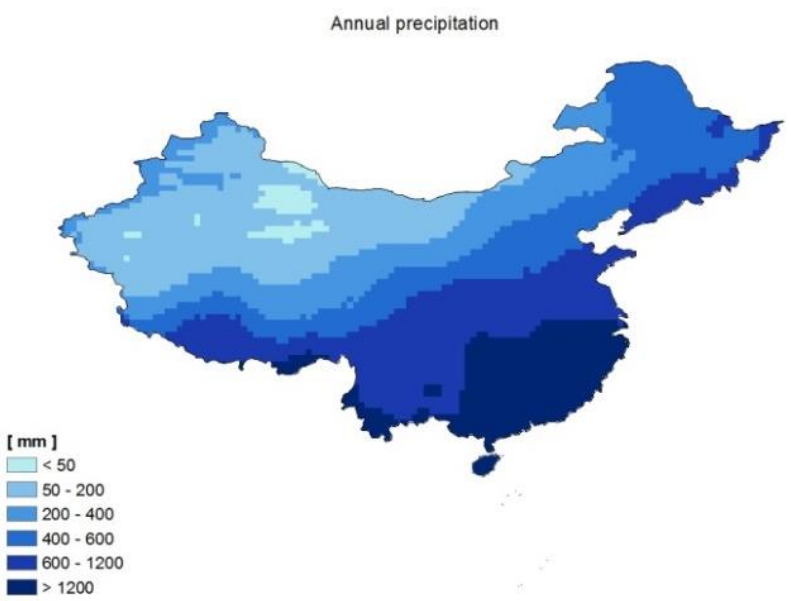

(a)

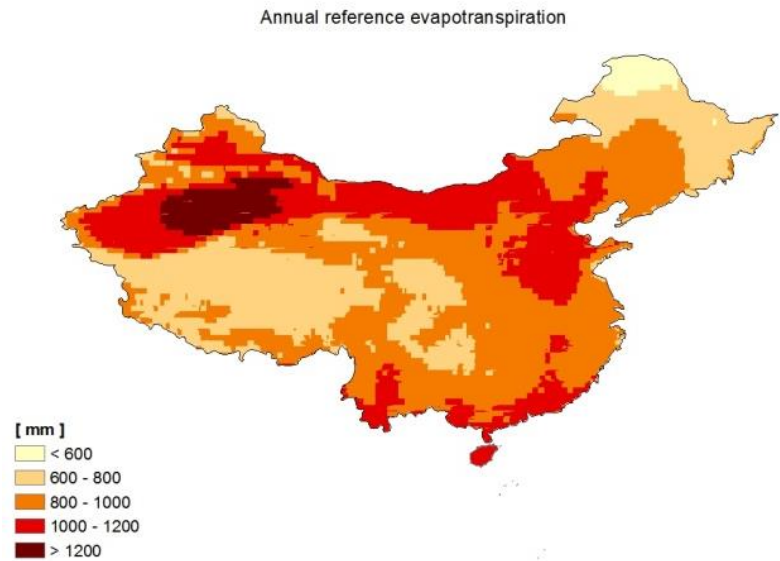

(b)

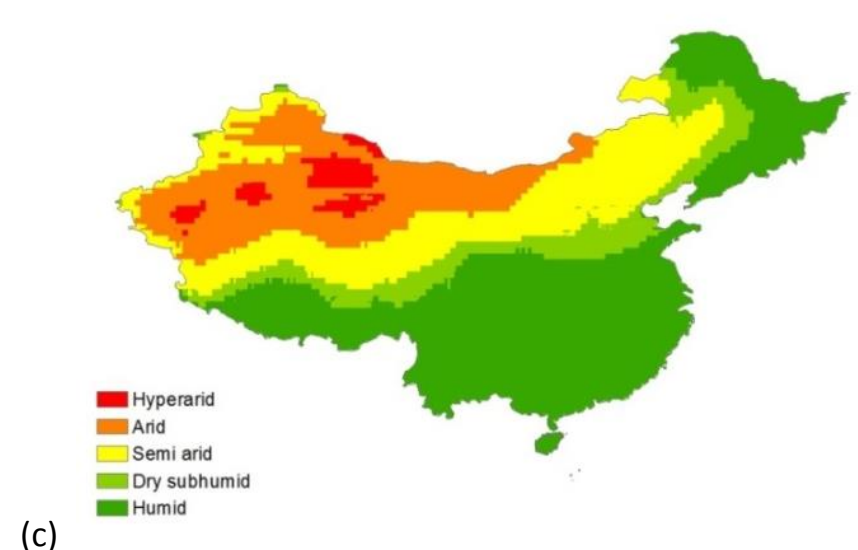

(c)

Figure 6.4 Zoning of annual precipitation (a), annual reference evapotranspiration (b), and aridity (c) in China (1961-2008). Data source: Harris et al. (2014). 


\subsection{Result}

\subsubsection{Benchmark levels for the consumptive WF as determined for different years and for rain-fed and irrigated croplands separately}

We calculated the benchmark levels at different production percentiles for the consumptive WF of winter wheat $\left(\mathrm{m}^{3} \mathrm{t}^{-1}\right)$ for the country as a whole, year by year, for the period 1961-2008. The results are summarized in Figure 6.5. The benchmarks, determined per year and per production percentile, generally vary within $\pm 20 \%$ of the long-term mean value over the period 1961-2008. We find that the best $10 \%$ of winter wheat production in China (with smallest WFs) has a maximum long-term average consumptive WF of $777 \mathrm{~m}^{3} \mathrm{t}^{-1}$, which is larger than the maximum consumptive WF of the best $10 \%$ of wheat production globally $\left(592 \mathrm{~m}^{3} \mathrm{t}^{-1}\right)$ that was reported by Mekonnen and Hoekstra (2014). We note here that the figures are not fully comparable, because Mekonnen and Hoekstra (2014) consider total wheat (both spring and winter wheat), use another model and consider another period. We find that the best $20 \%$ of winter wheat production in China has a maximum long-term average consumptive WF of $825 \mathrm{~m}^{3} \mathrm{t}^{-1}$, which is smaller than the reported maximum consumptive WF of the best $20 \%$ of wheat production globally $\left(992 \mathrm{~m}^{3} \mathrm{t}^{-1}\right)$. Finally, we find that the best $25 \%$ of winter wheat production in China has a maximum long-term average consumptive WF of $849 \mathrm{~m}^{3} \mathrm{t}^{-1}$, which is again smaller than the maximum consumptive WF of the best $25 \%$ of wheat production globally $\left(1069 \mathrm{~m}^{3} \mathrm{t}^{-1}\right)$.

The national average consumptive WF of rain-fed winter wheat $\left(1120 \mathrm{~m}^{3} \mathrm{t}^{-1}\right)$ is larger than the national average consumptive WF of irrigated winter wheat $\left(1075 \mathrm{~m}^{3} \mathrm{t}^{-1}\right)$. However, the benchmark levels determined by the best $10 \%, 20 \%$ and $25 \%$ of production for rain-fed winter wheat are lower than for irrigated winter wheat. The reason is that the yields in rain-fed production are generally higher $\left(9 \mathrm{tha}^{-1}\right.$ on average) than the yields in irrigated production ( $5 \mathrm{t} \mathrm{ha}^{-1}$ on average) at benchmark levels. The highest rain-fed yields occur in the southern wet area with sufficient precipitation over the cropping period, so that little water stress results in high rain-fed yields. The WF benchmarks for irrigated winter wheat are $8 \%$ (for the $10^{\text {th }}$ production percentile) to $10 \%$ (for the $25^{\text {th }}$ production percentile) higher than for rain-fed winter wheat. 


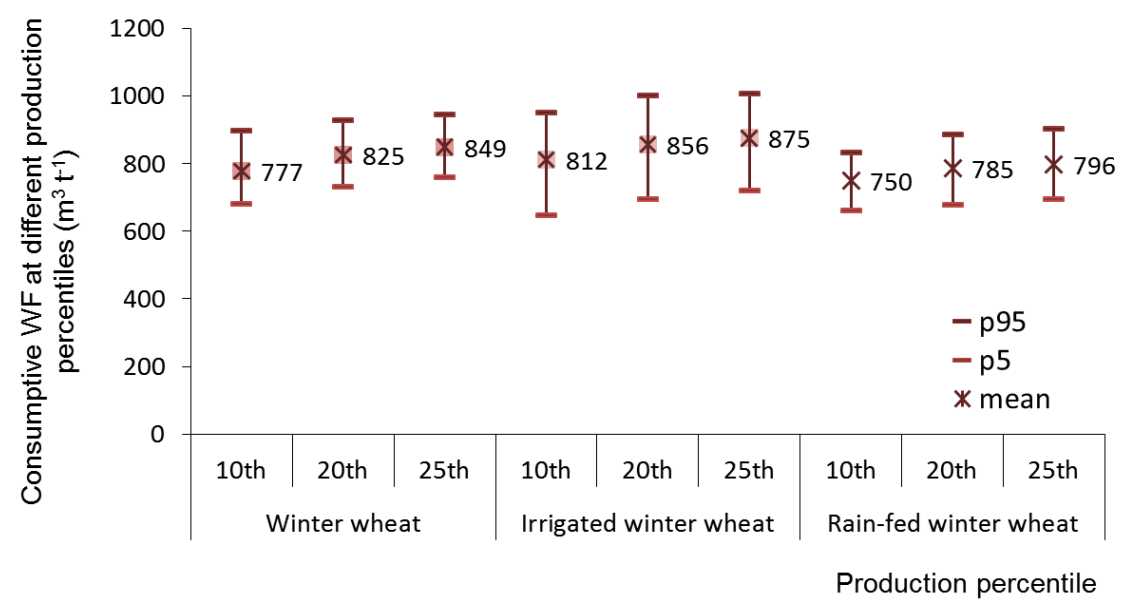

Figure 6.5 Benchmark levels for the consumptive WF of winter wheat in China at different production percentiles, considering all separate years in the period 1961-2008. Cross marks refer to the mean values; ranges refer to the 5\% - 95\% of accumulative frequencies.

\subsubsection{Benchmark levels for the consumptive WF for dry versus wet years}

In a relatively dry or wet year, when considering winter wheat areas in China as a whole, we do not find typically different consumptive WFs in winter wheat production (Table 6.2). The WF benchmarks are consistently higher in dry than in wet years (1-3\%), but the differences between benchmark levels for the consumptive WF for dry versus wet years are small compared to the variations within the dry and wet year categories $( \pm 11-14 \%)$.

Table 6.2 Benchmark levels for the consumptive WF benchmarks $\left(m^{3} t^{-1}\right)$ of winter wheat for relative dry, average and wet years in China.

\begin{tabular}{|c|c|c|c|c|c|}
\hline \multirow[b]{2}{*}{ Crop } & & \multicolumn{4}{|c|}{ Consumptive WF $\left(\mathrm{m}^{3} \mathrm{t}^{-1}\right)$ at different production percentiles* } \\
\hline & & 10th & 20th & 25th & Average \\
\hline \multirow{3}{*}{ Winter wheat } & Dry years & $787 \pm 69$ & $837 \pm 70$ & $858 \pm 71$ & $1103 \pm 82$ \\
\hline & Average years & $763 \pm 107$ & $826 \pm 72$ & $849 \pm 74$ & $1073 \pm 97$ \\
\hline & Wet years & $770 \pm 68$ & $813 \pm 60$ & $838 \pm 50$ & $1048 \pm 77$ \\
\hline \multirow{2}{*}{ Irrigated winter wheat } & Dry years & $822 \pm 118$ & $862 \pm 110$ & $876 \pm 112$ & $1095 \pm 110$ \\
\hline & Average years & $814 \pm 97$ & $856 \pm 97$ & $881 \pm 98$ & $1078 \pm 93$ \\
\hline
\end{tabular}




\begin{tabular}{llcccc}
\hline & Wet years & $799 \pm 97$ & $850 \pm 100$ & $870 \pm 96$ & $1052 \pm 96$ \\
\hline \multirow{3}{*}{ Rain-fed winter wheat } & Dry years & $757 \pm 44$ & $802 \pm 57$ & $812 \pm 56$ & $1121 \pm 97$ \\
& Average years & $736 \pm 62$ & $771 \pm 70$ & $783 \pm 70$ & $1074 \pm 133$ \\
& Wet years & $755 \pm 96$ & $784 \pm 103$ & $794 \pm 104$ & $1164 \pm 561$ \\
\hline
\end{tabular}

* Data are mean \pm S.D. for the years 1961-2008.

\subsubsection{Benchmark levels for the consumptive WF for warm versus cold years}

Overall, considering irrigated and rain-fed croplands together, WF benchmarks for relatively warm years are $7-8 \%$ smaller than for relatively cold years, which is not much when seen in the context of fluctuations in the WFs within the three temperature categories (Table 6.3). In irrigated areas, WF benchmarks for warm years are $11 \%$ smaller, on average, than for cold years. In rain-fed areas, WF benchmarks for warm years are smaller than for cold years as well, but WF benchmarks in average years are not in between the WF benchmarks found for cold and warm years but higher than both. The lower values in cold years relate to lower ET, while the lower values in warm years relate to higher yields.

Table 6.3 National consumptive WF benchmarks $\left(m^{3} t^{-1}\right)$ of winter wheat for relative cold, warm and average years in China.

\begin{tabular}{|c|c|c|c|c|c|}
\hline \multirow[b]{2}{*}{ Crop } & & \multicolumn{4}{|c|}{ Consumptive WF $\left(\mathrm{m}^{3} \mathrm{t}^{-1}\right)$ at different production percentiles ${ }^{*}$} \\
\hline & & 10th & 20th & 25th & Average \\
\hline \multirow{3}{*}{ Winter wheat } & Cold years & $795 \pm 101$ & $848 \pm 63$ & $870 \pm 67$ & $1103 \pm 96$ \\
\hline & Average years & $794 \pm 79$ & $840 \pm 66$ & $864 \pm 58$ & $1087 \pm 82$ \\
\hline & Warm years & $732 \pm 42$ & $788 \pm 58$ & $811 \pm 57$ & $1033 \pm 70$ \\
\hline \multirow{3}{*}{ Irrigated winter wheat } & Cold years & $862 \pm 86$ & $902 \pm 87$ & $924 \pm 87$ & $1121 \pm 86$ \\
\hline & Average years & $810 \pm 107$ & $863 \pm 102$ & $878 \pm 96$ & $1083 \pm 93$ \\
\hline & Warm years & $763 \pm 96$ & $804 \pm 93$ & $824 \pm 96$ & $1022 \pm 98$ \\
\hline \multirow{3}{*}{ Rain-fed winter wheat } & Cold years & $760 \pm 59$ & $791 \pm 68$ & $798 \pm 69$ & $1088 \pm 144$ \\
\hline & Average years & $772 \pm 95$ & $821 \pm 99$ & $831 \pm 100$ & $1218 \pm 553$ \\
\hline & Warm years & $716 \pm 31$ & $744 \pm 40$ & $761 \pm 44$ & $1053 \pm 63$ \\
\hline
\end{tabular}

* Data are mean \pm S.D. for the years 1961-2008.

The findings when considering different $\mathrm{ET}_{0}$ classes are similar when looking at the 
different temperature classes (Table 6.4). Overall, considering irrigated and rain-fed croplands together, WF benchmarks for years with high $\mathrm{ET}_{0}$ are on average $5 \%$ smaller than for years with average $\mathrm{ET}_{0}$ and only $2 \%$ smaller than for years with low $\mathrm{ET}_{0}$. Again, differences between consumptive WFs for years with relatively low or high $\mathrm{ET}_{0}$ are small when seen in the context of fluctuations in the WFs within the three $\mathrm{ET}_{0}$ categories $( \pm 3-6 \%)$.

Table 6.4 National consumptive WF benchmarks $\left(\mathrm{m}^{3} \mathrm{t}^{-1}\right)$ of winter wheat for relative low-, highand average-ETo years in China.

\begin{tabular}{|c|c|c|c|c|c|}
\hline \multirow[b]{2}{*}{ Crop } & & \multicolumn{4}{|c|}{ Consumptive WF $\left(\mathrm{m}^{3} \mathrm{t}^{-1}\right)$ at different production percentiles* } \\
\hline & & 10th & 20th & 25th & Average \\
\hline \multirow{3}{*}{ Winter wheat } & Low-ETo years & $774 \pm 99$ & $822 \pm 64$ & $841 \pm 62$ & $1065 \pm 82$ \\
\hline & Average years & $806 \pm 80$ & $846 \pm 73$ & $866 \pm 76$ & $1095 \pm 107$ \\
\hline & High-ET 0 years & $741 \pm 51$ & $808 \pm 62$ & $839 \pm 58$ & $1065 \pm 70$ \\
\hline \multirow{3}{*}{ Irrigated winter wheat } & Low-ETo years & $831 \pm 111$ & $874 \pm 108$ & $892 \pm 106$ & $1089 \pm 98$ \\
\hline & Average years & $820 \pm 105$ & $868 \pm 96$ & $887 \pm 96$ & $1073 \pm 103$ \\
\hline & High- $E T_{0}$ years & $784 \pm 93$ & $827 \pm 97$ & $847 \pm 97$ & $1064 \pm 102$ \\
\hline \multirow{3}{*}{ Rain-fed winter wheat } & Low-ETo years & $749 \pm 55$ & $774 \pm 56$ & $781 \pm 54$ & $1038 \pm 100$ \\
\hline & Average years & $784 \pm 90$ & $828 \pm 98$ & $841 \pm 98$ & $1249 \pm 550$ \\
\hline & High- $\mathrm{ET}_{0}$ years & $716 \pm 72$ & $755 \pm 59$ & $767 \pm 58$ & $1072 \pm 78$ \\
\hline
\end{tabular}

* Data are mean \pm S.D. for the years 1961-2008.

\subsubsection{Benchmark levels for the consumptive WF for different soil classes}

Tables 6.5 shows the consumptive WFs of winter wheat at different production percentiles in four soil classes in China. The simulated winter wheat production in sandy clayey soils accounts for $60 \%$ of national total, followed by the production in sandy soils $(24 \%)$, silty clayey soils (8\%) and loamy soils (8\%) in average over the studied period. No consistent trends can be observed when we compare the benchmarks across the different soil classes. Overall, when we take irrigated and rain-fed fields together, the WF benchmarks for sandy soils are 10-12\% lower than the WF benchmarks for loamy soils. More specifically, we find that the WF benchmarks for irrigated winter wheat in sandy soils are about $15 \%$ smaller than the WF benchmarks for the other three soil classes, due to relatively low ET. Without water stress, as is the case in the irrigated croplands, soil evaporation from sandy soils is less 
than from the other soil types because of the fast percolation of water below the root zone in the sandy soils, causing lower ET over the cropping period (Asseng et al., 2001). At rain-fed fields with limited water availability, crop yields are mainly affected by the soil water holding capacity. Therefore, consumptive WFs in sandy soils are larger than in the other three soils, due to the smaller crop yield in case of poorer water holding capacity. The observed differences in WFs of winter wheat in different soil classes agree with the experimental observations by Tolk and Howell (2012) for the case of irrigated sunflower in a semiarid environment as well as with the fieldwork-based simulations by Asseng et al. (2001) for irrigated and rain-fed wheat in the Mediterranean climatic region of Western Australia.

Table 6.5 Benchmark levels for the consumptive WF $\left(m^{3} t^{-1}\right)$ of winter wheat for different soil classes in China.

\begin{tabular}{|c|c|c|c|c|c|}
\hline \multirow[b]{2}{*}{ Crop } & \multirow[b]{2}{*}{ Soil class } & \multicolumn{4}{|c|}{ Consumptive WF $\left(\mathrm{m}^{3} \mathrm{t}^{-1}\right)$ at different production percentiles } \\
\hline & & 10th & 20th & 25th & Average \\
\hline \multirow{4}{*}{ Winter wheat } & Sandy & $748 \pm 143$ & $814 \pm 115$ & $834 \pm 116$ & $1017 \pm 125$ \\
\hline & Loamy & $846 \pm 53$ & $912 \pm 77$ & $928 \pm 73$ & $1108 \pm 74$ \\
\hline & Sandy clayey & $788 \pm 76$ & $848 \pm 61$ & $881 \pm 66$ & $1071 \pm 48$ \\
\hline & Silty clayey & $822 \pm 48$ & $895 \pm 43$ & $912 \pm 46$ & $963 \pm 22$ \\
\hline \multirow{4}{*}{ Irrigated winter wheat } & Sandy & $767 \pm 158$ & $782 \pm 177$ & $846 \pm 128$ & $1000 \pm 126$ \\
\hline & Loamy & $931 \pm 91$ & $937 \pm 93$ & $996 \pm 70$ & $1189 \pm 107$ \\
\hline & Sandy clayey & $879 \pm 98$ & $932 \pm 98$ & $969 \pm 102$ & $1164 \pm 100$ \\
\hline & Silty clayey & $920 \pm 68$ & $942 \pm 72$ & $958 \pm 66$ & $1070 \pm 52$ \\
\hline \multirow{4}{*}{ Rain-fed winter wheat } & Sandy & $785 \pm 58$ & $834 \pm 88$ & $850 \pm 96$ & $1151 \pm 272$ \\
\hline & Loamy & $757 \pm 77$ & $822 \pm 73$ & $843 \pm 73$ & $1040 \pm 160$ \\
\hline & Sandy clayey & $764 \pm 66$ & $799 \pm 68$ & $818 \pm 70$ & $1096 \pm 129$ \\
\hline & Silty clayey & $769 \pm 62$ & $814 \pm 60$ & $837 \pm 60$ & $931 \pm 103$ \\
\hline
\end{tabular}

* Data are mean \pm S.D. for the years 1961-2008.

\subsubsection{Benchmark levels for the consumptive WF for different climate zones}

Consumptive WFs of winter wheat at different production percentiles in arid and humid zones in China are shown in Table 6.6. Significant differences between the benchmarks for different climate zones can be observed. Overall, considering irrigated and rain-fed 
croplands together, WF benchmarks for the humid zone are 26\% (for the 10th production percentile) to $31 \%$ (for the 25 th production percentile) smaller than for the arid zone. The WF benchmarks for winter wheat in China as a whole (when we take the arid and humid zones together) are close to the benchmarks for the humid zone, caused by the fact that most (96\% in average over the study period) of the simulated winter wheat production in China occurs in the humid zone.

In the irrigated areas, WF benchmarks for the humid zone are 26-30\% smaller than for the arid zone; in the rain-fed areas, they are $29-43 \%$ smaller. The relatively large WFs in rain-fed fields in the arid zone logically follow from the water stress and resultant low yields. For the irrigated fields, the larger WFs in the arid zone are caused by the relatively high $\mathrm{ET}_{0}$ and ET. The results confirm the findings from previous studies that the WF of crops, especially rain-fed crops, is negatively correlated with precipitation and positively correlated with $\mathrm{ET}_{0}$ (Zwart et al., 2010; Zhuo et al., 2014). The differences between the WF benchmarks for irrigated and rain-fed winter wheat are $7-9 \%$ in the humid zone and $3-11 \%$ in the arid zone.

Table 6.6 Benchmarks for the consumptive WF $\left(m^{3} t^{-1}\right)$ of winter wheat for different climate zones in China.

\begin{tabular}{|c|c|c|c|c|c|}
\hline \multirow[b]{2}{*}{ Crop } & \multirow[b]{2}{*}{$\begin{array}{l}\text { Climate } \\
\text { zones }\end{array}$} & \multicolumn{4}{|c|}{ Consumptive WF $\left(\mathrm{m}^{3} \mathrm{t}^{-1}\right)$ at different production percentile* } \\
\hline & & 10th & 20th & 25th & Average \\
\hline \multirow{3}{*}{ Winter wheat } & Arid & $1042 \pm 100$ & $1170 \pm 130$ & $1224 \pm 125$ & $1757 \pm 200$ \\
\hline & Humid & $776 \pm 70$ & $819 \pm 66$ & $841 \pm 66$ & $1044 \pm 83$ \\
\hline & Overall & $777 \pm 72$ & $825 \pm 67$ & $849 \pm 65$ & $1075 \pm 87$ \\
\hline \multirow{3}{*}{$\begin{array}{l}\text { Irrigated winter } \\
\text { wheat }\end{array}$} & Arid & $1088 \pm 66$ & $1205 \pm 73$ & $1245 \pm 84$ & $1399 \pm 163$ \\
\hline & Humid & $807 \pm 104$ & $853 \pm 100$ & $872 \pm 99$ & $1055 \pm 97$ \\
\hline & Overall & $812 \pm 103$ & $856 \pm 100$ & $875 \pm 100$ & $1075 \pm 99$ \\
\hline \multirow{3}{*}{$\begin{array}{l}\text { Rain-fed winter } \\
\text { wheat }\end{array}$} & Arid & $1058 \pm 310$ & $1311 \pm 406$ & $1399 \pm 415$ & $2919 \pm 1004$ \\
\hline & Humid & $749 \pm 70$ & $784 \pm 78$ & $795 \pm 79$ & $1076 \pm 338$ \\
\hline & Overall & $750 \pm 70$ & $785 \pm 78$ & $796 \pm 78$ & $1120 \pm 332$ \\
\hline
\end{tabular}

* Data are mean \pm S.D. for the years 1961-2008. 
Figure 6.6 shows, for both the humid and arid part of China, for the various winter wheat production areas whether they contribute to the best $10 \%$ of national winter wheat production in that climate zone (in the sense of having smallest WFs), to the next best $10 \%$, to the best $5 \%$ after that, or to the worst $75 \%$ (with WFs beyond the $25^{\text {th }}$ percentile benchmark). Within the arid zone, consumptive WFs below the $25^{\text {th }}$ percentile benchmark level were mostly located in Xinjiang province, with relatively high irrigation density ( $98 \%$ of the harvested area). In the humid zone, consumptive WFs below the $25^{\text {th }}$ percentile benchmark level were gathered in the southwest, where $\mathrm{ET}_{0}$ is smaller than in other places (Figure 6.4b).

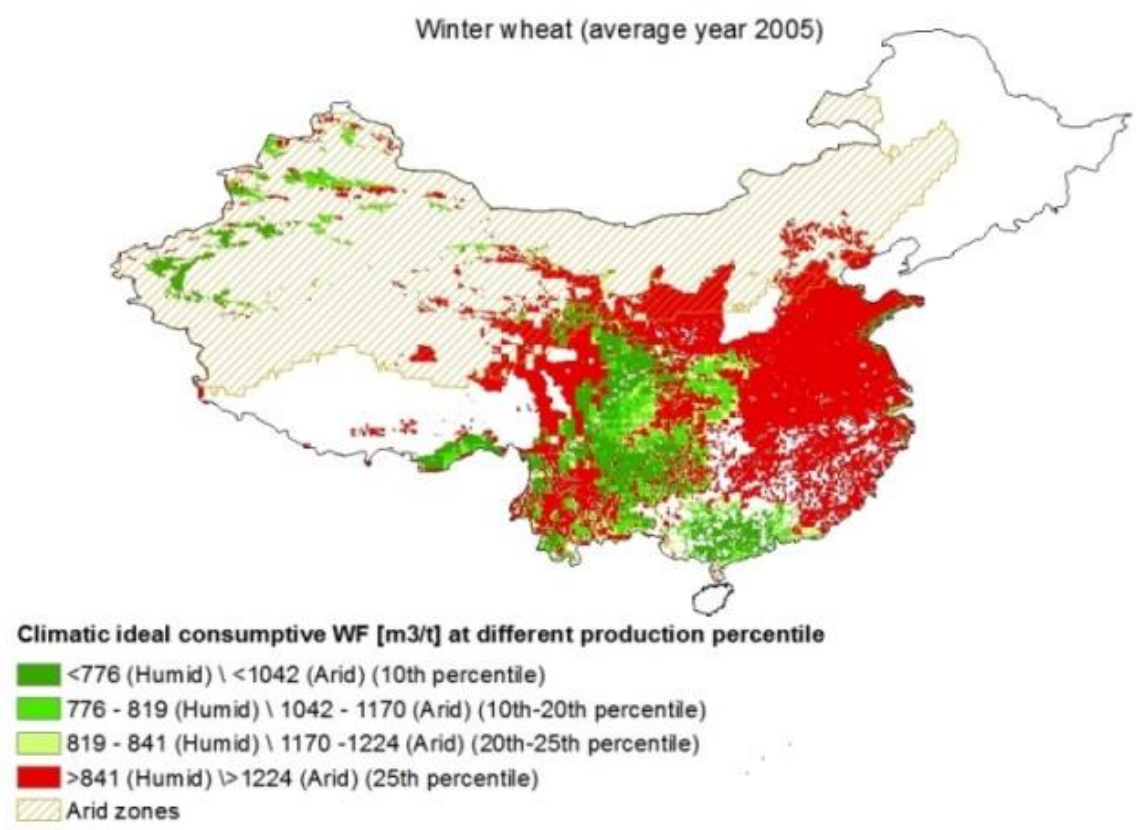

Figure 6.6 Simulated consumptive water footprints (WFs) of winter wheat, categorized into four classes (the best $10 \%$ of production, the next best $10 \%$, the second next best $5 \%$ and the worst $75 \%$ of production), accounting for different benchmark levels for humid versus arid part of China, for the year 2005 (climatic average year). 


\subsubsection{Water saving potential by reducing WFs to selected benchmark levels}

The WF benchmarks for different climate zones differ much more significantly (26-31\%) than for different soils (10-12\%). WF benchmarks differ even less if we compare irrigated versus rain-fed fields $(8-10 \%)$, warm versus cold years $(7-8 \%)$, or wet versus dry years (1-3\%). Therefore, when determining benchmark levels for the consumptive WF of a crop, it seems most useful to primarily distinguish between different climate zones, at least in the case of winter wheat in China. In this section, we analyse the potential water saving if actual consumptive WFs of winter wheat throughout China were reduced to the climate-specific benchmark levels set by the best $10 \%$ of Chinese winter wheat production $\left(1042 \mathrm{~m}^{3} \mathrm{t}^{-1}\right.$ for arid areas and $776 \mathrm{~m}^{3} \mathrm{t}^{-1}$ for humid areas), the best $20 \%$ of Chinese winter wheat production $\left(1170 \mathrm{~m}^{3} \mathrm{t}^{-1}\right.$ for arid areas and $819 \mathrm{~m}^{3} \mathrm{t}^{-1}$ for humid areas), or the best $25 \%$ of Chinese winter wheat production (1224 $\mathrm{m}^{3} \mathrm{t}^{-1}$ for arid areas and $841 \mathrm{~m}^{3} \mathrm{t}^{-1}$ for humid areas).

Taking the estimated consumptive WFs of winter wheat in 2005, an average climatic year, from Chapter 4, we find that consumptive WFs in $75 \%$ of the planted grids in arid zones and in $96 \%$ of the planted grids in humid zones are over the 25 th percentile benchmarks. This is largely due to low actual versus potential yields. Figure 6.7 shows differences between actual provincial yields of winter wheat (NBSC, 2013) and the simulated yield potentials from the current study (assuming no crops stresses except water stress in rain-fed areas). The largest yield gaps occur in the southern provinces in the humid zone. The largest yield gap was observed in Fujian province.

Table 6.7 shows the (green plus blue) water saving that would be achieved if actual consumptive WFs of winter wheat everywhere in China were reduced to the climate-differentiated WF benchmark levels set by the 10th, 20th and 25th percentiles of production, in an average year (2005). We find that if in both the arid and humid zone the actual consumptive WFs were reduced to the respective $25^{\text {th }}$ percentile benchmark level, the water saving in an average year would be $53 \%$ of the current water consumption at winter wheat fields in China, which is 201 billion $\mathrm{m}^{3} \mathrm{y}^{-1}$ in absolute terms. We further find that the water saving potential in the arid zone is substantially higher than in the humid zone. 
Actual yield vs. climatic ideal yield of winter wheat in China (2005)

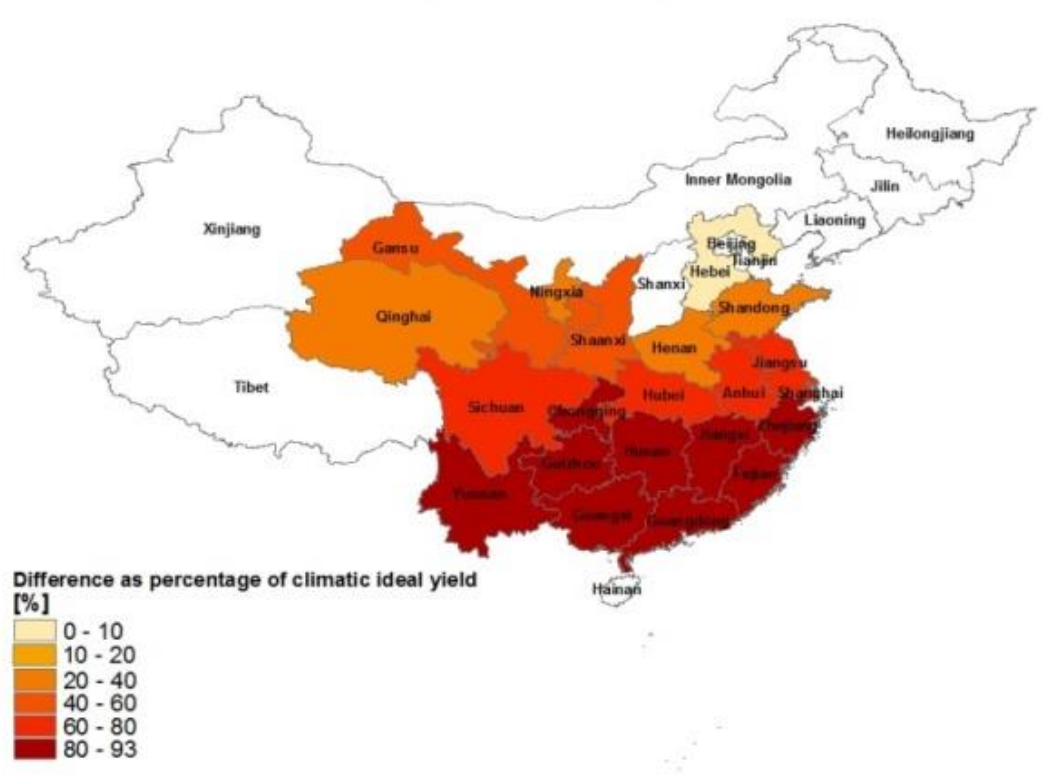

Figure 6.7 Differences between actual provincial yields of winter wheat in China in 2005 (NBSC, 2013) and simulated yields from the current study (assuming no crop stress except for water stress in rain-fed areas), expressed as percentage of the simulated yield.

Table 6.7 Water saving if actual consumptive WFs of winter wheat everywhere in China were reduced to the climate-differentiated WF benchmark levels set by the $10^{\text {th }}, 20^{\text {th }}$ and $25^{\text {th }}$ percentiles of production, in an average year (2005).

Water saving when actual consumptive WF of winter wheat everywhere in

Climate zones China were to be reduced to a certain percentile benchmark level

\begin{tabular}{llll} 
& 10 th & 20 th & 25 th \\
\hline Arid & $83 \%$ & $81 \%$ & $80 \%$ \\
Humid & $49 \%$ & $46 \%$ & $45 \%$ \\
Overall & $56 \%$ & $54 \%$ & $53 \%$ \\
\hline
\end{tabular}

* Data are mean \pm S.D. for the years 1961-2008. 


\subsubsection{Discussion}

The consumptive WF of a crop in $\mathrm{m}^{3} \mathrm{t}^{-1}$ most strongly depends on the crop yield in $\mathrm{t} \mathrm{ha}^{-1}$ and much less on the evapotranspiration from the crop over the growing period in $\mathrm{m}^{3} \mathrm{ha}^{-1}$ (Mekonnen and Hoekstra, 2011; Tuninetti et al., 2015). For evaluating our simulations of crop growth, we compared the current simulated averaged yields of winter wheat of Chinese provinces for 1961-1990 to the corresponding agro-climatic attainable yields at different agricultural input levels in the GAEZ database (FAO/IIASA, 2011) (Figure 6.8). The GAEZ agro-climatic attainable yields account for different levels of yield constraints from four factors in addition to water stress: (ii) pest, diseases and weed damages on plant growth, (ii) direct and indirect climatic damages on quality of produce, (iii) efficiency of farming operations, and (iv) frost hazards. Current simulated yields of irrigated winter wheat are closest to the agro-climatically attainable yields with intermediate input levels and the yields of rain-fed winter wheat are closest to the agro-climatically attainable yields with high input levels. The simulated national average yield in the current study $\left(6.5 \mathrm{t} \mathrm{ha}^{-1}\right)$ is $23 \%$ higher than the attainable wheat yield for China in the year $2000\left(5.3 \mathrm{t} \mathrm{ha}^{-1}\right)$ estimated by Mueller et al. (2012).

Further research could explore whether crop varieties used should play a role when developing WF benchmarks, given the fact that some crop varieties may inherently be more productive than others. On the other hand, one could also consider that choosing a productive crop variety is part of the managerial choices. Since crop variety is not a given environmental condition but a choice, one could argue that accepting a less strict WF reference level for a less productive crop variety cannot be justified.

An important remaining research question is also how combinations of specific techniques and practices can actually lead to the WF reductions that will be necessary in different locations if Chinese government would adopt certain WF benchmarks as targets to achieve greater water productivity. Suppose, for example, that two WF benchmarks for winter wheat were adopted in China: $1224 \mathrm{~m}^{3} \mathrm{t}^{-1}$ for arid areas and $841 \mathrm{~m}^{3} \mathrm{t}^{-1}$ for humid areas. Although the simulations suggest that these levels are feasible throughout the arid and humid zone, respectively, whatever is the soil, whether fields are rain-fed or irrigated, whether it is a cold 
or warm year, and whether it is a dry or wet year, in some places it will be harder and more would need to be done than in other places.

We studied benchmarks for combined green and blue WFs and did not look at each colour separately. For rain-fed lands, the benchmark levels presented in this study are obviously green WF benchmarks. For irrigated lands, the presented benchmark levels for overall consumptive WFs would need further specification into green and blue. Further research would need to be done to translate a certain benchmark level for the overall consumptive WF of a crop into a specific blue WF benchmark level per specific location as a function of the amount of rain per location, recognizing that the blue ratio in the WF will need to be larger if less green water is available.
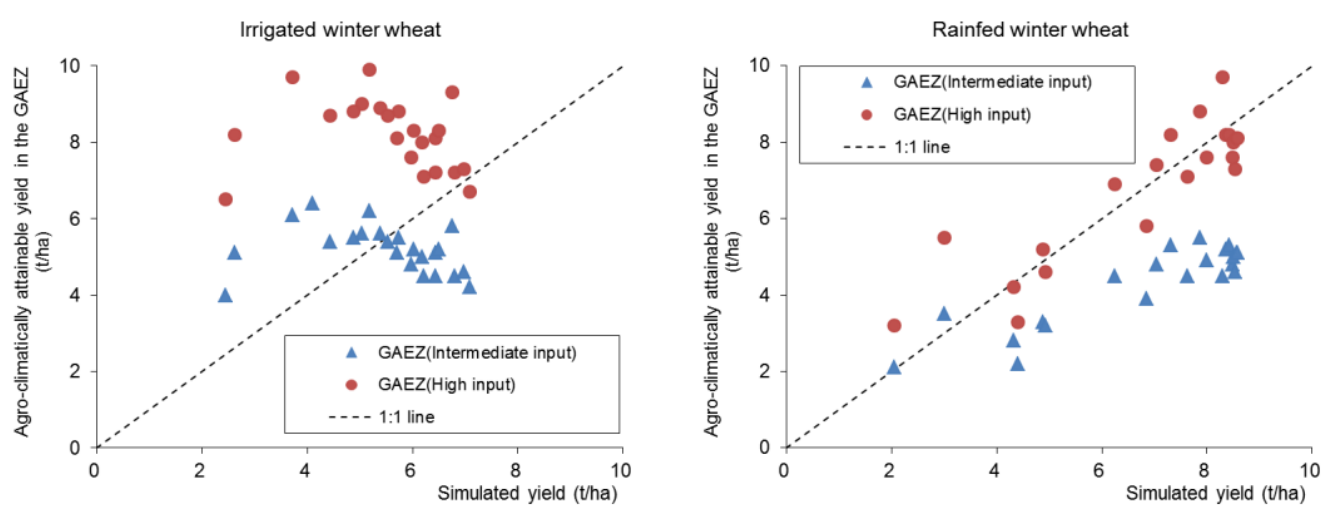

Figure 6.8 Comparison between the simulated yield of winter wheat and the agro-climatically attainable yield according to (FAO/IIASA, 2011) at provincial level in China. Averaged over the period 1961-1990.

\subsection{Conclusions}

Based on the case of winter wheat in China we find that (i) benchmark levels for the consumptive WF determined for individual years for the country as a whole remain within a range of $\pm 20 \%$ around long-term mean levels over 1961-2008; (ii) the WF benchmarks for irrigated winter wheat are $8-10 \%$ larger than those for rain-fed winter wheat; (iii) WF 
benchmarks for wet years are on average 1-3\% smaller than for dry years, (iv) WF benchmarks for warm years are on average $7-8 \%$ smaller than for cold years, (v) WF benchmarks differ by about $10-12 \%$ across different soil texture classes; and (vi) WF benchmarks for the humid zone are $26-31 \%$ smaller than for the arid zone, which has relatively higher $\mathrm{ET}_{0}$ in general and lower yields in rain-fed fields. Therefore, we conclude that when determining benchmark levels for the consumptive WF of a crop, it is useful to primarily distinguish between different climate zones. We estimated that when in both the arid and humid zone the actual consumptive WFs are reduced to climate-specific benchmark levels set by the $25^{\text {th }}$ percentile of production, the water saving in an average year would be $53 \%$ of the current water consumption at winter wheat fields in China, with greatest relative savings in the arid zone. 


\section{Conclusions and discussion}


The current work contributes to the advance of the field of water footprint assessment in different ways. First, FAO's crop water productivity model AquaCrop has been implemented in large scale WF simulations for the first time in the thesis (Chapters 3-6). A module to track, at daily basis, the green to blue ratio in soil moisture was developed in order to be able to separately estimate the green and blue fractions in ET and thus the green and blue fractions in the estimated total consumptive WF of crops. The modelling approach used in Chapters 3 and 4, making use of an advanced crop water productivity model and existing open-access global data sets on historical climate at a high spatial and temporal resolution, is applicable in similar WF studies for other river basins or countries in the world.

Second, the thesis offers the first comprehensive study of sensitivities and uncertainties in WF accounting (Chapter 2), a key contribution to the development of the water footprint assessment research field as pointed out by Chenoweth et al. (2014). The consumptive WFs of the crops studied (maize, soybean, rice, and wheat) were found to be most sensitive to changes in inputs on the reference evapotranspiration $\mathrm{ET}_{0}$ and the crop coefficient $\mathrm{K}_{\mathrm{c}}$. Uncertainties in key input variables together can generate $\pm 30 \%$ (at $95 \%$ confidence interval) of uncertainties in estimated WFs of crops. The recent global sensitivity analysis of WFs of the same four crops by Tuninetti et al. (2015) confirms our results on the sensitivity of WFs to $\mathrm{ET}_{0}$ and crop calendar. The general findings valid for both the YRB (Chapter 2) and the globe (Tuninetti et al., 2015) are (i) with an increased $\mathrm{ET}_{0}$, the WF of irrigated crops will increase through additional ET, while the WF of rain-fed crops will increase only if there is sufficient green water availability; (ii) shifting the planting date of spring and summer crops (e.g. rice and maize) may reduce the crop water requirement and thus lower the WF of crops.

Third, this thesis adds to the few studies carried out thus far on the inter- and intra- annual variation of WF of crops, blue water scarcity and inter-regional virtual water trade, through one case study for the YRB (Chapter 3), and another study for China as a whole (Chapter 4). Reductions in consumptive WFs per tonne of crop, driven by growing crop yields during past decades, were observed across the country. As a result, the increases in annual total green and blue WFs in crop production were much smaller than the growth in total crop 
production, and the WF per capita of crop consumption in China decreased by $23 \%$ over the period 1978-2008. How, counter-intuitively, the original virtual water flow from the water-rich South to the water-scarce North of China could reverse during the study period is explained in Chapter 4. The huge increase in the grey WF of crop production in the YRB (by factors of 24 and 36 for nitrogen and phosphorus, respectively) over the period 1961-2009 reveals the significant negative impact of agriculture on freshwater quality (Chapter 3). The results point at the importance of controlling the overuse of fertilizers from both a water quality and resource use perspective. A limitation in doing long-term historical analyses as in Chapters 3-4 lies in the limited availability of time series for all relevant variables. In the current work, the temporal and spatial variation in a number of crop parameters (e.g. harvest index, cropping calendar and the maximum root depth of each type of crop) and the annual variation of initial soil water content at the beginning of the crop period were not considered. The spatial changes in harvested crop area were simply assumed as a fraction of each grid cell with cropping area around the year 2000, matching province totals to annual provincial statistics. Another limitation in the work is the focus on water stress in crop production, not considering other stresses, like temperature stress (cold or heat stress) and biotic stress (e.g. insects and diseases).

Fourth, this is the first study showing WF and VW trade scenarios for China accounting for both climate change and various socio-economic drivers (Chapter 5). Changes in five driving factors were considered: climate, harvested crop area, technology, diet, and population. Four scenarios were constructed by making use of three of IPCC's shared socio-economic pathways and two of IPCC's representative concentration pathways. It is found that the historical trend of increasing crop yields as found in Chapter 4 is likely to continue into the future as a result of a projected wetter climate, an increasing $\mathrm{CO}_{2}$ concentration and improved technology. Accordingly, consumptive WFs per tonne of crop will continue to decrease towards 2050. Partly due to the projected decrease of China's population between 2030 and 2050, China may be able to attain its target of self-sufficiency in staple food supply and change into a net VW exporter through crop trade. Introducing the 'less meat' diet can further help to reduce the WF of food consumption. The directions of change regarding the WFs of crops and national VW trade as found in all four scenarios in 
the current work agree with previous studies (Fader et al., 2010; Pfister et al., 2011; Konar et al., 2013; Ercin and Hoekstra, 2014). It is acknowledged that the presented scenarios should not be interpreted as predictions; rather they sketch possible futures under different combinations of assumptions regarding main driving forces of change. The overall picture arising from the four presented scenarios for China is rather positive, but depends on a number of assumptions, including a wetter climate in the North with resultant increases in local rain-fed crop yields, improved yields in both irrigated and rain-fed agriculture from the adoption of better practices, a reducing population after 2030, and (in one of the scenarios presented) a changing diet towards less meat.

Finally, the work contributes to the development of knowledge on how to determine benchmarks as reference levels for consumptive WFs in crop production, by exploring the relevance of different environmental factors when developing WF benchmarks (Chapter 6). The main finding is that benchmarks for the consumptive WFs in crop production can best be developed separately for different climate zones, which is an important difference with the earlier suggestion by Mekonnen and Hoekstra (2014) that one global benchmark for the WF per crop could suffice. Based on the current case study for winter wheat in China it seems unnecessary to develop different WF benchmarks for rain-fed versus irrigated crops, for different types of years (wet or dry, cold or warm) or for different soil classes, but further study for other crops and other regions in the world is needed to confirm this. The approach developed in this thesis to study the sensitivity of setting benchmark values for the WF of crop production to different environmental factors can be applied in future studies in this field.

Future research is likely to add to and improve upon the current work in various ways. First, what is called a high spatial resolution in the current work may be seen as low in the near future, once better use of remote sensing will allow to do the sort of work undertaken in the current thesis at much higher spatial resolution. Second, where the current study basically relies on modelling in order to estimate ET and crop yields, a combined use of remote sensing products and modelling, validated by field observations, offers a new promising avenue. Third, given the fact that animal products account for nearly thirty percent of the 
WF of humanity (Hoekstra and Mekonnen, 2012), future long-term assessments of WFs focusing on livestock production and consumption will be urgently needed. The current study included feed crops and studied the impact of less meat in the diet, but a thorough understanding of the relation between the consumption of animal products and water resources use will need to include a study of (changes in) the feed composition of animals and the feed conversion efficiency of different animals and breeds, factors that were out of the scope of the current work. Fourth, in order to better understand the possible impact of consumptive WFs on catchment hydrology and to better inform policy making, the blue WF needs to be divided into surface water, renewable groundwater and fossil groundwater components (Hoekstra et al., 2011). Fifth, more future research should be done on green water scarcity (Schyns et al., 2015). In Chapter 3, we considered the long-term variation of blue water scarcity in the YRB, but it has to be acknowledged that green water plays a major role in crop production, even in irrigated agriculture, and that there is an upper limit to the sustainable use of green water resources in a basin (Hoekstra, 2014). Therefore, green water scarcity analysis over the long term is an essential element in understanding sustainable water consumption. Finally, for China, but also for other quickly developing countries, urbanization goes at a faster rate than economic growth (Yang, 2013), which will significantly influence inter-regional virtual water flows. The differences between the WFs of urban and rural consumption can be further analysed as well. Furthermore, even though the agricultural sector will remain the major water consumer, the WFs of the industrial and municipal sectors will increasingly become important, particularly in the regions of the urban centres. 


\section{References}

Abedinpour, M., Sarangi, A., Rajput, T., Singh, M., Pathak, H. and Ahmad, T. (2012) Performance evaluation of AquaCrop model for maize crop in a semi-arid environment. Agricultural Water Management 110, 55-66.

Ahn, H. (1996) Sensitivity for correlated input variables and propagated errors in evapotranspiration estimates from a humid region. Water Resources Research 32(8), 2507-2516.

Alcamo, J., Doll, P., Henrichs, T., Kaspar, F., Lehner, B., Rosch, T. and Siebert, S. (2003) Global estimates of water withdrawals and availability under current and future "business-as-usual" conditions. Hydrological Sciences Journal-Journal Des Sciences Hydrologiques 48(3), 339-348.

Aldaya, M.M. and Llamas, M. (2008) Water footprint analysis for the Guadiana river basin. Value of Water Research Report Series. No. 35. UNESCO-IHE. Delft, the Netherlands.

Allen, R.G., Pereira, L.S., Raes, D. and Smith, M. (1998) Crop evapotranspiration-Guidelines for computing crop water requirements-FAO Irrigation and drainage paper 56. FAO, Rome 300(9), D05109.

Andarzian, B., Bannayan, M., Steduto, P., Mazraeh, H., Barati, M., Barati, M. and Rahnama, A. (2011) Validation and testing of the AquaCrop model under full and deficit irrigated wheat production in Iran. Agricultural Water Management 100(1), 1-8.

Araya, A., Habtu, S., Hadgu, K.M., Kebede, A. and Dejene, T. (2010) Test of AquaCrop model in simulating biomass and yield of water deficient and irrigated barley (Hordeum vulgare). Agricultural Water Management 97(11), 1838-1846.

Asseng, S., Ewert, F., Rosenzweig, C., Jones, J.W., Hatfield, J.L., Ruane, A.C., Boote, K.J., Thorburn, P.J., Rotter, R.P., Cammarano, D., Brisson, N., Basso, B., Martre, P., Aggarwal, P.K., Angulo, C., Bertuzzi, P., Biernath, C., Challinor, A.J., Doltra, J., Gayler, S., Goldberg, R., Grant, R., Heng, L., Hooker, J., Hunt, L.A., Ingwersen, J., Izaurralde, R.C., Kersebaum, K.C., Muller, C., Naresh Kumar, S., Nendel, C., O/Leary, G., Olesen, J.E., Osborne, T.M., Palosuo, T., Priesack, E., Ripoche, D., Semenov, M.A., Shcherbak, I., Steduto, P., Stockle, C., Stratonovitch, P., Streck, T., Supit, I., Tao, F., Travasso, M., Waha, K., Wallach, D., White, J.W., Williams, J.R. and Wolf, J. (2013) Uncertainty in simulating wheat yields 
under climate change. Nature Climate Change 3(9), 827-832.

Asseng, S., Turner, N.C. and Keating, B.A. (2001) Analysis of water- and nitrogen-use efficiency of wheat in a Mediterranean climate. Plant and Soil 233(1), 127-143.

Barnett, J., Rogers, S., Webber, M., Finlayson, B. and Wang, M. (2015) Sustainability: Transfer project cannot meet China's water needs. Nature 527(7578), 295.

Batjes, N. (2012) ISRIC-WISE derived soil properties on a 5 by 5 arc-minutes global grid (ver. 1.2). ISRIC. Wageningen, The Netherlands.

Bocchiola, D., Nana, E. and Soncini, A. (2013) Impact of climate change scenarios on crop yield and water footprint of maize in the Po valley of Italy. Agricultural Water Management 116, 50-61.

Bouwman, A., Van der Hoek, K., Eickhout, B. and Soenario, I. (2005) Exploring changes in world ruminant production systems. Agricultural Systems 84(2), 121-153.

Bouwman, A.F., Lee, D.S., Asman, W.A.H., Dentener, F.J., VanderHoek, K.W. and Olivier, J.G.J. (1997) A global high-resolution emission inventory for ammonia. Global Biogeochemical Cycles 11(4), 561-587.

Bouwman, L., Goldewijk, K.K., Van Der Hoek, K.W., Beusen, A.H.W., Van Vuuren, D.P., Willems, J., Rufino, M.C. and Stehfest, E. (2013) Exploring global changes in nitrogen and phosphorus cycles in agriculture induced by livestock production over the 1900-2050 period. Proceedings of the National Academy of Sciences of the United States of America 110(52), 20882-20887.

Brauman, K.A., Siebert, S. and Foley, J.A. (2013) Improvements in crop water productivity increase water sustainability and food security - a global analysis. Environmental Research Letters 8(2), 024030.

Brown, A. and Matlock, M.D. (2011) A review of water scarcity indices and methodologies. White paper. 106. The Sustainability Consortium.

Bruinsma, J. (2003) World agriculture: towards 2015/2030: an FAO perspective, Earthscan, London, UK.

Bulsink, F., Hoekstra, A. and Booij, M. (2010) The water footprint of Indonesian provinces related to the consumption of crop products. Hydrology and Earth System Sciences 14(1), 119-128.

Cai, X. and Rosegrant, M.W. (2004) Optional water development strategies for the Yellow River Basin: Balancing agricultural and ecological water demands. Water Resources Research 40, 
W08S04.

Cai, X., Yang, Y.-C.E., Ringler, C., Zhao, J. and You, L. (2011) Agricultural water productivity assessment for the Yellow River Basin. Agricultural Water Management 98(8), 1297-1306.

Cai, Y., Wang, H.X., Wang, H.R. and Wang, H.L. (2009) Water footprint in the Yellow River basin. Journal of Beijing Normal University (Natural Science) 45, 616-620.

Cao, X.C., Wu, P.T., Wang, Y.B. and Zhao, X.N. (2014a) Assessing blue and green water utilisation in wheat production of China from the perspectives of water footprint and total water use. Hydrology and Earth System Sciences 18(8), 3165-3178.

Cao, X.C., Wu, P.T., Wang, Y.B. and Zhao, X.N. (2014b) Water footprint of grain product in irrigated farmland of China. Water Resources Management 28(8), 2213-2227.

Cao, X.C., Wu, P.T., Wang, Y.B. and Zhao, X.N. (2015) Challenge of water sources in urbanizing China: an analysis of agricultural water footprint. Polish Journal of Environmental Studies 24(1), 9-18.

Cao, X.C., Wu, P.T., Wang, Y.B., Zhao, X.N. and Li, S. (2011) Application of virtual water trade theory in inter-regional grain allocation and transportation in China. African Journal of Biotechnology 10(80), 18463-18471.

Chapagain, A.K., Hoekstra, A.Y. and Savenije, H.H.G. (2006) Water saving through international trade of agricultural products. Hydrology and Earth System Sciences 10(3), 455-468.

Chen, Y., Guo, G., Wang, G., Kang, S., Luo, H. and Zhang, D. (1995) Main crop water requirement and irrigation of China. Hydraulic and Electric Press, Beijing, China.

Chen, Z.M. and Chen, G.Q. (2013) Virtual water accounting for the globalized world economy: National water footprint and international virtual water trade. Ecological Indicators 28, 142-149.

Chenoweth, J., Hadjikakou, M. and Zoumides, C. (2014) Quantifying the human impact on water resources: a critical review of the water footprint concept. Hydrology and Earth System Sciences 18(6), 2325-2342.

Chilonda, P. and Otte, J. (2006) Indicators to monitor trends in livestock production at national, regional and international levels. Livestock Research for Rural Development 18(8), 117.

Chukalla, A., Krol, M. and Hoekstra, A. (2015) Green and blue water footprint reduction in irrigated agriculture: effect of irrigation techniques, irrigation strategies and mulching. Hydrology and Earth System Sciences 19, 4877-4891.

CIESIN, C. (2005) Gridded population of the world version 3 (GPWV3): population density 
grids. Palisades, NY: Socioeconomic Data and Applications Center (SEDAC). Columbia University.

Dalin, C. (2012) Evolution of the global virtual water trade network. Proceedings of the National Academy of Sciences of the United States of America 109(21), 8353-8353.

Dalin, C., Hanasaki, N., Qiu, H.G., Mauzerall, D.L. and Rodriguez-Iturbe, I. (2014) Water resources transfers through Chinese interprovincial and foreign food trade. Proceedings of the National Academy of Sciences of the United States of America 111(27), 9774-9779.

Dalin, C., Qiu, H., Hanasaki, N., Mauzerall, D.L. and Rodriguez-Iturbe, I. (2015) Balancing water resource conservation and food security in China. Proceedings of the National Academy of Sciences of the United States of America 112(15), 4588-4593.

De Fraiture, C., Wichelns, D., Rockstrom, J., Kemp-Benedict, E., Eriyagama, N., Gordon, L.J., Hanjra, M.A., Hoogeveen, J., Huber-Lee, A. and Karlberg, L. (2007) Water for food, water for life: a Comprehensive Assessment of Water Management in Agriculture. Molden, D. (ed), pp. 91-145, Earthscan, London, UK; International Water Management Institute, Colombo, Sri Lanka.

Dijkshoorn, K., van Engelen, V. and Huting, J. (2008) Soil and landform properties for LADA partner countries, ISRIC-World Soil Information and FAO, Wageningen, The Netherlands.

Doorenbos, J. and Kassam, A. (1979) Yield response to water. Irrigation and drainage paper. 33. FAO. Rome, Italy.

Droogers, P. and Allen, R.G. (2002) Estimating reference evapotranspiration under inaccurate data conditions. Irrigation and Drainage Systems 16(1), 33-45.

Du, S.F., Mroz, T.A., Zhai, F.Y. and Popkin, B.M. (2004) Rapid income growth adversely affects diet quality in China particularly for the poor! Social Science \& Medicine 59(7), 1505-1515.

Erb, K.-H., Haberl, H., Krausmann, F., Lauk, C., Plutzar, C., Steinberger, J.K., Müller, C., Bondeau, A., Waha, K. and Pollack, G. (2009) Eating the Planet: Feeding and fuelling the world sustainably, fairly and humanely - a scoping study. Commissioned by Compassion in World Farming and Friends of the Earch UK. Institute of Social Ecology and PIK Potsdam, Vienna, Potsdam.

Ercin, A.E. and Hoekstra, A.Y. (2014) Water footprint scenarios for 2050: A global analysis. Environment International 64, 71-82.

Estevez, J., Gavilan, P. and Berengena, J. (2009) Sensitivity analysis of a Penman-Monteith type 
equation to estimate reference evapotranspiration in southern Spain. Hydrological Processes 23(23), 3342-3353.

Fader, M., Gerten, D., Thammer, M., Heinke, J., Lotze-Campen, H., Lucht, W. and Cramer, W. (2011) Internal and external green-blue agricultural water footprints of nations, and related water and land savings through trade. Hydrology and Earth System Sciences 15(5), 1641-1660.

Fader, M., Rost, S., Muller, C., Bondeau, A. and Gerten, D. (2010) Virtual water content of temperate cereals and maize: Present and potential future patterns. Journal of Hydrology 384(3-4), 218-231.

Falkenmark, M. (1989) The massive water scarcity now threatening Africa: why isn't it being addressed? Ambio 18(2), 112-118.

Falkenmark, M. (2013) Growing water scarcity in agriculture: future challenge to global water security. Philosophical Transactions of the Royal Society a-Mathematical Physical and Engineering Sciences 371(2002), 20120410.

Falkenmark, M. and Rockstrom, J. (2006) The new blue and green water paradigm: Breaking new ground for water resources planning and management. Journal of Water Resources Planning and Management-Asce 132(3), 129-132.

Falkenmark, M. and Rockström, J. (2004) Balancing water for humans and nature: the new approach in ecohydrology, Earthscan, London, UK.

Falkenmark, M. and Widstrand, C. (1992) Population and water resources: a delicate balance. Population bulletin 47(3), 1-36.

Fang, D.L. and Chen, B. (2015) Ecological Network Analysis for a Virtual Water Network. Environmental Science \& Technology 49(11), 6722-6730.

FAO (2005) Livestock, Environment and Development Initiative 2005, Food and Agricultural Organization, Rome, Italy.

FAO (2007) Fertilizer use statistics. www.fao.org/ag/agp/fertistat/fst_fubc_en.asp.

FAO (2014a) AQUASTAT online database. www.fao.org/nr/water/aquastat/data/query.

FAO (2014b) FAOSTAT on-line database. http://faostat.fao.org.

FAO/IIASA (2011) Global Agro-ecological Zones (GAEZ v3.0). FAO Rome, Italy and IIASA, Laxenburg, Austria.

Farahani, H.J., Izzi, G. and Oweis, T.Y. (2009) Parameterization and evaluation of the AquaCrop model for full and deficit irrigated cotton. Agronomy Journal 101(3), 469-476. 
Fekete, B.M., Vorosmarty, C.J., Roads, J.O. and Willmott, C.J. (2004) Uncertainties in precipitation and their impacts on runoff estimates. Journal of Climate 17(2), 294-304.

Feng, K.S., Hubacek, K., Pfister, S., Yu, Y. and Sun, L.X. (2014) Virtual Scarce Water in China. Environmental Science \& Technology 48(14), 7704-7713.

Feng, K.S., Siu, Y.L., Guan, D.B. and Hubacek, K. (2012) Assessing regional virtual water flows and water footprints in the Yellow River Basin, China: A consumption based approach. Applied Geography 32(2), 691-701.

Foley, J.A., Ramankutty, N., Brauman, K.A., Cassidy, E.S., Gerber, J.S., Johnston, M., Mueller, N.D., O'Connell, C., Ray, D.K., West, P.C., Balzer, C., Bennett, E.M., Carpenter, S.R., Hill, J., Monfreda, C., Polasky, S., Rockstrom, J., Sheehan, J., Siebert, S., Tilman, D. and Zaks, D.P.M. (2011) Solutions for a cultivated planet. Nature 478(7369), 337-342.

Franke, N., Hoekstra, A. and Boyacioglu, H. (2013) Grey water footprint accounting: Tier 1 supporting guidelines. Value of Water Research Report Series. No.65. UNESCO-IHE, Delft, the Netherlands.

Galli, A., Wiedmann, T., Ercin, E., Knoblauch, D., Ewing, B. and Giljum, S. (2012) Integrating ecological, carbon and water footprint into a "footprint family" of indicators: definition and role in tracking human pressure on the planet. Ecological Indicators 16, 100-112.

Garcia-Vila, M., Fereres, E., Mateos, L., Orgaz, F. and Steduto, P. (2009) Deficit Irrigation Optimization of Cotton with AquaCrop. Agronomy Journal 101(3), 477-487.

Ge, L.Q., Xie, G.D., Zhang, C.X., Li, S.M., Qi, Y., Cao, S.Y. and He, T.T. (2011) An Evaluation of China's Water Footprint. Water Resources Management 25(10), 2633-2647.

Gong, P., Yin, Y.Y. and Yu, C.Q. (2011) China: Invest Wisely in Sustainable Water Use. Science 331(6022), 1264-1265.

Goyal, R.K. (2004) Sensitivity of evapotranspiration to global warming: a case study of arid zone of Rajasthan (India). Agricultural Water Management 69(1), 1-11.

Guan, D. and Hubacek, K. (2007) Assessment of regional trade and virtual water flows in China. Ecological Economics 61(1), 159-170.

Guieysse, B., Béchet, Q. and Shilton, A. (2013) Variability and uncertainty in water demand and water footprint assessments of fresh algae cultivation based on case studies from five climatic regions. Bioresource Technology 128, 317-323.

Haddeland, I., Heinke, J., Biemans, H., Eisner, S., Flörke, M., Hanasaki, N., Konzmann, M., Ludwig, F., Masaki, Y. and Schewe, J. (2014) Global water resources affected by human 
interventions and climate change. Proceedings of the National Academy of Sciences 111(9), 3251-3256.

Hamby, D.M. (1994) A Review of Techniques for Parameter Sensitivity Analysis of Environmental-Models. Environmental Monitoring and Assessment 32(2), 135-154.

Han, X. and Sun, C. (2013) Virtual Water Flow Patterns Embedded in Major Crops in China. Resources Science 35(8), 1567-1576.

Hanasaki, N., Fujimori, S., Yamamoto, T., Yoshikawa, S., Masaki, Y., Hijioka, Y., Kainuma, M., Kanamori, Y., Masui, T. and Takahashi, K. (2013a) A global water scarcity assessment under Shared Socio-economic Pathways-Part 1: Water use. Hydrology and Earth System Sciences 17(7), 2375-2391.

Hanasaki, N., Fujimori, S., Yamamoto, T., Yoshikawa, S., Masaki, Y., Hijioka, Y., Kainuma, M., Kanamori, Y., Masui, T. and Takahashi, K. (2013b) A global water scarcity assessment under Shared Socio-economic Pathways-Part 2: Water availability and scarcity. Hydrology and Earth System Sciences 17(7), 2393-2413.

Hanasaki, N., Inuzuka, T., Kanae, S. and Oki, T. (2010) An estimation of global virtual water flow and sources of water withdrawal for major crops and livestock products using a global hydrological model. Journal of Hydrology 384(3-4), 232-244.

Harris, I., Jones, P.D., Osborn, T.J. and Lister, D.H. (2014) Updated high-resolution grids of monthly climatic observations - the CRU TS3.10 Dataset. International Journal of Climatology 34(3), 623-642.

Hatfield, J.L., Boote, K.J., Kimball, B.A., Ziska, L.H., Izaurralde, R.C., Ort, D., Thomson, A.M. and Wolfe, D. (2011) Climate Impacts on Agriculture: Implications for Crop Production. Agronomy Journal 103(2), 351-370.

Herva, M., Franco, A., Carrasco, E.F. and Roca, E. (2011) Review of corporate environmental indicators. Journal of Cleaner Production 19(15), 1687-1699.

Hoekstra, A.Y. (2003) Virtual water trade: Proceedings of the international expert meeting on virtual water trade. Value of Water Research Report Series. No 12. UNESCO-IHE, Delft, The Netherlands.

Hoekstra, A.Y. (2013) The water footprint of modern consumer society, Routledge, London, UK.

Hoekstra, A.Y. (2014) Sustainable, efficient, and equitable water use: the three pillars under wise freshwater allocation. Wiley Interdisciplinary Reviews: Water 1(1), 31-40.

Hoekstra, A.Y. and Chapagain, A.K. (2007a) The water footprints of Morocco and the 
Netherlands: Global water use as a result of domestic consumption of agricultural commodities. Ecological Economics 64(1), 143-151.

Hoekstra, A.Y. and Chapagain, A.K. (2007b) Water footprints of nations: Water use by people as a function of their consumption pattern. Water Resources Management 21(1), 35-48.

Hoekstra, A.Y. and Chapagain, A.K. (2008) Globalization of water: Sharing the planet's freshwater resources, John Wiley \& Sons, UK.

Hoekstra, A.Y., Chapagain, A.K., Aldaya, M.M. and Mekonnen, M.M. (2011) The Water Footprint Assessment Manual: setting the global standard, Earthscan, London, UK.

Hoekstra, A.Y. and Hung, P.Q. (2005) Globalisation of water resources: international virtual water flows in relation to crop trade. Global Environmental Change-Human and Policy Dimensions 15(1), 45-56.

Hoekstra, A.Y. and Mekonnen, M.M. (2012) The water footprint of humanity. Proceedings of the National Academy of Sciences of the United States of America 109(9), 3232-3237.

Hoekstra, A.Y., Mekonnen, M.M., Chapagain, A.K., Mathews, R.E. and Richter, B.D. (2012) Global monthly water scarcity: blue water footprints versus blue water availability. PLoS One 7(2), e32688.

Hoekstra, A.Y. and Wiedmann, T.O. (2014) Humanity's unsustainable environmental footprint. Science 344(6188), 1114-1117.

Hoff, H. (2009) Global water resources and their management. Current Opinion in Environmental Sustainability 1(2), 141-147.

Hsiao, T.C., Heng, L., Steduto, P., Rojas-Lara, B., Raes, D. and Fereres, E. (2009) AquaCrop-The FAO Crop Model to Simulate Yield Response to Water: III. Parameterization and Testing for Maize. Agronomy Journal 101(3), 448-459.

Huang, J., Pray, C. and Rozelle, S. (2002) Enhancing the crops to feed the poor. Nature 418(6898), 678-684.

Hurtt, G.C., Chini, L.P., Frolking, S., Betts, R.A., Feddema, J., Fischer, G., Fisk, J.P., Hibbard, K., Houghton, R.A., Janetos, A., Jones, C.D., Kindermann, G., Kinoshita, T., Goldewijk, K.K., Riahi, K., Shevliakova, E., Smith, S., Stehfest, E., Thomson, A., Thornton, P., van Vuuren, D.P. and Wang, Y.P. (2011) Harmonization of land-use scenarios for the period 1500-2100: 600 years of global gridded annual land-use transitions, wood harvest, and resulting secondary lands. Climatic Change 109(1-2), 117-161.

IFA (2013) IFADATA: IFA statistical databases. www.fertilizer.org/ifa/ifadata/search. 
IIASA (2009) RCP Database. http://www.iiasa.ac.at/web-apps/tnt/RcpDb.

IIASA (2013) SSP Database. https://secure.iiasa.ac.at/web-apps/ene/SspDb/dsd.

IPCC (2014) Climate Change 2014: Synthesis Report. Contribution of Working Groups I, II and III to the Fifth Assessment Report of the Intergovernmental Panel on Climate Change. IPCC. Switherlands.

Iqbal, M.A., Shen, Y., Stricevic, R., Pei, H., Sun, H., Amiri, E., Penas, A. and del Rio, S. (2014) Evaluation of the FAO AquaCrop model for winter wheat on the North China Plain under deficit irrigation from field experiment to regional yield simulation. Agricultural Water Management 135, 61-72.

Jagtap, S.S. and Jones, J.W. (1989) Stability of Crop Coefficients under Different Climate and Irrigation Management-Practices. Irrigation Science 10(3), 231-244.

Jensen, M., Burman, R. and Allen, R. (1990) Evaporation and irrigation water requirements. ASCE Manuals and Reports on Eng. Practices No. 70. Am. Soc. Civil Eng., New York, NY, 978-970.

Jiang, Y. (2009) China's water scarcity. Journal of Environmental Management 90(11), 3185-3196.

Jiang, Y. (2015) China's water security: Current status, emerging challenges and future prospects. Environmental Science \& Policy 54, 106-125.

Jiang, Y.K., Cai, W.J., Du, P.F., Pan, W.Q. and Wang, C. (2015) Virtual water in interprovincial trade with implications for China's water policy. Journal of Cleaner Production 87, 655-665.

Jin, L., Cui, H., Li, B., Zhang, J., Dong, S. and Liu, P. (2012) Effects of integrated agronomic management practices on yield and nitrogen efficiency of summer maize in North China. Field Crops Research 134, 30-35.

Jin, X., Feng, H., Zhu, X., Li, Z., Song, S. and Hui, D. (2014) Assessment of the AquaCrop model for use in simulation of irrigated winter wheat canopy cover, biomass, and grain yield in the North China Plain. PLoS One 9(1), e86938.

Kampman, D., Hoekstra, A. and Krol, M. (2008) The water footprint of India. Value of Water Research Report Series 32, 1-152.

Katerji, N., Campi, P. and Mastrorilli, M. (2013) Productivity, evapotranspiration, and water use efficiency of corn and tomato crops simulated by AquaCrop under contrasting water stress conditions in the Mediterranean region. Agricultural Water Management 130, 14-26.

Keyzer, M.A., Merbis, M.D., Pavel, I.F.P.W. and van Wesenbeeck, C.F.A. (2005) Diet shifts 
towards meat and the effects on cereal use: can we feed the animals in 2030? Ecological Economics 55(2), 187-202.

Konar, M., Dalin, C., Suweis, S., Hanasaki, N., Rinaldo, A. and Rodriguez - Iturbe, I. (2011) Water for food: The global virtual water trade network. Water Resources Research 47(5), W05520.

Konar, M., Hussein, Z., Hanasaki, N., Mauzerall, D.L. and Rodriguez-Iturbe, I. (2013) Virtual water trade flows and savings under climate change. Hydrology and Earth System Sciences 17(8), 3219-3234.

Kriegler, E., O'Neill, B.C., Hallegatte, S., Kran, T., Lempert, R., Moss, R.H. and Wilbanks, T.J. (2010) Socio-economic scenario development for climate change analysis. CIRED Working Paper DT/WP No 2010-23. October 2010.

Lehner, B., Verdin, K. and Jarvis, A. (2008) New global hydrography derived from spaceborne elevation data. EOS, Transactions American Geophysical Union 89(10), 93-94.

Liu, C. and Zhang, S. (2002) Drying up of the Yellow River: its impacts and counter-measures. Mitigation and Adaptation Strategies for Global Change 7(3), 203-214.

Liu, J. and Savenije, H.H.G. (2008) Food consumption patterns and their effect on water requirement in China. Hydrology and Earth System Sciences 12(3), 887-898.

Liu, J. and Yang, W. (2012) Water sustainability for China and beyond. Science 337(6095), 649-650.

Liu, J., Zehnder, A.J.B. and Yang, H. (2009) Global consumptive water use for crop production: The importance of green water and virtual water. Water Resources Research 45(5), W05428.

Liu, J.G., Folberth, C., Yang, H., Rockstrom, J., Abbaspour, K. and Zehnder, A.J.B. (2013) A Global and Spatially Explicit Assessment of Climate Change Impacts on Crop Production and Consumptive Water Use. PLoS One 8(2), e57750.

Liu, J.G., Mooney, H., Hull, V., Davis, S.J., Gaskell, J., Hertel, T., Lubchenco, J., Seto, K.C., Gleick, P., Kremen, C. and Li, S.X. (2015) Systems integration for global sustainability. Science 347(6225), 963.

Liu, J.G. and Yang, H. (2010) Spatially explicit assessment of global consumptive water uses in cropland: Green and blue water. Journal of Hydrology 384(3-4), 187-197.

Liu, J.G., You, L.Z., Amini, M., Obersteiner, M., Herrero, M., Zehnder, A.J.B. and Yang, H. (2010) A high-resolution assessment on global nitrogen flows in cropland. Proceedings of 
the National Academy of Sciences of the United States of America 107(17), 8035-8040.

Liu, J.G., Zehnder, A.J.B. and Yang, H. (2007) Historical trends in China's virtual water trade. Water International 32(1), 78-90.

Liu, Q. and McVicar, T.R. (2012) Assessing climate change induced modification of Penman potential evaporation and runoff sensitivity in a large water-limited basin. Journal of Hydrology 464, 352-362.

Lu, C.H. and Fan, L. (2013) Winter wheat yield potentials and yield gaps in the North China Plain. Field Crops Research 143, 98-105.

Ma, J., Hoekstra, A.Y., Wang, H., Chapagain, A.K. and Wang, D. (2006) Virtual versus real water transfers within China. Philosophical Transactions of the Royal Society B-Biological Sciences 361(1469), 835-842.

Mattila, T., Leskinen, P., Soimakallio, S. and Sironen, S. (2012) Uncertainty in environmentally conscious decision making: beer or wine? The International Journal of Life Cycle Assessment 17(6), 696-705.

McMaster, G.S. and Wilhelm, W.W. (1997) Growing degree-days: one equation, two interpretations. Agricultural and Forest Meteorology 87(4), 291-300.

Mekonnen, M.M. (2011) Spatially and temporally explicit water footprint accounting. PhD thesis, University of Twente.

Mekonnen, M.M. and Hoekstra, A.Y. (2010) A global and high-resolution assessment of the green, blue and grey water footprint of wheat. Hydrology and Earth System Sciences 14, 1259-1276.

Mekonnen, M.M. and Hoekstra, A.Y. (2011) The green, blue and grey water footprint of crops and derived crop products. Hydrology and Earth System Sciences 15(5), 1577-1600.

Mekonnen, M.M. and Hoekstra, A.Y. (2012) A Global Assessment of the Water Footprint of Farm Animal Products. Ecosystems 15(3), 401-415.

Mekonnen, M.M. and Hoekstra, A.Y. (2014) Water footprint benchmarks for crop production: A first global assessment. Ecological Indicators 46, 214-223.

Mekonnen, M.M. and Hoekstra, A.Y. (2015) Global grey water footprint and water pollution levels related to anthropogenic nitrogen loads to fresh water. Environmental Science \& Technology 49, 12860-12868.

Mekonnen, M.M. and Hoekstra, A.Y. (2016) Four billion people facing severe water scarcity. Science Advances 2(2), e1500323. 
Meng, Q.F., Hou, P., Wu, L., Chen, X.P., Cui, Z.L. and Zhang, F.S. (2013) Understanding production potentials and yield gaps in intensive maize production in China. Field Crops Research 143, 91-97.

MEP (2002) Surface water quality standards in China (GB3838-2002), Ministry of Environmental Protection, Beijing, China.

Meyer, S.J., Hubbard, K.G. and Wilhite, D.A. (1989) Estimating Potential Evapotranspiration the Effect of Random and Systematic-Errors. Agricultural and Forest Meteorology 46(4), 285-296.

Meyer, V.R. (2007) Measurement uncertainty. Journal of Chromatography A 1158(1), 15-24.

Middleton, N. and Thomas, D.S.G. (1992) World atlas of desertification, Arnold, London, UK.

Middleton, N. and Thomas, D.S.G. (1997) World atlas of desertification, Arnold, London, UK.

MOA, NDRC, MOST, MOF, MLR, MEP, MWR and SFA (2015) National Plan of Sustainable Agriculture (2015-2030), Ministry of Agriculture of P. R. China; National Development and Reform Commission, P. R. China; Ministry of Science and Technology of P. R. China; Ministry of Finance of P.R.China; Ministry of Land and Resources of P.R.China; Ministry of Environmental Protection of P.R.China; Ministry of Water Resources of P.R.China; State Forestry Administration of P.R.China, Beijing, China.

Monfreda, C., Ramankutty, N. and Foley, J.A. (2008) Farming the planet: 2. Geographic distribution of crop areas, yields, physiological types, and net primary production in the year 2000. Global Biogeochemical Cycles 22(1), GB1022.

Moss, R.H., Edmonds, J.A., Hibbard, K.A., Manning, M.R., Rose, S.K., van Vuuren, D.P., Carter, T.R., Emori, S., Kainuma, M., Kram, T., Meehl, G.A., Mitchell, J.F.B., Nakicenovic, N., Riahi, K., Smith, S.J., Stouffer, R.J., Thomson, A.M., Weyant, J.P. and Wilbanks, T.J. (2010) The next generation of scenarios for climate change research and assessment. Nature 463(7282), 747-756.

$\mathrm{Mu}$, J.X. and Khan, S. (2009) The effect of climate change on the water and food nexus in China. Food Security 1(4), 413-430.

Mueller, N.D., Gerber, J.S., Johnston, M., Ray, D.K., Ramankutty, N. and Foley, J.A. (2012) Closing yield gaps through nutrient and water management. Nature 490(7419), 254-257.

MWR (2014) Water resources bulletin of China 2013, Ministry of Water Resources, P.R. China, Beijing, China.

MWR (2015) Water resources bulletin of China 2014, Ministry of Water Resources, P.R. China, 
Beijing, China.

NASMG (2010) Surveying and Mapping data sharing network. http://sms.webmap.cn/default.asp.

NBSC (2013) National data. National Bureau of Statistics, Beijing, China. http://data.stats.gov.cn/.

NDRC (2007) China's national climate change programme, National Development and Reform Commission, P. R. China, Beijing, China.

NDRC (2008) Long-term plan for national grain security (2008-2020), National Development and Reform Commission, P. R. China, Beijing, China.

Nonhebel, S. and Kastner, T. (2011) Changing demand for food, livestock feed and biofuels in the past and in the near future. Livestock Science 139(1), 3-10.

O’Neill, B.C., Carter, T.R., Ebi, K.L., Edmonds, J., Hallegatte, S., Kemp-Benedict, E., Kriegler, E., Mearns, L., Moss, R., Riahi, K., van Ruijven, B., van Vuuren, D. 2012. Meeting Report of the Workshop on The Nature and Use of New Socioeconomic Pathways for Climate Change Research, Boulder, CO, November 2-4, 2011.

Oki, T. and Kanae, S. (2006) Global hydrological cycles and world water resources. Science 313(5790), 1068-1072.

Parker, R.W. and Tyedmers, P.H. (2012) Uncertainty and natural variability in the ecological footprint of fisheries: A case study of reduction fisheries for meal and oil. Ecological Indicators 16, 76-83.

Perry, C. (2007) Efficient irrigation; inefficient communication; flawed recommendations. Irrigation and Drainage 56(4), 367-378.

Pfister, S., Bayer, P., Koehler, A. and Hellweg, S. (2011) Projected water consumption in future global agriculture: scenarios and related impacts. Science of the Total Environment 409(20), 4206-4216.

Phillips, D.L. and Marks, D.G. (1996) Spatial uncertainty analysis: Propagation of interpolation errors in spatially distributed models. Ecological Modelling 91(1-3), 213-229.

Piao, S., Ciais, P., Huang, Y., Shen, Z., Peng, S., Li, J., Zhou, L., Liu, H., Ma, Y. and Ding, Y. (2010) The impacts of climate change on water resources and agriculture in China. Nature 467(7311), 43-51.

Polasky, S., Carpenter, S.R., Folke, C. and Keeler, B. (2011) Decision-making under great uncertainty: environmental management in an era of global change. Trends in Ecology \& 
Evolution 26(8), 398-404.

Portmann, F.T., Siebert, S. and Doll, P. (2010) MIRCA2000-Global monthly irrigated and rainfed crop areas around the year 2000: A new high-resolution data set for agricultural and hydrological modeling. Global Biogeochemical Cycles 24, GB1011.

Qin, L., Jin, Y. and Duan, P. (2012) Impact of different sowing dates on green water footprint of maize in western Jilin Province. Shengtai Xuebao/Acta Ecologica Sinica 32(23), 7375-7382.

Raes, D., Steduto, P., Hsiao, T.C. and Fereres, E. (2009) AquaCrop-The FAO Crop Model to Simulate Yield Response to Water: II. Main Algorithms and Software Description. Agronomy Journal 101(3), 438-447.

Raes, D., steduto, P., Hsiao, T.C. and Fereres, E. (2011) Reference manual AquaCrop version 4.0. FAO. Rome, Italy.

Rallison, R.E. (1980) Origin and evolution of the SCS runoff equation,Symposium on Watershed Management, ASCE, New York, N.Y.,912-924.

Ramirez-Villegas, J. and Jarvis, A. (2010) Downscaling global circulation model outputs: the delta method decision and policy analysis Working Paper No. 1. Policy Analysis 1, 1-18.

Rao, S. and Riahi, K. (2006) The role of Non-CO2 greenhouse gases in climate change mitigation: Long-term scenarios for the 21st century. Energy Journal, 177-200.

Raskin, P., Gleick, P., Kirshen, P., Pontius, G. and Strzepek, K. (1997) Water futures: assessment of long-range patterns and problems. Comprehensive assessment of the freshwater resources of the world, Stockholm Environment Institute, Sweden.

Riahi, K., Grubler, A. and Nakicenovic, N. (2007) Scenarios of long-term socio-economic and environmental development under climate stabilization. Technological Forecasting and Social Change 74(7), 887-935.

Richter, B.D., Davis, M., Apse, C. and Konrad, C. (2012) A presumptive standard for environmental flow protection. River Research and Applications 28(8), 1312-1321.

Ringler, C., Cai, X., Wang, J., Ahmed, A., Xue, Y., Xu, Z., Yang, E., Jianshi, Z., Zhu, T. and Cheng, L. (2010) Yellow River basin: living with scarcity. Water International 35(5), 681-701.

Robinson, T.P., Franceschini, G. and Wint, W. (2007) The Food and Agriculture Organization's gridded livestock of the world. Vet Ital 43(3), 745-751.

Röös, E., Sundberg, C. and Hansson, P.-A. (2010) Uncertainties in the carbon footprint of food 
products: a case study on table potatoes. The International Journal of Life Cycle Assessment 15(5), 478-488.

Röös, E., Sundberg, C. and Hansson, P.-A. (2011) Uncertainties in the carbon footprint of refined wheat products: a case study on Swedish pasta. The International Journal of Life Cycle Assessment 16(4), 338-350.

Rosegrant, M.W., Leach, N. and Gerpacio, R.V. (1999) Alternative futures for world cereal and meat consumption. Proceedings of the Nutrition Society 58(2), 219-234.

Rost, S., Gerten, D., Bondeau, A., Lucht, W., Rohwer, J. and Schaphoff, S. (2008) Agricultural green and blue water consumption and its influence on the global water system. Water Resources Research 44(9), W09405.

Savenije, H. (2000) Water scarcity indicators; the deception of the numbers. Physics and Chemistry of the Earth, Part B: Hydrology, Oceans and Atmosphere 25(3), 199-204.

Schuol, J. and Abbaspour, K.C. (2007) Using monthly weather statistics to generate daily data in a SWAT model application to West Africa. Ecological Modelling 201(3-4), 301-311.

Schyns, J., Hoekstra, A. and Booij, M. (2015) Review and classification of indicators of green water availability and scarcity. Hydrology and Earth System Sciences 19(11), 4581-4608.

SCPRC (2010) No.1 Document of 2011, State Council of P. R. China, Beijing, China.

SCPRC (2014a) Middle Route Project (MRP), Office of the South-to-North Water Diversion Project Commission of the State Council, China.

SCPRC (2014b) No. 1 document of 2014, State Council of P. R. China, Beijing, China.

Semenov, M.A. and Stratonovitch, P. (2010) Use of multi-model ensembles from global climate models for assessment of climate change impacts. Climate Research 41(1), 1-14.

Sheldrick, W., Syers, J.K. and Lingard, J. (2003) Contribution of livestock excreta to nutrient balances. Nutrient Cycling in Agroecosystems 66(2), 119-131.

Shi, J., Liu, J. and Pinter, L. (2014) Recent evolution of China's virtual water trade: analysis of selected crops and considerations for policy. Hydrology and Earth System Sciences 18(4), 1349-1357.

Shiferaw, B., Prasanna, B.M., Hellin, J. and Banziger, M. (2011) Crops that feed the world 6. Past successes and future challenges to the role played by maize in global food security. Food Security 3(3), 307-327.

Shiklomanov, I.A. (2000) Appraisal and assessment of world water resources. Water International 25(1), 11-32. 
SIC (2005) Multi-regional input-output model for China (1997), Social Sciences Academic Press, Beijing, China.

Siebert, S. and Doll, P. (2010) Quantifying blue and green virtual water contents in global crop production as well as potential production losses without irrigation. Journal of Hydrology 384(3-4), 198-217.

Smakhtin, V., Revenga, C. and Döll, P. (2004a) A pilot global assessment of environmental water requirements and scarcity. Water International 29(3), 307-317.

Smakhtin, V., Revenga, C. and Döll, P. (2004b) Taking into account environmental water requirements in global-scale water resources assessments. Comprehensive Assessment Research Report. 2. Colombo, Sri Lanka: Comprehensive Assessment Secretariat.

Smil, V. (1999) Nitrogen in crop production: An account of global flows. Global Biogeochemical Cycles 13(2), 647-662.

Steduto, P., Hsiao, T.C. and Fereres, E. (2007) On the conservative behavior of biomass water productivity. Irrigation Science 25(3), 189-207.

Steduto, P., Hsiao, T.C., Raes, D. and Fereres, E. (2009) AquaCrop-The FAO Crop Model to Simulate Yield Response to Water: I. Concepts and Underlying Principles. Agronomy Journal 101(3), 426-437.

Stricevic, R., Cosic, M., Djurovic, N., Pejic, B. and Maksimovic, L. (2011) Assessment of the FAO AquaCrop model in the simulation of rainfed and supplementally irrigated maize, sugar beet and sunflower. Agricultural Water Management 98(10), 1615-1621.

Sun, H.Y., Zhang, X.Y., Chen, S.Y., Pei, D. and Liu, C.M. (2007) Effects of harvest and sowing time on the performance of the rotation of winter wheat-summer maize in the North China Plain. Industrial Crops and Products 25(3), 239-247.

Sun, S.K., Wu, P.T., Wang, Y.B. and Zhao, X.N. (2013a) Temporal variability of water footprint for maize production: the case of Beijing from 1978 to 2008. Water Resources Management 27(7), 2447-2463.

Sun, S.K., Wu, P.T., Wang, Y.B. and Zhao, X.N. (2013b) The virtual water content of major grain crops and virtual water flows between regions in China. Journal of the Science of Food and Agriculture 93(6), 1427-1437.

Sun, S.K., Wu, P.T., Wang, Y.B., Zhao, X.N., Liu, J. and Zhang, X.H. (2012a) The temporal and spatial variability of water footprint of grain: A case study of an irrigation district in China from 1960 to 2008. Journal of Food Agriculture \& Environment 10(3-4), 1246-1251. 
Sun, X.Y., Newham, L.T.H., Croke, B.F.W. and Norton, J.P. (2012b) Three complementary methods for sensitivity analysis of a water quality model. Environmental Modelling \& Software 37, 19-29.

Tao, F.L. and Zhang, Z. (2011) Impacts of climate change as a function of global mean temperature: maize productivity and water use in China. Climatic Change 105(3-4), 409-432.

Thomas, A. (2008a) Agricultural irrigation demand under present and future climate scenarios in China. Global and Planetary Change 60(3-4), 306-326.

Thomas, A. (2008b) Development and properties of 0.25-degree gridded evapotranspiration data fields of China for hydrological studies. Journal of Hydrology 358(3-4), 145-158.

Tolk, J.A. and Howell, T.A. (2012) Sunflower water productivity in four Great Plains soils. Field Crops Research 127, 120-128.

Trostle, R. (2008) Global Agricultural Supply and Demand: Factors Contributing to the Recent Increase in Food Commodity Prices. A report from the economic research services. USA.

Troutman, B.M. (1985) Errors and Parameter-Estimation in Precipitation-Runoff Modeling .1. Theory. Water Resources Research 21(8), 1195-1213.

Tuninetti, M., Tamea, S., D'Odorico, P., Laio, F. and Ridolfi, L. (2015) Global sensitivity of high - resolution estimates of crop water footprint. Water Resources Research 51, 8257-8272.

Van Beek, L., Wada, Y. and Bierkens, M.F. (2011) Global monthly water stress: 1. Water balance and water availability. Water Resources Research 47(7), W07517.

van Vuuren, D.P., Den Elzen, M.G.J., Lucas, P.L., Eickhout, B., Strengers, B.J., van Ruijven, B., Wonink, S. and van Houdt, R. (2007) Stabilizing greenhouse gas concentrations at low levels: an assessment of reduction strategies and costs. Climatic Change 81(2), 119-159.

van Vuuren, D.P., Edmonds, J., Kainuma, M., Riahi, K., Thomson, A., Hibbard, K., Hurtt, G.C., Kram, T., Krey, V., Lamarque, J.F., Masui, T., Meinshausen, M., Nakicenovic, N., Smith, S.J. and Rose, S.K. (2011) The representative concentration pathways: an overview. Climatic Change 109(1-2), 5-31.

Vanuytrecht, E., Raes, D. and Willems, P. (2014) Global sensitivity analysis of yield output from the water productivity model. Environmental Modelling \& Software 51, 323-332.

Vitousek, P.M., Naylor, R., Crews, T., David, M., Drinkwater, L., Holland, E., Johnes, P., Katzenberger, J., Martinelli, L. and Matson, P. (2009) Nutrient imbalances in agricultural 
development. Science 324(5934), 1519.

Vörösmarty, C.J., Green, P., Salisbury, J. and Lammers, R.B. (2000) Global water resources: vulnerability from climate change and population growth. Science 289(5477), 284-288.

Vörösmarty, C.J., Hoekstra, A., Bunn, S., Conway, D. and Gupta, J. (2015) Fresh water goes global. Science 349(6247), 478-479.

Vörösmarty, C.J., McIntyre, P.B., Gessner, M.O., Dudgeon, D., Prusevich, A., Green, P., Glidden, S., Bunn, S.E., Sullivan, C.A., Liermann, C.R. and Davies, P.M. (2010) Global threats to human water security and river biodiversity. Nature 467(7315), 555-561.

Wada, Y. (2013) Human and climate impacts on global water resources, PhD thesis, Utrecht University.

Wada, Y. and Bierkens, M.F.P. (2014) Sustainability of global water use: past reconstruction and future projections. Environmental Research Letters 9(10), 104003.

Wada, Y., Van Beek, L., Viviroli, D., Dürr, H.H., Weingartner, R. and Bierkens, M.F. (2011) Global monthly water stress: 2. Water demand and severity of water stress. Water Resources Research 47(7), W07518.

Wada, Y., Wisser, D., Eisner, S., Florke, M., Gerten, D., Haddeland, I., Hanasaki, N., Masaki, Y., Portmann, F.T., Stacke, T., Tessler, Z. and Schewe, J. (2013) Multimodel projections and uncertainties of irrigation water demand under climate change. Geophysical Research Letters 40(17), 4626-4632.

Walker, W.E., Harremoës, P., Rotmans, J., van der Sluijs, J.P., van Asselt, M.B., Janssen, P. and Krayer von Krauss, M.P. (2003) Defining uncertainty: a conceptual basis for uncertainty management in model-based decision support. Integrated assessment 4(1), 5-17.

Wang, G.Q. and Zhang, J.Y. (2015) Variation of water resources in the Huang-huai-hai areas and adaptive strategies to climate change. Quaternary International 380-381, 180-186.

Wang, Y.B., Wu, P.T., Zhao, X.N. and Engel, B.A. (2014) Virtual water flows of grain within China and its impact on water resource and grain security in 2010. Ecological Engineering 69, 255-264.

Wu, P.T., Zhao, X.N., Cao, X.C. and Hao, S.L. (2010) Status and thoughts of Chinese "agricultural north-to-south water diversion virtual engineering". Transactions of the Chinese Society of Agricultural Engineering 26(6), 1-6.

Xie, G., Han, D., Wang, X. and Lü, R. (2011) Harvest index and residue factor of cereal crops in China. Journal of China Agricultural University 16(1), 1-8. 
Xiong, W., Holman, I., Lin, E.D., Conway, D., Jiang, J.H., Xu, Y.L. and Li, Y. (2010) Climate change, water availability and future cereal production in China. Agriculture Ecosystems \& Environment 135(1-2), 58-69.

Xu, C.Y., Gong, L.B., Jiang, T., Chen, D.L. and Singh, V.P. (2006a) Analysis of spatial distribution and temporal trend of reference evapotranspiration and pan evaporation in Changjiang (Yangtze River) catchment. Journal of Hydrology 327(1-2), 81-93.

Xu, C.Y., Tunemar, L., Chen, Y.Q.D. and Singh, V.P. (2006b) Evaluation of seasonal and spatial variations of lumped water balance model sensitivity to precipitation data errors. Journal of Hydrology 324(1-4), 80-93.

$\mathrm{Xu}$, K., Milliman, J.D. and Xu, H. (2010) Temporal trend of precipitation and runoff in major Chinese Rivers since 1951. Global and Planetary Change 73(3), 219-232.

$\mathrm{Xu}, \mathrm{Z}$., Li, J. and Liu, C. (2007) Long - term trend analysis for major climate variables in the Yellow River basin. Hydrological Processes 21(14), 1935-1948.

Yang, H. (2014) China's South-North Water Transfer Project: now come the management challenges, pp. 17-19, IWA Publishing.

Yang, H., Pfister, S. and Bhaduri, A. (2013) Accounting for a scarce resource: virtual water and water footprint in the global water system. Current Opinion in Environmental Sustainability 5(6), 599-606.

Yang, X.J. (2013) China's rapid urbanization. Science 342(6156), 310.

Yang, Z., Sun, T., Cui, B., Chen, B. and Chen, G. (2009) Environmental flow requirements for integrated water resources allocation in the Yellow River Basin, China. Communications in Nonlinear Science and Numerical Simulation 14(5), 2469-2481.

Yao, F.M., Xu, Y.L., Lin, E.D., Yokozawa, M. and Zhang, J.H. (2007) Assessing the impacts of climate change on rice yields in the main rice areas of China. Climatic Change 80(3-4), 395-409.

YRCC (2006) Water use and planning, Yellow River Conservancy Commission, Zhengzhou, China.

YRCC (2011) Yellow River water resource bulletin 1998-2009, Yellow River Conservancy Commission, Zhengzhou, China.

YRCC (2013) Comprehensive planning of the Yellow River Basin for 2012-2030., Yellow River Conservancy Commission, Zhengzhou, China.

Yu, C.Q., Gong, P. and Yin, Y.Y. (2011) China's water crisis needs more than words. Nature 
470(7334), 307-307.

Yuan, M., Zhang, L., Gou, F., Su, Z., Spiertz, J. and van der Werf, W. (2013) Assessment of crop growth and water productivity for five C 3 species in semi-arid Inner Mongolia. Agricultural Water Management 122, 28-38.

Yunpeng, X., Sun, Y. and Ringler, C. (2015) Governance, Laws, and Water Interventions in the Yellow River Basin Over the Past 60 Years: From Supply-to Demand-Side Management. Institute, I. F. P. R. Washington, D. C., USA.

Zeng, Z., Liu, J., Koeneman, P.H., Zarate, E. and Hoekstra, A.Y. (2012) Assessing water footprint at river basin level: a case study for the Heihe River Basin in northwest China. Hydrology and Earth System Sciences 16(8), 2771-2781.

Zhang, C. and Anadon, L.D. (2014) A multi-regional input-output analysis of domestic virtual water trade and provincial water footprint in China. Ecological Economics 100, 159-172.

Zhang, F. and Zhu, Z. (1990) Harvest index for various crops in China. Scientia Agricultura Sinica 23(2), 83-87.

Zhang, L., Xia, J. and Hu, Z. (2009) Situation and problem analysis of water resource security in China. Resources and Environment in the Yangtze Basin 18(2), 116-120.

Zhang, T.Y., Yang, X.G., Wang, H.S., Li, Y. and Ye, Q. (2014) Climatic and technological ceilings for Chinese rice stagnation based on yield gaps and yield trend pattern analysis. Global Change Biology 20(4), 1289-1298.

Zhang, Y. and Qi, S. (2011) China multi-regional input-output models (2002, 2007), China Statistics Press, Beijing, China.

Zhang, Z., Shi, M. and Yang, H. (2012) Understanding Beijing's Water Challenge: A Decomposition Analysis of Changes in Beijing's Water Footprint between 1997 and 2007. Environmental Science \& Technology 46(22), 12373-12380.

Zhang, Z.Y., Yang, H. and Shi, M.J. (2011) Analyses of water footprint of Beijing in an interregional input-output framework. Ecological Economics 70(12), 2494-2502.

Zhao, C.F. and Chen, B. (2014) Driving Force Analysis of the Agricultural Water Footprint in China Based on the LMDI Method. Environmental Science \& Technology 48(21), 12723-12731.

Zhao, Q.B., Liu, J.G., Khabarov, N., Obersteiner, M. and Westphal, M. (2014) Impacts of climate change on virtual water content of crops in China. Ecological Informatics 19, 26-34. 
Zhao, T.B. and Fu, C.B. (2006) Comparison of products from ERA-40, NCEP-2, and CRU with station data for summer precipitation over China. Advances in Atmospheric Sciences 23(4), 593-604.

Zhao, X., Liu, J.G., Liu, Q.Y., Tillotson, M.R., Guan, D.B. and Hubacek, K. (2015) Physical and virtual water transfers for regional water stress alleviation in China. Proceedings of the National Academy of Sciences of the United States of America 112(4), 1031-1035.

Zhu, X., Li, Y., Li, M., Pan, Y. and Shi, P. (2013) Agricultural irrigation in China. Journal of Soil and Water Conservation 68(6), 147A-154A.

Zhu, X.F., Zhao, A.Z., Li, Y.Z. and Liu, X.F. (2015) Agricultural irrigation requirements under future climate scenarios in China. Journal of Arid Land 7(2), 224-237.

Zhuo, L., Mekonnen, M. and Hoekstra, A. (2014) Sensitivity and uncertainty in crop water footprint accounting: a case study for the Yellow River Basin. Hydrology and Earth System Sciences 18(6), 2219-2234.

Zhuo, L., Mekonnen, M.M. and Hoekstra, A.Y. (2016a) The effect of inter-annual variability of consumption, production, trade and climate on crop-related green and blue water footprints and inter-regional virtual water trade: A study for China (1978-2008). Water Research 94, 73-85.

Zhuo, L., Mekonnen, M.M., Hoekstra, A.Y. and Wada, Y. (2016b) Inter- and intra-annual variation of water footprint of crops and blue water scarcity in the Yellow River basin (1961-2009). Advances in Water Resources 87, 29-41.

Zwart, S.J., Bastiaanssen, W.G.M., de Fraiture, C. and Molden, D.J. (2010) A global benchmark map of water productivity for rainfed and irrigated wheat. Agricultural Water Management 97(10), 1617-1627. 


\section{Summary in Chinese}

在过去的几十年, 伴随着人口不断增加和经济快速增长, 尤其在大型快速发展中国家, 增 长的水资源消耗使全球有限水资源的可持续利用困难重重并成为对未来人类社会及自然的关 键挑战之一。基于在大流域及国家尺度高空间分辨率水足迹计算方法, 本研究以系统评估中国 过去、现在与未来的水足迹、水资源短缺及虚拟水流动为主要研究目的, 以农业为主要研究对 象, 针对水足迹评价研究中存在的不确定性、年度及年内变化及基准度制定等问题进行了探索 研究。因此, 本论文由五个主题章节研究 (第 2 章至第 5 章) 组成:

\section{一、 作物消耗型水足迹计算中的敏感性与不确定性分析: 以黄河流域为例}

本章以黄河流域四种主要作物为研究对象, 利用 'one-at-a-time' 方法及蒙特卡罗模拟

(Monte Carlo simulations) 方法, 分别对作物生长过程中蓝水及绿水足迹计算中由输入变 量内部变化及不确定性引起的输出结果敏感性与不确定性进行了定量分析。作物消耗型水足迹

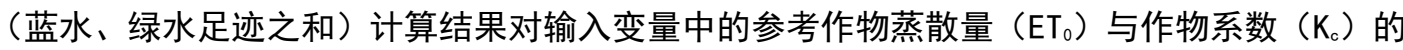
变化最为敏感。蓝水足迹对输入变量较绿水足迹更为敏感。由关键输入变量中的不确定性综合 引起的作物水足迹计算结果中的不确定为土30\%（95\%置信度）。

\section{二、黄河流域内作物生产水足迹与蓝水稀缺度（blue water scarcity）的年际及年内变化}

本章利用高空间分辨率作物水足迹计算及蓝水资源稀缺度评价方法, 模拟分析了黄河流域 1961-2009 年间十七类主要农作物生产蓝水、绿水与灰水足迹的年际间变化，及 1978-2009 年 间全流域蓝水稀缺度的月际间变化。过去半个世纪黄河流域灌溉农业的快速发展（灌溉耕地的 增加）及农业生产投入（肥料使用）的激增使作物单产翻倍增长，单产水足迹（立方米/吨） 随之显著下降。因此, 在所研究几十年间黄河流域作物生产年度总蓝水与绿水足迹（立方米／ 年）仅增长 $11 \%$ 。然而, 流域内与氮和磷相关的作物生产灰水足迹在同一时段分别增长了 24 和 26 倍, 反映出成倍增长的化肥消耗对流域内水质的不利影响和严重威胁。每年黄河流域在 七个月间（一月到七月）面对中度到强度蓝水资源稀缺。即使在丰水年中降雨最多的月份，流 域内仍有一半区域承受强度蓝水稀缺。

\section{三、中国作物产品的消费、生产、贸易及气候的年度变化对国内作物蓝水、绿水足迹及区域 间虚拟水贸易的影响}


本章对 1978-2008 年间中国境内由作物产品的消费、生产、贸易及气候的年度变化引起的 二十二类作物消耗型水足迹（蓝水、绿水足迹）及国内区域间虚拟水贸易的时空变化进行了计 算与分析。期间由作物单产增加驱动单产水足迹显著下降。因而在这段总产量与消费量都迅猛 增长的时期，中国人均农作物消费水足迹下降了 23\%，中国作物生产和消费所产生的年消耗型 水足迹只微量地分别增长了 $7 \%$ 和 $6 \%$ 。于此同时, 由于主要作物生产区的由南向北移动与持续 增加的由北向南的作物产品贸易, 中国现今通过作物运输由缺水区到富水区的虚拟水 “北水南 调”从 21 世纪初开始形成。每一个中国人农作物产品消费水足迹中有 $35 \%$ 来自于其所在省外。 另外, 国内区域间的虚拟水流动正由低单产蓝水足迹区向高单产蓝水足迹区, 这在 2008 年产 生了相当于全国作物生产蓝水足迹总和的 7\%的 “蓝水资源流失”。

\section{四、不同未来情景模式中的中国农产品消耗型水足迹和虚拟水贸易}

本章构建分析了四种不同未来情景模式下 2030 年与 2050 年的中国农产品生产和消费的蓝 水、绿水足迹和国家虚拟水贸易。在由政府间气候变化专门委员会（IPCC）第五次评估报告 （AR5）两个典型浓度路径（RCP2.6 与 RCP8.5）和三个共享的社会经济途径（SSP1-3）组成的 基本情景框架内, 本章中四个未来情景 (S1-4) 的构建考虑了五个驱动变量: 气候、作物收获 面积、技术进步、饮食结构与人口。分析得到: 与基准年 2005 年相比, 在所有情景模式中大 部分作物单产水足迹降低, 从而人均食品消费水足迹也下降。若将国民饮食结构中肉类产品比 重适当减小, 可以在 2050 年额外降低 $44 \%$ 的人均食品消费水足迹。在所有情景模式中, 在作 物单产提升即作物总产量升高基础上, 加之预计放缓的人口增长, 中国将进行角色转换从现在 的虚拟水净进口国转变为虚拟水净出口国。以上结果显示出中国有潜能在减少国家由农业生产 的水资源消耗量的同时，达到主粮自给的政府目标。

\section{五、不同环境下作物生产消耗型水足迹基准初探: 以中国冬小麦为例}

本章旨在探索在设定作物生产消耗型水足迹基准时对环境因素的区分。利用通过作物水 分生产率模型 AquaCrop、只考虑水分压力、在 5 弧分空间尺度上对 1961-2008 年间中国冬小麦 生产消耗型水足迹的模拟结果，分析比较了针对不同年间、灌溉与雨养、四种不同土壤种类以 及两种不同气候区情况下作物生产消耗型水足迹基准的不同。结果显示作物生产消耗型水足迹 基准的制定需考虑和针对不同的气候区域。中国冬小麦湿润区生产消耗型水足迹基准比干旱区 同级基准小 26-31\%。若将现实冬小麦消耗型水足迹在湿润、干旱区分别下调至相应气候区中对 应于最好 25\% 总产量的基准值, 可减少现在中国冬小麦生产总耗水量的 53\%。且相应水足迹下 
降的空间分布显示中国南方在作物单产和作物水分生产率的提高更具潜力。

\section{结论}

本论文研究对水足迹评估领域前沿主要有以下五点贡献：第一, 本论文研究实现了国际 粮农组织（FAO）作物水分生产模型 AquaCrop 在大尺度水足迹计算中的应用; 第二, 实现了第 一次对水足迹计算中敏感性和不确定性的综合分析评价; 第三, 在迄今为止仍只有极少数涉及 对作物水足迹、蓝水短缺以及虚拟水贸易长期年际及年内变化研究存在的情况下, 本文通过黄 河流域及中国的相关研究补充提高了同类研究的时空覆盖度; 第四, 第一次展示了中国在同时 考虑未来气候变化及不同社会经济变化驱动因素下的水足迹与虚拟水贸易情景模式; 最后, 本 论文通过探索针对不同环境因素的作物生产消耗型水足迹基准值的变化及相应结论，进一步促 进了对于如何制定作物生产水足迹基准的知识发展。 


\section{List of publications}

\section{Peer-reviewed papers}

Zhuo, L., Mekonnen, M. and Hoekstra, A. (2014) Sensitivity and uncertainty in crop water footprint accounting: a case study for the Yellow River Basin. Hydrology and Earth System Sciences 18(6), 2219-2234.

Zhuo, L., Mekonnen, M.M., Hoekstra, A.Y. and Wada, Y. (2016) Inter- and intra-annual variation of water footprint of crops and blue water scarcity in the Yellow River basin (1961-2009). Advances in Water Resources 87, 29-41.

Zhuo, L., Mekonnen, M.M. and Hoekstra, A.Y. (2016) The effect of inter-annual variability of consumption, production, trade and climate on crop-related green and blue water footprints and inter-regional virtual water trade: A study for China (1978-2008). Water Research 94, 73-85.

Zhuo, L., Mekonnen, M. M. and Hoekstra, A. Y. (2016) Consumptive water footprint and virtual water trade scenarios for China with a focus on crop production, consumption and trade. Environment International. Under review.

Zhuo, L., Mekonnen, M. M. and Hoekstra, A. Y. (2016) Benchmark levels for the consumptive water footprint of crop production for different environmental conditions: a case study for winter wheat in China. Hydrology and Earth System Sciences. Submitted.

\section{Report}

Zhuo, L., Mekonnen, M.M. and Hoekstra, A.Y. (2013) Sensitivity and uncertainty in crop water footprint accounting: A case study for the Yellow River Basin, Value of Water Research Report Series No.62, UNESCO-IHE, Delft, the Netherlands.

\section{Conference abstracts}

Zhuo, L., Mekonnen, M.M. and Hoekstra, A.Y. (2013) Sensitivity and uncertainty analysis for crop water footprint accounting at a basin level. American Geophysical Union, Fall 
Meeting 2013, abstract \#H21H-1148. San Francisco, U.S.A

Zhuo, L., Mekonnen, M.M. and Hoekstra, A.Y. (2015) Historical development of crop-related water footprints and inter-regional virtual water flows within China. Geophysical Research Abstracts 17, EGU2015-9391. EGU General Assembly 2015. Vienna, Austria.

Zhuo, L., Mekonnen, M. M., Hoekstra, A. Y. and Wada, Y. (2015) Historical development of water footprint of crops and blue water scarcity in the Yellow River Basin. World Water Congress XV, IWRA, abstract PS8.2005. Edinburgh, U.K 


\section{PROPOSITIONS}

Accompanying the thesis

\section{Past, current and future water footprints, water scarcity and virtual water flows in China by La Zhuo}

1. Over the last five decades, green and blue water footprints per tonne of crop have reduced significantly across China, due to improved yields, but the benefits of increased water productivity have been offset by the increased crop production.

2. Throughout the year, even in the wettest month in a wet year, about half of the area of the Yellow River Basin, the second largest river basin in China, suffered severe blue water scarcity.

3. The emergence of the North-to-South net virtual water flow in China shows that economics and governmental policies rather than regional differences in water endowments have been the driver of domestic trade, creating inter-regional water dependencies and worsening the water scarcity in the driest part of the country.

4. When determining benchmark levels for the consumptive water footprint of a crop, it is useful to primarily distinguish between different climate zones.

5. In most cases, consumers are unaware of how their consumption decision can affect freshwater resources in locations where the commodities are produced (Hoekstra and Chapagain, 2008; Hoff, 2009; Yang et al., 2013; Vörösmarty et al., 2015).

6. The water footprint concept enables visualizing the hidden freshwater used behind products and can assist in understanding the global character of freshwater demand and supply and in quantifying and mapping the effects of consumption and trade on water resources use (Hoekstra, 2003; Hoekstra and Chapagain, 2008; Hoekstra, 2013).

7. Facing increasing limited water supply for feeding growing population, satisfying additional economic and social development and maintaining ecology across China, higher efficiency in use, better quality treatment and fair allocation of the local water, especially in the drier North, are the key to keep pace with rising demands, not depending only on pumping water from South to North across the country (Tso, 2004; Barnett et al., 2015).

8. The water-resource challenge of the future is more complex then previously portrayed - it is not only a question of water allocation among irrigation, industry, and municipalities but involves difficult decisions for balancing green and blue water for food, nature and society (Falkenmark and Rockström, 2006).

9. There is no happiness except in the realization that we have accomplished something. - Henry Ford

These propositions are regarded as opposable and defendable, and have been approved as such by promoter Prof. dr. ir. A. Y. Hoekstra and co-promoter Dr. M. M. Mekonnen. 


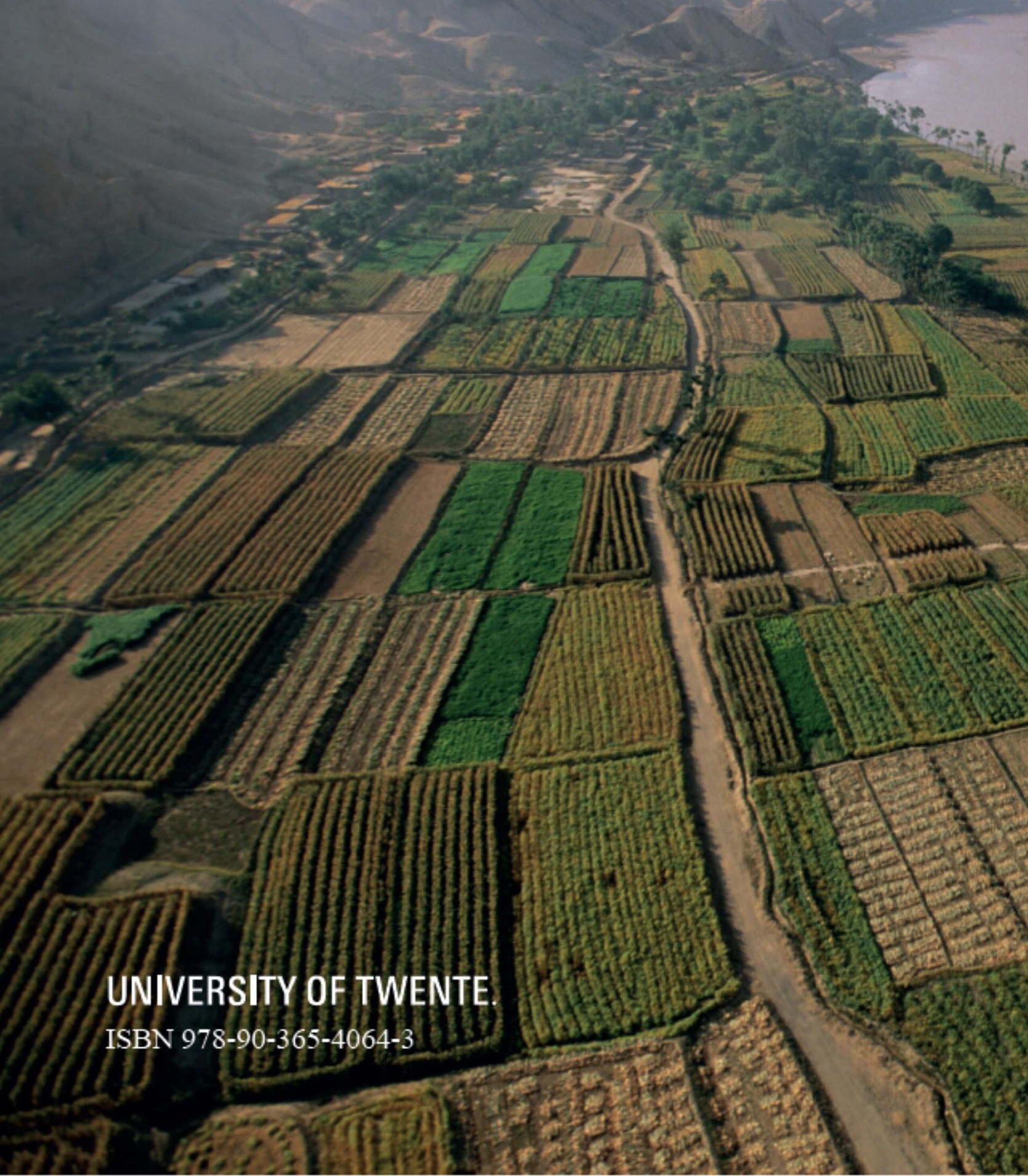

